\author{
UNIVERSIDADE DE SÃO PAULO \\ ESCOLA DE ENGENHARIA DE SÃO CARLOS \\ DEPARTAMENTO DE ENGENHARIA DE TRASNPORTES
}

\title{
AVALIAÇÃO DA QUALIDADE DO TRANSPORTE PÚBLICO SOB A ÓTICA DA MOBILIDADE URBANA SUSTENTÁVEL - O CASO DE FORTALEZA
}

ANA CECÍLIA LIMA MAIA

Dissertação apresentada à Escola de Engenharia de São Carlos da Universidade de São Paulo para obtenção do título de Mestre em Engenharia de Transportes.

Área de Concentração: Planejamento e Operação de Sistemas de Transportes

Orientador:

Prof. Dr. Antônio Nélson Rodrigues da Silva

São Carlos 
AUTORIZO A REPRODUÇÃO TOTAL OU PARCIAL DESTE TRABALHO, POR QUALQUER MEIO CONVENCIONAL OU ELETRÓNICO, PARA FINS DE ESTUDO E PESQUISA, DESDE QUE CITADA A FONTE.

M217a Maia, Ana Cecilia Lima

Avaliação da qualidade do transporte público sob a ótica da Mobilidade Urbana Sustentável - 0 Caso De Fortaleza / Ana Cecília Lima Maia; orientador Antônio Nelson Rodrigues da Silva. Sảo Carlos, 2013.

Dissertação (Mestrado) - Programa de Pós-Graduação em Engenharia de Transportes e Área de Concentração em Planejamento e Operação de Sistemas de Transporte -Escola de Engenharia de São Carlos da Universidade de São Paulo, 2013.

1. Mobilidade urbana. 2. Transporte público. 3. fndice de mobilidade urbana sustentável. 4. Região Metropolitana de Fortaleza. I. Titulo. 


\section{FOLHA DE JULGAMENTO}

Candidata: Engenheira ANA CECILIA LIMA MAIA.

Título da dissertação: "Avaliação da qualidade do transporte público sob a ótica da mobilidade urbana sustentável - o caso de Fortaleza".

Data da defesa: $21 / 06 / 2013$

Comissto Julgadora:

Resultado:

Prof. Associado Antônio Nélson Rodrigues da Silva (Orientador) AFROUASA (Escola de Engenharia de Sajo Carlos/EESC)

Prof. Dr. Gustavo Garcia Manzato APLONADA

(Universidade Estadual Paulista "Júlio de Mesquita Filho"/UNESP-Bauru)

Prof. Dr. Luiz Afonso dos Santos Senna

$\triangle P R O N D A$

(Universidade Federal do Rio Grande do Sul/UFRGS)

Coordenador do Programa de Pós-Graduação em Engenharia de Transportes:

Prof. Associado Antônio Nélson Rodrigues da Silva

Presidente da Comissão de Pós-Graduação:

Prof. Titular Denis Vinicius Coury 

À minha família, que sempre me apoiou e acreditou em mim em todos os momentos. 



\section{AGRADECIMENTOS}

Agradeço a Deus, pela oportunidade que me deu de poder conquistar mais uma grande etapa em minha vida, mesmo com todas as turbulências que apareceram no meio do caminho.

Ao Professor Antônio Nélson Rodrigues da Silva por ter se disponibilizado a me orientar nestes últimos meses, mesmo com tantas outras responsabilidades. Pela enorme paciência, pelo incentivo, pela credibilidade e pelos conselhos.

Ao Professor Mário Ângelo Nunes de Azevedo, que vem acompanhando a minha evolução acadêmica desde a minha graduação, que nunca se negou a me ajudar em nenhum momento, nem naqueles mais inconvenientes. Pelo apoio e incentivo, pela amizade construída, pela convivência, pelos ensinamentos, pelos conselhos. Por ser essa grande pessoa que transparece uma bondade e um carisma inigualáveis.

Ao Professor Edson Martins de Aguiar (in memorian) por ter sido meu orientador, me ensinando e me incentivando a sempre fazer a coisa certa.

À minha família (Márcia, César, José Maria, Lucas, Rafael e Gabriel), que sempre esteve ao meu lado, sendo o alicerce da minha vida. Por acreditar no meu potencial, sempre demonstrando orgulho pelas minhas conquistas, me dando carinho e amor em todos os momentos, e ajudando a me tornar a pessoa que sou hoje.

Ao meu namorado, Thiago, que sempre me deu tanto amor, tanto carinho, tantos conselhos, tantas "broncas", tantos elogios. Por toda paciência, e por ajudar a me tornar uma pessoa melhor e mais madura. Apesar da distância, conseguiu ser tão presente naqueles momentos fundamentais, que, muitas vezes, ela passava despercebida.

Às minhas amigas Camila Rodrigues e Thais Pamplona pela convivência nestes dois anos. Amigas de república, amigas de mestrado, amigas de festas, amigas de viagens, amigas de momentos difíceis, amigas de momentos felizes. Muito sucesso para todas nós. Obrigada por tudo.

À minha "irmã" de mestrado, Suzana Valverde, pelas "ajudinhas" técnicas de trabalho e, principalmente, pelas "ajudinhas" extra mestrado. Entramos no mesmo "barco", tivemos as mesmas turbulências, mas estamos alcançando nossos objetivos e, com certeza, teremos uma vida repleta de sucesso e felicidade. Obrigada, amiga. 
Aos meus amigos do STT. Em especial à Jéssica Santiago, Peolla Stein, Carlos Prado, Conrado Plaza, Marcela Navarro, Andressa Ng, Artur Piatti, Fernando Piva e Magaly, que me ajudaram de várias formas a concluir esta etapa e "cuidaram" muito bem de mim em todo esse período.

Aos amigos de Fortaleza, que nunca deixaram de torcer pelo meu sucesso. Vocês também tiveram grande participação nesta conquista. Em especial agradeço a Raisa Rios, Fabiane Girão, Paloma Medeiros, Lorena Guimarães, Maria Pinho, Kelvia Barros, Iuri Bessa, Felipe Coutinho. Obrigada!

Aos colegas de São Carlos, que me proporcionaram momentos incríveis e inesquecíveis nestes dois anos. Obrigada!

Aos órgãos que disponibilizaram os dados para esta pesquisa: ARCE, DETRAN-CE, ETUFOR, METROFOR.

À Coordenação de Aperfeiçoamento de Pessoal de Nível Superior (CAPES), pelo apoio financeiro dado durante o período de mestrado. 
"O êxito da vida não se mede pelo caminho que você conquistou, mas sim pelas dificuldades que superou no caminho."

(Abraham Lincoln) 



\section{MAIA, A. C. L. Avaliação da qualidade do Transporte público sob a ótica da Mobilidade}

Urbana Sustentável - O Caso de Fortaleza. 2013. Dissertação (Mestrado) - Escola de

Engenharia de São Carlos, Universidade de São Paulo, São Carlos, 2013.

Este trabalho apresentou um método de avaliação para sistemas de transporte público de uma cidade e da região metropolitana à qual ele pertence. No caso específico deste estudo, a cidade selecionada foi Fortaleza. A avaliação foi realizada do ponto de vista retrospectivo (1992, 2000 e 2010) e prospectivo (2014), com o propósito de destacar a importância da abordagem para o planejamento da mobilidade sustentável. A pesquisa foi motivada pelos crescentes problemas de mobilidade enfrentados pela população nos últimos anos. Projetos de ampliação da infraestrutura viária, bem como de criação de novos sistemas de transportes públicos são propostos com frequência, mas estes raramente são totalmente implantados ou executados. A estratégia de avaliação se baseia no Índice de Mobilidade Urbana Sustentável (IMUS), criado por Costa (2008). A estrutura do índice envolve 87 indicadores, que visam refletir diferentes impactos e perspectivas da mobilidade. Como o foco do estudo foi o transporte público, foram calculados apenas os 22 indicadores diretamente ligados ao tema. Os pesos da estrutura hierárquica foram redistribuídos para o índice resultante, que passou a ser chamado de IMUS-TP. O valor do índice foi calculado para cada um dos quatro anos do período de análise, de forma a avaliar os respectivos níveis de mobilidade urbana sustentável. Em geral, os resultados mostraram melhorias nos valores dos indicadores ao longo do tempo. Alguns indicadores, no entanto, apresentaram problemas. Isto produziu efeitos negativos sobre os valores do índice encontrados para Fortaleza (IMUS-TP, igual a 0,463) e para a região metropolitana (IMUS-TP-RMF, igual a 0,407) em 2010. Mesmo considerando todos os projetos previstos para 2014, os valores de IMUS-TP e IMUS-TP-RMF deverão chegar a apenas 0,612 e 0,500, respectivamente. Estes valores não são altos, mas eles certamente mostram melhorias no sistema de transporte público. Algumas das melhorias esperadas são: priorização do transporte público, investimentos na integração dos sistemas de transporte, subsídios públicos para o sistema de transporte metropolitano, mais interação entre os sistemas de transporte urbano e metropolitano, e procedimentos eficazes para a atualização dos bancos de dados. Os valores do índice mostram que estas medidas, embora importantes porque melhorarão as condições de mobilidade na cidade de Fortaleza e na região metropolitana, não resolverão definitivamente o problema.

Palavras chave: Mobilidade urbana, transporte público, Índice de mobilidade urbana sustentável, Fortaleza. 

MAIA, A. C. L. Assessing the quality of public transport from the perspective of Sustainable Mobility - The Case of Fortaleza. 2013. Dissertação (MSc) - Escola de Engenharia de São Carlos, Universidade de São Paulo, São Carlos, 2013.

This study introduces a method for the assessment of the public transportation systems of a single city and also of the metropolitan region it belongs to. In the case of this particular investigation, the selected city was Fortaleza, Brazil. The evaluation was conducted for three periods in the past (i.e., the years 1992, 2000, and 2010), and one in the future, which is the year 2014. The purpose was to highlight the importance of the approach for sustainable mobility planning. The growing mobility problems faced by the population in the recent past have been the motivation for this research. Projects for road infrastructure improvement and for the creation of new public transportation systems are frequently proposed, but rarely built or fully implemented. The evaluation approach is based on the Index of Sustainable Urban Mobility (I_SUM or IMUS, in Portuguese) created by Costa (2008). The index framework involves 87 indicators, which are meant to cover distinct impacts and perspectives of mobility. As the focus of the study was on public transportation, only the 22 indicators directly linked to the subject were calculated. The weights of the hierarchical structure were redistributed to the resulting index, which was then called IMUS-TP. The index value was calculated for each of the four years period of analysis, for assessing the respective levels of sustainable urban mobility. In general, the results showed improvements in the values of the indicators throughout time. Some indicators, however, had problems. This had a negative effect on the index values found for Fortaleza (IMUS-TP, equal to 0.463) and for the metropolitan region (IMUS-TP-RMF, equal to 0.407) in 2010. Even considering all projects proposed for 2014, the values of IMUS-TP and IMUS-TP-RMF are expected to reach only 0.612 and 0.500 , respectively. These values are not high, but they certainly show improvements in the public transportation system. Some of the expected improvements are: priorization of public transport, investments in the integration of transport systems, public subsidies to the metropolitan transit system, more interaction between urban and metropolitan transit systems, and effective procedures for the update of databases. The index values show that these measures, although important because they will improve the mobility conditions in the city of Fortaleza and in the metropolitan region, will not be able to definitely solve the problem.

Keywords: urban mobility, public transportation, Index of Sustainable Urban Mobility, Fortaleza. 



\section{LISTA DE FIGURAS}

Figura 2.1 - Serviço de transporte público em Portland (LRTA, 2009) ..................................30

Figura 2.2 - Rede Integrada de Transporte em Curitiba (Fonte: URBS, 2013)....................... 32

Figura 2.3 - Propostas de Gudmundsson (2001) para mobilidade sustentável em espaços urbanos

Figura 3.1 - Hierarquia de temas e indicadores do IMUS referentes ao transporte público ....44

Figura 4.1 - Divisões Administrativas em Fortaleza (Fonte: ETUFOR, 2012) .......................50

Figura 4.2 - Mapa da Região Metropolitana de Fortaleza (Fonte: IPECE, 2009) ...................51

Figura 4.3 - Valores do IMUS-TP e seus limites inferiores e superiores, para cada cenário...55

Figura 4.4 - Comparação com o IMUS-TP de Curitiba …...................................................57

Figura 4.5 - Dimensões de Sustentabilidade para o IMUS-TP .............................................58

Figura 4.6 - Contribuição de cada tema para a formação do IMUS-TP dos cenários 1992, 2000,2010 e 2014

Figura 4.7 - Classificação geral dos indicadores do IMUS-TP por cenário 60

Figura 4.8 - Classificação detalhada dos indicadores do IMUS-TP por cenário. As barras horizontais representam os cenários de 1992, 2000, 2010, 2014, de cima para baixo, por indicador.

Figura 4.9 - Cobertura atual das linhas de ônibus do município de Fortaleza, considerando bandas de 300 metros ao redor das rotas.

Figura 4.10 - Vias para transporte coletivo a) em 1992 b) em 2000 c) em 2010 d) em 2014.. 64

Figura 4.11 - Localização dos terminais intermodais previstos para Fortaleza em 2014.........68

Figura 4.12 - Valores do IMUS-TP RMF e seus limites inferiores e superiores, para cada cenário. 73

Figura 4.13 - Diferença entre IMUS-TP e IMUS-TP RMF 74

Figura 4.14 - Dimensões de sustentabilidade para o IMUS-TP RMF. 75

Figura 4.15 - Contribuição de cada tema para a formação do IMUS-TP RMF por cenário .... 76

Figura 4.16 - Classificação geral dos indicadores do IMUS-TP RMF por cenário. 77 
Figura 4.17 - Classificação detalhada dos indicadores do IMUS-TP RMF por cenário. As barras horizontais representam os cenários de 1992, 2000, 2010, 2014, de cima para baixo, por indicador.

Figura 4.18 - Cobertura espacial das linhas de ônibus da RMF com detalhe das bandas (ou buffers)

Figura 4.19 - Estágio da estação intermodal da Parangaba (Fonte: METROFOR, 2012) ....... 84

Figura 4.20 - Estações de metrô intermodais (Linha Sul) previstas para 2014 (Fonte: METROFOR, 2012) 84 


\section{LISTA DE TABELAS}

Tabela 2.1 - Síntese de indicadores para avaliar a qualidade do transporte público urbano .... 33

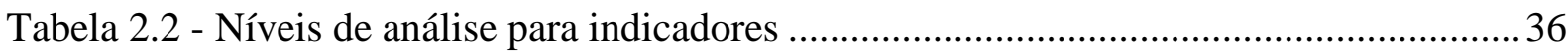

Tabela 2.3 - DomínIOS, Temas e Indicadores do IMUS e seus respectivos pesos .................. 39

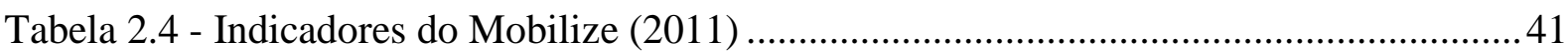

Tabela 2.5 - Estrutura do Índice de Mobilidade Sustentável................................................ 42

Tabela 3.1- Pesos para DomínIOs (PD), Temas (PT) e Indicadores (PI) no IMUS-TP........... 45

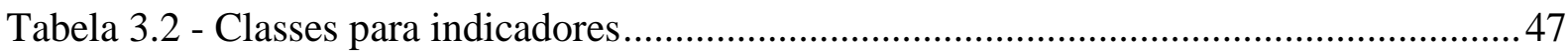

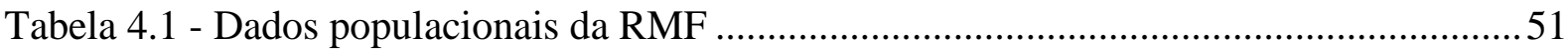

Tabela 4.2 - Escores normalizados, parcelas do IMUS-TP (ou seja, escores normalizados multiplicados pelos respectivos pesos) e valores do IMUS-TP por cenário ............................54

Tabela 4.3 - Escores normalizados do IMUS-TP RMF, parcelas do IMUS-TP RMF (ou seja, escores normalizados multiplicados pelos respectivos pesos) e valores do IMUS-TP RMF por

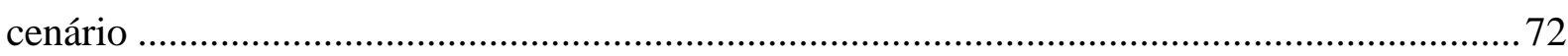





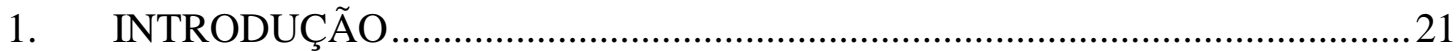

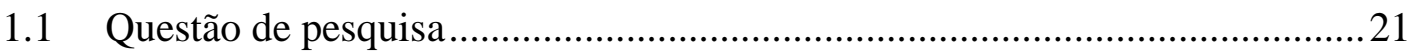

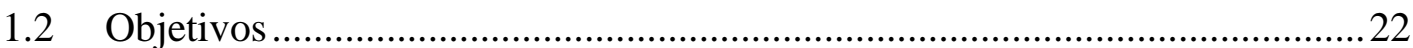

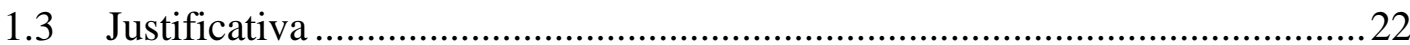

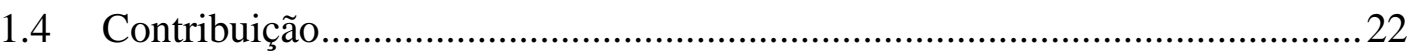

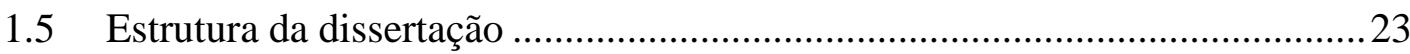

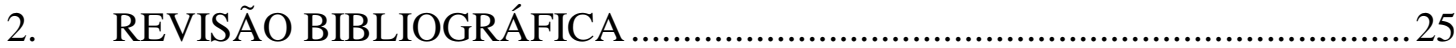

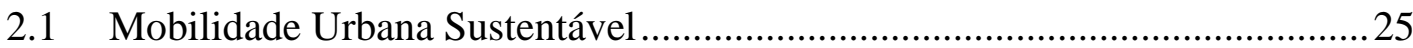

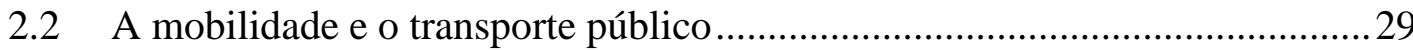

2.3 Avaliação da qualidade do transporte público ................................................ 32

2.4 Metodologias de avaliação da gestão de mobilidade urbana ........................... 35

2.4.1 O Índice de Mobilidade Urbana Sustentável ..........................................37

2.4.2 Outras abordagens de monitoramento da mobilidade .............................41

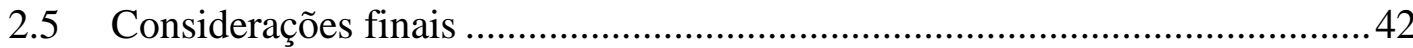

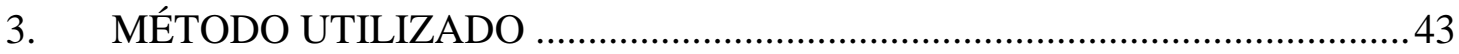

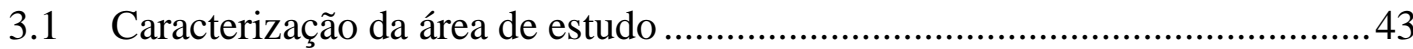

3.2 Escolha da metodologia de avaliação ..........................................................4 43

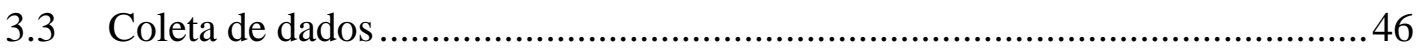

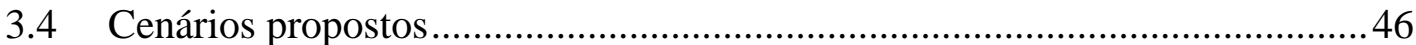

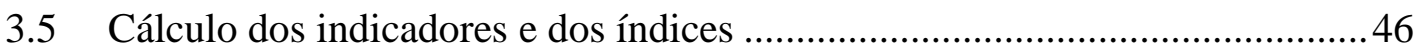

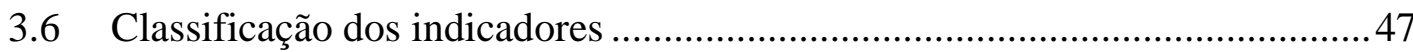

3.7 Construção de diagnósticos e propostas de melhorias ....................................48

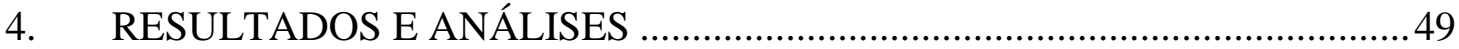

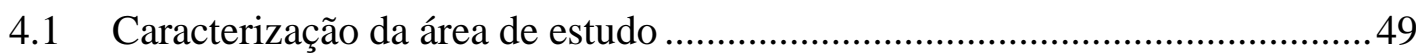


4.1.1 A cidade de Fortaleza ........................................................................ 49

4.1.2 A Região Metropolitana de Fortaleza.................................................... 50

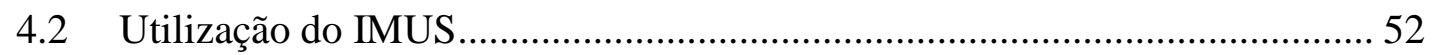

4.3 Aplicação do IMUS-TP na cidade de Fortaleza ............................................ 52

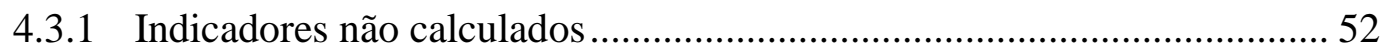

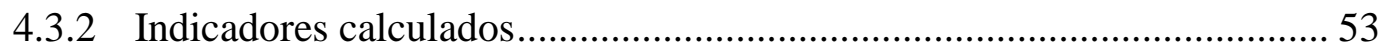

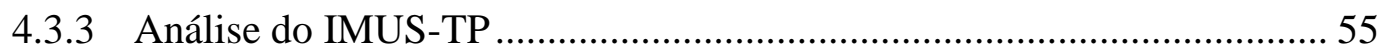

4.3.4 Análise dos resultados do IMUS-TP por tema .................................. 58

4.3.5 Classificação e análise dos resultados do IMUS-TP por indicador........... 60

4.4 Aplicação do IMUS-TP RMF na Região Metropolitana de Fortaleza ........... 69

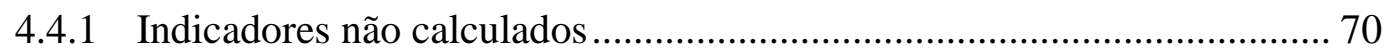

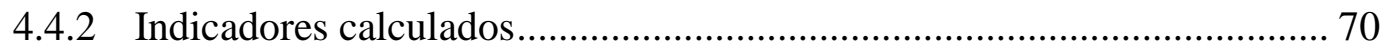

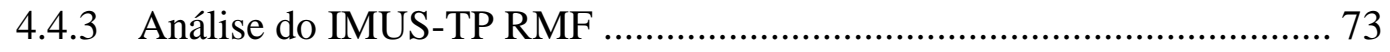

4.4.4 Análise dos resultados do IMUS-TP por tema ...................................... 75

4.4.5 Classificação e análise dos resultados do IMUS-TP RMF por indicador 77

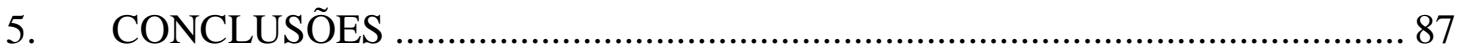

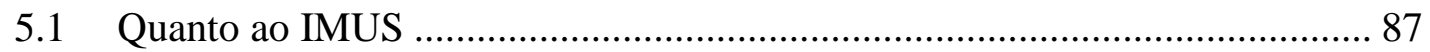

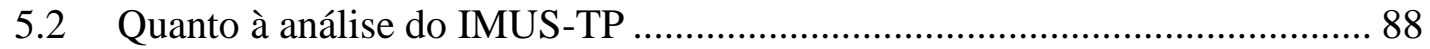

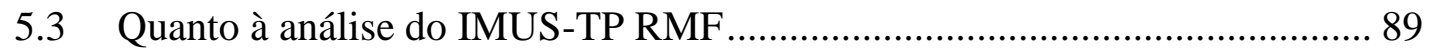

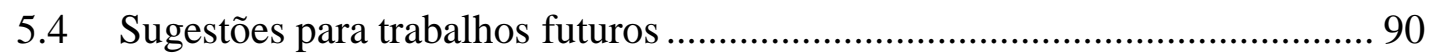

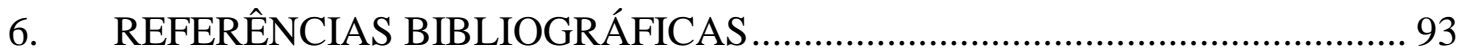




\section{INTRODUÇão}

O crescimento acelerado e não planejado das cidades vem gerando inúmeros transtornos para a população das cidades brasileiras. Problemas como inadequação da oferta de transporte coletivo, congestionamentos e poluição causados pelo uso intenso do automóvel, carência de investimentos públicos e necessidade de políticas públicas articuladas nacionalmente dão margens para que o modelo de mobilidade urbana de hoje possa ser classificado como insustentável (IPEA, 2011). Visto isso, existe uma preocupação significativa por parte de técnicos e gestores ligados ao desenvolvimento urbano e aos sistemas de transportes, bem como ao uso do espaço público, para melhorar esta situação.

A cidade de Fortaleza e sua região metropolitana passam constantemente por transformações envolvendo a mobilidade das pessoas no seu entorno. Ampliações de infraestrutura e aumento da oferta de transporte público são algumas medidas tomadas no intuito de melhorar a qualidade de vida. No entanto, é necessário que haja todo um acompanhamento por parte de órgãos responsáveis pelo desenvolvimento urbano da cidade, evitando transtornos e prejuízos à população.

A proposta central desta pesquisa focou na contribuição que o sistema de transporte público de uma cidade de grande porte traz e pode trazer para a mobilidade sustentável. Para isso, foi interessante a realização de uma análise retrospectiva e uma análise prospectiva. Foram avaliados alguns aspectos importantes no passado que serão, por sua vez, considerados no futuro. Portanto, foi proposta a construção de quatro cenários $(1992,2000,2010,2014)$. O objeto de estudo de caso foi a cidade de Fortaleza e sua Região Metropolitana.

\subsection{Questão de pesquisa}

A partir da problemática discutida anteriormente, surge a seguinte questão de pesquisa: "De que forma o sistema de transporte público da cidade de Fortaleza, bem como de sua região metropolitana, pode contribuir para a mobilidade sustentável?" 


\subsection{Objetivos}

O objetivo principal deste trabalho foi avaliar a contribuição do sistema de transporte público de uma cidade de grande porte para a mobilidade sustentável, do ponto de vista retrospectivo e prospectivo. Alguns objetivos específicos podem ser destacados:

- Aprofundar os conhecimentos sobre transporte urbano, mobilidade sustentável e índices de avaliação;

- Diagnosticar a situação do sistema de transporte público de Fortaleza e de sua região metropolitana (no passado e no presente);

- Verificar as possíveis deficiências do sistema;

- Avaliar as propostas de desenvolvimento para o ano de 2014 (futuro);

- Propor melhorias futuras para a mobilidade de Fortaleza.

\subsection{Justificativa}

A população de Fortaleza vem enfrentando inúmeros problemas de mobilidade nos últimos anos. Propostas de ampliações da infraestrutura viária, bem como de implantação de novos sistemas de transporte público se tornam cada vez mais frequentes, mas nem todas costumam ser aprovadas ou colocadas em prática. Alguns projetos, devido ao seu ritmo lento, acabam causando transtornos na cidade. Portanto, é necessário avaliar o tratamento do sistema de transporte público ao longo dos anos, e verificar se as propostas mais recentes, de fato, trarão melhorias para a qualidade do serviço na cidade.

\subsection{Contribuição}

A principal contribuição desta pesquisa consiste em um diagnóstico da gestão da mobilidade urbana, restrita ao sistema de transporte público de Fortaleza e de sua Região Metropolitana, até o momento atual. Com relação ao futuro, se houver necessidade, serão propostas algumas mudanças nos projetos para 2014, de acordo com o grau de deficiência dos indicadores estudados. Estas deficiências serão determinadas pela avaliação do sistema de transporte público da cidade feita a partir da metodologia usada para calcular o Índice de Mobilidade Urbana Sustentável (IMUS), tendo em vista a melhoria da qualidade de vida da população. 


\subsection{Estrutura da dissertação}

No primeiro capítulo foi discutida uma introdução sobre o tema em questão, onde foram explicitados a problemática, a questão de pesquisa, os objetivos geral e específicos, a justificativa e a contribuição. O capítulo dois foi concentrado em uma revisão bibliográfica acerca de conceitos e definições no âmbito do transporte público urbano, mobilidade urbana sustentável e características de métodos de avaliação para sistemas de transporte público e mobilidade urbana. No capítulo três foi apresentado o método utilizado na pesquisa, justificando a escolha da metodologia. No capítulo quatro foram apresentados os resultados obtidos e uma avaliação da mobilidade sustentável para a cidade de Fortaleza e de sua região metropolitana, levando em consideração os cenários construídos. Por fim, no capítulo cinco foram dispostas as conclusões desta pesquisa e as recomendações para trabalhos futuros. 


\section{REVISÃo BIBLIOGRÁFICA}

O objetivo desta pesquisa prevê uma avaliação do sistema de transporte público em uma cidade de grande porte, através do uso do Índice de Mobilidade Urbana Sustentável (Costa, 2008), visando à melhoria da qualidade de vida das pessoas. Para isso, se fez necessária uma revisão da literatura baseada em conceitos e definições no âmbito da mobilidade urbana sustentável, do transporte público urbano, e características de métodos de avaliação de sistemas de transporte público e da gestão da mobilidade urbana. A revisão é apresentada nas próximas seções deste capítulo e foi imprescindivel para o desenvolvimento da pesquisa, ampliando, deste modo, o conhecimento na área.

\subsection{Mobilidade Urbana Sustentável}

O processo de urbanização observado nos países desenvolvidos durante o século XX resultou em uma grande concentração populacional em algumas cidades. Hoje, esse processo também ocorre no Brasil. Essa situação gera inúmeros conflitos entre pessoas de diferentes níveis de renda pela apropriação e o uso de espaços públicos. Os grandes centros urbanos começam a se tornar palco de viagens mais demoradas, da perda de mobilidade das pessoas, congestionamentos, do aumento da poluição, do desperdício de energia, dos acidentes, das mortes, e do aumento da frota de veículos particulares (BOARETO, 2008).

A partir deste contexto surge uma preocupação intensa no que diz respeito à mobilidade urbana. Ainda existe muita confusão quanto à definição deste termo. Muitos acreditam que ele envolve apenas a prestação de serviços de transportes, principalmente dos modos motorizados. Desta forma, a análise da mobilidade estaria restrita apenas à circulação de automóveis e ao uso dos transportes coletivos (AZEVEDO FILHO, 2012).

No entanto, este conceito também envolve o uso e ocupação do solo, e a interação entre estes dois sistemas. De acordo com Mitchell (2008), na sua comparação entre cidades e pessoas, o funcionamento das metrópoles depende, principalmente, de um bom planejamento do uso do solo junto com um sistema de transporte eficiente.

$\mathrm{O}$ modelo de mobilidade adotado no século XX era voltado para investimentos públicos em trânsito e infraestrutura viária para a maioria das cidades, resultando em uma maior exclusão social. Boareto (2008) acredita que o governo deve pensar na mobilidade 
urbana como sendo o resultado de uma política pública. Souza (2006) resume política pública como o campo do conhecimento que tenta "colocar o governo em ação", analisar esta ação e propor mudanças no andamento desta. Depois de formuladas, as políticas públicas se transformam em planos, programas, projetos, base de dados ou sistema de informação e pesquisa, que quando implantadas são submetidas a sistemas de monitoramento e avaliação.

Daí surge o desejo de se construir cidades sustentáveis, o que tem sido objeto de vários estudos. Estes estudos incluem o desenvolvimento de um novo conceito para a mobilidade, que mantenha o foco na melhoria das condições de mobilidade e acessibilidade, visando uma melhor qualidade de vida para os cidadãos urbanos e buscando alcançar a sustentabilidade (RODRIGUES DA SILVA et al., 2008).

De acordo com o Ministério das Cidades (MCIDADES, 2012), a Mobilidade Urbana Sustentável é o resultado de um conjunto de políticas de transporte e circulação que deve proporcionar o acesso amplo e democrático ao espaço urbano, através da priorização efetiva dos modos não motorizados e coletivos de transportes, de forma segura, socialmente inclusiva e ecologicamente sustentável.

Em 2012, foi instituída, através de força de lei, a Política Nacional de Mobilidade Urbana, que consiste em um instrumento da política de desenvolvimento urbano, tendo como objetivo integrar os diversos modos de transporte e melhorar a acessibilidade e mobilidade de pessoas e cargas no território do Município (BRASIL, 2012). Segundo esta lei, a Política Nacional de Mobilidade Urbana procura seguir as seguintes diretrizes:

\footnotetext{
“...I - integração com a política de desenvolvimento urbano e respectivas políticas setoriais de habitação, saneamento básico, planejamento e gestão do uso do solo no âmbito dos entes federativos; II - prioridade dos modos de transportes não motorizados sobre os motorizados e dos serviços de transporte público coletivo sobre o transporte individual motorizado; III - integração entre os modos e serviços de transporte urbano; IV - mitigação dos custos ambientais, sociais e econômicos dos deslocamentos de pessoas e cargas na cidade; $\mathrm{V}$ - incentivo ao desenvolvimento científico-tecnológico e ao uso de energias renováveis e menos poluentes; VI - priorização de projetos de transporte público coletivo estruturadores do território e indutores do desenvolvimento urbano integrado; e VII - integração entre as cidades gêmeas localizadas na faixa de fronteira com outros países sobre a linha divisória internacional."
}

Conforme publicação do IPEA (2011), esta lei veio contribuir para enfrentar o quadro de falta de sustentabilidade que predomina hoje, dando aos municípios ferramentas para melhorar as condições de mobilidade das pessoas nas cidades brasileiras. A partir da aplicação dos seus princípios e diretrizes, é possível idealizar o nível de cidade que se pode alcançar (NÉSPOLI, 2013): 
- cidadãos com amplo acesso aos bens e serviços, acesso universal ao transporte;

- viagens mais curtas;

- tratamento aos usuários de transporte por ônibus como cidadãos de primeira classe;

- sistemas mais confiáveis, regulares e pontuais;

- passageiros bem informados;

- pessoas tratadas como pessoas humanas;

- calçadas uniformes, bem conservadas;

- pedestres com prioridade sobre o transporte motorizado;

- veículos trafegando em velocidade moderada;

- onde é possível andar de bicicleta;

- e onde, enfim, crianças, jovens, adultos e idosos podem ir e vir com tranquilidade, conforto e segurança.

Vale lembrar que os projetos e decisões implantadas devem estar sempre integrados com todos os demais, facilitando, assim, o caminho para se construir cidades mais sustentáveis. No entanto, é importante que o processo de gestão de cada região exija a colaboração entre os setores da Administração Pública, que interferem na mobilidade urbana, no que diz respeito às suas atribuições, buscando, assim, atingir seus objetivos com eficiência e qualidade.

O conceito de sustentabilidade distingue crescimento (aumento da quantidade) de desenvolvimento (maior qualidade). Procura se concentrar nos resultados de bem-estar social como saúde e educação, em vez de riqueza material. Este conceito vem colaborar para a mudança de paradigma que está ocorrendo no planejamento dos transportes (LITMAN, 2009). No entanto, o desenvolvimento sustentável não depende só de planos e programas com foco na sustentabilidade, mas também da existência de barreiras para implantação e oportunidades para inovação.

Miranda et al. (2009) buscaram avaliar a reação de técnicos e gestores de transportes de uma cidade média, localizada no interior de São Paulo, quanto a uma proposta preliminar de um plano de mobilidade que continha os conceitos de sustentabilidade. O principal objetivo era identificar possíveis barreiras para a implantação desse tipo de plano. Os resultados obtidos levaram a três principais conclusões: os técnicos e gestores ainda não parecem dominar integralmente o conceito de mobilidade urbana sustentável; uma das 
barreiras para a implantação de um plano de mobilidade pode ainda estar no arranjo legal que vincula esse plano ao plano diretor municipal e outros dispositivos legais já consolidados; e a prioridade de ação ainda é voltada para o modo motorizado individual, apesar dos técnicos acreditarem que os modos não motorizados e o transporte público são as melhores opções.

Curtis e Low (2012) retratam a realidade da mobilidade vivida pela população de três cidades da Austrália (Melbourne, Sydney e Perth). Os autores estudaram como as barreiras institucionais influenciam na transição entre o planejamento tradicional e sustentável, e refletem sobre como é possível superá-las. Eles explicam como o uso ilimitado do carro está deixando de ser a peça central para os planejadores urbanos. Entre os principais motivos está o fracasso de programas maciços e caros de construção de autoestradas urbanas, a perspectiva de crescimento da população nas cidades e o aumento do preço do combustível, estimulando o aumento do uso do transporte público.

A teoria da dependência da trajetória (do inglês, Path Dependence) explica porque as coisas continuam praticamente inalteradas apesar da necessidade de mudanças, segundo os autores. Eles ainda concluem que a mudança pode levar um longo tempo para a sua aprovação geral e sua aplicação generalizada, além de ocorrer em momentos críticos e envolver uma rede de atores (ativistas sociais, líderes comunitários, burocratas, políticos, profissionais e acadêmicos).

Rodrigues da Silva (2013), em sua análise sobre o trabalho de Curtis e Low (2012), comenta sobre a crença dos autores no efeito do discurso de técnicos, políticos e acadêmicos, que para eles desempenham um papel fundamental na mudança de paradigma. Divide ainda a obra em quatro partes: análise de documentos estaduais e federais da segunda metade do século XX que estão relacionados com a infraestrutura viária e o transporte público das cidades de Melbourne, Sydney e Perth; análise dos estudos de impacto ambiental e outros relatórios de planejamento dos grandes projetos de construção de estradas desenvolvidos nas três cidades; estudo sobre as instituições, e, sobretudo, sobre suas regras e procedimentos; entrevistas com pessoas influentes sobre as decisões acerca de infraestrutura viária e transporte público.

A importância das abordagens utilizadas durante a pesquisa também é retratada, apesar do número de cidades investigadas ter sido pequeno, fator que pode vir a motivar uma ampliação do estudo para várias outras cidades do mundo, de acordo com Rodrigues da Silva (2013). Por fim, o autor afirma que a obra vem proporcionar uma grande contribuição no 
campo de planejamento de transportes, se tornando uma referência importante para os planejadores, formuladores de políticas e tomadores de decisão (incluindo os políticos), bem como estudantes.

Farla et al. (2010) abordam, em seu estudo, quais seriam as principais barreiras e interdependências que podem influenciar no processo de transição para a mobilidade sustentável. As barreiras podem ser classificadas em tecnológicas e institucionais. Os autores propuseram quatro caminhos de transição (biocombustíveis, hibridização de veículos, gás natural e biogás e hidrogênio para transporte), que apresentaram três tipos de barreiras: barreiras relacionadas com componentes de tecnologia e veículos; barreiras relacionadas com infraestruturas físicas e barreiras relacionadas com infraestruturas institucionais.

Estudos sobre barreiras para o desenvolvimento sustentável vêm se disseminando pelo mundo. A importância sobre esta discussão é bem clara no meio do planejamento de transportes, no intuito de conduzir os gestores e especialistas a tomar decisões precisas e eficazes.

\subsection{A mobilidade e o transporte público}

O sistema de transporte público pode ser considerado um segmento estruturador da organização e composição do território, causando vários impactos no desenvolvimento econômico e social das cidades (MORAIS, J.S., 2012). Este tipo de sistema deve ser garantido aos cidadãos pelo poder publico, assegurando o direito de ir e vir, com conforto, qualidade, segurança e com uma tarifa razoável. Isto se trata de uma necessidade básica da sociedade (FERRAZ e TORRES, 2004).

De acordo com Curtis e Low (2012), um sistema de transporte urbano sustentável é aquele que atende a uma variedade de objetivos além de simplesmente mobilidade, alguns dos quais se apresentam intangíveis, como a melhoria da qualidade do espaço urbano. A equidade nos deslocamentos vem se tornando cada vez mais importante, mas sua avaliação ainda é um fator negligenciado.

Atualmente, o problema do transporte público é tratado como um conjunto bastante complexo de vários outros problemas que se inter-relacionam entre si. Estes problemas se resumem basicamente em congestionamentos, baixa qualidade de serviços de transporte público, falta de transporte adequado para certos grupos, problemas financeiros e impactos 
ambientais. Segundo Black (1995), eles podem ser agrupados em três categorias principais: congestionamentos, mobilidade e impactos auxiliares.

Desde a década de 1990, a ideia de integração entre modos de transporte virou uma tendência, culminando na fundação de agências responsáveis pela coordenação do transporte público desempenhando funções como controle de estacionamento, regulação do tráfego, e incorporação de trânsito de pedestres em áreas sinalizadas, atraindo um grande número de pessoas para as cidades. Visto isso, hoje, os melhores serviços de transporte público se encontram em cidades que possuam sistema de integração de todos os modos de transporte e uma boa coordenação de transporte público, tráfego nas ruas e trânsito de pedestres. Alguns exemplos são Munique, Paris, Portland, Estocolmo e Toronto. (VUCHIC, 2007) A Figura 2.1 mostra, a título de exemplo, o serviço de transporte público ofertado em Portland.

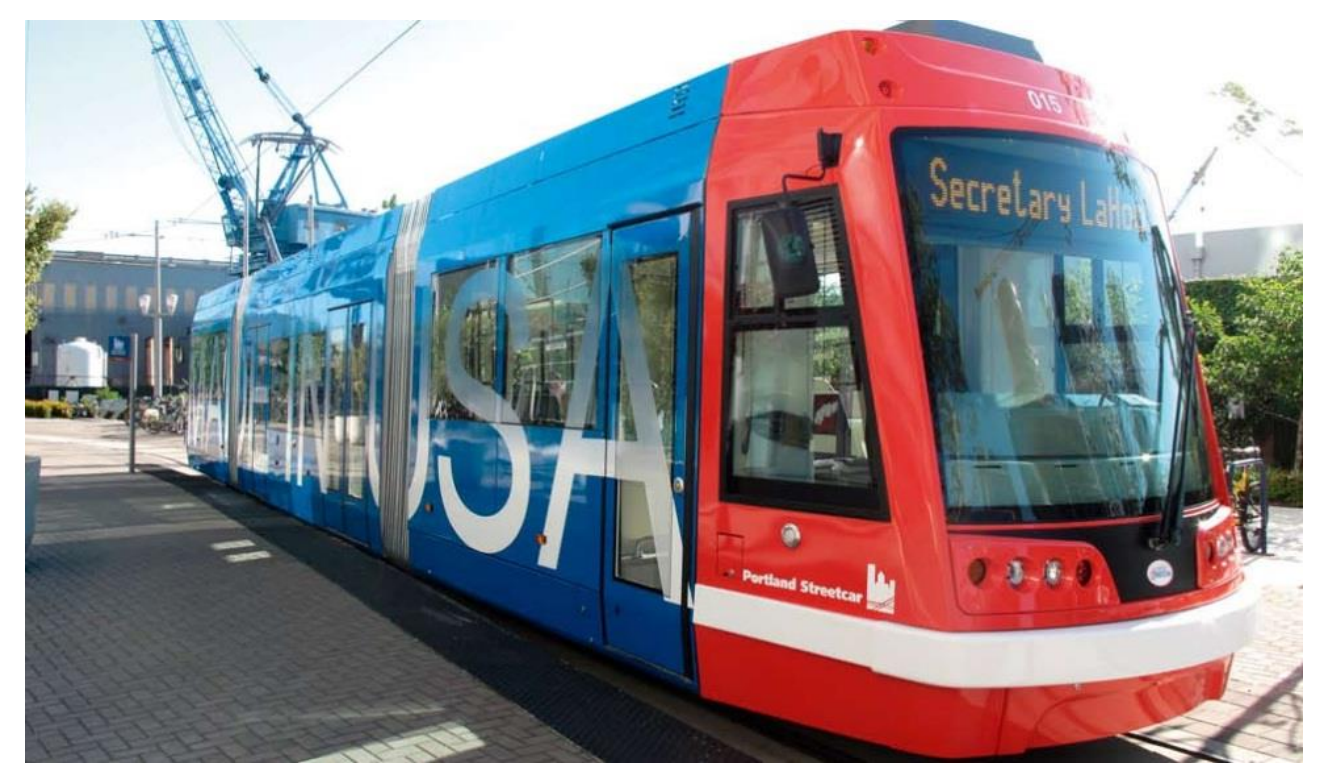

Figura 2.1 - Serviço de transporte público em Portland (LRTA, 2009)

A concepção sobre transporte urbano ainda se mostra inadequada, o que vem causando inúmeros problemas tecnológicos, como a seleção incorreta dos modos e da queda de conhecimento técnico na área de transporte público urbano. Deste modo, para que se consiga um sistema de transporte urbano eficiente e saudável para as cidades, é fundamental que haja uma boa compreensão de duas áreas (VUCHIC, 2007):

- Planejamento, organização e política;

- Sistemas de transporte público urbano e tecnologia.

Um bom sistema de transporte público pode gerar uma maior atração por parte da população, fazendo com que o uso do transporte privado diminua, e haja uma melhoria na 
mobilidade urbana. Para Albano e Senna (1996), o termo "transporte" pode ser entendido como sendo a interseção da economia com as questões do meio ambiente. Daí a explicação para sua forte ligação com o desenvolvimento sustentável, que consiste na qualidade de vida projetada para o futuro. Um progresso importante nos últimos anos foi o surgimento do termo "transporte sustentável". Este termo define o transporte que garante o atendimento das necessidades de transporte e mobilidade sem comprometer as gerações futuras (BLACK, 1996).

As cidades brasileiras vêm buscando promover melhorias no âmbito do transporte público, vendo neste tipo de sistema uma das soluções para reduzir os congestionamentos e acidentes de trânsito. A qualidade do transporte público está diretamente ligada à eficiência de aplicação de políticas públicas que envolvam o conceito de sustentabilidade.

Uma das cidades brasileiras que se destacam pela qualidade do seu sistema de transporte público é Curitiba, localizada no estado do Paraná. Em 1974, foi criada a Rede Integrada de Transporte (RIT), que contava com uma infraestrutura diferenciada dotada de canaletas exclusivas para ônibus, o que melhorou consideravelmente a logística de transporte da cidade (URBS, 2013). O projeto foi desenvolvido pelo prefeito da época, o arquiteto Jaime Lerner. A partir desta iniciativa, o transporte público de Curitiba vem evoluindo no decorrer dos anos (tarifa social, construção de terminais fechados, estações tubo, criação de linhas diretas, veículos biarticulados, implantação do sistema de bilhetagem eletrônica, etc.), agregando melhorias à mobilidade urbana. (Figura 2.2)

Atualmente, a cidade de Curitiba pode até ser considerada um benchmarking em mobilidade sustentável (MIRANDA, 2010; MIRANDA e RODRIGUES DA SILVA, 2012), devido às suas boas práticas de planejamento urbano e de transporte. No entanto, apesar de ser referência para o transporte público, a cidade ainda deixa a desejar no que diz respeito ao incentivo de modos não motorizados. 


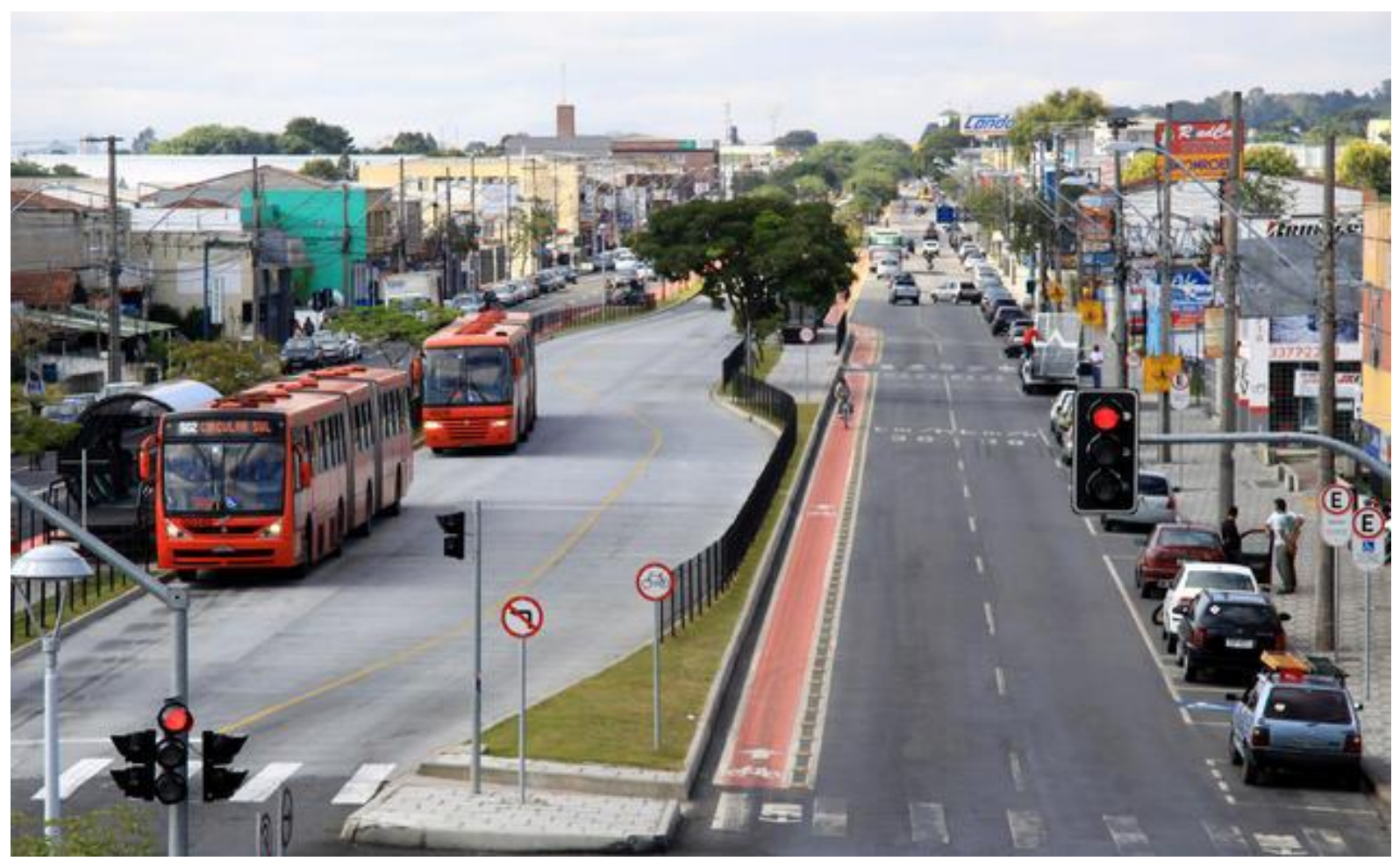

Figura 2.2 - Rede Integrada de Transporte em Curitiba (Fonte: URBS, 2013)

\subsection{Avaliação da qualidade do transporte público}

Avaliar a qualidade do transporte público de uma cidade é uma das formas de contribuir para o processo de aperfeiçoamento do seu desempenho. É importante analisar as visões dos diversos setores envolvidos (usuários, comunidade, governo, trabalhadores e empresários). Esta tarefa pode ser realizada observando uma série de aspectos: acessibilidade, frequência de atendimento, tempo de viagem, lotação, confiabilidade, segurança, características dos ônibus, características dos locais de parada, sistema de informações, conectividade, comportamento dos operadores e estado das vias (FERRAZ e TORRES, 2004).

Várias formas de avaliação no âmbito do transporte público vêm sendo arquitetadas e utilizadas para garantir maior precisão e credibilidade dos resultados alcançados. Dentre elas podem ser citadas: pesquisa de opinião e entrevistas (MAIA, 2010; CAVALCANTE NETO, 2009; RODRIGUES e SORRATINI, 2008; RODRIGUES, 2006), análise de cluster, árvore de decisão e regressão logística (PITOMBO et al., 2010); análise de componentes principais (CHAVES, 2010); análise exploratória de dados espaciais (AZEVEDO FILHO et al., 2010) e teoria das representações e percepção da qualidade (MORAIS, J. S., 2012). 
Todas elas levam em consideração alguns indicadores de qualidade que permitem diagnosticar cada situação analisada.

Rodrigues e Sorratini (2008), por exemplo, se propuseram a analisar o serviço de transporte público por ônibus ofertado na cidade de Uberlândia, localizada no estado de Minas Gerais. Sua análise foi baseada, principalmente, em uma pesquisa de opinião realizada com os usuários (amostra) e em indicadores de qualidade para este serviço de transporte. As pesquisas mostraram que os indicadores "lotação", "confiabilidade", "estado das vias", "segurança", "frequência de atendimento", "características dos veículos" e "características dos locais de parada" possuem um maior grau de importância para os usuários.

Além da análise com relação à importância de cada indicador, foi feita uma análise dos padrões de aceitabilidade para os usuários. Com isso, surgiram ainda "tempo de viagem" e "sistema de informação" como indicadores deficientes. Portanto, estes aspectos merecem uma atenção diferenciada por parte dos técnicos e gestores da área. Os autores tratam ainda sobre o fato da escolha dos indicadores mais apropriados para avaliar cada situação. A Tabela 2.1 mostra os principais indicadores de avaliação da qualidade do transporte público encontrados na literatura, segundo Rodrigues e Sorratini (2008).

Tabela 2.1 - Síntese de indicadores para avaliar a qualidade do transporte público urbano

\begin{tabular}{|c|c|}
\hline Autor (es) & Indicadores \\
\hline $\begin{array}{l}\text { Waisman }{ }^{1}(1983 \\
\text { apud Rodrigues, } \\
\text { 2006, p. } 15\end{array}$ & $\begin{array}{l}\text { Comparabilidade, cobertura, resposta à necessidade, compreensibilidade, } \\
\text { flexibilidade, incentivos para o alcance de melhorias e disponibilidade de dados. }\end{array}$ \\
\hline Lima Jr. (1995) & $\begin{array}{c}\text { Mercados regulamentados ou sem diferenciação de produto, produto intangível, } \\
\text { produção e consumo simultâneos, grandes oscilações de demanda, indivisibilidade } \\
\text { da oferta, processos e produtos heterogêneos, satisfação com o produto e com o } \\
\text { processo, interação com o meio ambiente, rede de processos e parcerias e } \\
\text { diferenças tecnológicas. }\end{array}$ \\
\hline $\begin{array}{l}\text { Transit Capacity } \\
\text { and Quality of } \\
\text { Service Manual } \\
\text { (TCRP, 2003) }\end{array}$ & $\begin{array}{c}\text { Frequência, horas de serviço, cobertura do serviço, demanda de passageiros, } \\
\text { confiabilidade do serviço, diferença de tempos de viagem entre o automóvel e o } \\
\text { ônibus. }\end{array}$ \\
\hline $\begin{array}{l}\text { Ferraz e Torres } \\
\qquad(2004)\end{array}$ & $\begin{array}{c}\text { Acessibilidade, frequência de atendimento, tempo de viagem, lotação, } \\
\text { confiabilidade, segurança, características dos veículos, características dos locais } \\
\text { de parada, sistema de informação, conectividade, comportamento dos operadores, } \\
\text { e estado das vias. }\end{array}$ \\
\hline
\end{tabular}

Fonte: Adaptado de Rodrigues e Sorratini (2008)

${ }^{1}$ Waisman, J. (1983) Avaliação do desempenho de sistemas de ônibus, em cidades de médio porte, em função de sua produtividade, eficiência operacional e qualidade dos serviços. Tese (Doutorado) - Escola de Engenharia de São Carlos, Universidade de São Paulo, São Carlos. 
Segundo Pitombo et al. (2010), o sistema de transporte público da cidade de Salvador, localizada no estado da Bahia, apresenta problemas como o excesso de linhas concorrentes nos principais corredores, baixa frequência e falta de confiabilidade entre as partidas, atendimento temporal deficiente, extensões e tempos de viagem críticos, saturação das estações e infraestrutura deficiente, além da falta de segurança dentro dos coletivos. Com isso, os autores buscaram analisar o desempenho do sistema por meio de ferramentas espaciais e de análise multivariada (análise de Cluster, árvore de decisão e regressão logística), sob a ótica dos usuários. Os resultados mostraram "confiabilidade", "segurança", "tarifa" e "locais de parada" como os aspectos críticos do sistema. A análise espacial apontou que a parcela da população mais descontente está localizada nas regiões mais pobres da cidade (Subúrbio e Miolo).

Em sua pesquisa, Chaves (2010) buscou avaliar o grau de satisfação de usuários e gestores quanto ao serviço de transporte público prestado na Região Metropolitana de Belém, localizada no estado do Pará, a partir de modelos de qualidade desenvolvidos com o método de Análise de Componentes Principais (ACP). Este método consiste em uma das técnicas de análise multivariada e tenta transformar linearmente as variáveis originais em variáveis inéditas. Em um primeiro momento foram realizadas pesquisas de satisfação com os usuários e gestores, contemplando aspectos referentes ao "tempo de viagem", "pontualidade", "frequência de atendimento" e "lotação"; à "segurança"; à informação; ao "capital humano" e “área social", ao "conforto" e "acessibilidade". Os resultados da pesquisa mostram a insatisfação dos usuários com relação à qualidade do serviço, enquanto que os gestores acreditam que o sistema oferece um bom serviço. A redistribuição do espaço e circulação dos pedestres, ciclistas e passageiros do transporte público, e o uso dos modelos propostos como base para ações de planejamento, controle e gestão do setor público e privado se encontram entre as sugestões do trabalho.

Azevedo Filho et al. (2010) analisaram os dados de uma pesquisa realizada com moradores da cidade de São Carlos sobre dois modos de transporte: carro e ônibus. A metodologia utilizada foi a Análise Exploratória de Dados Espaciais (do inglês, Exploratory Spatial Data Analysis - ESDA), que permite a identificação de padrões de associação espacial, observações atípicas e instabilidade espacial dos dados analisados. Alguns resultados mostram que os usuários de transporte público, que vivem longe do centro da cidade, apontam "lotação" e "frequência de atendimento" como os aspectos mais problemáticos. A partir daí, viu-se a necessidade de melhorias no sistema. 
O estudo de Morais, J. S. (2012) propõe uma metodologia para avaliar a qualidade do sistema de transporte público urbano por ônibus da cidade de Goiânia, localizada no estado de Goiás, com base na Teoria das Representações Sociais e na Percepção da Qualidade (Psicologia Social). A ideia surgiu para entender o que influencia na escolha das pessoas e como elas percebem e reagem ao ambiente. Foram realizadas algumas entrevistas com representantes de diferentes setores da sociedade. Os resultados, de um modo geral, mostram a insatisfação dos entrevistados com relação ao serviço oferecido na cidade. A autora acredita que a metodologia proposta pode ser uma solução inovadora para a melhoria da mobilidade urbana de forma sustentável nas cidades.

Cada metodologia possui sua relevância específica na atividade de avaliação de sistemas de transporte público. Esta seção tentou manter o foco nos resultados das aplicações de cada metodologia, não sendo aprofundado o estudo sobre cada uma.

\subsection{Metodologias de avaliação da gestão de mobilidade urbana}

Os objetivos políticos de vários países quanto aos seus sistemas de transporte estão se resumindo em alcançar padrões de mobilidade sustentável, prosperidade econômica e melhoria da qualidade de vida. Para medir o desempenho destes sistemas e políticas de transporte, a busca por indicadores vem aumentando (GUDMUNDSSON, 2001).

Litman (2009) afirma que, no processo de planejamento de transportes, os indicadores são ferramentas importantes que facilitam a tomada de decisões e o progresso das medidas adotadas. No entanto, eles devem ser selecionados com precaução, para que sua coleta e análise sejam possíveis e para que consigam refletir os impactos e perspectivas de cada situação. Os indicadores podem refletir vários níveis de análise, conforme mostra a Tabela 2.2. Segundo Richardsson (2005), estes níveis devem adequar-se aos aspectos ambientais, sociais e econômicos de uma sociedade, que são as três dimensões que formam o tripé da sustentabilidade.

Alguns princípios podem auxiliar na escolha dos indicadores, segundo Litman (2009): os indicadores devem abranger cada uma das principais categorias (abrangente e equilibrado); os indicadores devem ser escolhidos de acordo com a viabilidade de coleta dos dados necessários, além da comprovação da qualidade adequada destes (dados viáveis para coleta); os indicadores devem ser facilmente compreendidos pelo público em geral e úteis para os tomadores de decisão (compreensíveis e úteis); dependendo do tipo de análise, alguns dados 
podem precisar ser desagregados (desagregação); é importante padronizar as unidades de referência (unidades de referência); os indicadores devem refletir impactos finais, tendo cuidado para uma possível dupla contagem de impactos (níveis de análise); a análise dos indicadores deve alcançar objetivos específicos e mensuráveis (metas de desempenho).

Tabela 2.2 - Níveis de análise para indicadores

\begin{tabular}{cl}
\hline Níveis & \multicolumn{1}{c}{ Exemplos } \\
\hline Tendências Externas & $\begin{array}{l}\text { Mudanças na população, renda, atividade econômica, pressões políticas, } \\
\text { etc. }\end{array}$ \\
\hline Processo de tomada de decisão & $\begin{array}{l}\text { Processo de planejamento, política de preços, envolvimento das partes } \\
\text { interessadas, etc. }\end{array}$ \\
\hline Políticas & $\begin{array}{l}\text { Projetos de instalações e operações, serviços de transporte, preços, } \\
\text { informações do usuário, etc. }\end{array}$ \\
\hline Respostas & $\begin{array}{l}\text { Viagem (Volume de tráfego, escolha do modo, etc.), emissão de } \\
\text { poluentes, acidentes, padrões de desenvolvimento do solo, etc. }\end{array}$ \\
\hline Impactos cumulativos & $\begin{array}{l}\text { Mudanças na poluição ambiental, níveis de risco de tráfego, } \\
\text { acessibilidade em geral, custos de transporte, etc. }\end{array}$ \\
\hline Efeitos humanos e ambientais & $\begin{array}{l}\text { Mudanças na exposição à poluição, saúde, acidentes de trânsito e } \\
\text { mortes, produtividade ecológica, etc. }\end{array}$ \\
\hline Impactos econômicos & $\begin{array}{l}\text { Danos materiais, despesas médicas, perda de produtividade, de } \\
\text { mitigação e compensação de custos. }\end{array}$ \\
\hline Avaliação de Desempenho & Capacidade de atingir metas especificadas. \\
\hline Fonte: Adaptado de Litman (2009)
\end{tabular}

Fonte: Adaptado de Litman (2009)

Segundo Rodrigues da Silva et al. (2008), alguns países europeus têm sido pioneiros no que diz respeito a busca por um novo conceito de mobilidade e no desenvolvimento e aplicação de indicadores como ferramentas de monitoramento de implementação de estratégias e políticas relacionadas. Existem várias metodologias que envolvem estudos sobre mobilidade urbana e estão sendo desenvolvidas no decorrer dos anos. Gudmundsson (2001) propôs algumas alternativas que podem garantir a mobilidade sustentável no espaço urbano, conforme mostra a Figura 2.3. 


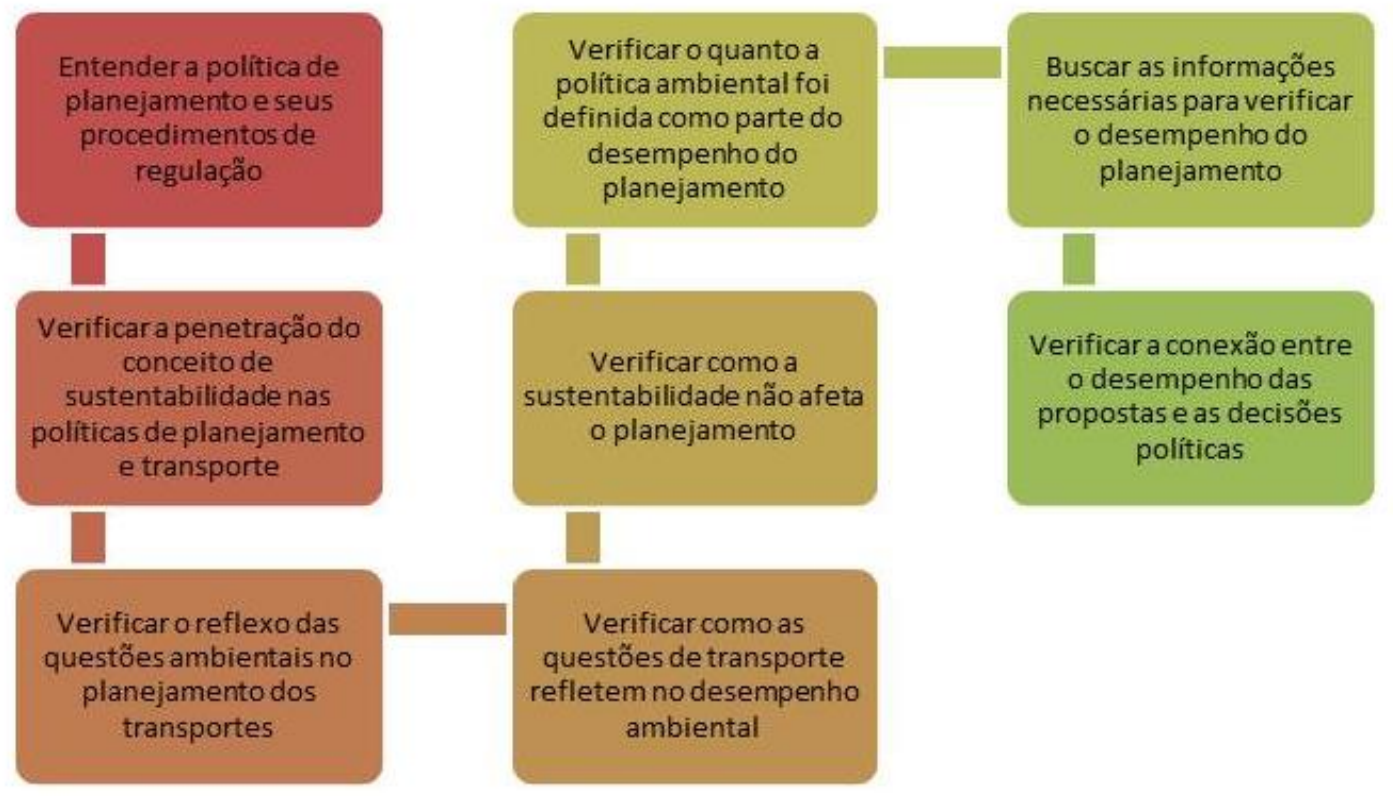

Figura 2.3 - Propostas de Gudmundsson (2001) para mobilidade sustentável em espaços urbanos

\subsubsection{O Índice de Mobilidade Urbana Sustentável}

Costa (2008) elaborou o Índice de Mobilidade Urbana Sustentável - IMUS com o intuito de oferecer algum suporte à gestão da mobilidade e à formulação de políticas públicas nos municípios. Este Índice busca combinar Domínios e Temas necessários ao monitoramento da mobilidade urbana, abordando os princípios fundamentais do desenvolvimento sustentável. Ele possui uma estrutura hierárquica baseada em um conjunto de indicadores que são destinados a traduzir os diversos impactos e perspectivas da mobilidade, sendo baseados em dados de fácil obtenção e cálculo direto. Algumas características do índice que merecem destaque:

- É baseado em uma hierarquia de critérios baseada em conceitos e elementos identificados por técnicos e gestores atuantes no âmbito do planejamento urbano e dos transportes de onze cidades ou regiões metropolitanas brasileiras;

- Possui um sistema de pesos para os critérios. Os pesos foram obtidos através de consulta a especialistas de diferentes países (Brasil, Portugal, Estados Unidos, Austrália e Alemanha). A partir destes pesos, é possível identificar a importância relativa dos elementos e conceitos considerados no índice, bem como avaliar o impacto de alterações ocorridas nas três dimensões da sustentabilidade: social, ambiental e econômica; 
- Contém um modelo de agregação de critérios, permitindo compensações de critérios com pesos baixos por critérios com pesos altos entre os 9 Domínios, 37 Temas e 87 Indicadores que compõem o índice;

- Constitui ferramenta de fácil entendimento e aplicação, por não exigir o uso de programas de computador específicos ou de modelos matemáticos complexos. Os cálculos são realizados por meio de planilha eletrônica e/ou calculadora.

Na Tabela 2.3 são apresentados os Domínios, Temas e Indicadores que compõem o IMUS, juntamente com seus respectivos pesos em destaque. De acordo com a autora, após a definição dos pesos, um processo de normalização permite o cálculo de um escore normalizado, para cada indicador, entre 0 e 1 . A partir destes escores normalizados, será obtido o valor global do IMUS, com a mesma escala de variação definida para os indicadores, entre 0 e 1 . Em sua estrutura existem tanto indicadores quantitativos como indicadores qualitativos.

Esta metodologia já foi aplicada em algumas cidades, como São Carlos (COSTA, 2008), Curitiba (MIRANDA, 2010; MIRANDA e RODRIGUES DA SILVA, 2012), Anápolis (MORAIS, T. S, 2012), São Paulo (COSTA, 2011) e Distrito Federal (PONTES, 2010). Atualmente, vários outros locais estão tentando implantá-la como ferramenta de avaliação e monitoramento. 
Tabela 2.3 - DomínIOS, Temas e Indicadores do IMUS e seus respectivos pesos

\begin{tabular}{|c|c|c|}
\hline Domínio & Tema & Indicador \\
\hline \multirow{4}{*}{ 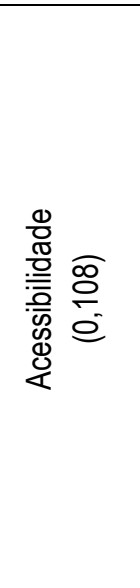 } & Acessibilidade aos sistemas de transporte $(0,29)$ & $\begin{array}{l}\text { - Acessibilidade ao transporte público }(0,333) \\
\text { - Transporte público para pessoas com necessidades especiais } \\
(0,333) \\
\text { - Despesas com transportes }(0,333)\end{array}$ \\
\hline & Acessibilidade universal $(0,28)$ & $\begin{array}{l}\text { - Travessias adaptadas para pessoas com necessidades } \\
\text { especiais }(0,200) \\
\text { - Acessibilidade aos espaços abertos }(0,200) \\
\text { - Vagas de estacionamento para pessoas com necessidades } \\
\text { especiais }(0,200) \\
\text { - Acessibilidade a edifícios públicos }(0,200) \\
\text { - Acessibilidade aos serviços essenciais }(0,200)\end{array}$ \\
\hline & Barreiras físicas $(0,22)$ & - Fragmentação urbana $(1,00)$ \\
\hline & $\begin{array}{l}\text { Legislação para pessoas com necessidades } \\
\text { especiais }(0,21)\end{array}$ & - Ações para acessibilidade universal $(1,00)$ \\
\hline \multirow{2}{*}{ 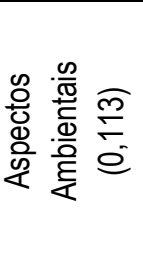 } & Controle dos impactos no meio ambiente $(0,52)$ & $\begin{array}{l}\text { - Emissões de } \mathrm{CO}(0,250) \\
\text { - Emissões de } \mathrm{CO}_{2}(0,250) \\
\text { - População exposta ao ruído de tráfego }(0,250) \\
\text { - Estudos de Impacto Ambiental - EIA }(0,250)\end{array}$ \\
\hline & Recursos naturais $(0,48)$ & $\begin{array}{l}\text { - Consumo de combustível }(0,500) \\
\text { - Uso de energia limpa e combustíveis alternativos }(0,500)\end{array}$ \\
\hline \multirow{5}{*}{ 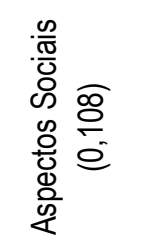 } & Apoio ao cidadão $(0,21)$ & - Informação disponível ao cidadão $(1,000)$ \\
\hline & Inclusão social $(0,2)$ & - Equidade vertical (renda) $(1,000)$ \\
\hline & Educação e cidadania $(0,19)$ & - Educação para o desenvolvimento sustentável $(1,000)$ \\
\hline & Participação popular $(0,19)$ & - Participação na tomada de decisão $(1,000)$ \\
\hline & Qualidade de vida $(0,21)$ & - Qualidade de vida $(1,000)$ \\
\hline \multirow{3}{*}{ 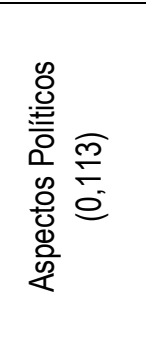 } & Integração de ações políticas $(0,34)$ & $\begin{array}{l}\text { - Integração entre níveis de governo }(0,500) \\
\text { - Parcerias público-privadas }(0,500)\end{array}$ \\
\hline & Captação e gerenciamento de recursos $(0,33)$ & $\begin{array}{l}\text { - Captação de recursos }(0,250) \\
\text { - Investimentos em sistemas de transporte }(0,250) \\
\text { - Distribuição dos recursos (coletivo x privado) }(0,250) \\
\text { - Distribuição dos recursos (motorizados x não motorizados) } \\
(0,250)\end{array}$ \\
\hline & Política de mobilidade urbana $(0,33)$ & - Política de mobilidade urbana $(1,00)$ \\
\hline \multirow[t]{2}{*}{ 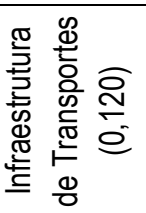 } & $\begin{array}{l}\text { Provisão e manutenção da infraestrutura de } \\
\text { transportes }(0,46)\end{array}$ & $\begin{array}{l}\text { - Densidade e conectividade da rede viária }(0,250) \\
\text { - Vias pavimentadas }(0,250) \\
\text { - Despesas com manutenção da infraestrutura }(0,250) \\
\text { - Sinalização viária }(0,250)\end{array}$ \\
\hline & Distribuição da infraestrutura de transporte $(0,54)$ & - Vias para transporte coletivo $(1,000)$ \\
\hline \multirow{3}{*}{ 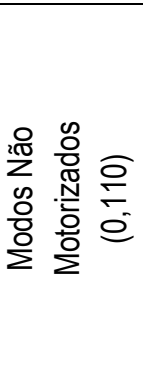 } & Transporte cicloviário $(0,31)$ & $\begin{array}{l}\text { - Extensão e conectividade de ciclovias }(0,333) \\
\text { - Frotas de bicicletas }(0,333) \\
\text { - Estacionamento de bicicletas }(0,333)\end{array}$ \\
\hline & Deslocamentos a pé $(0,34)$ & $\begin{array}{l}\text { - Vias para pedestres }(0,500) \\
\text { - Vias com calçadas }(0,500)\end{array}$ \\
\hline & Redução de viagens $(0,35)$ & $\begin{array}{l}\text { - Distância de viagem }(0,250) \\
\text { - Tempo de viagem }(0,250) \\
\text { - Número de viagens }(0,250) \\
\text { - Ações para redução do tráfego motorizado }(0,250)\end{array}$ \\
\hline
\end{tabular}

Fonte: Adaptado de Costa (2008). 


\begin{tabular}{|c|c|c|}
\hline Domínio & Tema & Indicador \\
\hline \multirow{8}{*}{ 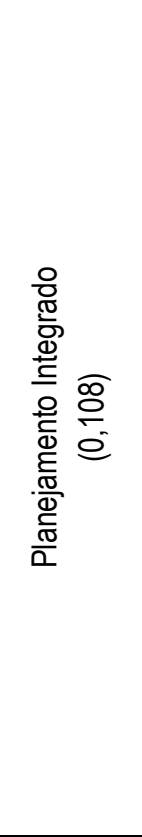 } & Capacitação de gestores $(0,12)$ & $\begin{array}{l}\text { - Nível de formação de técnicos e gestores }(0,500) \\
\text { - Capacitação de técnicos e gestores }(0,500)\end{array}$ \\
\hline & Áreas centrais e de interesse histórico $(0,11)$ & - Vitalidade do centro $(1,000)$ \\
\hline & Integração regional $(0,12)$ & - Consórcios intermunicipais $(1,000)$ \\
\hline & Transparência do processo de planejamento $(0,12)$ & - Transparência e responsabilidade $(1,000)$ \\
\hline & Planejamento e controle do uso e ocupação do solo $(0,14)$ & $\begin{array}{l}\text { - Vazios urbanos }(0,200) \\
\text { - Crescimento urbano }(0,200) \\
\text { - Densidade populacional urbana }(0,200) \\
\text { - Índice de uso misto }(0,200) \\
\text { - Ocupações irregulares }(0,200)\end{array}$ \\
\hline & Planejamento estratégico e integrado $(0,14)$ & $\begin{array}{l}\text { - Planejamento urbano, ambiental e de transporte } \\
\text { integrado }(0,500) \\
\text { - Efetivação e continuidade das ações }(0,500)\end{array}$ \\
\hline & $\begin{array}{l}\text { Planejamento da infraestrutura urbana e equipamentos } \\
\text { urbanos }(0,13)\end{array}$ & $\begin{array}{l}\text { - Parques e áreas verdes }(0,333) \\
\text { - Equipamentos urbanos (escolas) }(0,333) \\
\text { - Equipamentos urbanos (postos de saúde) }(0,333)\end{array}$ \\
\hline & Plano diretor e legislação urbanística $(0,12)$ & $\begin{array}{l}\text { - Plano diretor }(0,333) \\
\text { - Legislação urbanística }(0,333) \\
\text { - Cumprimento da legislação urbanística }(0,333)\end{array}$ \\
\hline \multirow{5}{*}{ 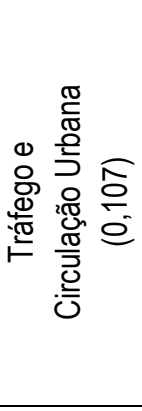 } & Acidentes de trânsito $(0,21)$ & $\begin{array}{l}\text { - Acidentes de trânsito }(0,333) \\
\text { - Acidentes com pedestres e ciclistas }(0,333) \\
\text { - Prevenção de acidentes }(0,333)\end{array}$ \\
\hline & Educação para o trânsito $(0,19)$ & - Educação para o trânsito $(1,000)$ \\
\hline & Fluidez e circulação $(0,19)$ & $\begin{array}{l}\text { - Congestionamento }(0,500) \\
\text { - Velocidade média do tráfego }(0,500)\end{array}$ \\
\hline & Operação e fiscalização de trânsito $(0,20)$ & - Violação das leis de trânsito $(1,000)$ \\
\hline & Transporte individual $(0,21)$ & $\begin{array}{l}\text { - Índice de motorização }(0,500) \\
\text { - Taxa de ocupação de veículos }(0,500) \\
\end{array}$ \\
\hline \multirow{5}{*}{ 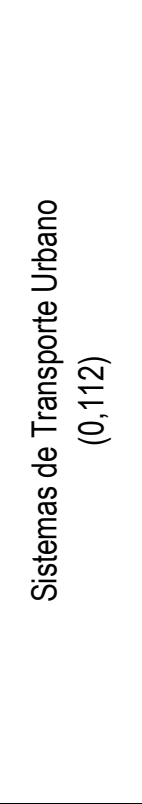 } & Disponibilidade e qualidade do transporte público $(0,23)$ & $\begin{array}{l}\text { - Extensão da rede de transporte público }(0,125) \\
\text { - Frequência de atendimento do transporte público }(0,125) \\
\text { - Pontualidade }(0,125) \\
\text { - Velocidade média do transporte público }(0,125) \\
\text { - Idade média da frota de transporte público }(0,125) \\
\text { - Índice de passageiros por quilômetro }(0,125) \\
\text { - Passageiros transportados anualmente }(0,125) \\
\text { - Satisfação do usuário com o serviço de transporte público } \\
(0,125)\end{array}$ \\
\hline & Diversificação modal $(0,18)$ & $\begin{array}{l}\text { - Diversidade de modos de transporte }(0,333) \\
\text { - Transporte coletivo x transporte individual }(0,333) \\
\text { - Modos não motorizados x modos motorizados }(0,333)\end{array}$ \\
\hline & Regulação e fiscalização do transporte público $(0,18)$ & $\begin{array}{l}\text { - Contratos e licitações }(0,500) \\
\text { - Transporte informal }(0,500)\end{array}$ \\
\hline & Integração do transporte público $(0,22)$ & $\begin{array}{l}\text { - Terminais intermodais }(0,500) \\
\text { - Integração do transporte público }(0,500)\end{array}$ \\
\hline & Política tarifária $(0,19)$ & $\begin{array}{l}\text { - Descontos e gratuidades }(0,333) \\
\text { - Tarifas de transporte }(0,333) \\
\text { - Subsídios públicos }(0,333)\end{array}$ \\
\hline
\end{tabular}

Fonte: Adaptado de Costa (2008). 


\subsubsection{Outras abordagens de monitoramento da mobilidade}

Existem outras metodologias que utilizam indicadores para avaliar a mobilidade urbana nas cidades brasileiras. Dentre elas está a metodologia proposta por Mobilize (2011), que envolve uma nota global obtida através da média de cinco indicadores. No entanto, seu principal objetivo consiste na comparação entre localidades.

Os indicadores (Tabela 2.4) foram construídos a partir dos seguintes objetivos específicos: reduzir a necessidade de viagens motorizadas, favorecer os deslocamentos por modos coletivos e não motorizados de transportes, proporcionar mobilidade a pessoas com deficiência, tornar o transporte coletivo acessível a todos os cidadãos e promover a utilização de fontes energéticas renováveis no setor de transportes. Sua nota é atribuída de acordo com uma medida do seu desempenho.

Tabela 2.4 - Indicadores do Mobilize (2011)

\begin{tabular}{l}
\hline Porcentagem de ônibus municipais adaptados a pessoas com deficiência física; \\
\hline Mortos em acidentes de trânsito (por 100.000 habitantes); \\
\hline $\begin{array}{l}\text { Extensão de vias adequadas ao trânsito de bicicletas em relação à extensão do sistema } \\
\text { viário; }\end{array}$ \\
\hline Razão entre a renda média mensal e a tarifa simples de ônibus urbano; \\
\hline Razão entre o número de viagens por modos individuais motorizados de transporte e o \\
número total de viagens.
\end{tabular}

Machado e Dominguez (2012) argumentam que a maioria das cidades brasileiras apresenta escassez de informações, o que dificulta o cálculo dos indicadores de mobilidade sustentável. Nesse contexto, os autores propuseram o Índice de Mobilidade Sustentável (IMS). Os indicadores selecionados requerem informações quantitativas e seus dados são coletados anualmente, facilitando a obtenção das informações necessárias. Três dimensões (social, ambiental e econômica) são consideradas e cada uma delas é composta por três temas. Cada tema, por sua vez, possui um indicador. A Tabela 2.5 relaciona os temas e indicadores com seus respectivos pesos, atribuídos a partir da consulta aos técnicos das administrações locais. Os autores introduzem ainda o conceito de "direção", que indica a contribuição positiva (aumentar) ou negativa (diminuir) de cada indicador. São calculados os valores de cada dimensão (subíndices) e a soma destes três valores forma o IMS. 
Tabela 2.5 - Estrutura do Índice de Mobilidade Sustentável

\begin{tabular}{|c|c|c|c|}
\hline Dimensão & Tema & Indicador & Direção \\
\hline \multirow{3}{*}{$\begin{array}{l}\text { Social } \\
(0,44)\end{array}$} & Acidentes com mortes & $\begin{array}{l}\text { \% de mortes em acidentes de } \\
\text { trânsito / frota de veículos }(0,36)\end{array}$ & Diminuir \\
\hline & Oferta de transporte coletivo & $\begin{array}{l}\text { Passageiros transportados per capita } \\
(0,34)\end{array}$ & Aumentar \\
\hline & Intermodalidade & $\begin{array}{l}\text { Número de estações intermodais } \\
(0,30)\end{array}$ & Aumentar \\
\hline \multirow{3}{*}{$\begin{array}{c}\text { Econômica } \\
(0,29)\end{array}$} & $\begin{array}{l}\text { Orçamento gasto em transporte } \\
\text { (tarifa) }\end{array}$ & $\begin{array}{l}\text { Valor médio da tarifa*mês / Salário } \\
\text { mínimo }(0,40)\end{array}$ & Diminuir \\
\hline & Eficiência do transporte coletivo & $\begin{array}{l}\text { Índice de passageiros por km (IPK) } \\
(0,31)\end{array}$ & Aumentar \\
\hline & $\begin{array}{l}\text { Investimentos públicos no setor } \\
\text { transportes }\end{array}$ & $\begin{array}{l}\% \text { de gastos em transportes / PIB } \\
(0,29)\end{array}$ & Aumentar \\
\hline \multirow{3}{*}{$\begin{array}{l}\text { Ambiental } \\
(0,27)\end{array}$} & Taxa de motorização & $\begin{array}{l}\text { Número de veículos em circulação } \\
\text { per capita }(0,45)\end{array}$ & Diminuir \\
\hline & Consumo de combustíveis fósseis & $\begin{array}{l}\text { Venda de combustível fóssil } \\
\text { (gasolina + diesel) per capita }(0,33)\end{array}$ & Diminuir \\
\hline & $\begin{array}{l}\text { Consumo de combustíveis } \\
\text { alternativos }\end{array}$ & $\begin{array}{l}\text { Venda de álcool hidratado per } \\
\text { capita }(0,22)\end{array}$ & Diminuir \\
\hline
\end{tabular}

Fonte: Machado e Dominguez (2012)

\subsection{Considerações finais}

Neste capítulo foi feita uma revisão e análise de conceitos e métodos adotados para transporte público e mobilidade urbana, que apresentam diferentes abordagens. Isto possibilitou um maior aprofundamento nos conhecimentos sobre o assunto e a percepção do problema complexo que envolve a mobilidade das cidades. Algumas iniciativas já foram tomadas no que diz respeito ao desenvolvimento e uso de instrumentos de monitoramento da situação, e isso é considerado um avanço na área de planejamento de transportes. A continuação da pesquisa consiste na coleta de dados e aplicação de uma das metodologias apresentadas anteriormente para a avaliação da qualidade do transporte público sob a ótica da mobilidade urbana sustentável, realizada para diferentes cenários. 


\section{MÉTODO UTILIZADO}

Este capítulo tratará da descrição dos procedimentos utilizados para o desenvolvimento da pesquisa. Com base na revisão da literatura, prosseguiu-se para as seguintes etapas: caracterização da área de estudo, escolha da metodologia de avaliação, coleta de dados, cenários propostos, cálculo dos indicadores, classificação dos indicadores, construção de diagnósticos e propostas de melhorias.

\subsection{Caracterização da área de estudo}

A área de estudo desta pesquisa consistiu no município de Fortaleza, capital do estado do Ceará, localizado na região Nordeste do Brasil, juntamente com a sua Região Metropolitana, composta por mais 14 municípios. O fato de Fortaleza ser considerada uma cidade de grande porte influenciou na escolha da mesma para o estudo. Outro motivo foi o fato de Fortaleza ser a cidade de origem da autora, o que possibilitou uma maior facilidade de obtenção dos dados, visto que a mesma já trabalhou nesta área. Ainda relevante para a pesquisa foi o fato de que a cidade de Fortaleza será uma das sedes da Copa do Mundo de 2014, o que pressupõe várias modificações no âmbito da mobilidade e do transporte público.

\subsection{Escolha da metodologia de avaliação}

O Índice de Mobilidade Urbana Sustentável (IMUS), desenvolvido por Costa (2008), foi a metodologia escolhida para o desenvolvimento deste estudo. Esta escolha deveu-se à experiência do grupo de pesquisa dos seus autores, à experiência em outras aplicações da mesma ferramenta e à possibilidade de contribuir para o seu aperfeiçoamento. O IMUS é adequado a este tipo de estudo, considerando a facilidade de aplicação e cálculo dos indicadores, bem como da análise dos resultados obtidos.

O IMUS é obtido através da composição de nove DoMínIOS, que se dividem em 37

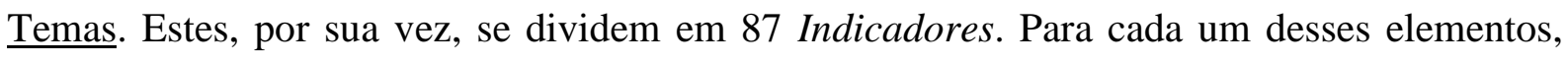
Costa (2008) especificou pesos, fazendo com que o valor final do índice variasse de zero (pior situação) a um (melhor situação). Porém, para este estudo, com foco no sistema de transporte público da cidade de Fortaleza, restringiu-se o cálculo do índice àqueles Indicadores diretamente relacionados ao segmento em questão. Estes constituem um conjunto de 22 Indicadores que envolvem sete Temas, conforme apresentado na Figura 3.1. 


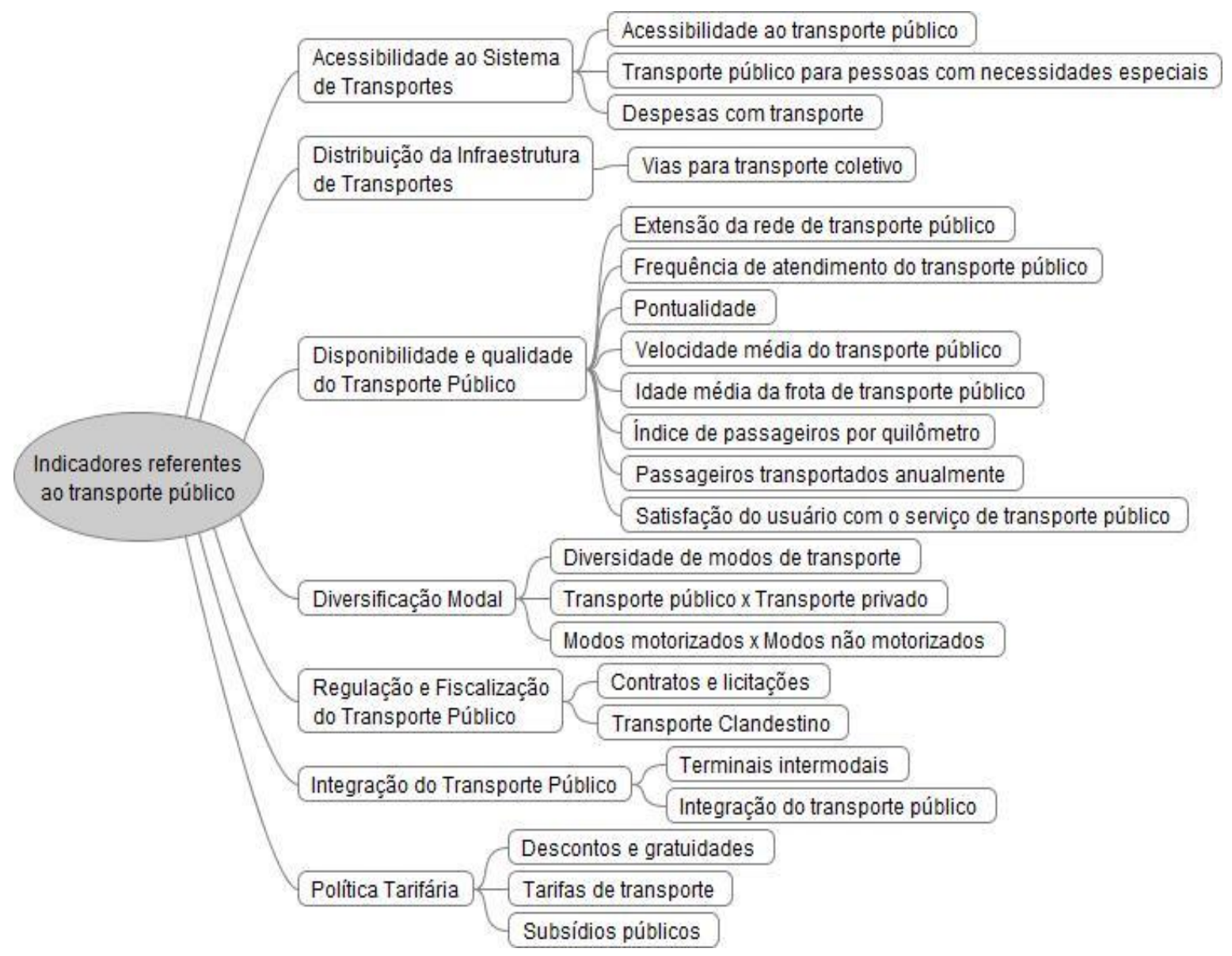

Figura 3.1 - Hierarquia de temas e indicadores do IMUS referentes ao transporte público

Para a utilização deste "novo" índice, aqui denominado IMUS-TP, foi necessário o cálculo de novos pesos, guardando a mesma relevância de cada Indicador no "IMUS original", mas ainda produzindo um valor final variando entre 0 e 1 . Os novos valores de pesos atribuídos aos DomíNIOS (PD), Temas (PT) e Indicadores (PI) estão discriminados na Tabela 3.1. Uma pequena definição de cada indicador também é apresentada na mesma tabela. A coluna 'P $\mathrm{Final}$ ' é obtida através da multiplicação entre PD, PT e PI. Vale ressaltar que estes indicadores são os mesmos destacados com um fundo cinza na Tabela 2.3, onde estão discriminados os seus pesos originais. 
Tabela 3.1- Pesos para DoMínIOs (PD), Temas (PT) e Indicadores (PI) no IMUS-TP

\begin{tabular}{|c|c|c|c|c|c|}
\hline \multirow{2}{*}{ Indicador } & \multirow{2}{*}{ Definição } & \multicolumn{4}{|c|}{ Pesos adaptados } \\
\hline & & PD & PT & PI & $\mathbf{P}_{\text {Final }}$ \\
\hline $\begin{array}{l}\text { Acessibilidade ao transporte } \\
\text { público }\end{array}$ & $\begin{array}{l}\text { \% da população urbana na área de cobertura } \\
\text { do transporte público }\end{array}$ & \multirow{3}{*}{0,150} & \multirow{3}{*}{1,000} & 0,333 & 0,050 \\
\hline $\begin{array}{l}\text { Transporte público para pessoas } \\
\text { com necessidades especiais }\end{array}$ & $\begin{array}{l}\text { \% dos veículos de transporte público por } \\
\text { onnibus adaptada para pessoas com } \\
\text { necessidades especiais }\end{array}$ & & & 0,333 & 0,050 \\
\hline Despesas com transportes & $\begin{array}{l}\% \text { da renda mensal gasta com transporte } \\
\text { público. }\end{array}$ & & & 0,333 & 0,050 \\
\hline Vias para transporte coletivo & $\begin{array}{l}\text { \% da área urbana atendida por vias } \\
\text { exclusivas ou preferenciais para transporte } \\
\text { coletivo por ônibus. }\end{array}$ & 0,312 & 1,000 & 1,000 & 0,312 \\
\hline $\begin{array}{l}\text { Extensão da rede transporte } \\
\text { público }\end{array}$ & $\begin{array}{l}\text { Extensão da rede de transporte público em } \\
\text { relação à extensão total de vias }\end{array}$ & \multirow{18}{*}{0,538} & \multirow{8}{*}{0,230} & 0,125 & 0,015 \\
\hline $\begin{array}{l}\text { Frequência de atendimento do } \\
\text { transporte público }\end{array}$ & $\begin{array}{l}\text { Frequência média dos ônibus, nos dias úteis } \\
\text { e períodos de pico. }\end{array}$ & & & 0,125 & 0,015 \\
\hline Pontualidade & $\begin{array}{l}\% \text { das viagens de transporte coletivo por } \\
\text { onibus respeitando o horário. }\end{array}$ & & & 0,125 & 0,015 \\
\hline $\begin{array}{l}\text { Velocidade média do transporte } \\
\text { público }\end{array}$ & $\begin{array}{l}\text { Velocidade média do transporte público por } \\
\text { ônibus. }\end{array}$ & & & 0,125 & 0,015 \\
\hline $\begin{array}{l}\text { Idade média da frota de } \\
\text { transporte público }\end{array}$ & $\begin{array}{l}\text { Idade média da frota de ônibus e micro- } \\
\text { ônibus urbanos no ano de referência. }\end{array}$ & & & 0,125 & 0,015 \\
\hline $\begin{array}{l}\text { Índice de passageiros por } \\
\text { quilômetro }\end{array}$ & $\begin{array}{l}\text { Razão entre passageiros transportados e a } \\
\text { quilometragem percorrida por ônibus. }\end{array}$ & & & 0,125 & 0,015 \\
\hline $\begin{array}{l}\text { Passageiros transportados } \\
\text { anualmente }\end{array}$ & $\begin{array}{l}\text { Variação percentual do número de } \\
\text { passageiros transportados pelos serviços de } \\
\text { transporte público urbano em } 2 \text { anos. }\end{array}$ & & & 0,125 & 0,015 \\
\hline $\begin{array}{l}\text { Satisfação do usuário com o } \\
\text { serviço de transporte público }\end{array}$ & $\begin{array}{l}\text { \% da população satisfeita com o serviço de } \\
\text { transporte público urbano e metropolitano. }\end{array}$ & & & 0,125 & 0,015 \\
\hline $\begin{array}{l}\text { Diversidade de modos de } \\
\text { transporte }\end{array}$ & $\begin{array}{l}\text { Número de modos de transporte disponíveis } \\
\text { na cidade. }\end{array}$ & & \multirow{3}{*}{0,180} & 0,333 & 0,032 \\
\hline $\begin{array}{l}\text { Transporte coletivo } \mathrm{x} \text { transporte } \\
\text { individual }\end{array}$ & $\begin{array}{l}\text { Razão entre viagens diárias feitas por } \\
\text { modos coletivos e viagens diárias feitas por } \\
\text { modos individuais motorizados. }\end{array}$ & & & 0,333 & 0,032 \\
\hline $\begin{array}{l}\text { Modos não motorizados } \mathrm{x} \\
\text { modos motorizados }\end{array}$ & $\begin{array}{l}\text { Razão entre viagens diárias por modos não } \\
\text { motorizados e viagens diárias por modos } \\
\text { motorizados de transporte. }\end{array}$ & & & 0,333 & 0,032 \\
\hline Contratos e licitações & $\begin{array}{l}\% \text { dos contratos de operação de transporte } \\
\text { público regularizados. }\end{array}$ & & \multirow{2}{*}{0,180} & 0,500 & 0,048 \\
\hline Transporte clandestino & $\begin{array}{l}\text { Participação do transporte clandestino ou } \\
\text { irregular nos deslocamentos urbanos. }\end{array}$ & & & 0,500 & 0,048 \\
\hline Terminais intermodais & $\begin{array}{l}\text { \% dos terminais de transporte } \\
\text { urbano/metropolitano de passageiros com } \\
\text { integração física de } 2 \text { ou mais modos. }\end{array}$ & & \multirow[t]{2}{*}{0,220} & 0,500 & 0,059 \\
\hline Integração do transporte público & $\begin{array}{l}\text { Grau de integração do sistema de transporte } \\
\text { público urbano e metropolitano. }\end{array}$ & & & 0,500 & 0,059 \\
\hline Descontos e gratuidades & $\begin{array}{l}\text { \% dos usuários do transporte público com } \\
\text { descontos ou gratuidade do valor da tarifa. }\end{array}$ & & \multirow{3}{*}{0,190} & 0,333 & 0,034 \\
\hline Tarifas de transporte & $\begin{array}{l}\text { Variação percentual das tarifas comparada a } \\
\text { índices inflacionários para o mesmo } \\
\text { período. }\end{array}$ & & & 0,333 & 0,034 \\
\hline Subsídios públicos & $\begin{array}{l}\text { Subsídios públicos oferecidos aos sistemas } \\
\text { de transporte urbano/metropolitano. }\end{array}$ & & & 0,333 & 0,034 \\
\hline
\end{tabular}




\subsection{Coleta de dados}

A fase de coleta de dados foi baseada, principalmente, em entrevistas realizadas com técnicos e gestores de órgãos responsáveis pelo desenvolvimento urbano e sistemas de transportes de Fortaleza. Também foi realizada pesquisa em sítios oficiais da Internet de instituições que possuem alguma ingerência no sistema.

Esta fase foi dividida em duas etapas. A primeira etapa englobou aqueles dados referentes apenas ao município de Fortaleza, cujas principais fontes foram a Empresa de Transporte Urbano de Fortaleza (ETUFOR, 2012), a Autarquia Municipal de Trânsito, Serviços Públicos e de Cidadania de Fortaleza (AMC, 2012), e a Companhia Cearense de Transportes Metropolitanos (METROFOR, 2012). A segunda etapa da coleta englobou aqueles dados referentes apenas ao sistema de transporte metropolitano, cujas principais fontes foram o Departamento Estadual de Trânsito (DETRAN-CE, 2012), a Companhia Cearense de Transportes Metropolitanos (METROFOR, 2012) e a Agência Reguladora de Serviços Públicos Delegados do Estado do Ceará (ARCE, 2012). Esta fase foi realizada dentro de um período de quatro meses, de novembro de 2012 a fevereiro de 2013.

\subsection{Cenários propostos}

Foi proposta a construção de quatro cenários que contemplaram os anos de 1992, 2000, 2010 e 2014. Com isso, foi possível fazer uma avaliação, tanto retrospectiva como prospectiva, do sistema de transporte público de Fortaleza e do sistema metropolitano. A escolha destes quatro cenários se deu por motivos específicos. Em 1992, foi criado o Sistema de Transporte Integrado de Fortaleza (SITFOR), considerado uma grande transformação para o sistema de transportes e mobilidade na cidade (ETUFOR, 2012). Os cenários para os anos de 2000 e 2010 se justificam pela maior facilidade em obter dados demográficos, provenientes dos censos demográficos (IBGE, 2000, 2010). Finalmente, a escolha do ano de 2014 se deu pelo fato de que a cidade de Fortaleza será uma das sedes da Copa do Mundo de Futebol de 2014, evento para o qual estão sendo realizadas várias obras que afetarão a cidade como um todo e, particularmente, o seu sistema de transporte público.

\subsection{Cálculo dos indicadores e dos índices}

Uma vez obtidos os dados, se prosseguiu para a fase de cálculo dos indicadores do IMUS-TP. Seguindo as diretrizes indicadas no trabalho de Costa (2008), esses valores, também chamados escores, foram normalizados, variando numa escala entre 0 (zero) e 1 
(um). Multiplicando-se o valor do escore normalizado de cada indicador pelos respectivos pesos de DomínIo, Tema e Indicador, produziu-se a parcela de cada indicador do valor do IMUS-TP. A somatória destas parcelas constituiu o valor do índice.

Não foi possível o cálculo do conjunto completo de Indicadores para cada cenário. Nestes casos, o peso dos indicadores não calculados foi redistribuído entre os demais que fizessem parte do mesmo Tema. Para melhorar as condições de comparação entre os cenários, foram feitos cálculos do IMUS-TP considerando escores normalizados para aqueles indicadores não calculados com valor igual a 1 (IMUS-TP sup) ou 0 (IMUS-TP inf). Estes valores representam os limites que se pode chegar, caso se obtenham os dados faltantes em outro momento. Para o cenário de 2010, foi possível ainda fazer uma análise comparativa com Curitiba, cidade reconhecida como referência em se tratando de transporte público (MIRANDA, 2010; MIRANDA e RODRIGUES DA SILVA, 2012).

O mesmo processo de cálculo realizado para a análise de Fortaleza (IMUS-TP) foi adotado para a análise da Região Metropolitana de Fortaleza (IMUS-TP RMF). Em virtude do modo como foi feita a coleta de dados, para esta segunda etapa (RMF), todos os dados coletados foram agregados, optando-se por ponderações, caso necessário, de acordo com a definição de cada indicador, conforme explicitado na memória de cálculo (Anexo). Além da análise do índice global, foram analisados os valores encontrados para as três dimensões de sustentabilidade.

\subsection{Classificação dos indicadores}

Após a normalização dos indicadores, optou-se por classificar os mesmos de acordo com seu escore normalizado, no intuito de verificar quais os indicadores que se encontravam em pior situação. Foram criadas cinco classes com escalas específicas, como mostra a Tabela 3.2. A tabela inclui ainda a classe "Vazio", na qual foram inseridos os indicadores que não foram calculados durante o processo.

Tabela 3.2 - Classes para indicadores

\begin{tabular}{ccc}
\hline COR & CLASSE & INTERVALO \\
\hline & Ótimo & 0,80 A 1,00 \\
\hline Bom & 0,60 A 0,80 \\
\hline Regular & 0,40 A 0,60 \\
\hline Ruim & 0,20 A 0,40 \\
\hline Crítico & 0,00 A 0,20 \\
\hline Vazio & - \\
\hline
\end{tabular}




\subsection{Construção de diagnósticos e propostas de melhorias}

Após a classificação dos indicadores, foi feita uma análise dos mesmos, visando identificar suas principais deficiências em cada cenário específico. Com base nesta análise, foi possível fazer um diagnóstico dos cenários do sistema de transporte público da cidade e da Região Metropolitana para os anos de 1992, 2000 e 2010, bem como a previsão do diagnóstico do cenário de 2014.

A partir dos diagnósticos construídos foi possível avaliar as deficiências encontradas com a aplicação do IMUS-TP e do IMUS-TP RMF para os diferentes cenários. Com isso, foram apontadas algumas propostas de melhorias para a mobilidade na cidade de Fortaleza, tendo em vista, principalmente, a melhoria daqueles indicadores mais deficientes (ou seja, aqueles que se apresentaram como "ruim" ou "crítico" em mais de um cenário), que, no caso, acabam se tornando prioritários. 


\section{RESULTADOS E ANÁLISES}

Neste capítulo serão apresentados e analisados os resultados obtidos a partir da aplicação do IMUS-TP na cidade de Fortaleza e em sua Região Metropolitana (IMUS-TP RMF). Primeiramente foi feita uma caracterização da área de estudo em questão. Em seguida, foi discutida a utilização do IMUS neste estudo, a aplicação do IMUS-TP e IMUS-TP RMF, investigando o comportamento dos seus indicadores e construindo um diagnóstico para cada cenário, tal como sugerido no método.

\subsection{Caracterização da área de estudo}

Primeiramente, foi feita a caracterização da cidade de Fortaleza em particular, e em seguida, da sua Região Metropolitana, conforme os itens a seguir.

\subsubsection{A cidade de Fortaleza}

Em 1726, foi fundado o município de Fortaleza no nordeste brasileiro. O município se localiza no litoral norte do estado do Ceará, possuindo uma área de $315 \mathrm{~km}^{2}$. Tem como limites: ao norte e à leste com o Oceano Atlântico e os municípios de Eusébio e Aquiraz; ao sul com os municípios de Pacatuba e Itaitinga; e à oeste com os municípios de Caucaia e Maracanaú (ETUFOR, 2012). De acordo com o IBGE (2010), a sua população é de 2.452.185 habitantes, o que resulta em uma densidade populacional de 7.786,52 hab./km². Com esta população, Fortaleza pode ser considerada uma cidade de grande porte.

A cidade de Fortaleza possui 118 bairros. Para facilitar a sua gestão foram criadas sete divisões administrativas (Figura 4.1), conhecidas como Secretarias Executivas Regionais SER. Estas visam promover uma gestão mais participativa e acessível, executando obras e prestando serviços públicos em suas áreas de abrangência, economizando, assim, tempo, esforços e recursos dos cidadãos. 


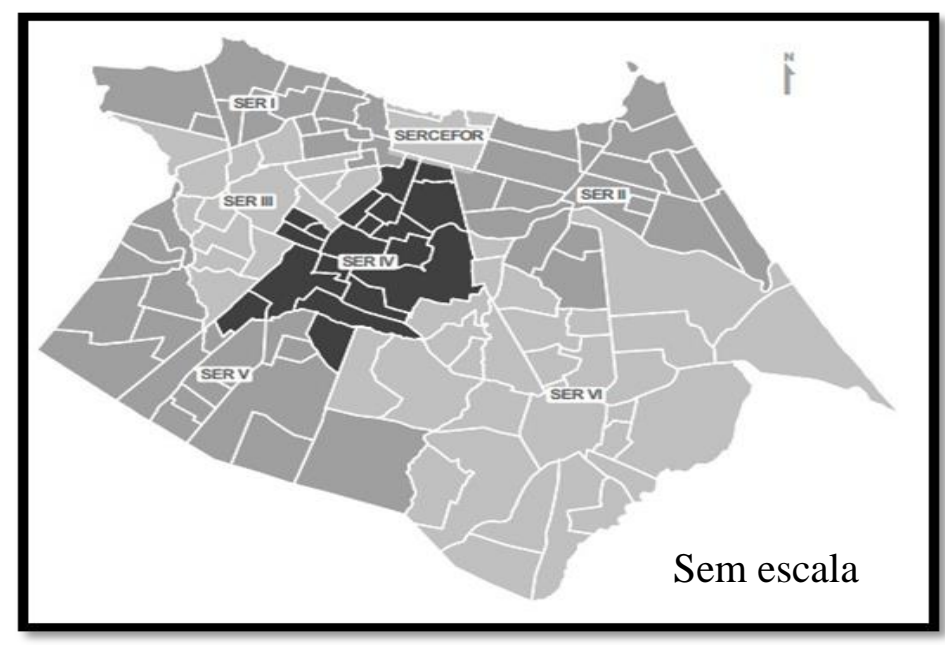

Figura 4.1 - Divisões Administrativas em Fortaleza (Fonte: ETUFOR, 2012)

O sistema de transportes na cidade de Fortaleza é planejado pela Secretaria Municipal de Planejamento do Orçamento, que é responsável por formular as diretrizes no plano diretor e em planos específicos. Basicamente, o sistema é constituído por 11.500 ruas e avenidas, aproximadamente, sete terminais integrados de ônibus urbano, dois terminais não integrados, duas rodoviárias, um porto e um aeroporto.

A gestão dos transportes urbanos é dividida entre três órgãos principais. Primeiro, temse a Autarquia Municipal de Trânsito, Serviços Públicos e de Cidadania de Fortaleza (AMC), que está diretamente ligada à fiscalização do trânsito na cidade. Em seguida, tem-se a Empresa de Transporte Urbano de Fortaleza (ETUFOR), que é responsável pelo controle, regulação e fiscalização dos sistemas de transportes coletivos da cidade: ônibus, táxi, mototáxi, e outros. Esta empresa também é responsável pelo gerenciamento dos terminais de ônibus. Por fim, existe a Companhia Cearense de Transportes Metropolitanos (METROFOR), responsável pelo controle do sistema de trens urbanos e, em breve, pelo metrô de Fortaleza e da sua região metropolitana.

\subsubsection{A Região Metropolitana de Fortaleza}

A Região Metropolitana de Fortaleza (RMF), instituída pela Lei Complementar $n^{\circ} 18 / 1999$, que por sua vez foi alterada pela Lei Complementar $n^{\circ} 78 / 2009$, é composta por 15 municípios. São eles: Aquiraz, Caucaia, Eusébio, Fortaleza, Guaiúba, Itaitinga, Maracanaú, Maranguape, Pacatuba, Pacajus, Horizonte, Chorozinho, São Gonçalo do Amarante, Pindoretama e Cascavel, como pode ser visto na Figura 4.2 (Relatório Anual ARCE, 2011). A Tabela 4.1 mostra dados populacionais dos municípios da RMF. 


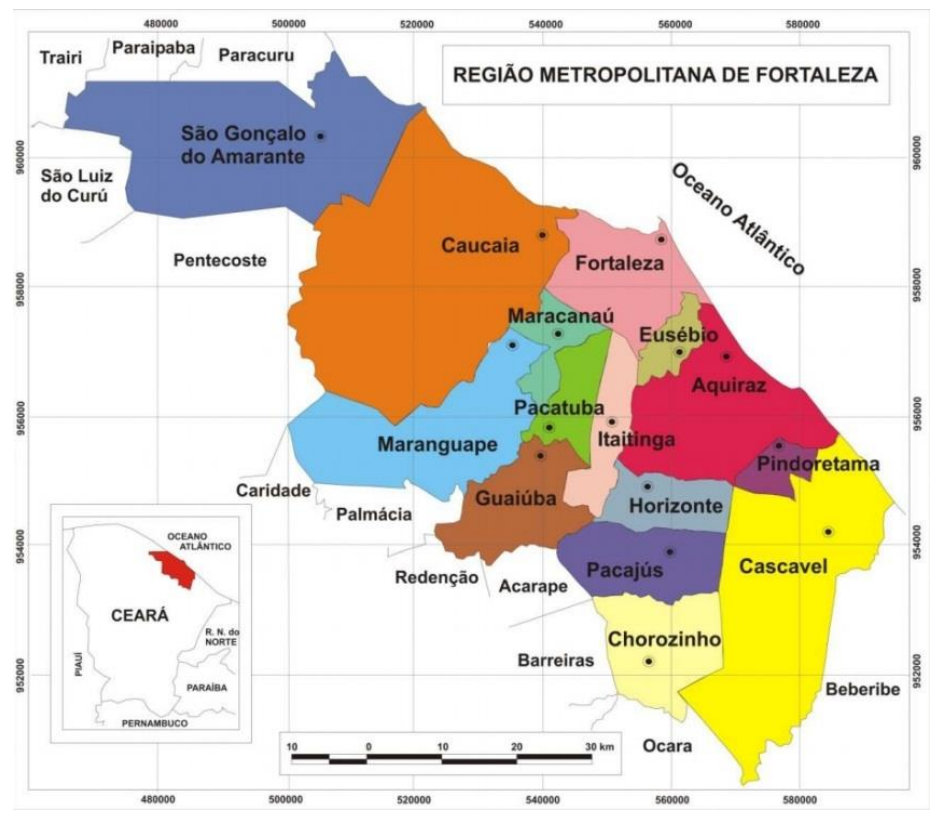

Figura 4.2 - Mapa da Região Metropolitana de Fortaleza (Fonte: IPECE, 2009)

Tabela 4.1 - Dados populacionais da RMF

\begin{tabular}{lrrr}
\hline \multicolumn{1}{c}{ Município } & $\begin{array}{c}\text { População } \\
(\mathbf{2 0 1 0})\end{array}$ & Área $\left.\mathbf{( k m}^{2}\right)$ & $\begin{array}{c}\text { Densidade } \\
\text { Populacional } \\
\left(\mathbf{h a b} / \mathbf{k m}^{2}\right)\end{array}$ \\
\hline Aquiraz & 72.628 & 482,573 & 150,50 \\
Cascavel & 66.142 & 837,325 & 78,99 \\
Caucaia & 325.441 & 1228,506 & 265,93 \\
Chorozinho & 18.915 & 278,413 & 67,94 \\
Eusébio & 46.033 & 79,005 & 582,64 \\
Fortaleza & 2.452 .185 & 314,930 & $7.786,52$ \\
Guaiúba & 24.091 & 267,128 & 94,83 \\
Horizonte & 55.187 & 159,980 & 344,96 \\
Itaitinga & 35.817 & 151,437 & 236,52 \\
Maracanaú & 209.057 & 106,648 & $1.877,75$ \\
Maranguape & 113.561 & 590,873 & 192,19 \\
Pacajus & 61.838 & 254,479 & 243,00 \\
Pacatuba & 72.299 & 131,994 & 498,35 \\
Pindoretama & 18.683 & 72,964 & 256,06 \\
São Gonçalo do Amarante & 43.890 & 834,448 & 52,34 \\
\hline Fonte: IBGE (2010) & & &
\end{tabular}

Fonte: IBGE (2010)

Na RMF funcionam o Sistema de Transporte Rodoviário Intermunicipal do Estado do Ceará (STIP) e os Terminais Rodoviários. O STIP é dividido em dois tipos de serviços: 
Serviços Regulares de Transporte Rodoviário Intermunicipal de Passageiros e Serviços de Transporte Rodoviário Intermunicipal de Passageiros por Fretamento. Os Serviços Regulares, por sua vez, são divididos em Serviço Regular Interurbano e Serviço Regular Metropolitano. Devido a algumas características operacionais, os municípios de Pindoretama e Cascavel são atendidos pelo Serviço Regular Interurbano. Neste estudo foi considerado apenas o Serviço Regular Metropolitano.

\subsection{Utilização do IMUS}

A aplicação do IMUS neste estudo facilitou a identificação dos aspectos negativos e prioritários do sistema de transporte público da Região Metropolitana de Fortaleza, mostrando os principais efeitos das possíveis intervenções. Durante o processo de cálculo, foi comprovada a facilidade de entendimento e manuseio da ferramenta, o que proporcionou uma maior praticidade na análise dos resultados.

A adaptação da ferramenta para a construção do IMUS-TP, objetivando avaliar um segmento específico de mobilidade urbana (transporte público) ressalta a sua flexibilidade como uma vantagem. À medida que foram sendo analisados os resultados, pôde-se ainda avaliar criticamente os indicadores. Sua revisão é extremamente importante no trabalho de aperfeiçoamento do IMUS.

\subsection{Aplicação do IMUS-TP na cidade de Fortaleza}

A aplicação do IMUS-TP na cidade de Fortaleza contempla desde a coleta de dados até a proposição de melhorias, conforme mostram os itens a seguir.

\subsubsection{Indicadores não calculados}

Algumas informações necessárias para o cálculo do IMUS não foram obtidas. Isto se deu tanto pela inexistência de documentos antigos como pela falta da prática de monitoramento contínuo e detalhado do sistema de transporte público da cidade. Em consequência disto, os indicadores listados a seguir não puderam ser calculados (os números entre parênteses se referem aos cenários para os quais isso ocorreu).

- Despesas com transporte (1992, 2014);

- Extensão da rede de transporte público (1992, 2000); 
- Satisfação do usuário com o serviço de transporte público (1992);

- Transporte coletivo x transporte individual (1992, 2010, 2014);

- Modos não motorizados x modos motorizados (1992, 2010, 2014).

É nítida a importância de se desenvolver bases de dados que contenham estas informações, para que possam servir como acervo para futuras pesquisas. É necessário levantar, principalmente, informações dos anos mais antigos. Para os indicadores "Transporte coletivo x transporte individual" e "Modos não motorizados x modos motorizados" verificouse a necessidade de investimentos para o desenvolvimento de uma Matriz Origem-Destino mais atualizada. Em 1996, foi desenvolvida uma Matriz Origem-Destino pela Companhia Cearense de Transportes Metropolitanos (METROFOR). Desde então, a mesma vem sendo expandida para estudos mais recentes.

\subsubsection{Indicadores calculados}

Dos 22 indicadores considerados, foram calculados 17 para o cenário de "1992", 21 para o de "2000", 20 para o de "2010” e 19 para o de "2014”. O maior número de indicadores calculados para o cenário "2000" deve-se à proximidade do período com a realização de estudos mais detalhados sobre o sistema de transportes urbanos. Vale ressaltar que no ano de 2000 foi finalizado um Plano de Transporte Urbano para a cidade de Fortaleza, o qual continha informações detalhadas sobre a divisão modal. Este tipo de documento não existe para nenhum dos outros cenários.

Tendo em vista a existência de alguns indicadores de caráter qualitativo, a comparação direta dos escores fica prejudicada nestes casos. Por este motivo, as análises foram baseadas nos valores normalizados e nas parcelas do IMUS-TP de cada indicador. Na memória de cálculo (Anexo) pode ser encontrada toda a descrição dos cálculos aqui realizados. A Tabela 4.2 mostra os valores normalizados obtidos para cada indicador e suas respectivas parcelas no IMUS-TP obtidas com planilha de cálculo utilizada neste estudo, bem como o valor global do índice. Estas informações são mostradas para cada cenário. As células não preenchidas correspondem aos indicadores não calculados. As parcelas do IMUS-TP são encontradas a partir da multiplicação dos valores normalizados pelos valores de pesos de DoMíNIOS, $\underline{\text { Temas }}$ e Indicadores, ressaltados na Tabela 3.1. 
Tabela 4.2 - Escores normalizados, parcelas do IMUS-TP (ou seja, escores normalizados multiplicados pelos respectivos pesos) e valores do IMUS-TP por cenário

\begin{tabular}{|c|c|c|c|c|c|c|c|c|}
\hline \multirow[b]{2}{*}{ Indicadores } & \multicolumn{2}{|c|}{1992} & \multicolumn{2}{|c|}{2000} & \multicolumn{2}{|c|}{2010} & \multicolumn{2}{|c|}{2014} \\
\hline & $\begin{array}{c}\text { Escores } \\
\text { Normalizados }\end{array}$ & $\begin{array}{c}\text { Parcelas } \\
\text { do } \\
\text { IMUS-TP }\end{array}$ & $\begin{array}{c}\text { Escores } \\
\text { Normalizados }\end{array}$ & $\begin{array}{c}\text { Parcelas } \\
\text { do } \\
\text { IMUS-TP }\end{array}$ & $\begin{array}{c}\text { Escores } \\
\text { Normalizados }\end{array}$ & $\begin{array}{c}\text { Parcelas } \\
\text { do } \\
\text { IMUS-TP }\end{array}$ & $\begin{array}{c}\text { Escores } \\
\text { Normalizados }\end{array}$ & $\begin{array}{c}\text { Parcelas } \\
\text { do } \\
\text { IMUS-TP }\end{array}$ \\
\hline Acessibilidade ao transporte público & 0,826 & 0,0620 & 0,882 & 0,0441 & 0,993 & 0,0497 & 0,993 & 0,0745 \\
\hline Transporte público para pessoas com necessidades especiais & 0,000 & 0,0000 & 0,000 & 0,0000 & 0,530 & 0,0265 & 1,000 & 0,0750 \\
\hline Despesas com transportes & - & 0,0000 & 0,988 & 0,0494 & 0,737 & 0,0369 & 0,037 & 0,0000 \\
\hline Vias para transporte coletivo & 0,035 & 0,0110 & 0,013 & 0,0041 & 0,041 & 0,0129 & 0,260 & 0,0812 \\
\hline Extensão da rede transporte público & - & 0,0000 & - & 0,0000 & 0,075 & 0,0012 & 0,089 & 0,0014 \\
\hline Frequência de atendimento do transporte público & 1,000 & 0,0206 & 0,950 & 0,0168 & 0,875 & 0,0135 & 1,000 & 0,0155 \\
\hline Pontualidade & 0,958 & 0,0197 & 0,933 & 0,0165 & 0,977 & 0,0151 & 0,945 & 0,0146 \\
\hline Velocidade média do transporte público & 0,600 & 0,0124 & 0,500 & 0,0088 & 0,415 & 0,0064 & 0,500 & 0,0077 \\
\hline Idade média da frota de transporte público & 1,000 & 0,0206 & 1,000 & 0,0177 & 1,000 & 0,0155 & 1,000 & 0,0155 \\
\hline Índice de passageiros por quilômetro & 0,135 & 0,0028 & 0,000 & 0,0000 & 0,000 & 0,0000 & 0,045 & 0,0007 \\
\hline Passageiros transportados anualmente & 0,250 & 0,0052 & 0,750 & 0,0133 & 0,500 & 0,0077 & 0,750 & 0,0116 \\
\hline Satisfação do usuário com o serviço de transporte público & & 0,0000 & 0,540 & 0,0095 & 0,400 & 0,0062 & 0,800 & 0,0124 \\
\hline Diversidade de modos de transporte & 0,750 & 0,0726 & 0,750 & 0,0242 & 0,750 & 0,0726 & 0,750 & 0,0726 \\
\hline Transporte coletivo $\mathrm{x}$ transporte individual & - & 0,0000 & 0,293 & 0,0094 & - & 0,0000 & - & 0,0000 \\
\hline Modos não motorizados x modos motorizados & - & 0,0000 & 0,000 & 0,0000 & - & 0,0000 & - & 0,0000 \\
\hline Contratos e licitações & 1,000 & 0,0484 & 1,000 & 0,0484 & 0,858 & 0,0415 & 1,000 & 0,0484 \\
\hline Transporte clandestino & 0,000 & 0,0000 & 1,000 & 0,0484 & 1,000 & 0,0484 & 1,000 & 0,0484 \\
\hline Terminais intermodais & 0,000 & 0,0000 & 0,000 & 0,0000 & 0,000 & 0,0000 & 0,286 & 0,0169 \\
\hline Integração do transporte público & 0,250 & 0,0148 & 0,250 & 0,0148 & 0,500 & 0,0296 & 1,000 & 0,0591 \\
\hline Descontos e gratuidades & 0,584 & 0,0199 & 0,367 & 0,0125 & 0,675 & 0,0230 & 0,675 & 0,0230 \\
\hline Tarifas de transporte & 0,000 & 0,0000 & 0,000 & 0,0000 & 0,660 & 0,0225 & 0,000 & 0,0000 \\
\hline Subsídios públicos & 0,000 & 0,0000 & 0,000 & 0,0000 & 1,000 & 0,0341 & 1,000 & 0,0341 \\
\hline Valores do IMUS-TP por cen & & 0,3099 & & 0,3378 & & 0,4631 & & 0,6124 \\
\hline
\end{tabular}




\subsubsection{Análise do IMUS-TP}

A carência de dados não inviabilizou o cálculo do IMUS-TP. Os valores dos indicadores não calculados foram redistribuídos entre os indicadores de mesmo Tema. Foram propostas duas situações hipotéticas, no caso destes dados serem obtidos em outro momento. A primeira no caso dos indicadores não calculados obterem valor máximo (escore um), em que o valor do índice seria igual a IMUS-TP sup, indicando o limite superior que o IMUS-TP pode chegar. A segunda no caso destes mesmos indicadores obterem valor mínimo (escore

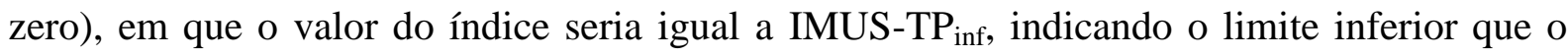
IMUS-TP pode chegar. A Figura 4.3 apresenta estas situações, inclusive a situação real (IMUS-TP).

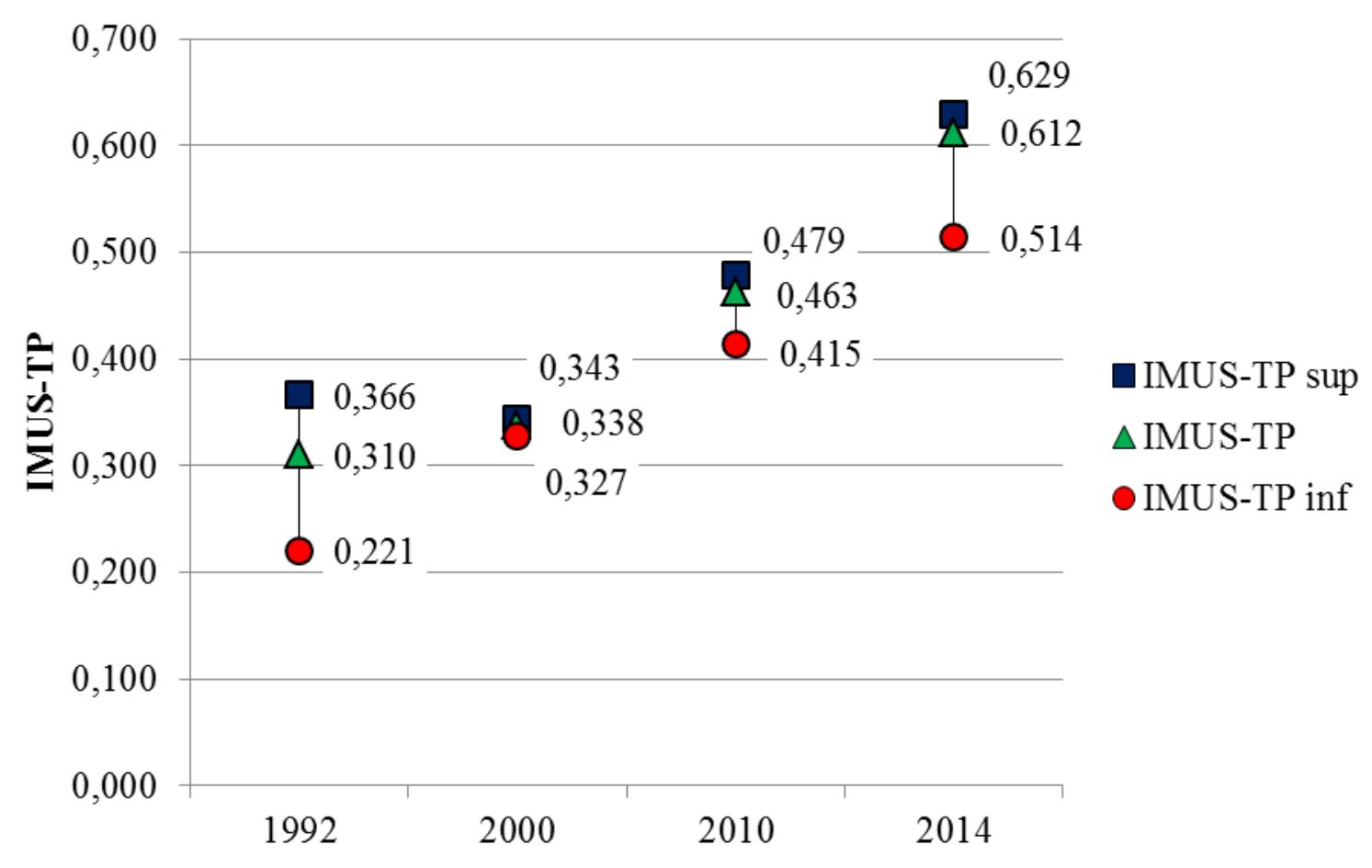

Figura 4.3 - Valores do IMUS-TP e seus limites inferiores e superiores, para cada cenário.

Pode-se notar que o intervalo em que podem variar os valores do IMUS-TP para cada cenário é tanto menor quanto maior for o número de indicadores calculados. Por exemplo, para o ano de 2000 houve uma maior quantidade de dados calculados, o que resultou em um menor intervalo para a possível variação do índice. Já para o ano de 1992, observa-se que 
houve uma maior variação e, para os anos de 2010 e 2014, observam-se variações intermediárias.

Os cenários para os anos de 1992 e 2000 se mostraram ruins em comparação com o cenário de 2010 e o de 2014. Pode-se visualizar uma evolução no índice, mesmo que o intervalo entre os cenários não seja uniforme: de 1992 para 2000 houve um crescimento de 9\%, deste para 2010 de 37\% e, para 2014 prevê-se um crescimento de 32\%. Para o cenário de 2010 (atual) o valor do IMUS-TP é igual a 0,463, o que é bem distante do que se espera para uma mobilidade sustentável (IMUS-TP $=1$ ). Percebe-se daí a necessidade de melhorias em vários aspectos dos indicadores aqui considerados.

Vale ressaltar que o cenário de 2014 é baseado nos projetos previstos para estarem prontos até a Copa do Mundo. No entanto, ainda que estes projetos sejam executados plenamente, a cidade de Fortaleza ainda necessitará de mais atenção e investimentos na área de transporte público e da mobilidade urbana como um todo, visto que o valor do IMUS-TP previsto para este cenário é de 0,612. É importante se conhecer as deficiências pontuais de cada indicador para que estas apontem a necessidade ou não de intervenções.

Com relação ao cenário de 2010, pode-se ainda fazer uma comparação com a cidade de Curitiba, considerada um benchmark no âmbito da mobilidade sustentável, que apresentou um valor global de IMUS de 0,754. A partir da memória de cálculo do trabalho de Miranda (2010), este valor foi recalculado para se obter o IMUS-TP de Curitiba, mostrado na Figura 4.4. Observa-se que, entre o valor do IMUS-TP para Curitiba e o valor do IMUS-TP para Fortaleza, existe uma diferença considerável de $38 \%$ em relação ao maior valor, fazendo com que as duas realidades se distanciem uma da outra.

No que diz respeito aos indicadores, 12 dos 22 indicadores presentes no cálculo do IMUS-TP obtiveram um melhor desempenho para a cidade de Curitiba. Foram eles: “Transporte público para pessoas com necessidades especiais", "Despesas com transporte”, "Vias para transporte coletivo", "Extensão da rede de transporte público", "Frequência de atendimento do transporte público", "Pontualidade", "Velocidade média do transporte público", "Índice de passageiros por quilômetro", "Satisfação do usuário com o serviço de transporte público", "Contratos e licitações", "Integração do transporte público" e "Descontos e gratuidades". 


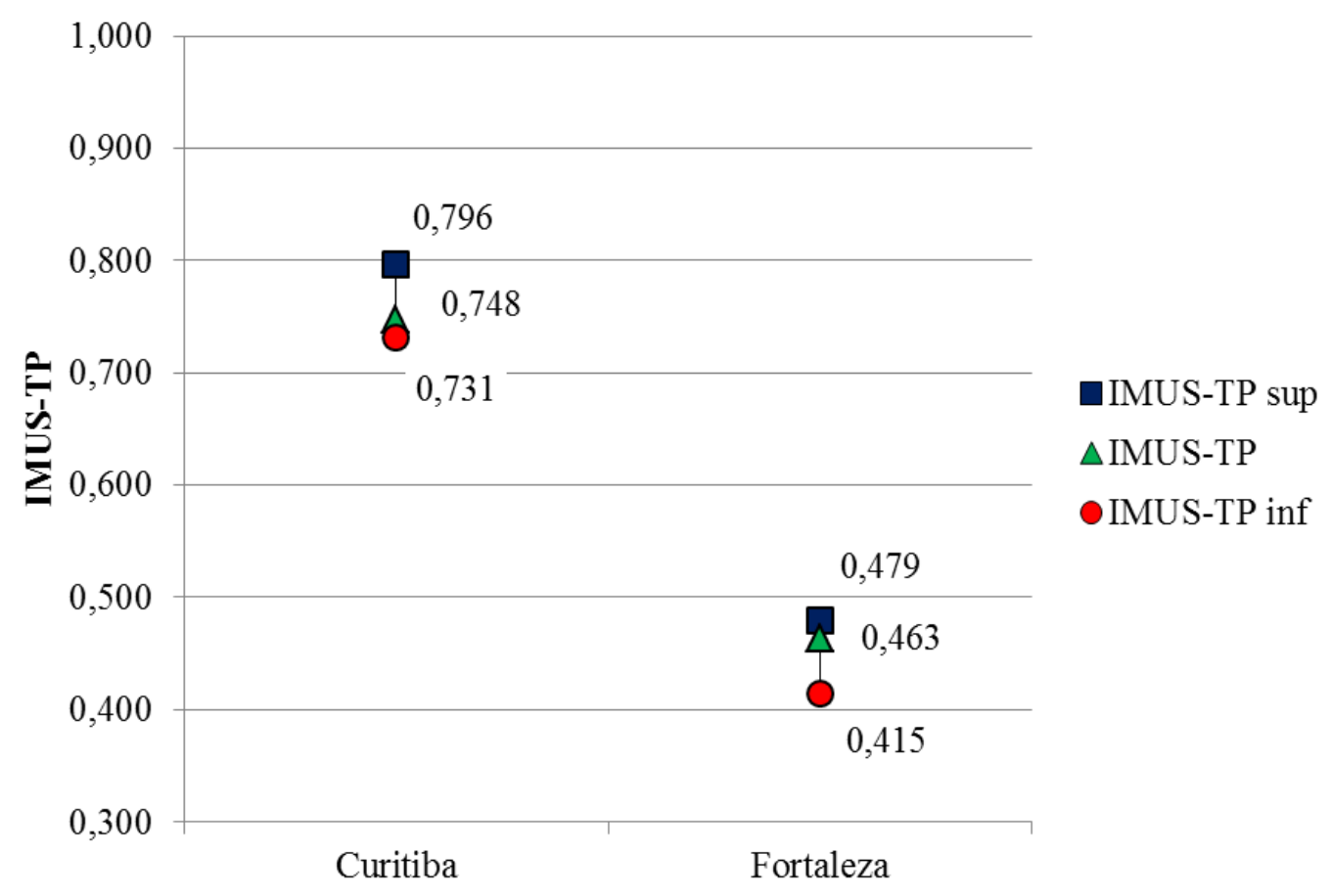

Figura 4.4 - Comparação com o IMUS-TP de Curitiba

No que diz respeito às dimensões de sustentabilidade (Figura 4.5), elas apresentaram os mesmos valores para todos os cenários. A Dimensão Social $(0,108)$ foi a que apresentou a melhor avaliação, seguida da Dimensão Econômica (0,107). A Dimensão Ambiental apresentou o pior resultado, igual a 0,095. Visto isso, é nítida a importância de se tentar equilibrar as três dimensões para o transporte público do município de Fortaleza, dando maior prioridade à Dimensão Ambiental. Isso pode ser feito investindo naqueles indicadores que apresentaram nesta dimensão os maiores pesos com menores parcelas do IMUS-TP, como "Transporte coletivo $x$ transporte individual" e "Modos não motorizados $x$ Modos motorizados", que foram calculados apenas para o cenário de 2000 em virtude da falta de uma Matriz Origem-Destino para os outros cenários. 


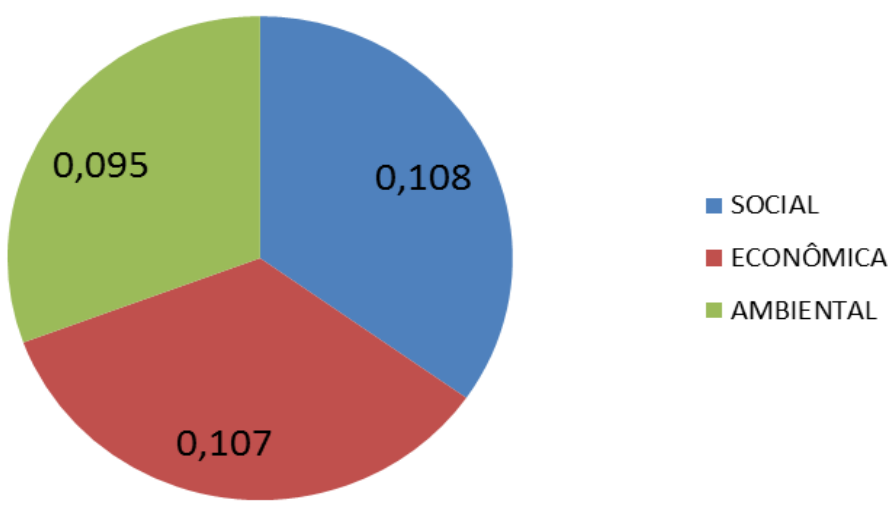

Figura 4.5 - Dimensões de Sustentabilidade para o IMUS-TP

\subsubsection{Análise dos resultados do IMUS-TP por tema}

Apesar de existirem três DomínIOS envolvidos, uma análise por Temas se torna mais adequada neste caso, visto que o DomínIO "SiSTEMA DE TRANSPORTE URBANO" abrange 18 indicadores, enquanto “ACESSIBILIDADE” e "INFRAESTRUTURA DE TRANSPORTE” abrangem três e um, respectivamente. A análise por Temas utiliza as parcelas do IMUS-TP e pode ser feita considerando duas situações. Na primeira todos os indicadores são analisados, enquanto que na segunda são analisados apenas aqueles indicadores comuns para todos os $\underline{\text { Temas }}$ (Figura 4.6).

De acordo com a parte de cima da Figura 4.6, os Temas que se apresentaram piores foram "Distribuição da Infraestrutura de Transporte" e "Integração do Transporte Público". Isso acontece devido o fato dos indicadores "Vias para transporte coletivo", "Terminais intermodais" e "Integração do transporte público" terem apresentado valores ruins para todos os cenários.

A quantidade de indicadores calculados para cada cenário causa algum efeito sobre o valor do IMUS-TP. Para descartar este efeito, optou-se por fazer uma nova estimativa do IMUS-TP, considerando apenas os indicadores calculados para todos os cenários. A diferença pode ser avaliada fazendo uma comparação entre os gráficos da Figura 4.6. Para esta condição, existe um total de 17 indicadores. Observa-se que, para o cenário de 1992, o valor do IMUS-TP permaneceu constante, devido ao fato dos 17 indicadores comuns serem os mesmos para as duas situações da Figura 4.6. Para os outros três cenários seu valor sofreu uma redução. Vale ressaltar que a constatação referente aos temas "Distribuição da 
Infraestrutura de Transporte" e "Integração do Transporte Público", feita sobre a primeira parte da Figura 4.6, se manteve constante.

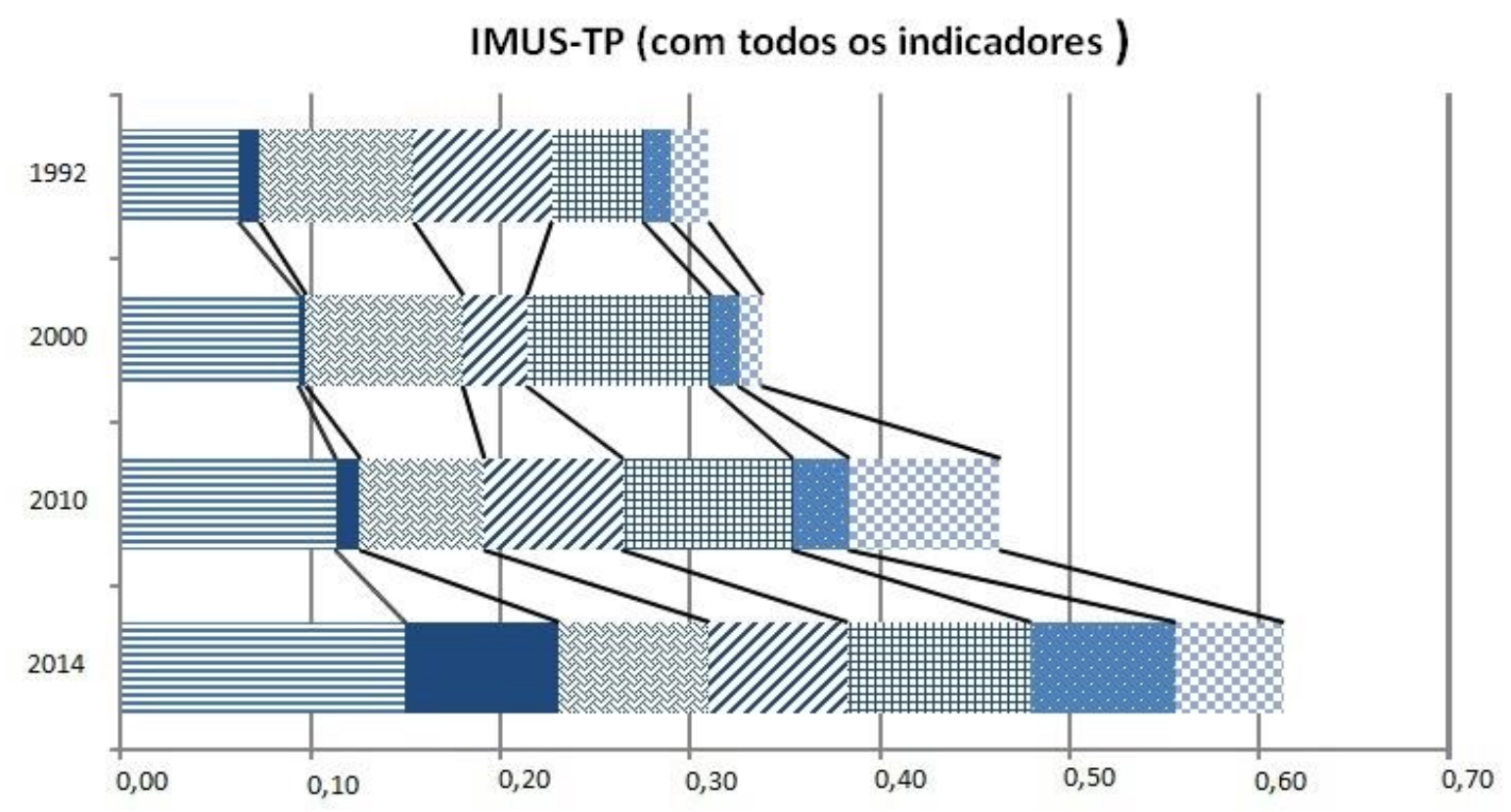

\section{IMUS-TP (com indicadores comuns)}

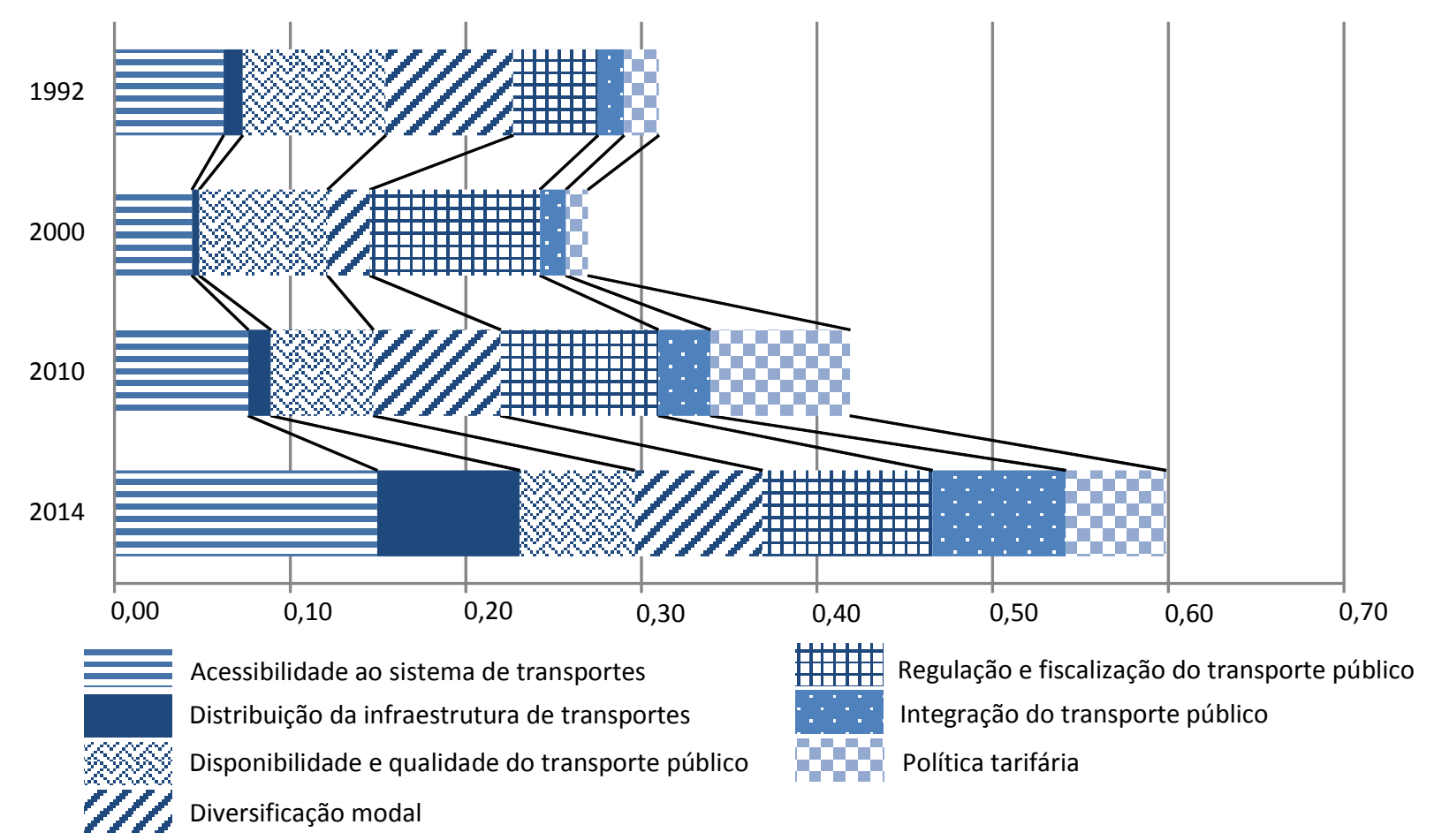

Figura 4.6 - Contribuição de cada tema para a formação do IMUS-TP dos cenários 1992, 2000, 2010 e 2014 


\subsubsection{Classificação e análise dos resultados do IMUS-TP por indicador}

Para facilitar sua análise, os indicadores foram classificados de acordo com seus escores normalizados em seis classes especificadas: "Crítico" (0,00 a 0,20), "Ruim" $(0,20$ a 0,40), "Regular" (0,40 a 0,60), "Bom" (0,60 a 0,80), “Ótimo" (0,80 a 1,00) e "Vazio". A Figura 4.7 mostra um resumo geral por cenário.

Pode-se observar no gráfico que houve uma evolução dos cenários com relação aos indicadores. A quantidade de indicadores "ótimos" e "bons" (7, 10, 11 e 13) apresentou um crescimento, o que traduz uma melhoria. Com relação à quantidade de indicadores "regulares", "ruins" e "críticos”, pode-se verificar que houve uma redução.

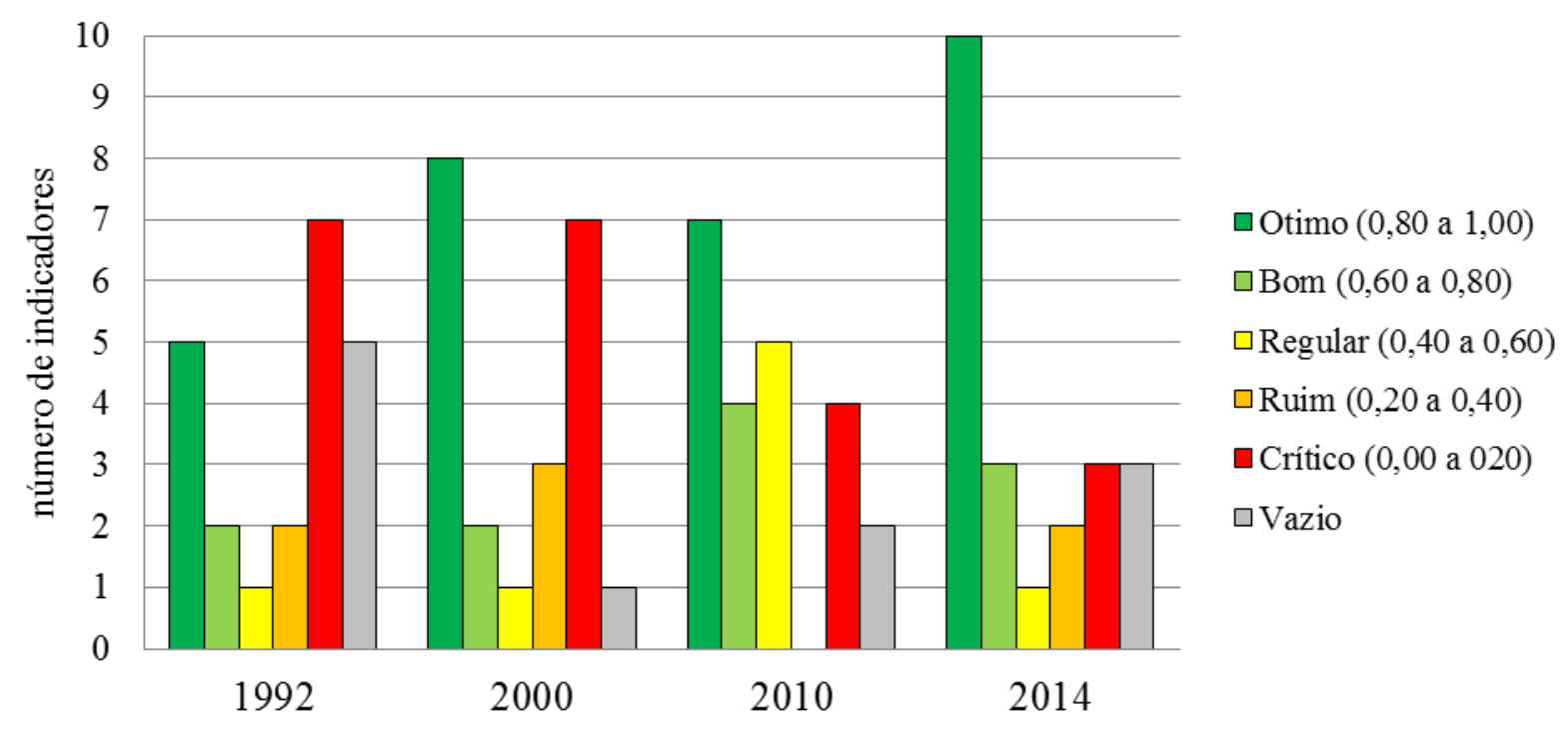

Figura 4.7 - Classificação geral dos indicadores do IMUS-TP por cenário

A Figura 4.8 apresenta a classificação detalhada de cada indicador conforme mudam os cenários, o que, juntamente com a memória de cálculo (Anexo) oferece subsídios para uma análise por indicador. As barras horizontais representam os cenários de 1992, 2000, 2010 e 2014, de cima para baixo, por indicador. 


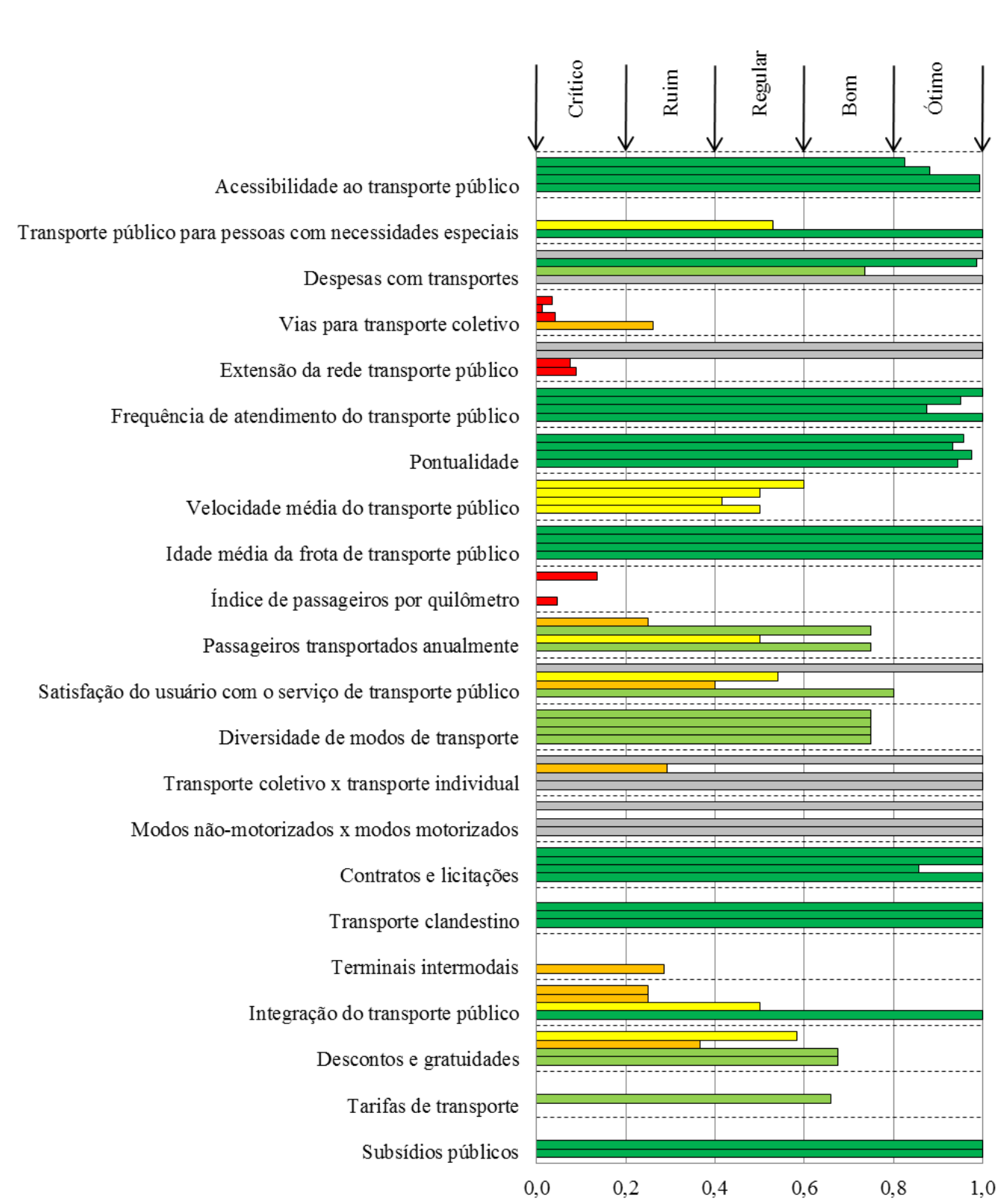

Figura 4.8 - Classificação detalhada dos indicadores do IMUS-TP por cenário. As barras horizontais representam os cenários de 1992, 2000, 2010, 2014, de cima para baixo, por indicador.

O indicador "Acessibilidade ao transporte público" apresentou um ótimo desempenho para todos os cenários. Com isso, pode-se afirmar que a cobertura espacial do transporte público do município de Fortaleza é muito boa, desde os cenários mais antigos. Na Figura 4.9 pode ser visualizada esta cobertura para o cenário atual (2010). 


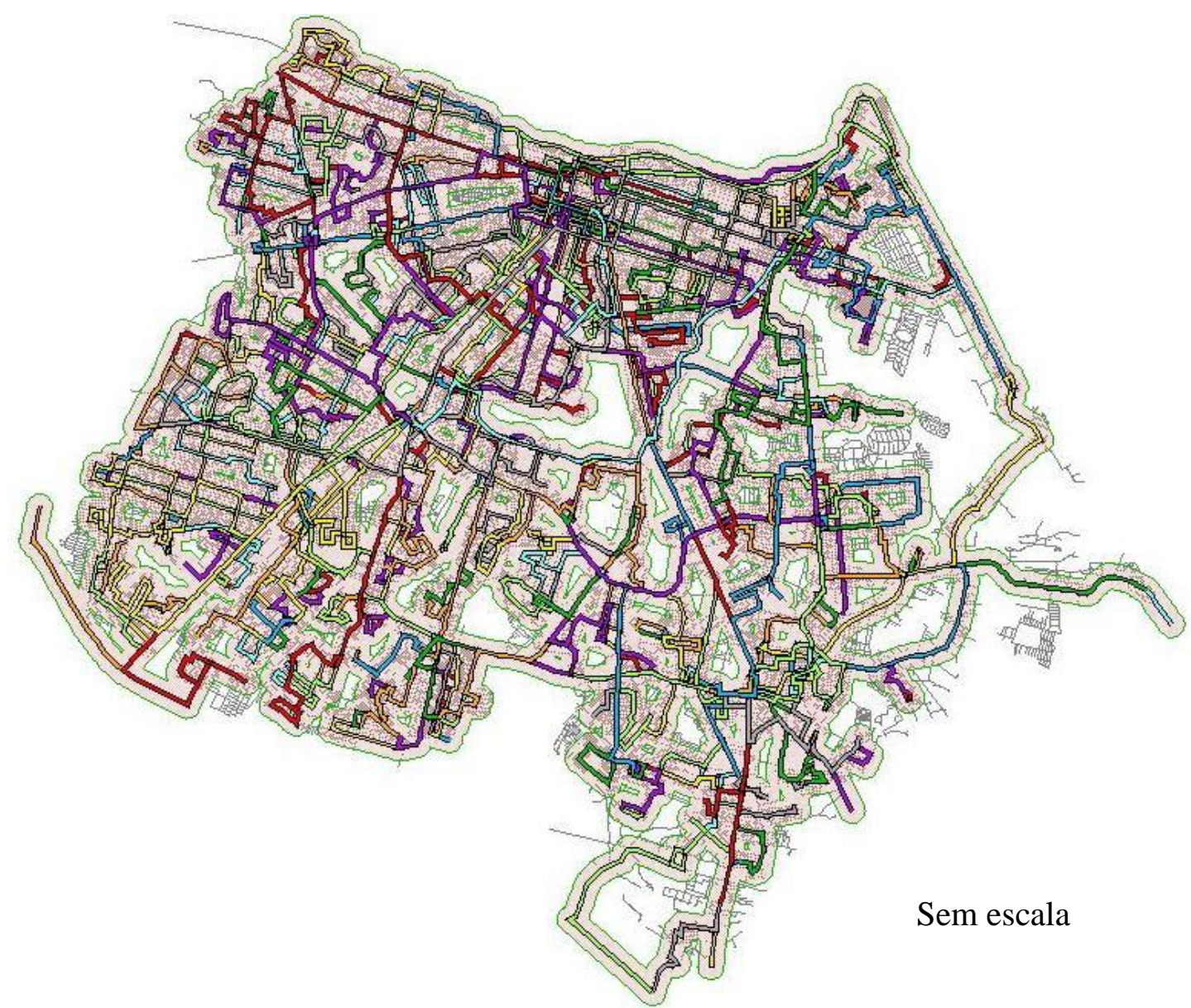

Figura 4.9 - Cobertura atual das linhas de ônibus do município de Fortaleza, considerando bandas de 300 metros ao redor das rotas.

O indicador "Transporte público para pessoas com necessidades especiais" obteve três desempenhos diferentes conforme a mudança de cenários. Para os cenários de 1992 e 2000, o indicador se apresentou crítico devido à ausência de veículos adaptados nesta época, o que lhe atribui valor zero. Segundo o técnico da ETUFOR ouvido para a pesquisa, esses veículos começaram a entrar em operação entre os anos de 2004 e 2005. Para o cenário de 2010, este indicador se apresentou regular, com 53\% da frota já adaptada. Até o ano de 2014, de acordo com a legislação federal brasileira (Brasil, 2004), 100\% dos veículos utilizados para o transporte público deverão estar adequados para o acesso universal, fazendo com que, para este cenário, o valor deste indicador chegue ao seu máximo (100\%). Vale ressaltar que, com o cumprimento da referida lei, será propícia a exclusão deste indicador do cálculo do IMUS-TP, já que será uma obrigatoriedade ele se manter no seu valor máximo.

O indicador "Despesas com transporte" foi calculado para os cenários de 2000 e 2010, apresentando desempenhos ótimo e bom, respectivamente. Ele se refere à parcela da renda 
mensal pessoal ou domiciliar utilizada para gastos com transporte público. É importante que se desenvolva um banco de dados envolvendo a renda média domiciliar e pessoal, e informações sobre a parcela da população que utiliza o serviço de transporte público, geralmente encontradas em uma pesquisa Origem-Destino, que seja de fácil acesso aos pesquisadores.

O indicador "Vias para transporte coletivo" se apresentou crítico para os cenários de 1992 e 2000. Isso aconteceu em virtude da pequena extensão de vias exclusivas ou preferenciais para ônibus (4 e $2 \mathrm{~km}$, respectivamente). Esses trechos configuram áreas de influência que cobriam, respectivamente, apenas 3,53\% e 1,30\% da área urbana, como mostram os mapas (a) e (b) da Figura 4.10. Para o cenário atual (2010) percebe-se uma melhora mínima desta cobertura, com a implantação de nove trechos de faixas preferenciais que, juntamente com as vias exclusivas já existentes, aumentam a cobertura para $4,13 \%$ da área urbana (Figura 4.10c). Mesmo assim, o indicador ainda se apresenta crítico. Com base nos projetos para o ano de 2014, a perspectiva para este cenário se mostra ruim, mesmo apresentando um aumento de 84\% (de 4,13\% em 2010 para 26\% em 2014), aproximadamente, no valor do indicador. (Figura 4.10d)

Vale ressaltar que este indicador é o que possui o maior peso final, de 0,312 (Tabela 3.1 ), o que representa 31,2\% do valor do IMUS-TP. Isso era de se esperar, já que por meio de uma priorização eficaz do transporte público no município de Fortaleza, não apenas este indicador melhoraria seu desempenho, mas também vários outros que estão a ele diretamente relacionados. Com isso, a iniciativa desta priorização é extremamente importante para uma melhoria visível na mobilidade atual de Fortaleza.

O indicador "Extensão da rede de transporte público" não foi calculado para os cenários de 1992 e 2000 devido à falta de informações acerca da extensão total do sistema viário da época. No cenário de 2010 este indicador obteve um desempenho crítico, com a rede de transporte público cobrindo apenas 26\% da extensão do sistema viário. Para o ano de 2014 não está previsto um grande crescimento na rede de transporte coletivo, onde está incluída a adição de mais de $50 \mathrm{~km}$ de linhas ferroviárias (VLT e metrô). Todavia, este indicador entra em conflito com o indicador "Acessibilidade ao transporte público", visto que uma rede de transportes que cobre $26 \%$ da extensão da malha viária proporciona uma cobertura espacial de 99\% da área urbana. Um dos motivos para que isto aconteça é o fato das linhas de ônibus 
atuais possuírem itinerários parecidos, fazendo com que suas configurações se sobreponham. A criação de um plano de racionalização para estas linhas seria uma possível solução.

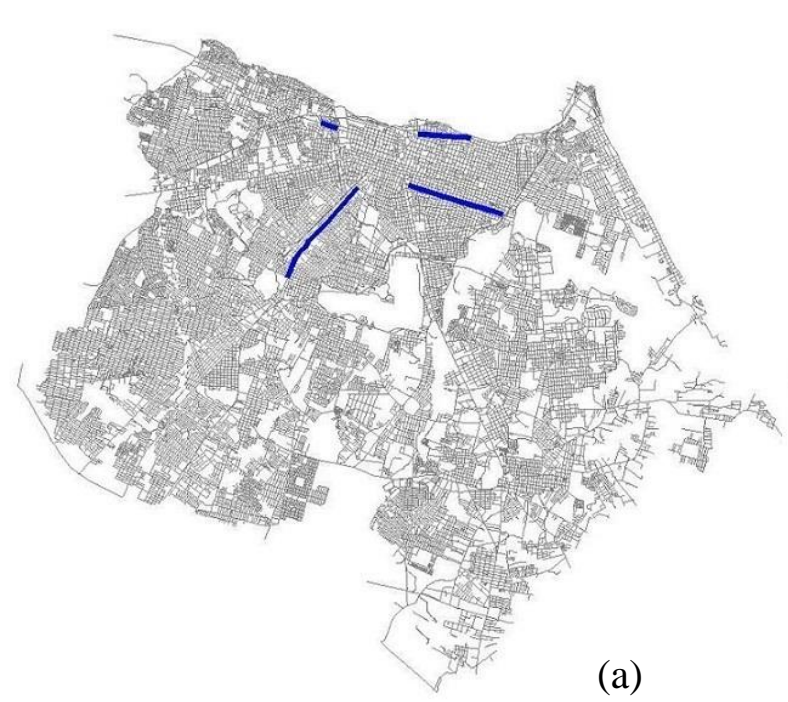

(a)

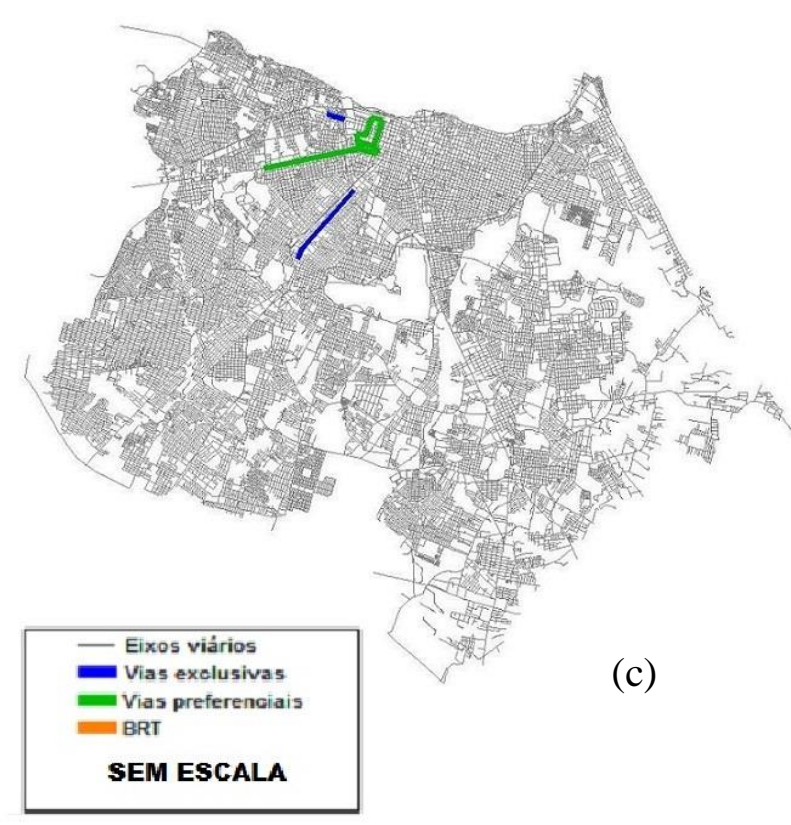

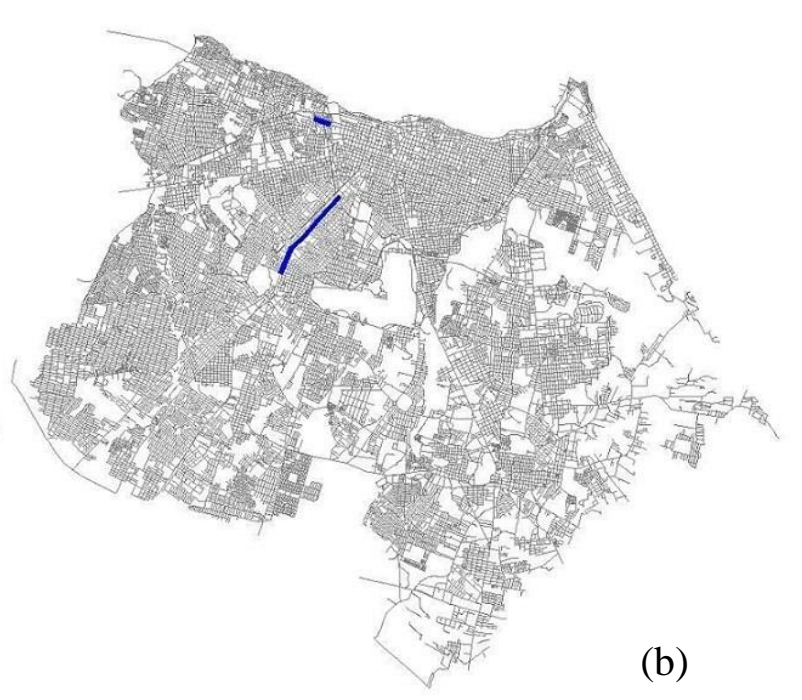

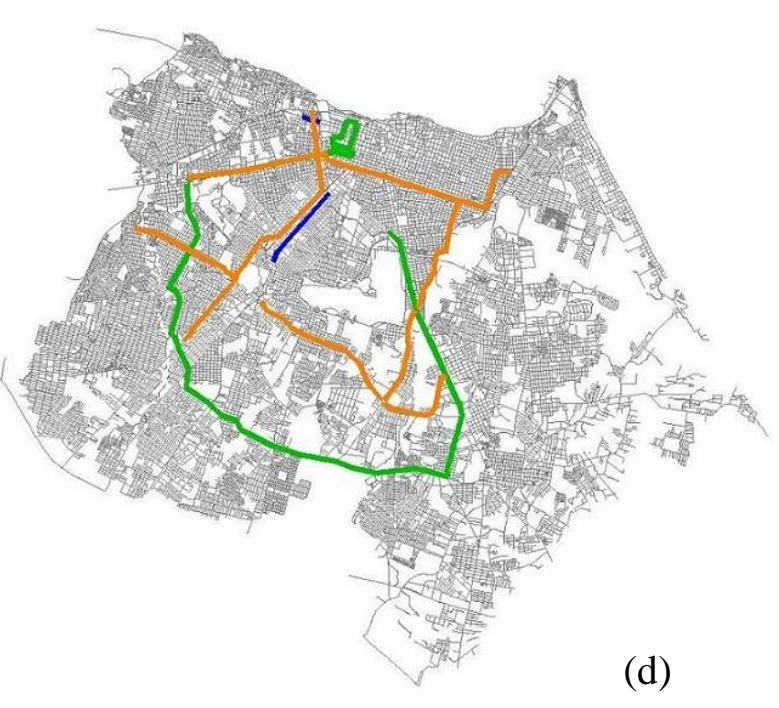

Figura 4.10 - Vias para transporte coletivo a) em 1992 b) em 2000 c) em 2010 d) em 2014

$\mathrm{O}$ indicador "Frequência de atendimento do transporte público" apresentou ótimo desempenho para todos os cenários. Ele se refere à frequência média de veículos de transporte coletivo por ônibus em linhas urbanas no município, nos dias úteis e períodos de pico. A maior frequência encontrada foi de 17,5 minutos para o cenário 2010, o que, segundo o técnico da ETUFOR ouvido para a pesquisa, pode ser resultado do aumento dos 
congestionamentos no município de Fortaleza. O indicador "Pontualidade" também apresentou ótimo desempenho para todos os cenários. No entanto, este é um dos indicadores que podem apresentar baixo grau de confiabilidade, visto que suas informações são obtidas através das empresas de ônibus que operam em Fortaleza atualmente. É importante que haja uma fiscalização constante de técnicos da ETUFOR para que estes valores se tornem mais confiáveis.

O indicador "Velocidade média de transporte público" permaneceu em situação regular em todos os cenários, variando entre $22 \mathrm{~km} / \mathrm{h}$ (1992) e 18 km/h (2010). Para o cenário de 2014 a previsão é que se consiga voltar à velocidade média de $20 \mathrm{~km} / \mathrm{h}$, caso sejam implantadas as melhorias previstas para o sistema de transportes, como o início da operação do BRT (da sigla original em inglês Bus Rapid Transit) e do BRS (da sigla original em inglês Bus Rapid Service), o que, no entanto, ainda mantém a sua classificação regular. Considerando o cenário atual, não se pode divisar solução para este problema que não envolva um tratamento prioritário para a circulação dos veículos do transporte público. Isto, certamente, deverá exigir a implantação de algum tipo de medida de restrição ao uso do automóvel.

O indicador "Idade média da frota de transporte público" apresentou um ótimo desempenho para todos os cenários, visto que a idade média dos veículos de transporte público operando em Fortaleza é inferior a cinco anos (valor sugerido como o desejável por Costa, 2008). Isso se deve ao fato de que todo ano boa parte da frota é renovada, proporcionando maior conforto e segurança para o seu usuário.

$\mathrm{O}$ indicador "Índice de passageiros por quilômetro" apresentou um desempenho crítico para todos os cenários. Para o cenário de 1992 o valor deste indicador é de apenas 2,77. Para os cenários de 2000 e 2010, houve uma redução deste indicador levando o valor normalizado do escore para zero. Esta redução pode ser explicada pelo aumento do número de linhas de ônibus e a consequente expansão da quilometragem rodada, ao mesmo tempo em que houve queda da demanda em virtude de condições econômicas adversas e a entrada em operação de um sistema concorrente operado com veículos menores. Não se tem previsão de melhoria desse índice para o cenário de 2014 com relação ao cenário de 1992 (“crítico”), a não ser que as intervenções previstas para melhorar a qualidade do sistema de transportes para a Copa de 2014 venham acompanhadas de um "Plano de Mobilidade Urbana" que aponte medidas para racionalização do sistema. 
O indicador "Passageiros transportados anualmente" obteve desempenho ruim para o cenário de 1992, desempenho bom para os cenários de 2000 e 2014 e um desempenho regular para o cenário de 2010. Este indicador se refere à variação, em termos percentuais, do número de passageiros transportados pelos serviços de transporte público urbano no município para um período de dois anos. No caso dos cenários de 1992 e 2010, foi observado um decréscimo inferior a 25\% de passageiros transportados entre os anos de 1991 a 1993 e os anos de 2009 a 2011, respectivamente. Para 1992, isso pode ter ocorrido devido ao período de transição do antigo sistema de transporte público para o Sistema Integrado de Transportes de Fortaleza. No caso do cenário de 2000, foi observado um acréscimo (embora inferior a 25\%) dos passageiros transportados. Para o cenário de 2014, um técnico da ETUFOR ouvido a respeito estima que ocorrerá um acréscimo (também inferior a 25\%) dos passageiros transportados entre os anos de 2012 a 2014. Isso deve acontecer devido à Copa do Mundo de 2014, evento que atrairá uma grande quantidade de turistas das regiões próximas, atraindo também uma grande demanda para o sistema de transporte público.

O indicador "Satisfação do usuário com o serviço de transporte público" apresentou desempenhos diferentes para os cenários de 2000, 2010 e 2014. Para o cenário de 1992, o indicador não pôde ser calculado devido à ausência de pesquisa de opinião na época. Para o cenário de 2000, seu desempenho foi regular, devido ao fato de 54\% dos usuários considerarem o sistema de transporte público "bom" ou "ótimo". Para o cenário de 2010, essa parcela de usuários sofreu uma redução de $26 \%$, aproximadamente, fazendo com que o desempenho do indicador passasse para ruim. Isso indica que a operação do Sistema integrado em 1992 e a iniciativa da integração temporal entre 2008 e 2009 já não são suficientes para satisfazer as exigências do usuário. Por isso, os projetos de 2014 contemplam melhorias no sistema que pretendem elevar o desempenho deste indicador para "bom" (80\%).

O indicador "Diversidade de modos de transporte" apresentou bom desempenho para todos os cenários, devido ao fato do município de Fortaleza apresentar seis tipos de modos em operação. São eles: a pé, bicicleta, automóvel, táxi, ônibus e ferroviário. Para o cenário de 2014 não existe previsão de quaisquer modos além dos já existentes. Os indicadores "Transporte coletivo $x$ transporte individual" e "Modos não motorizados $x$ modos motorizados" apresentaram desempenho "ruim" e "crítico", respectivamente, para o cenário de 2000. Este foi o único cenário para o qual esses indicadores puderam ser calculados devido à existência de um Plano de Transporte Urbano contendo a divisão modal da época para o município. Visto isso, é nítida a necessidade de pesquisas para o desenvolvimento de uma 
Matriz Origem-Destino atualizada ou obtenção de informações sobre divisão modal para que esses indicadores vazios sejam preenchidos, possibilitando a análise dos mesmos.

O indicador "Contratos e licitações" apresentou um ótimo desempenho para todos os cenários. Isso mostra o compromisso das empresas de transporte urbano do município de Fortaleza na regularização dos seus serviços, conforme exigido em lei. Para o cenário atual (2010), o valor do indicador é inferior ao dos outros cenários devido ao vencimento das permissões dos micro-ônibus. Porém, elas já se encontram em andamento e estarão regularizadas até o ano de 2014. O indicador "Transporte clandestino" apresentou desempenho crítico para o cenário de 1992, devido à participação expressiva dos serviços de transporte não regularizados no município. Para os cenários de 2000, 2010 e 2014 apresentou ótimo desempenho, o que mostra que este tipo de serviço foi sendo combatido até que, hoje, sua participação se tornasse praticamente insignificante.

O indicador "Terminais intermodais" se apresentou "crítico" para os cenários de 1992, 2000 e 2010, pois nenhum dos terminais existentes hoje na cidade permite a integração física de dois ou mais modos de transporte público. Com os projetos para 2014, apenas dois terminais (Parangaba e Papicu), como mostra a Figura 4.11, se enquadrarão nesta categoria, permitindo a integração entre ônibus e metrô, o que deverá melhorar o desempenho deste indicador. 


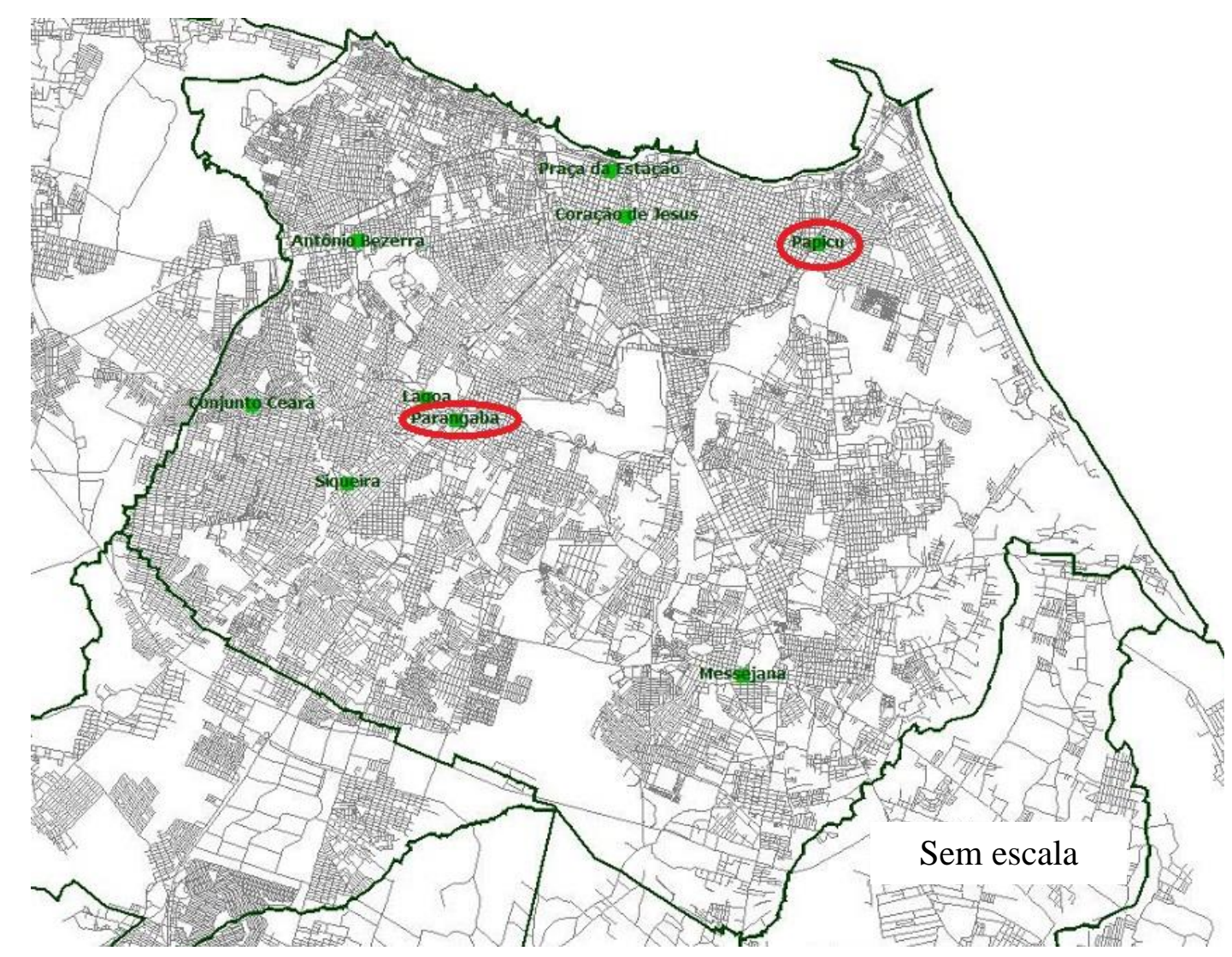

Figura 4.11 - Localização dos terminais intermodais previstos para Fortaleza em 2014

O indicador "Integração do transporte público" se refere ao grau de integração entre os sistemas de transporte público urbano e metropolitano. Para os cenários de 1992 e 2000, apresentou um desempenho ruim devido à prática de integração física e tarifária apenas no interior de terminais fechados, com transferências intramodais. Segundo o técnico ouvido, a integração temporal iniciou por volta de 2008. Para o cenário de 2010, este tipo de integração é praticado apenas na área central da cidade, classificando o indicador como "bom”. Para o cenário de 2014, os projetos preveem que o sistema de transporte público urbano seja totalmente integrado com o sistema metropolitano por meio de bilhete eletrônico único para integração intra e intermodal. Com essa melhoria, espera-se inclusive que a demanda por transporte público aumente consideravelmente.

O indicador "Descontos e gratuidades" apresenta um desempenho regular para o cenário de 1992. Já para o cenário de 2000, o indicador apresenta um desempenho ruim. Apesar do número de embarques ter diminuído neste ano (2000), o número de descontos e gratuidades aumentou, o que explica a redução do escore. Costa (2008) indica que até 10\% dos embarques podem ser realizados com descontos ou gratuidades. Acima disso, é necessário 
tomar alguma providência no intuito de atrair novos usuários para o sistema. Para os cenários de 2010 e 2014, o indicador é classificado como bom, pois apenas 23\% dos embarques realizados possuem algum desconto ou gratuidade.

O indicador "Tarifas de transporte" trata da variação percentual da tarifa em comparação com a variação do índice inflacionário para um mesmo período. Para o cenário de 2010, o indicador apresentou um desempenho bom, tendo em vista que o comportamento da tarifa reflete um aumento inferior ao índice IPCA (Índice Nacional de Preços ao Consumidor Amplo). Para os cenários de 1992, 2000, e 2014 seu desempenho é crítico, visto que o comportamento da tarifa para este período reflete um aumento superior ao índice IPCA. Com isso, pode-se perceber que elevar as tarifas de transporte público para suprir os gastos do sistema talvez não seja uma solução adequada. Investir na atração de novos usuários e na obtenção de mais subsídios pode ser uma opção mais viável para contornar o problema.

O indicador "Subsídios públicos" apresentou desempenho crítico para os cenários de 1992 e 2000, pois, segundo o técnico, não existia nenhum tipo de subsídio para o sistema de transporte público da época. Para o cenário de 2010, existem quatro tipos de subsídios: Imposto sobre Serviço (ISS); Taxa de vistoria mensal (portadores de deficiência); Taxa de gerenciamento; ICMS (Imposto sobre Circulação de Mercadorias e prestação de Serviços) do óleo diesel). Estes atuam para a totalidade do sistema de transporte público urbano, visando à redução da tarifa de transporte. Estes mesmos subsídios também irão atuar no ano de 2014. Com isso, o indicador apresenta um desempenho ótimo para estes dois últimos cenários.

\subsection{Aplicação do IMUS-TP RMF na Região Metropolitana de Fortaleza}

Para o sistema de transporte metropolitano, o monitoramento é realizado principalmente pela Agência Reguladora de Serviços Públicos Delegados do Estado do Ceará (ARCE), que conta também com o auxílio do Departamento Estadual de Trânsito (DETRANCE) e da Companhia Cearense de Transportes Metropolitanos (METROFOR). Por esse motivo, durante o processo de coleta de informações, os dados foram obtidos separadamente. Primeiramente, foram coletados os dados referentes ao sistema urbano de Fortaleza, e em seguida os dados referentes ao sistema metropolitano. Com isso, estes dados foram agregados para que fossem capazes de representar toda a Região Metropolitana de Fortaleza. Para facilitar o entendimento, o índice para esta análise foi denominado de IMUS-TP RMF. Assim 
como a aplicação do IMUS-TP, a aplicação do IMUS-TP RMF também contempla desde a coleta de dados até a proposição de melhorias, conforme mostram os itens a seguir.

\subsubsection{Indicadores não calculados}

Muitas informações acerca do sistema metropolitano não foram obtidas, impossibilitando, assim, a agregação de alguns dados e, consequentemente, o cálculo de certos indicadores, listados a seguir (os números entre parênteses se referem aos cenários para os quais isso ocorreu).

- Despesas com transporte (1992, 2000, 2014);

- Extensão da rede de transporte público (1992, 2000);

- Frequência de atendimento do transporte público (1992, 2000, 2014);

- Pontualidade (2010, 2014);

- Velocidade média do transporte público (2014);

- Idade média da frota de transporte público (2014);

- Índice de passageiros por quilômetro (2014);

- Passageiros transportados anualmente (1992, 2014);

- Satisfação do usuário com o serviço de transporte público (2014);

- Transporte coletivo x Transporte individual (1992, 2000, 2010, 2014);

- Modos não motorizados x modos motorizados (1992, 2000, 2010, 2014);

- Descontos e gratuidades (1992, 2014);

- Tarifas de transporte $(1992,2014)$;

Pode-se perceber que o maior número de indicadores não calculados se deu para o cenário de 2014. Talvez pela dificuldade de prever os seus comportamentos para este ano específico. Os indicadores listados reforçam os apontamentos feitos para a aplicação do IMUS-TP: necessidade do desenvolvimento de bases de dados, principalmente com informações sobre os anos mais antigos, e a necessidade de obtenção de Matrizes OrigemDestino atualizadas.

\subsubsection{Indicadores calculados}

Dos 22 indicadores, foram calculados 14 para o cenário de "1992", 17 para o de “2000”, 19 para o de "2010” e 9 para o de "2014”. Segundo o técnico da ARCE consultado, 
muitas informações antigas referentes aos indicadores do cenário de 1992 não existem mais. Até 2003, o órgão responsável pelo sistema metropolitano era o DETRAN-CE. Com relação aos projetos para 2014, os órgãos deram poucas informações.

A Tabela 4.3 mostra os valores normalizados obtidos para cada indicador e suas respectivas parcelas no IMUS-TP RMF, obtidas com a planilha de cálculo utilizada neste estudo, bem como os valores globais do índice. As células não preenchidas representam os indicadores não calculados para a Região Metropolitana. 
Tabela 4.3 - Escores normalizados do IMUS-TP RMF, parcelas do IMUS-TP RMF (ou seja, escores normalizados multiplicados pelos respectivos pesos) e valores do IMUSTP RMF por cenário

\begin{tabular}{|c|c|c|c|c|c|c|c|c|}
\hline \multirow[b]{2}{*}{ Indicadores } & \multicolumn{2}{|c|}{1992} & \multicolumn{2}{|c|}{2000} & \multicolumn{2}{|c|}{2010} & \multicolumn{2}{|c|}{2014} \\
\hline & $\begin{array}{c}\text { Escores } \\
\text { Normalizados }\end{array}$ & $\begin{array}{c}\text { Parcelas } \\
\text { IMUS-TP } \\
\text { RMF } \\
\end{array}$ & $\begin{array}{c}\text { Escores } \\
\text { Normalizados }\end{array}$ & $\begin{array}{c}\text { Parcelas } \\
\text { IMUS-TP } \\
\text { RMF }\end{array}$ & $\begin{array}{c}\text { Escores } \\
\text { Normalizados }\end{array}$ & $\begin{array}{c}\text { Parcelas } \\
\text { IMUS-TP } \\
\text { RMF } \\
\end{array}$ & $\begin{array}{c}\text { Escores } \\
\text { Normalizados }\end{array}$ & $\begin{array}{c}\text { Parcelas } \\
\text { IMUS-TP } \\
\text { RMF } \\
\end{array}$ \\
\hline Acessibilidade ao transporte público & 0,844 & 0,0633 & 0,884 & 0,0663 & 0,804 & 0,0402 & - & 0,0000 \\
\hline Transporte público para pessoas com necessidades especiais & 0,000 & 0,0000 & 0,000 & 0,0000 & 0,423 & 0,0212 & 1,000 & 0,1500 \\
\hline Despesas com transportes & - & 0,0000 & - & 0,0000 & 0,668 & 0,0334 & - & 0,0000 \\
\hline Vias para transporte coletivo & 0,015 & 0,0047 & 0,006 & 0,0019 & 0,018 & 0,0056 & 0,111 & 0,0347 \\
\hline Extensão da rede transporte público & - & 0,0000 & - & 0,0000 & 0,000 & 0,0000 & 0,000 & 0,0000 \\
\hline Frequência de atendimento do transporte público & - & 0,0000 & - & 0,0000 & 0,300 & 0,0053 & - & 0,0000 \\
\hline Pontualidade & 0,870 & 0,0215 & 0,855 & 0,0176 & - & 0,0000 & - & 0,0000 \\
\hline Velocidade média do transporte público & 1,000 & 0,0247 & 1,000 & 0,0206 & 0,650 & 0,0115 & - & 0,0000 \\
\hline Idade média da frota de transporte público & 1,000 & 0,0247 & 1,000 & 0,0206 & 1,000 & 0,0177 & - & 0,0000 \\
\hline Índice de passageiros por quilômetro & 0,000 & 0,0000 & 0,000 & 0,0000 & 0,000 & 0,0000 & - & 0,0000 \\
\hline Passageiros transportados anualmente & - & 0,0000 & 0,250 & 0,0052 & 0,750 & 0,0133 & - & 0,0000 \\
\hline Satisfação do usuário com o serviço de transporte público & 0,750 & 0,0186 & 0,750 & 0,0155 & 0,640 & 0,0113 & - & 0,0000 \\
\hline Diversidade de modos de transporte & 0,750 & 0,0726 & 0,750 & 0,0726 & 0,750 & 0,0726 & 0,750 & 0,0726 \\
\hline Transporte coletivo $\mathrm{x}$ transporte individual & - & 0,0000 & - & 0,0000 & - & 0,0000 & - & 0,0000 \\
\hline Modos não motorizados x modos motorizados & - & 0,0000 & - & 0,0000 & - & 0,0000 & - & 0,0000 \\
\hline Contratos e licitações & 0,686 & 0,0332 & 0,767 & 0,0371 & 0,747 & 0,0361 & 1,000 & 0,0484 \\
\hline Transporte clandestino & 0,000 & 0,0000 & 0,250 & 0,0121 & 0,750 & 0,0363 & 0,750 & 0,0363 \\
\hline Terminais intermodais & 0,000 & 0,0000 & 0,000 & 0,0000 & 0,000 & 0,0000 & 0,537 & 0,0317 \\
\hline Integração do transporte público & 0,250 & 0,0148 & 0,250 & 0,0148 & 0,500 & 0,0296 & 0,750 & 0,0444 \\
\hline Descontos e gratuidades & - & 0,0000 & 0,443 & 0,0151 & 0,685 & 0,0233 & - & 0,0000 \\
\hline Tarifas de transporte & - & 0,0000 & 0,660 & 0,0225 & 0,660 & 0,0225 & - & 0,0000 \\
\hline Subsídios públicos & 0,000 & 0,0000 & 0,000 & 0,0000 & 0,800 & 0,0272 & 0,800 & 0,0817 \\
\hline Valores do IMUS-TP RMF por cenário & & 0,2781 & & 0,3218 & & 0,4071 & & 0,4998 \\
\hline
\end{tabular}




\subsubsection{Análise do IMUS-TP RMF}

A carência de dados também não inviabilizou o cálculo do IMUS-TP RMF. Para isso, foi feita a mesma redistribuição utilizada para o cálculo do IMUS-TP, descrito no item 4.3.2.

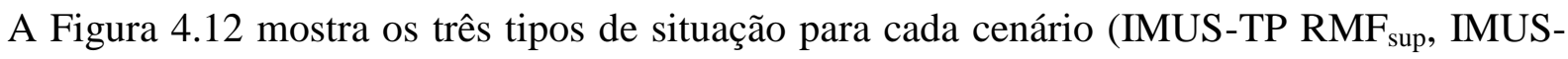

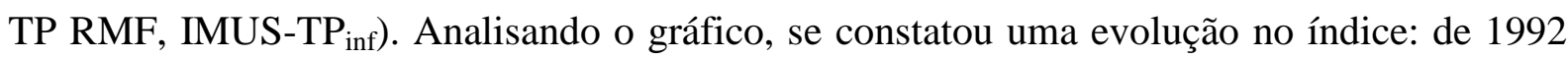
para 2000 houve um crescimento de 13,7\%, deste para 2010 de 20,9\%, e para 2014 prevê-se um crescimento de 18,6\%. Comparando com o IMUS-TP, percebeu-se que esta evolução ocorreu em um ritmo mais lento. Para o ano de 2014, o IMUS-TP RMF encontrado foi de 0,500, considerado um valor intermediário. Pode-se ainda perceber que o IMUS-TP RMF para este cenário (2014) é maior do que o IMUS-TP sup da Figura 4.3. Isto leva a crer que as melhorias poderão elevar ainda mais o índice. No entanto, existe um grau maior de incertezas, referente ao número de vazios encontrados para este cenário.

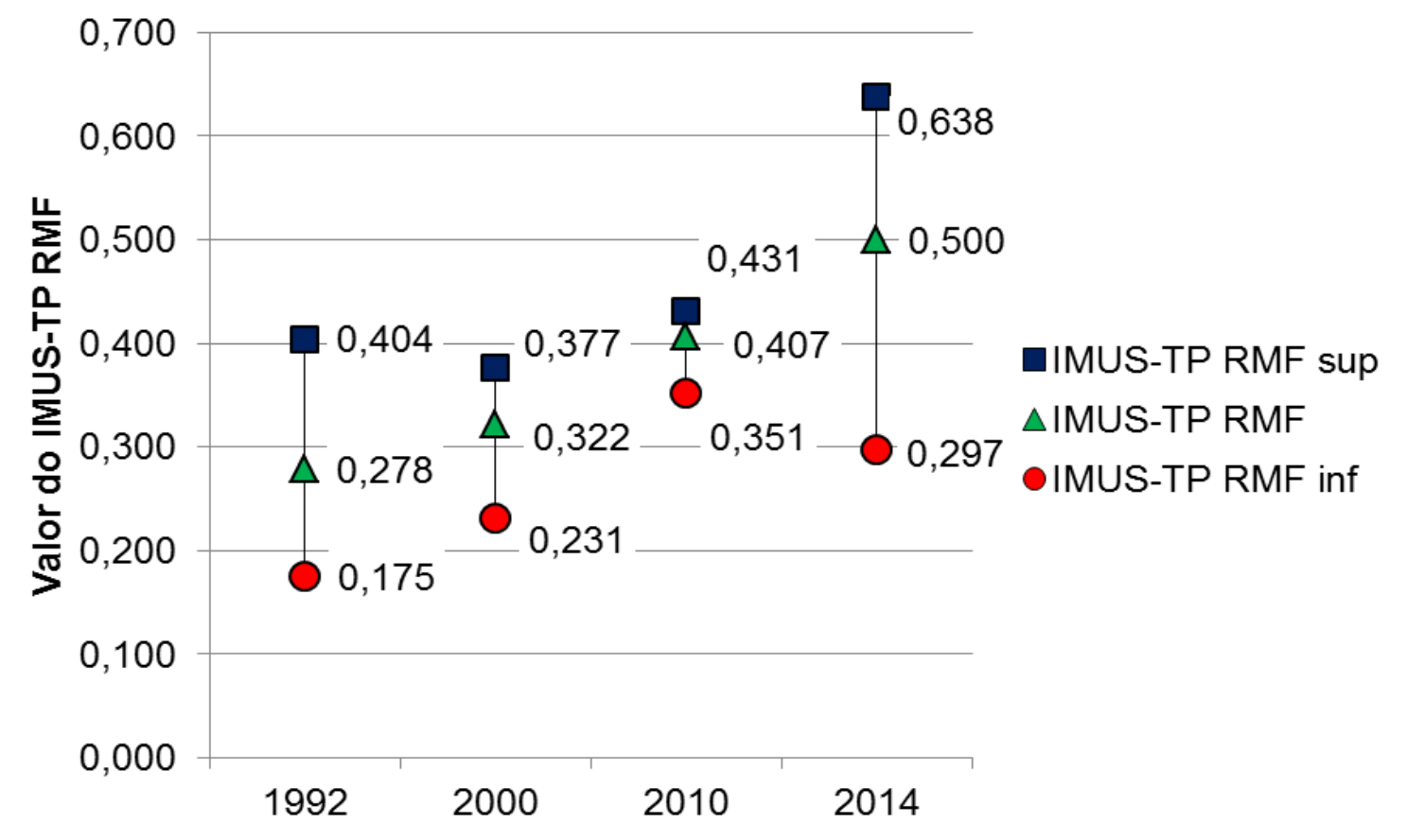

Figura 4.12 - Valores do IMUS-TP RMF e seus limites inferiores e superiores, para cada cenário.

Após a agregação dos dados metropolitanos, houve decréscimos nos valores do IMUS-TP RMF com relação aos valores do IMUS-TP para todos os cenários (Figura 4.13). Isto já era de se esperar, devido à maior deficiência do sistema metropolitano comparada com 
o sistema de transporte urbano. Apesar da diferença, o valor do IMUS-TP RMF para o cenário de 2010 foi de 0,40, considerado ainda regular, mas insatisfatório, mostrando aí a necessidade de mais melhorias quando considerados todos os municípios da RMF.

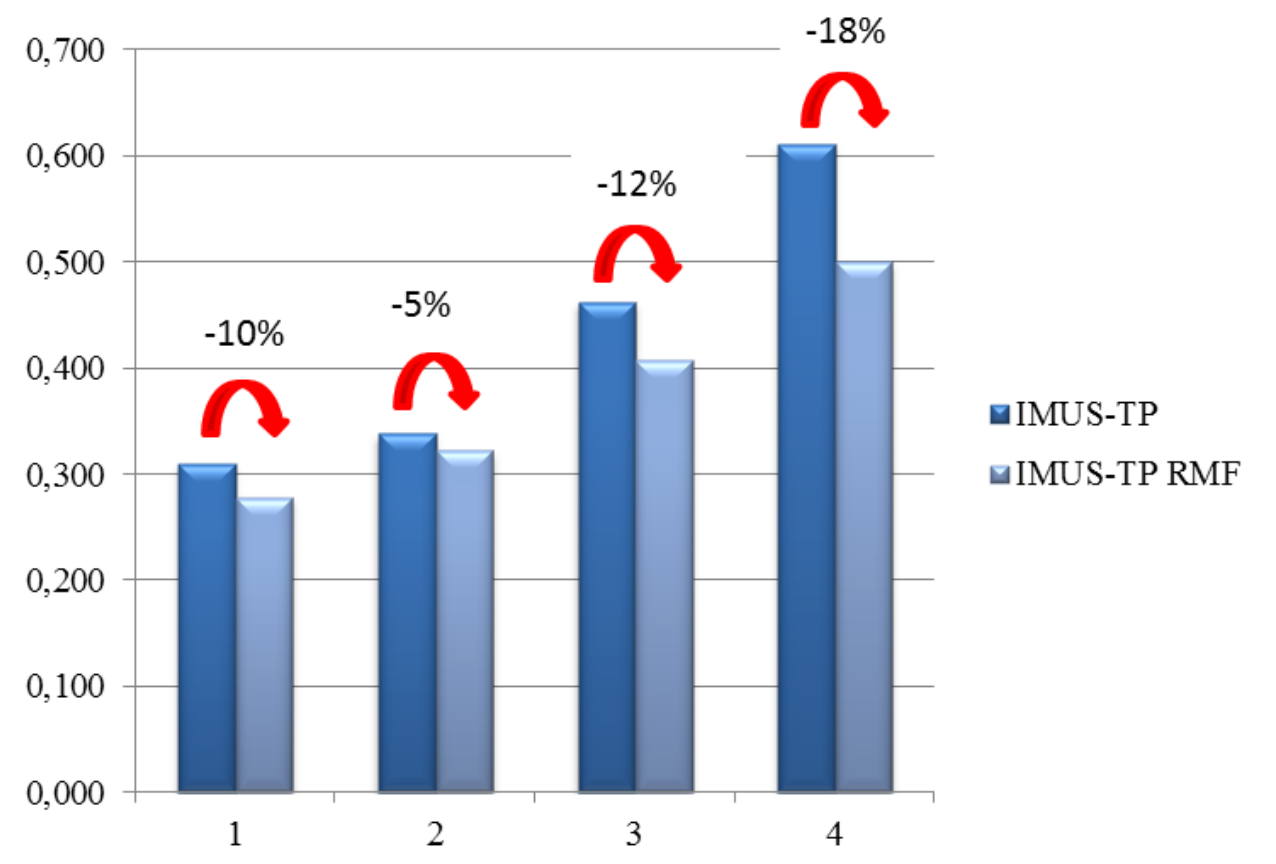

Figura 4.13 - Diferença entre IMUS-TP e IMUS-TP RMF

No que diz respeito às dimensões de sustentabilidade (Figura 4.14), para todos os cenários elas também apresentaram os mesmos valores. A Dimensão Econômica $(0,055)$ foi a que apresentou a melhor avaliação, seguida das Dimensões Social e Ambiental (0,053). Estes valores se apresentaram bem inferiores aos encontrados na análise para Fortaleza. Para as dimensões Econômica e Social houve um decréscimo em torno de 50\% Para a dimensão Ambiental, o decréscimo foi de aproximadamente 45\%. Em compensação, houve um maior equilíbrio entre as três dimensões, o que é um ponto positivo. 


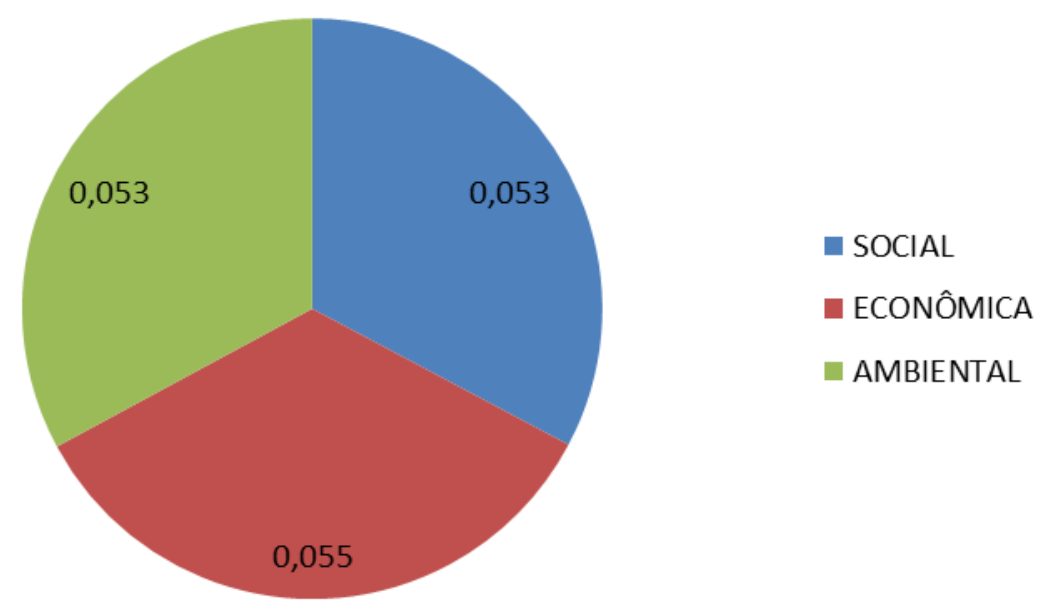

Figura 4.14 - Dimensões de sustentabilidade para o IMUS-TP RMF

\subsubsection{Análise dos resultados do IMUS-TP por tema}

A análise por Temas a seguir utilizou as parcelas do IMUS-TP RMF e foi feita considerando duas situações. Na primeira foram analisados todos os indicadores, enquanto que na segunda foram analisados apenas aqueles indicadores comuns para todos os Temas (Figura 4.15).

De acordo com a parte de cima da Figura 4.15, os Temas que se apresentaram piores foram: "Distribuição da Infraestrutura de Transporte" e "Integração do Transporte Público". Isso vem reforçar os apontamentos feitos na análise por Temas do IMUS-TP sobre as deficiências nos indicadores "Vias para transporte coletivo", "Terminais intermodais" e "Integração do transporte público".

A quantidade de indicadores calculados para cada cenário causa algum efeito sobre o valor do IMUS-TP RMF. Para descartar este efeito, optou-se por fazer uma nova estimativa do índice, considerando apenas os indicadores calculados para todos os cenários. A diferença pode ser avaliada fazendo uma comparação entre os gráficos da Figura 4.15. Para esta condição, existe um total de 8 indicadores. Observa-se redução para os cenários de 1992, 2000 e 2010, e que a constatação sobre os temas "Distribuição da Infraestrutura de

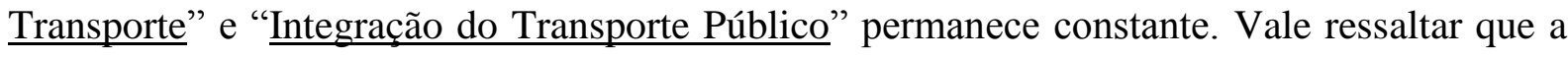
quantidade de indicadores comuns aos quatro cenários é bem menor do que a quantidade para o IMUS-TP devido ao número de "vazios" para o cenário de 2014 (13). 
IMUS-TP RMF (com todos os indicadores)

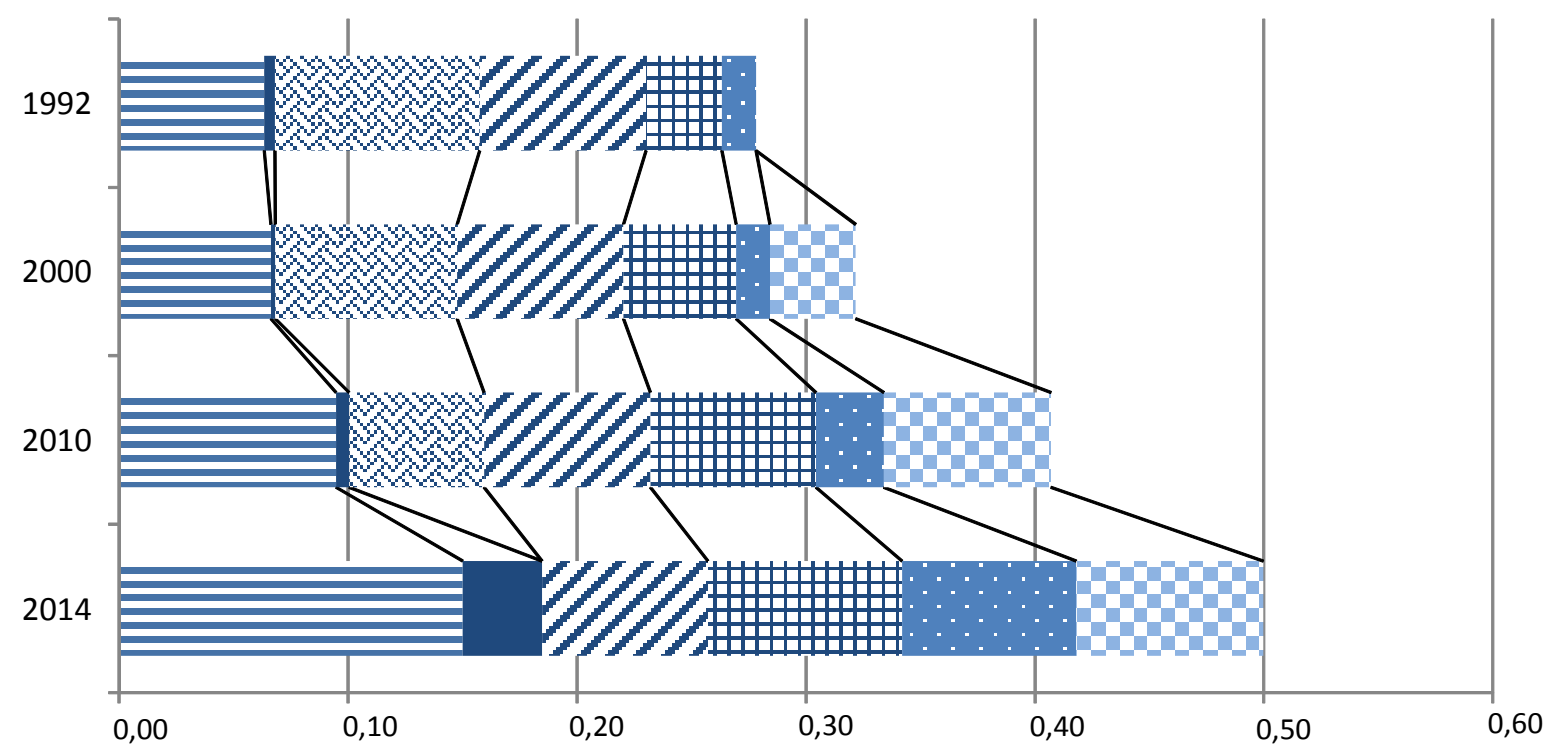

\section{IMUS-TP RMF (com indicadores comuns)}

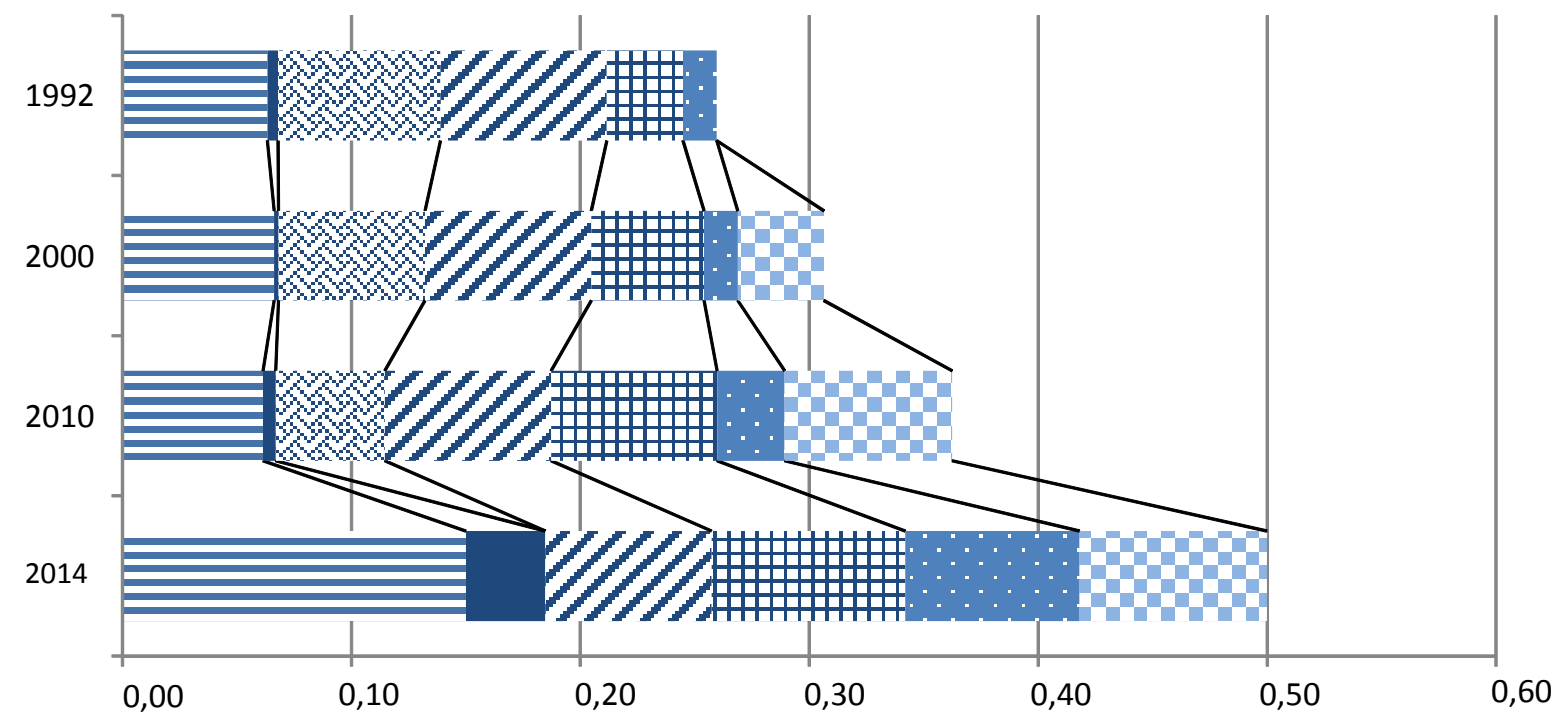

Acessibilidade ao sistema de transportes

Distribuição da infraestrutura de transportes

\#冊冊 Regulação e fiscalização do transporte público

Disponibilidade e qualidade do transporte público $\because$ Integração do transporte público

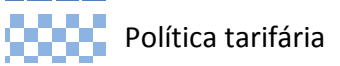

Diversificação modal

Figura 4.15 - Contribuição de cada tema para a formação do IMUS-TP RMF por cenário 


\subsubsection{Classificação e análise dos resultados do IMUS-TP RMF por indicador}

Os indicadores para o IMUS-TP RMF também foram classificados de acordo com seus escores normalizados nas seis classes especificadas no item 3.6: "Crítico" $(0,00$ a 0,20), "Ruim" (0,20 a 0,40), "Regular" (0,40 a 0,60), "Bom" (0,60 a 0,80), "Ótimo" (0,80 a 1,00) e "Vazio". A Figura 4.16 mostra um resumo geral por cenário.

Pode-se observar no gráfico que houve uma evolução apenas nos três primeiros cenários com relação aos indicadores. A quantidade de indicadores "ótimos" e "bons" (7, 8, 12) apresentou crescimento, traduzindo uma melhoria até o cenário atual. No cenário de 2014 houve uma queda nesta quantidade (6). Uma das possíveis explicações para isto é a grande quantidade de indicadores não calculados ("Vazio") observados para este cenário, impossibilitando a análise de seus comportamentos. Com relação à quantidade de indicadores "regulares", "ruins" e "críticos", pode-se verificar que houve uma redução a partir do cenário de 2000 em diante $(9,7,3)$.

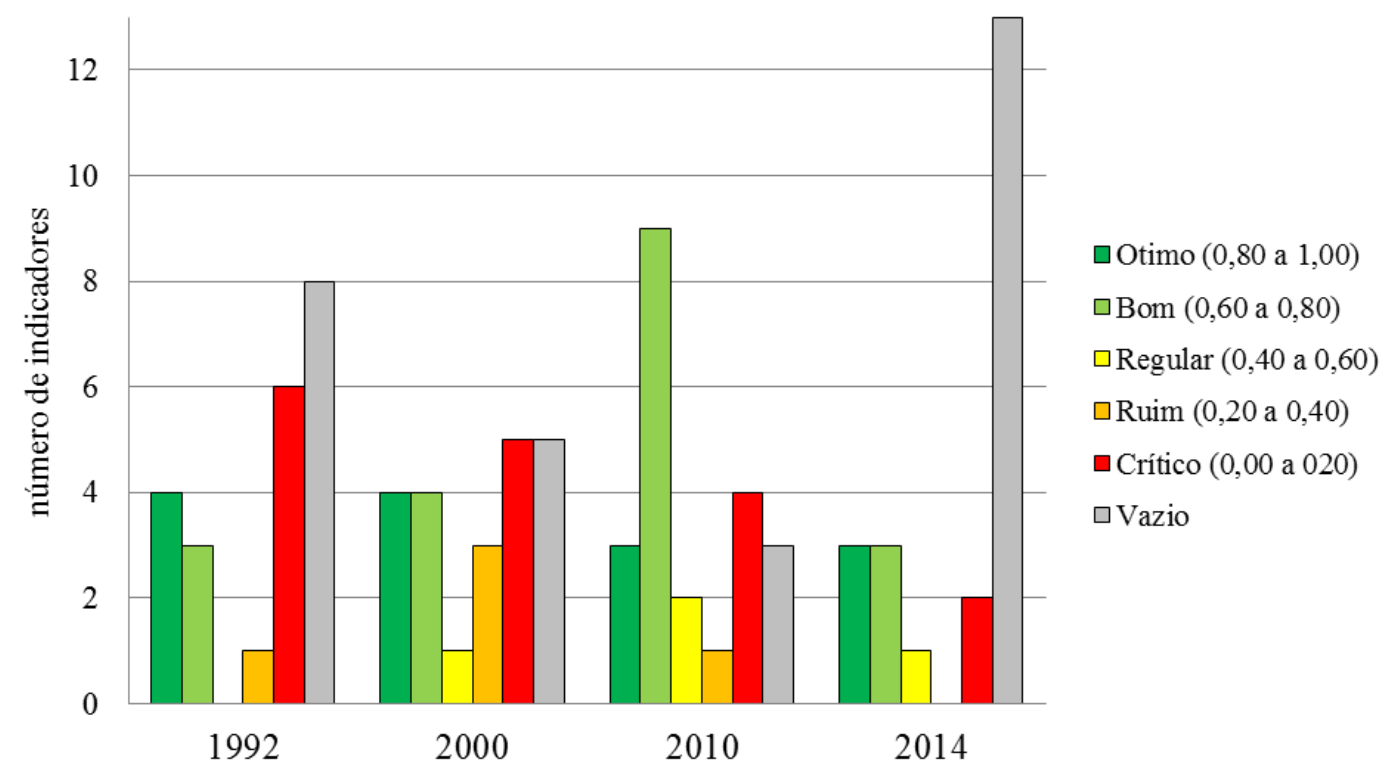

Figura 4.16 - Classificação geral dos indicadores do IMUS-TP RMF por cenário

A Figura 4.17 apresenta a classificação detalhada de cada indicador do IMUS-TP RMF conforme mudam os cenários, o que, juntamente com a memória de cálculo (Anexo), dá subsídio à análise por indicador. As barras horizontais representam os cenários de 1992, 2000, 2010 e 2014, de cima para baixo, por indicador. 


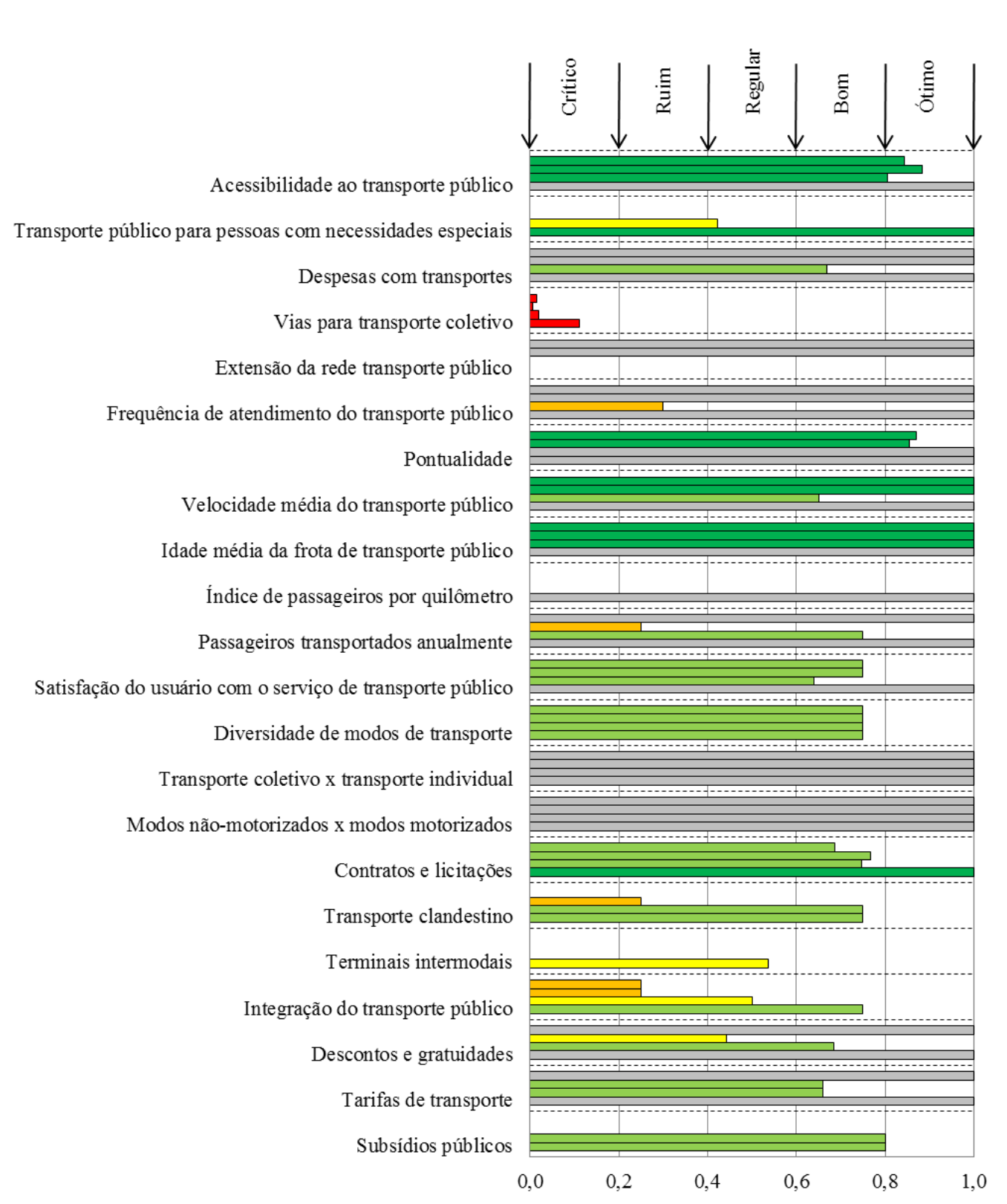

Figura 4.17 - Classificação detalhada dos indicadores do IMUS-TP RMF por cenário. As barras horizontais representam os cenários de 1992, 2000, 2010, 2014, de cima para baixo, por indicador.

O indicador "Acessibilidade ao transporte público" apresentou ótimos desempenhos para os três primeiros cenários $(1992,2000,2010)$. Isso mostra que, quando considerado o sistema de transporte público de toda a Região Metropolitana, percebe-se ainda uma boa cobertura espacial. Para o cenário de 2014, apesar de existirem as informações referentes à acessibilidade do sistema para a cidade de Fortaleza, estas não foram disponibilizadas para os demais municípios da RMF, impossibilitando a agregação dos dados, e, assim, o cálculo deste indicador. A Figura 4.18 mostra a cobertura espacial das linhas da RMF para o cenário atual (2010). 

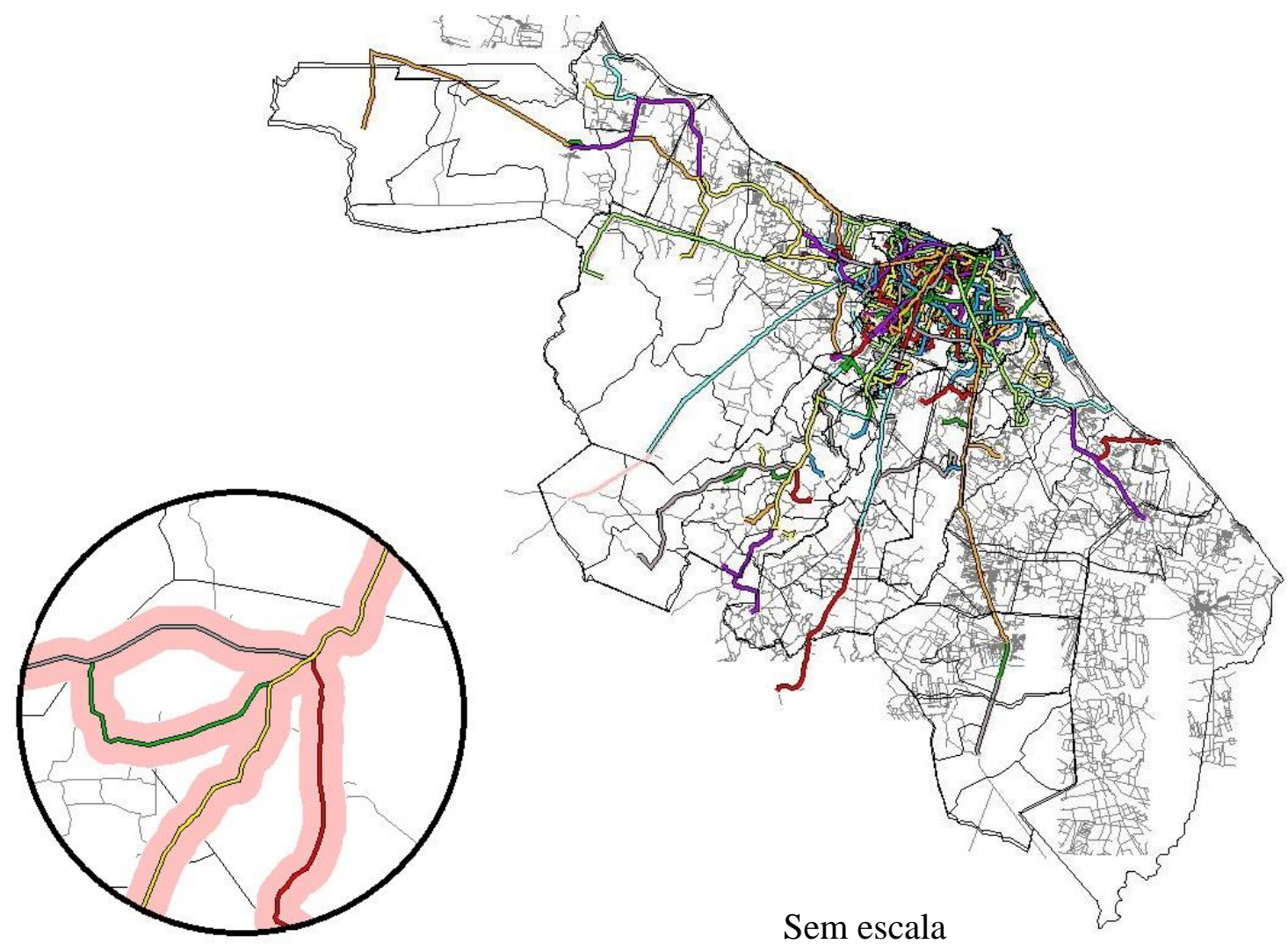

Figura 4.18 - Cobertura espacial das linhas de ônibus da RMF com detalhe das bandas (ou buffers)

$\mathrm{O}$ indicador "Transporte para pessoas com necessidades especiais" obteve desempenhos críticos para os cenários de 1992 e 2000, devido à inexistência de veículos adaptados na RMF. Para o cenário de 2010, apesar de não existirem veículos adaptados no sistema de transporte público metropolitano, com a agregação dos dados, o indicador ainda mostrou um desempenho regular, mesmo apresentando um escore normalizado menor do que o encontrado na análise do IMUS-TP. Isso se explica devido à ponderação dos dados ter sido feita a partir da frota total de veículos, sendo a frota do sistema urbano bem maior do que a frota do sistema metropolitano. Para o cenário de 2014, também se aplica a legislação federal brasileira (Brasil, 2004), que obriga as cidades brasileiras a adaptar $100 \%$ dos veículos de transporte público para o acesso universal.

O indicador "Despesas com transporte" foi calculado apenas para o cenário de 2010, quando obteve um bom desempenho, mantendo o mesmo comportamento observado na análise do IMUS-TP. Este indicador talvez não retrate a realidade do sistema na RMF, devido à falta de integração do sistema metropolitano com o sistema urbano, fazendo com que alguns usuários necessitem pagar uma segunda tarifa para chegar ao seu destino final. 
O indicador "Vias para transporte coletivo" apresentou desempenhos críticos para todos os cenários, apresentando valores normalizados bem inferiores aos valores encontrados na análise do IMUS-TP. Isso já era de esperar, pelo fato de não haver incidência e nem previsão de vias exclusivas ou preferenciais na RMF, exceto em Fortaleza. Portanto, o cálculo deste indicador foi realizado com base nas extensões de vias exclusivas e preferenciais de Fortaleza (Figura 4.10), sendo agora relacionadas com uma área urbanizada bem maior. Vale lembrar que este indicador é o que possui maior peso. Portanto, para elevar o IMUS-TP RMF é necessário que se façam investimentos na priorização do transporte público, tanto para Fortaleza como para os demais municípios da RMF, permitindo algum tipo de interação.

O indicador "Extensão da rede de transporte público" foi calculado apenas para os cenários de 2010 e de 2014, devido à falta de informações sobre a extensão total do sistema viário para os outros cenários. $\mathrm{O}$ indicador apresentou desempenhos críticos, com a rede de transporte público cobrindo apenas 16,3\% e 14,6\%, respectivamente. Estes valores foram inferiores aos encontrados na análise do IMUS-TP (26,0\% e 27,0\%) devido ao aumento significativo da extensão total do sistema viário. O conflito com o indicador "Acessibilidade ao transporte público" observado na análise do IMUS-TP permanece, visto que uma rede de transportes de $16,3 \%$ da extensão da malha viária proporciona uma cobertura espacial de $82,4 \%$ da área urbana. A sobreposição das configurações das linhas em Fortaleza continua sendo um possível motivo para este fato. A criação de um plano de racionalização para todas as linhas, sejam elas urbanas ou metropolitanas, permanece como uma possível solução. Outra possível justificativa no caso da RMF diz respeito à consideração de vias localizadas em áreas rurais, onde, muitas vezes, não existe cobertura do sistema de transporte público.

O indicador "Frequência de atendimento do transporte público" foi calculado apenas para o cenário de 2010, devido ao fato de todas as frequências das linhas da RMF já estarem agregadas em uma base de SIG (Sistema de Informações Geográficas) fornecida pela ARCE. Para os outros cenários, não foi encontrado nenhum elemento de ponderação que possibilitasse o cálculo do indicador. Para o cenário calculado, este indicador apresentou um desempenho ruim, com uma frequência de atendimento de 29 minutos, que é considerada alta por Costa (2008). Este fato pode ser atribuído ao baixo número de linhas metropolitanas e à grande extensão das mesmas, tornando as viagens mais longas. Outro fator também pode ser o congestionamento que ocorre em certos pontos de Fortaleza nos horários de pico, o que dificulta a saída dos veículos metropolitanos da cidade. Para o cenário de 2014, está previsto 
que as linhas metropolitanas passem apenas a tangenciar o município de Fortaleza, o que deve melhorar este aspecto dos congestionamentos e aumentar o desempenho deste indicador.

O indicador "Pontualidade" só foi calculado para os dois primeiros cenários, 1992 e 2000, apresentando ótimos desempenhos, tal como na análise do IMUS-TP. Devido à falta de confiabilidade dos relatórios sobre a programação das viagens fornecidos pelas empresas metropolitanas, a ARCE optou por deixar de monitorá-los. É importante que exista uma fiscalização periódica de todas as viagens ocorridas na RMF para que o valor do IMUS-TP RMF aumente, aproximando a mobilidade urbana do termo sustentável.

O desempenho do indicador "Velocidade média do transporte público" melhorou bastante com relação ao desempenho encontrado na análise do IMUS-TP. Para os cenários de 1992 e 2000, ele passou de regular para ótimo. Para o cenário de 2010, passou de regular para bom. Isso ocorre pelo fato do elemento de ponderação utilizado ter sido a quilometragem percorrida, maior para o sistema metropolitano, que, por sua vez, também apresenta maior velocidade (mais de $25 \mathrm{~km} / \mathrm{h}$ para 1992 e 2000, e $25 \mathrm{~km} / \mathrm{h}$ para 2010) do que o sistema urbano (em torno de $20 \mathrm{~km} / \mathrm{h}$ para os três cenários). Para o cenário de 2014, não foi possível calcular o indicador por falta de informações. É essencial que sejam feitas pesquisas de velocidade periodicamente, para que haja subsídio para projeções futuras.

O indicador "Idade média da frota de transporte público" obteve ótimos desempenhos para os três primeiros cenários, mesmo comportamento observado na análise do IMUS-TP. Isso mostra que tanto os veículos do sistema de transporte urbano como os veículos do sistema metropolitano vêm sendo renovados periodicamente. Visto isso, pode-se prever que para o cenário de 2014 este indicador ainda se apresentará como ótimo, apesar de não terem sido obtidas informações a respeito da idade média dos veículos do sistema metropolitano para este ano.

O indicador "Índice de passageiros por quilômetro" apresentou desempenhos críticos para os três primeiros cenários. Para o cenário de 1992 o valor deste indicador foi de apenas 1,89, valor inferior ao encontrado na análise do IMUS-TP. Para os cenários de 2000 e de 2010, houve ainda uma redução deste indicador, o que fez com que o valor normalizado do escore permanecesse zero, mesmo comportamento observado na análise do IMUS-TP. Não existe qualquer previsão para este indicador com relação ao cenário de 2014, exceto para Fortaleza, que ainda apresenta um desempenho crítico. É necessário que os projetos previstos para a Copa de 2014 incluam toda a Região Metropolitana, melhorando assim a qualidade e 
garantindo maior demanda para os sistemas urbano e metropolitano, o que mudaria a classe do indicador.

O indicador "Passageiros transportados anualmente" foi calculado apenas para os cenários de 2000 e de 2010. Para o cenário de 2000, apresentou um desempenho regular devido ao decréscimo do número de passageiros transportados em dois anos ter sido inferior a $25 \%$. Percebe-se que o desempenho do indicador passou de "bom" (IMUS-TP) para "ruim" (IMUS-TP RMF) neste cenário. Para o cenário de 2010, o indicador apresentou bom desempenho, devido ao crescimento do número de passageiros transportados em dois anos ter sido inferior a $25 \%$. Neste caso, percebeu-se que o desempenho do indicador melhorou de “regular" para "bom”. Não existe previsão para a RMF para o ano de 2014, exceto para Fortaleza. É de extrema importância que sejam organizados bancos de dados com as informações sobre passageiros transportados anualmente que possibilitem previsões futuras. Investir no transporte público garantirá maior atratividade ao seu usuário, melhorando, assim, o desempenho deste indicador.

O indicador "Satisfação do usuário com o serviço de transporte público" apresentou bons desempenhos para os três primeiros cenários. Para os cenários de 1992 e 2000, foi obtido que $75 \%$ dos usuários estavam satisfeitos com o sistema. Percebeu-se uma melhoria no seu desempenho para o ano de 2000 em relação ao valor de Fortaleza, tendo em vista que na análise do IMUS-TP o valor do indicador foi de apenas 54\% ("regular"). Para o cenário de 2010, foi observado que $64 \%$ dos usuários estavam satisfeitos com o sistema de transporte da RMF. Portanto, percebe-se aí também uma melhoria no seu desempenho em relação à Fortaleza, tendo em vista que na análise do IMUS-TP o valor do indicador foi de apenas $40 \%$ ("regular"). Apesar de não terem sido obtidas quaisquer informações sobre a satisfação do usuário para o ano de 2014, espera-se que este percentual aumente com as obras previstas para a Copa do Mundo. Com o início da operação do metrô, o sistema de transporte público por ônibus irá “desafogar”, podendo atender melhor às exigências da população.

O indicador "Diversidade de modos de transporte" apresentou bons desempenhos para todos os cenários, mesmo comportamento observado na análise do IMUS-TP. A RMF dispõe dos mesmos modos de transporte que operam em Fortaleza: a pé, bicicleta, automóvel, táxi, ônibus e ferroviário. Os indicadores "Transporte coletivo $x$ transporte individual" e "Modos não motorizados $x$ modos motorizados" não foram calculados para nenhum cenário. A partir daí, é de suma importância a iniciativa para o desenvolvimento de uma pesquisa Origem- 
Destino tanto para Fortaleza e sua Região Metropolitana, como para muitas outras cidades brasileiras.

O indicador "Contratos e licitações" apresentou bons desempenhos para os três primeiros cenários. Isso mostra o compromisso das empresas de transporte metropolitano, assim como o das empresas de transporte urbano, comprovado na análise do IMUS-TP. Para o cenário de 2014, o técnico da ARCE garantiu que até este ano todos os contratos das empresas metropolitanas estarão regularizados, assim como os contratos das empresas urbanas.

O indicador "Transporte clandestino" apresentou desempenho crítico para o cenário de 1992, mesmo comportamento observado na análise do IMUS-TP. Isso mostra a grande participação do transporte informal naquela época. Para o cenário de 2000, apesar da participação quase insignificante deste tipo de serviço na cidade de Fortaleza, nos demais municípios da Região Metropolitana ela ainda se fazia expressiva, o que fez com que o desempenho do indicador decaísse de ótimo (IMUS-TP) para ruim (IMUS-TP RMF). Para os cenários de 2010 e 2014, o indicador obteve bom desempenho, apesar de ainda mostrar uma pequena participação do transporte clandestino na RMF, maior do que a observada na análise do IMUS-TP.

O indicador "Terminais intermodais" se apresentou crítico nos três primeiros cenários devido à inexistência de terminais desse tipo, tanto na cidade de Fortaleza como nos demais municípios da RMF. Já para o cenário de 2014, além dos dois terminais intermodais em Fortaleza (Figura 4.11), estão previstas mais 20 estações de metrô (Linha Sul) que permitirão integração intermodal, melhorando o desempenho do indicador de "ruim" (IMUS-TP) para "regular" (IMUS-TP RMF). A Figura 4.19 mostra o estágio em que se encontra a estação da Parangaba e a Figura 4.20 mostra a localização de todas as outras estações.

O indicador "Integração do transporte público" apresentou o mesmo comportamento observado na análise do IMUS-TP para os três primeiros cenários ("ruim", "ruim" e “regular", respectivamente). Para o cenário de 2014, a RMF ainda não apresentará um sistema totalmente integrado com o uso de bilhete único, exceto Fortaleza, fazendo com que o desempenho do indicador decaia de ótimo (IMUS-TP) para bom (IMUS-TP RMF). Em todo caso, esta evolução no sistema de integração da RMF vai influenciar na atração de novos usuários para o sistema de transporte público. 


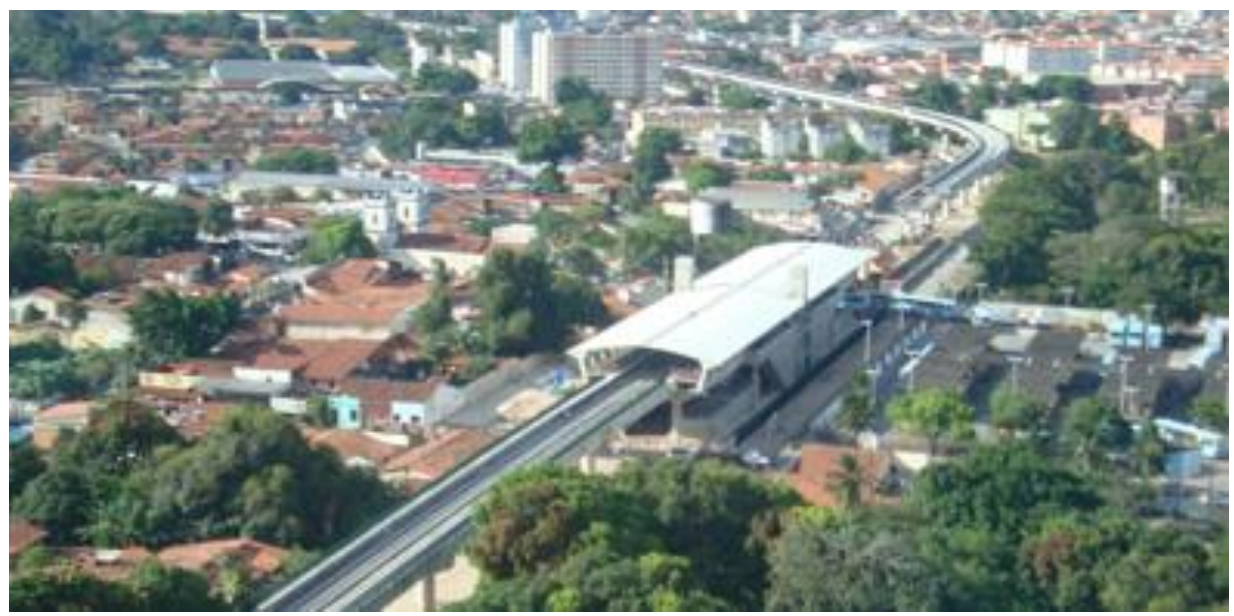

Figura 4.19 - Estágio da estação intermodal da Parangaba (Fonte: METROFOR, 2012)

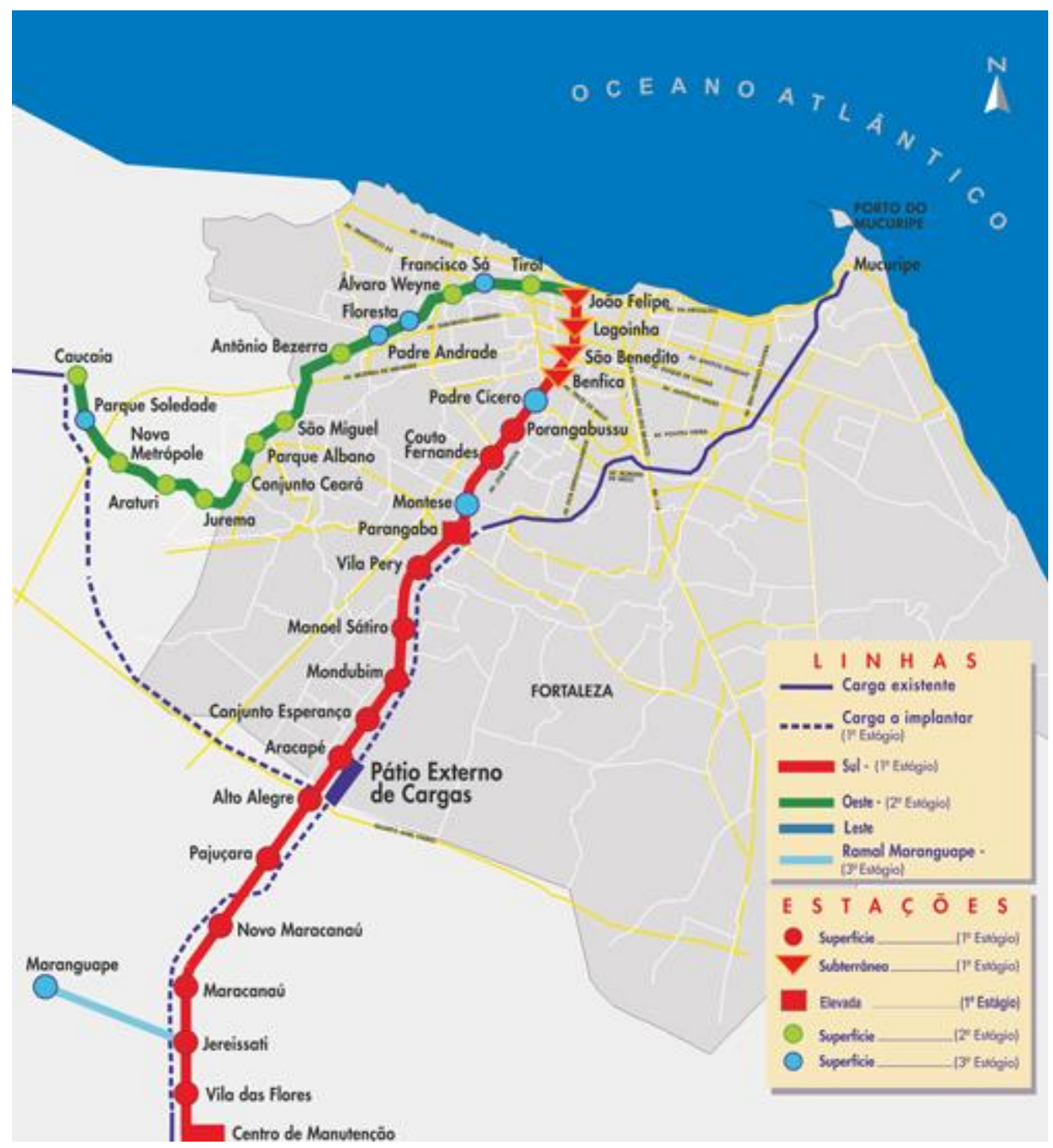

Figura 4.20 - Estações de metrô intermodais (Linha Sul) previstas para 2014 (Fonte: METROFOR, 2012) 
O indicador "Descontos e gratuidades" foi calculado apenas para os cenários de 2000 e 2010. Para o cenário de 2000, seu desempenho foi regular, apresentando uma parcela de descontos e gratuidades sobre o número de embarques total de $32,3 \%$, valor inferior ao encontrado na análise do IMUS-TP (35,3\%). Vale ressaltar que, para o sistema metropolitano, até o ano de 2005 os embarques com desconto não eram computados. Portanto, para este sistema, até o cenário de 2000 só foram considerados os embarques com gratuidades (número que girava em torno de $4 \%$ do total de embarques). Para o cenário de 2010, o valor obtido para este indicador foi de 22,6\%, inferior ao valor encontrado na análise do IMUS-TP $(23,0 \%)$, mas que mantém o seu bom desempenho. Não existe uma previsão por parte dos técnicos a respeito do cenário de 2014.

O indicador "Tarifas de transporte" foi calculado apenas para os cenários de 2000 e 2010. Para o cenário de 2000 ele apresentou bom desempenho devido ao comportamento da tarifa refletir um aumento inferior ao índice IPCA. Percebe-se então que o seu desempenho melhorou quando comparado com o comportamento observado na análise do IMUS-TP (“crítico"). Para o cenário de 2010, seu desempenho também se apresentou "bom”, assim como na análise do IMUS-TP. Para que esse quadro não seja piorado tendo em vista o cenário de 2014, o desenvolvimento de ações para atrair novos usuários e congelar ou diminuir a tarifa vigente pode ser uma boa opção.

O indicador "Subsídios públicos" se apresentou crítico nos cenários de 1992 e 2000, devido à ausência de qualquer subsídio para o sistema de transporte público da Região Metropolitana de Fortaleza. Para os cenários de 2010 e 2014, apesar de existirem subsídios para a totalidade do sistema de transporte urbano de Fortaleza, o sistema metropolitano não conta com qualquer subsídio, fazendo com que o desempenho deste indicador passe de “ótimo” (IMUS-TP) para “bom” (IMUS-TP RMF). 


\section{CONCLUSÕeS}

Neste trabalho foi realizada uma avaliação da qualidade do sistema de transporte público da Região Metropolitana de Fortaleza, e da cidade de Fortaleza em particular, a partir da metodologia adaptada do Índice de Mobilidade Urbana Sustentável (IMUS), proposto por Costa (2008). Foi proposto um "novo" índice, composto de parte dos indicadores do IMUS, denominado IMUS-TP, aplicado a quatro cenários (1992, 2000, 2010 e 2014). Neste capítulo serão apresentadas as principais conclusões construídas a partir das análises dos resultados mostradas anteriormente. Este capítulo foi dividido em quatro partes: conclusões quanto ao IMUS, quanto à análise do IMUS-TP, quanto à análise do IMUS-TP RMF e sugestões para trabalhos futuros.

\subsection{Quanto ao IMUS}

Sistemas de indicadores como o IMUS facilitam muito o entendimento de todos sobre o que deve ser priorizado e qual o possível efeito das diferentes intervenções que podem ocorrer. A sua aplicação é relativamente simples, desde que as instituições públicas organizem um sistema de coleta, armazenamento e tratamento de dados. A maior parte deles já é coletada rotineiramente em cidades de médio e grande porte.

Neste trabalho foi possível adaptar esta ferramenta possibilitando a avaliação de um sistema de transporte público de uma cidade de grande porte. Esta flexibilidade é um aspecto positivo desta metodologia. Uma crítica construída durante o processo de aplicação do índice diz respeito ao indicador "Extensão da rede de transporte público". Para que ele possua um ótimo desempenho é necessário que as rotas de transporte público cubram o sistema viário da cidade quase que completamente (Costa, 2008), mesmo que a cobertura espacial das suas configurações seja muito boa, como pode ser visto nas análises realizadas neste trabalho. Portanto, é importante a revisão dos valores de referência para este indicador.

Não se trata apenas de implantação de medidas pontuais que envolvam aspectos de um

ou outro indicador. É preciso que se consolide um processo contínuo de planejamento e monitoramento da mobilidade, envolvendo toda a sociedade. A participação dos vários segmentos da população é fundamental para que o resultado do planejamento seja aceito e 
tenha mais chance de ser implantado. Isto pode ser evidenciado no estudo feito por Zambon et al. (2010), no qual é proposta uma fusão entre o IMUS e o sistema PLANUTS, ferramenta que auxilia no planejamento e monitoramento da mobilidade urbana, no intuito de incorporar a participação popular no processo de tomada de decisão.

\subsection{Quanto à análise do IMUS-TP}

Com relação à aplicação do IMUS-TP na cidade de Fortaleza, foram encontradas dificuldades para se obter todos os dados necessários para o cálculo do índice. Isto pode ser consequência da falta de prática constante do monitoramento e planejamento do sistema. Mesmo assim, foi possível avaliar a situação de cada cenário.

Para o cenário atual (2010), o IMUS-TP apresenta um valor ruim (abaixo de 0,500 em uma escala de 0 a 1) e, mesmo com a execução dos projetos previstos para 2014, este valor não deverá atingir níveis satisfatórios $(0,612)$. De acordo com a tabela 3.2, o IMUS-TP para o cenário de 2010 pode ser classificado como regular, e para 2014, como bom. A comparação com a cidade de Curitiba pode demonstrar um caminho para Fortaleza aperfeiçoar o seu sistema de transporte público. No que diz respeito às dimensões de sustentabilidade, pode-se perceber que existe um pequeno desequilíbrio, mostrando que a dimensão ambiental requer uma maior atenção por parte dos órgãos responsáveis no momento de colocar os projetos de mobilidade em prática.

Com base nestas constatações, buscou-se encontrar nos indicadores aquelas deficiências pontuais que poderiam influenciar o valor do índice. Na comparação dos quatro cenários, percebeu-se que o número de indicadores classificados como "ótimo" ou "bom" aumentou, mas que ainda existem aqueles que representam aspectos carentes de intervenções para melhorar os escores, o que irá aumentar a qualidade do transporte público. Estes são, principalmente, os que receberam classificação "ruim" ou "crítico".

Considerando a iniciativa de priorização do sistema de transporte público, pode-se começar pelo aumento da extensão de faixas exclusivas ou preferenciais, o que afetará diretamente o indicador "Vias para transporte coletivo" ("crítico" nos cenários de 1992, 2000 e 2010; "ruim" no cenário de 2014) e irá fazer com que a "Velocidade média do transporte

público" ("regular" nos quatro cenários) também melhore. Assim, os custos de operação devem diminuir e o nível do serviço deve melhorar. Melhor serviço propicia aumento de demanda, o que deve aumentar o "Índice de passageiros por quilômetro (IPK)". Maior IPK e 
menores custos podem tirar a pressão de um possível aumento tarifário que está prejudicando o futuro do indicador "Tarifas de transporte".

Outro aspecto importante diz respeito ao sistema de integração física e tarifária. O aumento de pontos de integração física e uma maior facilidade de integração temporal ampliariam muito o conjunto de possibilidades de percursos para os usuários. Isto deve tornar o sistema mais atrativo, tanto em termos de tempo quanto de custo de viagem, o que deve atrair maior demanda. Trata-se de um processo gradativo de se buscar uma mudança na escolha modal, com o favorecimento de modos mais sustentáveis.

Com relação à dimensão ambiental, merecem destaque os indicadores "Transporte coletivo x Transporte individual" e "Modos não motorizados x Modos motorizados", que apresentam peso alto e baixo valor. A melhora nos valores destes indicadores depende, entre outras coisas, de investimento em campanhas de motivação para o uso de transportes mais sustentáveis. Além disso, a realização de pesquisas Origem-Destino é importante para o seu monitoramento.

\subsection{Quanto à análise do IMUS-TP RMF}

Com relação à aplicação do IMUS-TP na Região Metropolitana de Fortaleza, além dos dados não obtidos para o sistema de transporte urbano de Fortaleza, a inexistência de vários dados do sistema metropolitano impossibilitou o cálculo de alguns indicadores. Entretanto, este fator também não impediu a avaliação dos quatro cenários.

Para o cenário atual (2010), o IMUS-TP RMF também apresenta um valor ruim $(0,407)$ e, mesmo com a execução dos projetos previstos para 2014, este valor não deverá atingir níveis satisfatórios (0,500). De acordo com a tabela 3.2, o IMUS-TP RMF para os cenários de 2010 e 2014 podem ser classificado como regulares. Vale ressaltar que o número de vazios para este cenário foi significativo. No que diz respeito às dimensões de sustentabilidade, pode-se perceber que existe um maior equilíbrio entre as elas quando são levados em consideração os demais municípios da Região Metropolitana de Fortaleza, ainda que a análise mostre que as dimensões ambiental e social requeiram maior atenção do que a econômica.

Com base nestas constatações, também se buscou encontrar as deficiências pontuais nos indicadores. Percebeu-se que o número de indicadores classificados como "ótimo" ou 
"bom" aumentou nos três primeiros cenários. Para os indicadores classificados como "ruim" ou "crítico", percebeu-se que houve um pequeno crescimento do cenário de 1992 para o cenário de 2000 (de 7 para 8), que diminui nos dois próximos cenários (para 5 e 2 em 2010 e 2014, respectivamente). Este fato aponta uma melhoria na mobilidade da Região Metropolitana de Fortaleza.

A investigação por indicador para a análise do IMUS-TP RMF veio reforçar os aspectos prioritários apontados na análise do IMUS-TP. Além disso, verificou-se a grande deficiência do indicador "Frequência de atendimento do transporte público" nesta análise. $\mathrm{O}$ técnico do DETRAN-CE afirmou que as linhas metropolitanas até o ano de 2014 não irão mais operar dentro de Fortaleza, passando a tangenciá-la apenas. Esta mudança pode vir a melhorar significativamente o desempenho do indicador se atrelada a ações que venham a priorizar o sistema de transporte público na RMF.

Outro aspecto importante diz respeito aos "Subsídios públicos". É importante que haja uma preocupação por parte dos órgãos responsáveis pelo sistema metropolitano com relação aos seus subsídios, contribuindo para a mobilidade sustentável de toda a Região Metropolitana de Fortaleza. Por fim, é imprescindível que exista uma interação entre os órgãos responsáveis pela operação do sistema de transporte metropolitano e os órgãos responsáveis pela operação do sistema de transporte urbano de Fortaleza para que juntos possam alcançar seus objetivos.

\subsection{Sugestões para trabalhos futuros}

Os resultados obtidos com a aplicação do IMUS-TP em Fortaleza revelaram problemas com o indicador "Extensão da rede de transporte público". O seu método de avaliação é um tanto exigente, visto que para apresentar um bom desempenho é necessário que a rede de transporte público da cidade possua uma extensão praticamente coincidente com a extensão total do sistema viário daquela cidade, mesmo que a cobertura espacial do sistema seja bastante abrangente. Miranda (2010), que aplicou o IMUS na cidade de Curitiba, também verificou a mesma deficiência neste indicador. Com isso, sugere-se uma revisão na forma de avaliar este indicador, aperfeiçoando a ferramenta para a sua utilização em trabalhos futuros.

É importante que os demais indicadores do IMUS, não contemplados neste trabalho, sejam calculados, possibilitando avaliar a contribuição do segmento de transporte público no cálculo do Índice para Fortaleza, além de comparações com outras cidades. Outra sugestão se 
trata da reavaliação do sistema com o IMUS-TP após o ano de 2014, para fins de verificação e comparação com os resultados hoje obtidos. Outra sugestão importante seria estimar indicadores como "Despesas com transportes" que não foram calculados para o cenário de 2014. 


\section{REFERÊNCIAS BIBLIOGRÁFICAS}

ALBANO, J. F.; SENNA, L. A. S. Desenvolvimento Sustentável e Transportes. In: X ANPET - Congresso da Associação Nacional de Ensino e Pesquisa em Transportes, Brasília, 1996. p. $65-72$

AMC. Autarquia Municipal de Trânsito, Serviços Públicos e Cidadania. Prefeitura Municipal de Fortaleza. 2012. Disponível em: 〈http://www.fortaleza.ce.gov.br/amc〉. Acesso em: 12/07/2012.

ARCE. Agência Reguladora de Serviços Públicos Delegados do Estado do Ceará. Governo do Estado do Ceará. 2012. Disponível em: <http://www.arce.ce.gov.br>. Acesso em: $12 / 10 / 2012$.

ARCE. Relatório Anual 2011. Agência Reguladora de Serviços Públicos Delegados do Estado do Ceará. Governo do Estado do Ceará. 2011 Disponível em: <http://www.arce.ce.gov.br/index.php/relatorios-de-gestao>. Acesso: 12/09/2012.

AZEVEDO FILHO, M. A. N. Análise do processo de planejamento dos transportes como contribuição para a mobilidade urbana sustentável. Tese (Doutorado). Escola de Engenharia de São Carlos, Universidade de São Paulo, São Carlos, 2012.

AZEVEDO FILHO, M. A. N. e RODRIGUES DA SILVA, A. N. Uma avaliação retrospectiva de Belém do Pará sob a ótica da Mobilidade Sustentável. Congresso Nacional de Ensino e Pesquisa em Transportes, Joinville-SC, 2012.

AZEVEDO FILHO, M. A. N. D.; SILVA, L. M. D.; RODRIGUES DA SILVA, A. N. A Spatial Analysis of Factors Affecting Public and Private Motorized Trips. In: CODATU XIV - Sustainable transport and the quality of life in the city, 2010, Buenos Aires: Buenos Aires: CODATU - Cooperation for urban mobility in the developing world, p. 1-16.

BLACK, A. Urban Mass Transportation Planning. New York: McGraw-Hill, 1995.

BLACK, W. R. Sustainable Transportation: A U.S. Perspective. Journal of Transport Geography, 4(3), 151-159, 1996.

BOARETO, R. A política de mobilidade urbana e a construção de cidades sustentáveis. Revista dos Transportes Públicos, ANTP, 2008. p. 143-160.

BRASIL. Decreto no 5.296 de 2 de dezembro de 2004. Regulamenta as Leis nos 10.048, de 8 de novembro de 2000, que dá prioridade de atendimento às pessoas que especifica, e 10.098, de 19 de dezembro de 2000, que estabelece normas gerais e critérios básicos para a promoção da acessibilidade das pessoas portadoras de deficiência ou com mobilidade reduzida, e dá outras providência. Brasília, 2004. Disponível em: 
<http://www.planalto.gov.br/ccivil_03/_ato2004-2006/2004/decreto/d5296.htm>. Acesso em: 21/08/2012.

BRASIL. Lei $\mathrm{n}^{\mathbf{0}}$ 12.587, de 03 de janeiro de 2012. Institui as diretrizes da Política Nacional de Mobilidade Urbana e dá outras providências. Brasília. 2012. Disponível em: http://www.planalto.gov.br/ccivil_03/_Ato2011-2014/2012/Lei/L12587.htm. Acesso em: $06 / 01 / 2013$

CALIPER (Ed.). TransCAD - Transportation Planning Software - Version 5.0 GIS User's Guide. Newton: Caliper Corporation, 2007.

CAVAlCANTE NETO, C. C. Transporte Público Urbano por ônibus: Análise da qualidade do Sistema Integrado de Fortaleza. (Monografia). Centro de Tecnologia, Universidade Federal do Ceará, Fortaleza, 2009.

CHAVES, J. F. Sistema de transporte público urbano: análises de modelos da qualidade na visão de gestores e usuários de ônibus da região metropolitana de Belém-RMB no estado do Pará-Brasil. Dissertação (Mestrado). Instituto Universitário de Lisboa: Lisboa, 2010.

COSTA, M. S. Um Índice de Mobilidade Urbana Sustentável. Tese (Doutorado). Escola de Engenharia de São Carlos, Universidade de São Paulo, São Carlos, 2008.

COSTA, M. S. An evaluation of the Index of Sustainable Urban Mobility (I_SUM) in São Paulo, Brazil. Programa de Pós-doutorado "Mobility Cultures in Megacities". Institute for Mobility Research - ifmo e Technische Universität München. Munique, 2011.

CURTIS, C.; LOW, N. Institutional barriers to sustainable transport. Ashgate, Farnham, Surrey (2012).

DETRAN-CE. Portal do Departamento Estadual de Trânsito. Governo do Estado do Ceará. Disponível em: <http://portal.detran.ce.gov.br/>. Acesso em: 12/07/2012.

ETUFOR. Empresa de Transporte Urbano de Fortaleza - Início. Prefeitura Municipal de Fortaleza. Empresa de Transporte Urbano de Fortaleza. Disponível em: <http://www.fortaleza.ce.gov.br/etufor/>. Acesso em: 12/07/2012.

FARLA, J.; ALKEMADE, F.; SUURS, R. A. A. Analysis of barriers in the transition toward sustainable mobility in the Netherlands. Technological Forecasting and Social Change, 2008. $\quad$ p. 1260-1269. Disponível em: <http://www.sciencedirect.com/science/article/pii/S0040162510000661>. Acesso em: 02/03/2013.

FERRAZ, A. C. P.; TORRES, I. G. E. Transporte Público Urbano. Rima, São Carlos, 2004.

GEIPOT. Passageiros transportados por trem em Fortaleza. Anuário Estatístico de dos Transportes. Empresa Brasileira de Planejamento de Transportes. Disponível em: <http://www.geipot.gov.br/NovaWeb/IndexAnuario.htm>. Acesso em: 03/04/2012. 
GUDMUNDSSON, H. Indicators and performance measures for transportation, environment and sustainability in North America. Relatório do German Marshall Fund Fellowship 2000. Individual Study Tour October 2000. Research Notes n 148. 2001.

IBGE. Censo Demográfico 2000. Instituto Brasileiro de Geografia e Estatística. Disponível em: http://www.ibge.gov.br/home/estatistica/populacao/default_censo_2000.shtm. Acesso em: 05/09/2011.

IBGE. Censo Demográfico 2010. Instituto Brasileiro de Geografia e Estatística. Disponível em: http://www.ibge.gov.br/home/estatistica/populacao/censo2010/default.shtm>. Acesso em: 05/09/2011.

IPEA. A Nova Lei de Diretrizes da Política Nacional de Mobilidade Urbana. (Comunicados do IPEA). Instituto de Pesquisa Econômica Aplicada, Brasília, 2011.

IPECE. Perfil da Renda Domiciliar dos Municípios e Macrorregiões de Planejamento do Estado do Ceará. Instituto de Pesquisa e Estratégias Econômicas do Ceará. Governo do Estado do Ceará, Fortaleza, 2011.

Lima Jr., O. F. Qualidade em serviços de transportes: conceituação e procedimentos para diagnóstico. São Paulo, Tese (Doutorado) - Escola Politécnica, Universidade de São Paulo, 1995.

LITMAN, T. Sustainable Transportation Indicators: A Recommended Research Program For Developing Sustainable Transportation Indicators and Data. In: Transportation Research Board $88^{\text {th }}$ Annual Meeting, 2009, Washington, D.C. TRB, p. 1-14.

LRTA. LRT x BUSES: Why Portland chose light rail. Tramways \& Urban Transit. 2009. Disponível em: <www.tramnews.net>. Acesso em: 03/05/2012.

MACHADO, L.; DOMINGUEZ, E. M. Índice de Mobilidade Sustentável: Uma ferramenta de auxílio ao planejamento urbano. In: PLURIS 2012 - Congresso Luso Brasileiro para o Planejamento Urbano, Regional, Integrado e Sustentável, 2012, Brasília. PLURIS, p. 1-12.

MAIA, A. C. L. Avaliação do sistema de transporte público de passageiros do Campus do Pici. (Monografia). Centro de Tecnologia, Universidade Federal do Ceará, Fortaleza, 2010.

MCIDADES. Política Nacional de Mobilidade Urbana. Ministério das Cidades. Disponível em:

<http://www.cidades.gov.br/index.php?option=com_content\&view=article\&id=1003\&Itemid $=177>$. Acesso em: 12/12/2012.

METROFOR. Portal da Companhia Cearense de Transportes Metropolitanos. Governo do Estado do Ceará. Disponível em: <http://www.metrofor.ce.gov.br/>. Acesso em: $12 / 07 / 2012$. 
METROFOR. Implantação do Projeto Metrofor. Governo do Estado do Ceará. 2012. Disponível em: <http://www.metrofor.ce.gov.br/index.php/o-projeto/implantacao>. Acesso em: 10/04/2012.

METROFOR. Projeto da linha Parangaba-Mucuripe. Governo do Estado do Ceará. 2012. Disponível em: <http://www.metrofor.ce.gov.br/index.php/noticias/43839-governo-adequaprojeto-da-linha-parangaba-mucuripe-para-diminuir-impactos>. Acesso em: 10/04/2012.

MITCHELL, B. Cidades engasgam com automóveis. Entrevista para a revista Mega Cidades, OESP, agosto 2008.

MIRANDA, H. F. Mobilidade Urbana Sustentável e o Caso de Curitiba. Dissertação (Mestrado). Escola de Engenharia de São Carlos, Universidade de São Paulo, São Carlos, 2010.

MIRANDA, H. D. F.; RODRIGUES DA SILVA, A. N. Benchmarking sustainable urban mobility: The case of Curitiba, Brazil. Transport Policy, v. 21, n. 0, p. 141-151, 2012.

MIRANDA, H. D. F.; MANCINI, M. T.; AZEVEDO FILHO, M. A. N. D.; ALVES, V. F. B.; RODRIGUES DA SILVA, A. N. Barreiras para a Implantação de Planos de Mobilidade. In: XXIII ANPET - Congresso de Pesquisa e Ensino em Transportes, 2009, Vitória. ANPET, p. 1-12.

MOBILIZE. Estudo Mobilize 2011: Diagnóstico da mobilidade urbana sustentável em capitais brasileiras. São Paulo: Associação Abaporu, 2011.

MORAIS, J. S. Proposta de método para avaliação da qualidade do transporte público urbano por ônibus utilizando a teoria das representações sociais. Dissertação (Mestrado). Universidade de Brasília, Brasília, 2012.

MORAIS, T. C. Avaliação e seleção de alternativas para a promoção da mobilidade urbana sustentável - O Caso de Anápolis, Goiás. Dissertação (Mestrado). Escola de Engenharia de São Carlos, Universidade de São Paulo, São Carlos, 2012.

NÉSPOLI, L. C. M. Lei de Mobilidade Urbana - Do papel para as ruas. Revista dos Transportes Públicos. Editorial. ANTP, 2013.

PITOMBO, C. S.; FERNANDES, V. O.; ALIXANDRINI JUNIOR, M. J.; SANTOS, D. V. C.; TEIXEIRA, T. C. S. Aplicação conjunta de técnicas de análise multivariada de dados e análise espacial exploratória para avaliação do desempenho de transporte público por ônibus. In: XXIV ANPET - Congresso de Pesquisa e Ensino em Transportes, Salvador, 2010.

PMF. Plano de Transporte Urbano de Fortaleza - PTUF. Prefeitura Municipal de Fortaleza. Fortaleza, 2000.

PONTES, T. F. Avaliação da Mobilidade Urbana na Área Metropolitana de Brasília. Dissertação (Mestrado). Faculdade de Arquitetura e Urbanismo, Universidade de Brasília, Brasília, 2010. 
QGIS. Quantum GIS - User Guide - Version 1.7.0 'Wroclaw'. http://www.qgis.org: Quantum GIS Development Team, 2011.

RICHARDSSON, B. C. Sustainable Transport: analysis framework. Journal of Transport Geography, 13, p. 29-39, 2005. Disponível: <http://www.sciencedirect.com>. Acesso em: 06/05/2013.

RODRIGUES DA SILVA, A. N.; COSTA, M. D.; MACEDO, M. H. Multiple views of sustainable urban mobility: The case of Brazil. Transport Policy, v. 15, n. 6, p. 350-360, 2008.

RODRIGUES DA SILVA, A. N. Institutional barriers to sustainable transport, C. Curtis, N. Low. Journal of Transport Geography. (Book Review). 2013.

RODRIGUES, M. A.; SORRATINI, J. A. A qualidade no transporte coletivo urbano. Congresso Nacional de Ensino e Pesquisa em Transportes-ANPET, Fortaleza-CE, 2008.

RODRIGUES, M. O. Avaliação da qualidade do transporte coletivo da cidade de São Carlos. Dissertação (Mestrado) - Escola de Engenharia de São Carlos, Universidade de São Paulo, São Carlos, 2006.

SOUZA, C. Políticas públicas: uma revisão da literatura. Sociologias, Porto Alegre, n. 16, dez. 2006. Disponível em <http://www.scielo.br/pdf/soc/n16/a03n16.pdf>. Acesso em $16 / 04 / 2013$.

TCRP - Transit Cooperative Research Program - Report 100. Transit Capacity and Quality of Service Manual, $2^{\text {nd }}$ Edition. Transportation Research Board, Washington, DC, 2003.

URBS. Rede Integrada de Transportes de Curitiba. Urbanização de Curitiba S/S. Disponível em: <http://www.urbs.curitiba.pr.gov.br/transporte/rede-integrada-de-transporte>. Acesso em 27/04/2013.

VUCHIC, V. R. Urban Transit: Systems and Technology. Wiley, 2007. 602

ZAMBON, K. L.; MAGAGNIN, R. C.; MANGIERI, R. L.; RODRIGUES DA SILVA, A. N. Incorporando a participação popular ao índice de mobilidade urbana sustentável através da WWW. Artigo apresentado no IV Congresso Luso-Brasileiro para o Planejamento Urbano, Regional, Integrado, Sustentável - PLURIS, Faro, Portugal, 2010. 


\section{ANEXO - MEMÓRIA DE CÁLCULO}

Este anexo consiste na memória de cálculo dos indicadores baseada na coleta de dados realizada e nas diretrizes do trabalho de Costa (2008). Estão discriminadas as fontes de dados, o método de cálculo, escore e normalização, e os valores de referência para cada indicador. A memória está dividida em duas cores para facilitar a compreensão: preto, para os indicadores relativos à cidade de Fortaleza, e azul, para os indicadores relativos à Região Metropolitana de Fortaleza. 


\begin{tabular}{ll}
\hline \hline Domínio & Acessibilidade \\
\hline Tema & $\begin{array}{l}\text { Acessibilidade aos sistemas de } \\
\text { transportes }\end{array}$ \\
\hline Indicador & Acessibilidade ao transporte público \\
\hline Definição & $\begin{array}{l}\text { Porcentagem da população urbana } \\
\text { residente na área de cobertura de um } \\
\text { ponto de acesso aos serviços de } \\
\text { transporte público, considerando todos os } \\
\text { modos disponíveis. }\end{array}$ \\
\hline \hline
\end{tabular}

Fontes de Dados - Fortaleza

\begin{tabular}{lll}
\hline 1992 & $\cdot$ & $\begin{array}{l}\text { Empresa de Transporte Urbano de } \\
\text { Fortaleza - ETUFOR }\end{array}$ \\
\hline 2000 & $\cdot$ & $\begin{array}{l}\text { Empresa de Transporte Urbano de } \\
\text { Fortaleza - ETUFOR }\end{array}$ \\
\hline \multirow{2}{*}{$\cdot \begin{array}{l}\text { Base georreferenciada do município } \\
(2012)-\text { ETUFOR }\end{array}$} & $\begin{array}{l}\text { Base de pontos de acesso para ônibus } \\
(2012) \text { - ETUFOR }\end{array}$ \\
& $\cdot \begin{array}{l}\text { Base Setores Censitários IBGE (2010) } \\
2014\end{array}$ & $\begin{array}{l}\text { Empresa de Transporte Urbano de } \\
\text { Fortaleza - ETUFOR }\end{array}$ \\
\hline
\end{tabular}

Fontes de Dados - Região Metropolitana

\begin{tabular}{|c|c|}
\hline 1992 & $\begin{array}{l}\text { - Departamento de Trânsito do Ceará } \\
\text { (Núcleo Técnico de Transportes) } \\
\text { - Empresa de Transporte Urbano de } \\
\text { Fortaleza-ETUFOR }\end{array}$ \\
\hline 2000 & $\begin{array}{l}\text { - Departamento de Trânsito do Ceará } \\
\text { (Núcleo Técnico de Transportes) } \\
\text { - Empresa de Transporte Urbano de } \\
\text { Fortaleza-ETUFOR }\end{array}$ \\
\hline 2010 & $\begin{array}{l}\text { - ARCE - Agência Reguladora de Serviços } \\
\text { Públicos Delegados do Estado do Ceará } \\
\text { - Base georreferenciada, Base de linhas e } \\
\text { Base de Setores Censitários }\end{array}$ \\
\hline 2014 & $\begin{array}{l}\text { - Não foram obtidas informações para este } \\
\text { cálculo }\end{array}$ \\
\hline
\end{tabular}

\section{Método de Cálculo - Fortaleza}

- População urbana do município segundo o Censo 1991 (IBGE, 2012) = 1.768.637 habitantes

- De 1992 a 2000, houve um crescimento de $5 \%$ na porcentagem da população 1992 urbana residente na área de cobertura de um ponto de acesso aos serviços de transporte público (Técnico)

- População residente na área de cobertura $=1.492 .376$ habitantes

- Razão $=84,38 \%$

- População urbana do município segundo o Censo 2000 (IBGE, 2012) $=2.141 .402$ habitantes

- De 2000 a 2012, houve um crescimento de $10 \%$ na porcentagem da população urbana residente na área de cobertura de um ponto de acesso aos serviços de transporte público (Técnico)

- População residente na área de cobertura $=1.913 .985$ habitantes

- Razão $=89,38 \%$

- Ferramentas auxiliares: Calculadora e Sistema de Informações Geográficas

- Utilização do arquivo geográfico com as vias percorridas pelo sistema de transporte coletivo por ônibus

- Adição da base de setores censitários do IBGE

2010

- Criação de uma banda ao redor das vias, com largura de $300 \mathrm{~m}$, considerando junção das áreas sobrepostas

- Cálculo da população na área total coberta pela banda ao redor das linhas (Só linhas): 2.436.871 habitantes

- População urbana do município segundo o Censo 2010 (IBGE, 2012) - 2.452.185 habitantes

- Razão $=99,38 \%$

- Não está previsto o aumento da cobertura espacial para este cenário. Adotou-se a mesma porcentagem do ano de 2010 (Técnico)

Método de Cálculo - Região Metropolitana

- De acordo com técnico do DETRAN, a cobertura espacial da rede de transporte público metropolitana sempre foi muito boa, girando em torno de $90 \%$ nesta época

- População residente na área de cobertura em Fortaleza = 1.492.376 habitantes

- População urbana RMF - Fortaleza = 692.190 habitantes

1992 - População residente na área de cobertura na RMF excluindo Fortaleza $(90 \%)=$ 622.971 habitantes

- $\quad$ População RMF + Fortaleza $=2.460 .827$ habitantes

- População residente na área de cobertura RMF + Fortaleza $=2.115 .347$ habitantes

- O Score é obtido pela razão entre a população total da camada da banda e a população urbana do município

- Razão $=2.115 .347 / 2.460 .827=85,96 \%$

- De acordo com o técnico do DETRAN, em 2000 a cobertura espacial da rede permaneceu praticamente a mesma $(90 \%)$

- População residente na área de cobertura em Fortaleza $=1.913 .985$ habitantes

- População urbana RMF - Fortaleza = 915.367 habitantes na RMF excluindo Fortaleza $(90 \%)=$ 823.830 habitantes

- População RMF + Fortaleza $=3.056 .769$ habitantes

- População residente na área de cobertura RMF + Fortaleza $=2.737 .815$ habitantes

- O Score é obtido pela razão entre a população total da camada da banda e a população urbana do município

- Razão $=2.737 .815 / 3.056 .769=89,57 \%$

- Ferramentas auxiliares: Calculadora e Sistema de Informações Geográficas

2010 - Utilização do arquivo geográfico com as vias percorridas pelo sistema de transporte coletivo por ônibus

- Adição da base de setores censitários do 


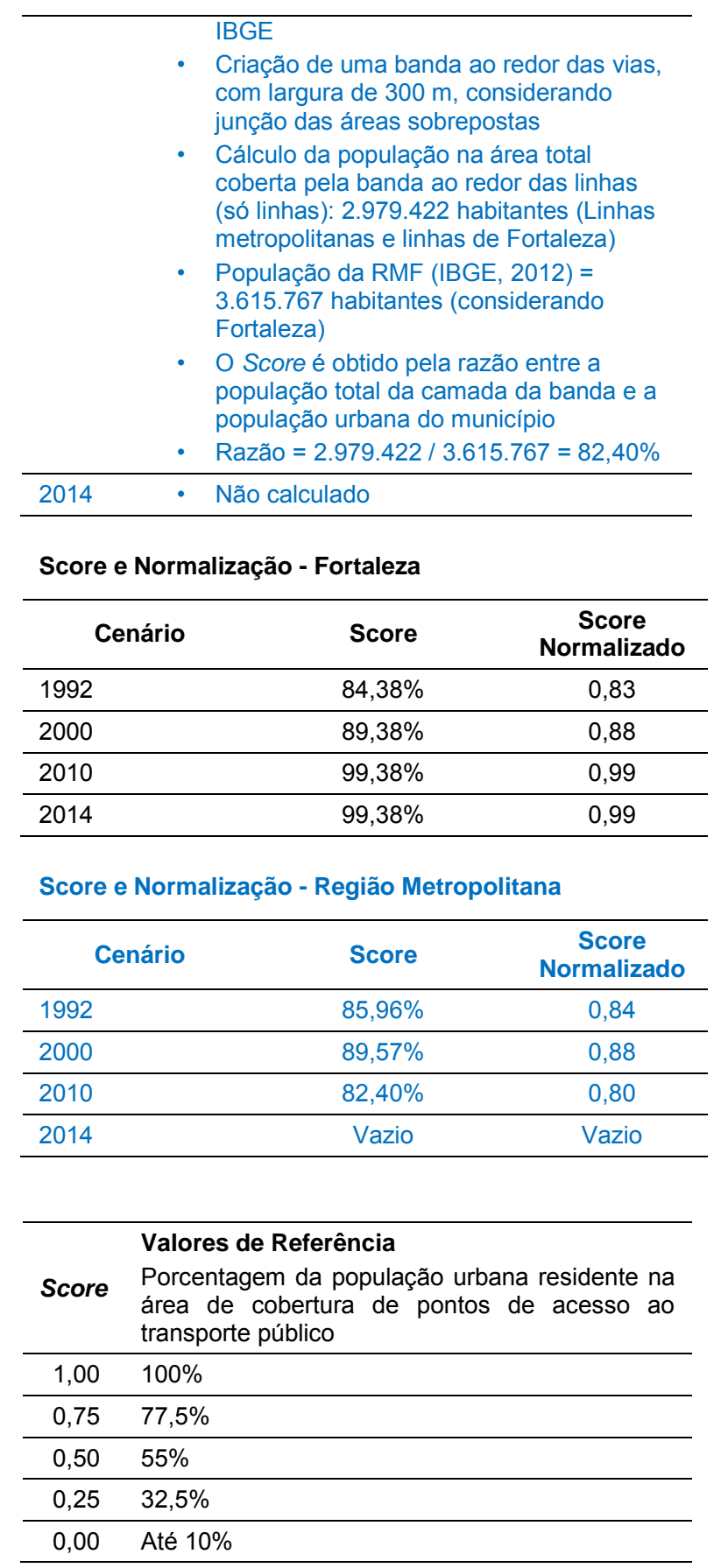




\begin{tabular}{ll}
\hline \hline Domínio & Acessibilidade \\
\hline Tema & Acessibilidade aos sistemas de transportes \\
\hline Indicador & $\begin{array}{l}\text { Transporte público para pessoas com } \\
\text { necessidades especiais }\end{array}$ \\
\hline Definição & $\begin{array}{l}\text { Porcentagem dos veículos da frota } \\
\text { municipal de transporte público por ônibus } \\
\text { adaptada para pessoas com necessidades } \\
\text { especiais e restrições de mobilidade. }\end{array}$ \\
\hline Fontes de Dados - Fortaleza \\
\hline 1992 & Empresa de Transporte Urbano de \\
\hline 2000 & Fortaleza - ETUFOR \\
\hline 2010 & \\
\hline
\end{tabular}

Fontes de Dados - Região Metropolitana

\begin{tabular}{lll}
\hline 1992 & $\begin{array}{l}\text { ARCE - Agência Reguladora de Serviços } \\
\text { Públicos Delegados do Estado do Ceará }\end{array}$ \\
\hline 2000 & $\begin{array}{l}\text { Empresa de Transporte Urbano de } \\
\text { Fortaleza - ETUFOR (Técnico) }\end{array}$ \\
\hline 2014 & \\
\hline
\end{tabular}

\section{Método de Cálculo - Região Metropolitana}

- Não existia nenhum veículo adaptado na época

1992

- Obs: Veículos adaptados a partir de 2004/2005 (Técnico)

- Não existia nenhum veículo adaptado na época

2000

- Obs: Veículos adaptados a partir de 2004/2005 (Técnico)

- Frota de ônibus $(2012)=1926$

- Frota de vans $(2012)=320$

2010 - Número de ônibus adaptados (2012) = 1064

- Número de vans adaptadas $(2012)=127$

- Razão $=1191 / 2246=53 \%$

- O Decreto $n^{\circ} 5.296$, de 2 de dezembro de 2004, prevê que, até o ano de 2014,

$2014 \quad 100 \%$ da frota de veículos de transporte público esteja totalmente adaptada (Técnico)

Método de Cálculo - Região Metropolitana

\begin{tabular}{|c|c|c|}
\hline 1992 & & $\begin{array}{l}\text { Não existia nenhum veículo adaptado na } \\
\text { época }\end{array}$ \\
\hline 2000 & • & $\begin{array}{l}\text { Não existia nenhum veículo adaptado na } \\
\text { época }\end{array}$ \\
\hline 2010 & - & $\begin{array}{l}\text { Frota de ônibus + vans de Fortaleza }= \\
2.246 \\
\text { Frota de ônibus + vans de Fortaleza } \\
\text { adaptados }=1.191 \\
\text { Frota de ônibus metropolitanos }(2012)= \\
571 \\
\text { Frota metropolitana adaptada }=0 \\
\text { Frota total da RMF }=2.817 \\
\text { Frota adaptada da RMF }=1.191 \\
\text { Razão }=1.191 / 2.817=42 \%\end{array}$ \\
\hline 2014 & • & O Decreto $n^{\circ} 5.296$, de 2 de dezembro de \\
\hline
\end{tabular}

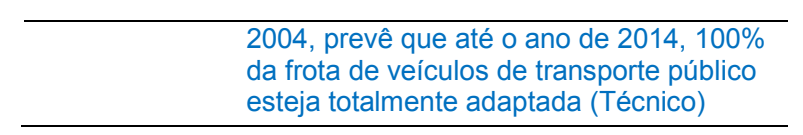

Score e Normalização - Fortaleza

\begin{tabular}{lcc}
\hline Cenário & Score & $\begin{array}{c}\text { Score } \\
\text { Normalizado }\end{array}$ \\
\hline 1992 & $0 \%$ & 0,00 \\
\hline 2000 & $0 \%$ & 0,00 \\
\hline 2010 & $53 \%$ & 0,53 \\
\hline 2014 & $100 \%$ & 1,00 \\
\hline
\end{tabular}

Score e Normalização - Região Metropolitana

\begin{tabular}{ccc}
\hline Cenário & Score & $\begin{array}{c}\text { Score } \\
\text { Normalizado }\end{array}$ \\
\hline 1992 & $0 \%$ & 0,00 \\
\hline 2000 & $0 \%$ & 0,00 \\
\hline 2010 & $42 \%$ & 0,42 \\
\hline 2014 & $100 \%$ & 1,00 \\
\hline
\end{tabular}

\begin{tabular}{|c|c|}
\hline & Valores de Referência \\
\hline Score & $\begin{array}{l}\text { Porcentagem da frota municipal de ônibus } \\
\text { urbano adaptada para pessoas com } \\
\text { necessidades especiais ou restrições de } \\
\text { mobilidade }\end{array}$ \\
\hline 1,00 & $\begin{array}{l}\text { Mais de } 75 \% \text { (ou há serviços especiais para } \\
\text { transporte de pessoas com necessidades } \\
\text { especiais) }\end{array}$ \\
\hline 0,75 & $75 \%$ \\
\hline 0,50 & $50 \%$ \\
\hline 0,25 & $25 \%$ \\
\hline 0,00 & $\begin{array}{l}0 \text { (ou não há serviços especiais para transporte } \\
\text { de pessoas com necessidades especiais) }\end{array}$ \\
\hline
\end{tabular}




\begin{tabular}{ll}
\hline \hline Domínio & Acessibilidade \\
\hline Tema & Acessibilidade aos sistemas de transportes \\
\hline Indicador & Despesas com Transportes \\
\hline Definição & $\begin{array}{l}\text { Porcentagem da renda mensal pessoal (ou } \\
\text { do domicílio) gasta com transporte público. }\end{array}$ \\
\hline \hline
\end{tabular}

Fontes de Dados - Fortaleza

\begin{tabular}{lll}
\hline 1992 & & $\begin{array}{l}\text { Empresa de Transporte Urbano de } \\
\text { Fortaleza - ETUFOR } \\
2000\end{array}$ \\
\hline 2010 & Relatório ETUFOR - histórico de tarifas \\
\hline 2014 & $\begin{array}{l}\text { Empresa de Transporte Urbano de } \\
\text { Fortaleza - ETUFOR }\end{array}$ \\
\hline
\end{tabular}

Fontes de Dados - Região Metropolitana

\begin{tabular}{ll}
\hline 1992 & $\begin{array}{l}\text { Não foram obtidas informações para este } \\
\text { cálculo }\end{array}$ \\
\hline 2000 & $\begin{array}{l}\text { Não foram obtidas informações para este } \\
\text { cálculo }\end{array}$ \\
\hline 2010 & $\begin{array}{l}\text { ARCE - Agência Reguladora de Serviços } \\
\text { Públicos Delegados do Estado do Ceará }\end{array}$ \\
\hline 2014 & $\begin{array}{l}\text { Não foram obtidas informações para este } \\
\text { cálculo }\end{array}$ \\
\hline
\end{tabular}

\section{Método de Cálculo - Fortaleza}

- Tarifa de transporte público por ônibus no ano de 1992 (julho) $=\mathrm{Cr} \$ 1.000$ (ETUFOR)

- Considerou-se uma média de duas viagens por dia ( $\mathrm{Cr} \$ 2.000)$

1992 - Multiplicando-se esse número por 22 dias úteis tem-se uma despesa mensal total de $\mathrm{Cr} \$ 44.000$

- Não foram obtidas informações acerca da renda mensal pessoal ou domiciliar desta época

- A partir da base de setores censitários, calculou-se uma renda média domicilia de $\mathrm{R} \$ 754,90$ (Adotando que toda a população utilizava o sistema de TPU)

- Tarifa de transporte público por ônibus no ano de $2000=\mathrm{R} \$ 0,90$ (ETUFOR)

- Considerou-se uma média de duas viagens por dia $(R \$ 1,80)$

- Multiplicando-se esse número por 22 dias úteis tem-se uma despesa mensal total de $\mathrm{R} \$ 39,60$

- Razão $=39,60 / 754,90=0,0525(5,25 \%)$

- Renda mensal pessoal ou domiciliar $=$ $\mathrm{R} \$ 857,54$ (IPECE, 2011) (Adotando que toda a população utilizava o sistema de TPU)

- Tarifa de transporte público por ônibus no ano de $2010=\mathrm{R} \$ 2,00$ (ETUFOR)

- Considerou-se uma média de duas viagens por dia $=\mathrm{R} \$ 4,00$

- Multiplicando-se esse número por 22 dias úteis tem-se uma despesa mensal total de $\mathrm{R} \$ 88,00$

- Razão $=88,00 / 857,54=0,1026$ $(10,26 \%)$
- Tarifa de transporte público por ônibus no ano de $2014=\mathrm{R} \$ 2,25$ (Previsão ETUFOR)

- Considerou-se uma média de duas viagens por dia $=\mathrm{R} \$ 5,00$

2014 - Multiplicando-se esse número por 22 dias úteis tem-se uma despesa mensal total de $\mathrm{R} \$ 110,00$

- Não foram obtidas informações sobre a renda mensal domiciliar

Método de Cálculo - Região Metropolitana

\begin{tabular}{|c|c|c|}
\hline 1992 & • & Não calculado \\
\hline 2000 & - & Não calculado \\
\hline \multirow{5}{*}{2010} & - & $\begin{array}{l}\text { Rendas médias mensais domiciliares } \\
\text { (IPECE, 2011) } \\
\text { Renda média mensal domiciliar total = R } \$ \\
703,28 \text { (ponderada a partir das } \\
\text { populações dos municípios para este ano) }\end{array}$ \\
\hline & - & $\begin{array}{l}\text { Tarifa de transporte público por ônibus no } \\
\text { ano de } 2010=R \$ 1,86 \text { (Tarifa calculada } \\
\text { para o indicador "Tarifas de transporte") }\end{array}$ \\
\hline & & $\begin{array}{l}\text { Considerou-se uma média de duas } \\
\text { viagens por dia = } R \$ 3,72\end{array}$ \\
\hline & - & $\begin{array}{l}\text { Multiplicando-se esse número por } 22 \text { dias } \\
\text { úteis tem-se uma despesa mensal total de } \\
\mathrm{R} \$ 81,84 \text {. }\end{array}$ \\
\hline & - & $\begin{array}{l}\text { Razão = 81,84 / 703,28 = 0,1164 } \\
(11,64 \%)\end{array}$ \\
\hline 2014 & - & Não calculado \\
\hline
\end{tabular}

Score e Normalização - Fortaleza

\begin{tabular}{lcc}
\hline Cenário & Score & $\begin{array}{c}\text { Score } \\
\text { Normalizado }\end{array}$ \\
\hline 1992 & Vazio & Vazio \\
\hline 2000 & $5,25 \%$ & 0,99 \\
\hline 2010 & $10,26 \%$ & 0,74 \\
\hline 2014 & Vazio & Vazio \\
\hline
\end{tabular}

Score e Normalização - Região Metropolitana

\begin{tabular}{lcc}
\hline Cenário & Score & $\begin{array}{c}\text { Score } \\
\text { Normalizado }\end{array}$ \\
\hline 1992 & Vazio & Vazio \\
\hline 2000 & Vazio & Vazio \\
\hline 2010 & $11,64 \%$ & 0,67 \\
\hline 2014 & Vazio & Vazio \\
\hline
\end{tabular}

\begin{tabular}{ll}
\hline Score & $\begin{array}{l}\text { Valores de Referência } \\
\text { Porcentagem da renda mensal pessoal (ou } \\
\text { domiciliar) relativa a despesas com transporte } \\
\text { público }\end{array}$ \\
\hline 1,00 & Até $5 \%$ \\
\hline 0,75 & $10 \%$ \\
\hline 0,50 & $15 \%$ \\
\hline 0,25 & $20 \%$ \\
\hline 0,00 & Mais de $20 \%$ \\
\hline
\end{tabular}




\begin{tabular}{ll}
\hline \hline Domínio & Infraestrutura de Transportes \\
\hline Tema & Distribuição da infraestrutura de transportes \\
\hline Indicador & Vias para transporte coletivo \\
\hline Definição & $\begin{array}{l}\text { Porcentagem da área urbana da cidade } \\
\text { atendida por vias exclusivas ou } \\
\text { preferenciais para transporte coletivo por } \\
\text { ônibus. }\end{array}$ \\
\hline \hline
\end{tabular}

Fontes de Dados - Fortaleza

\begin{tabular}{|c|c|}
\hline 1992 & $\begin{array}{ll}\text { - Empresa de Transporte Urbano de } \\
\text { Fortaleza-ETUFOR } \\
\text { - } \text { Relatórios ETUFOR } \\
\end{array}$ \\
\hline 2000 & \multirow{2}{*}{$\begin{array}{ll}\text { - } & \text { Empresa de Transporte Urbano de } \\
\text { Fortaleza - ETUFOR } \\
\text { - Relatórios ETUFOR } \\
\text { - Área urbanizada de Fortaleza (Quantum } \\
\text { Gis) }\end{array}$} \\
\hline 2010 & \\
\hline 2014 & $\begin{array}{l}\text { - Empresa de Transporte Urbano de } \\
\text { Fortaleza - ETUFOR (Técnico) }\end{array}$ \\
\hline
\end{tabular}

Fontes de Dados - Região Metropolitana

\begin{tabular}{ll}
\hline 1992 & ETUFOR - Empresa de Transporte \\
\hline 2000 & \begin{tabular}{l} 
Urbano de Fortaleza (Técnico) \\
ARCE - Agência Reguladora de Serviços \\
\hline 2010
\end{tabular} Públicos Delegados do Estado do Ceará \\
\hline 2014
\end{tabular}

\section{Método de Cálculo - Fortaleza}

- Vias exclusivas (contra fluxo):

- Av. João Pessoa entre a Rua Juvenal Galeno e a Rua 15 de novembro (3,9 km)

- Av. Antônio Sales entre Rua D. Leopoldina e a Rua Monsenhor Catão $(3,3 \mathrm{~km})$

- Av. Monsenhor Tabosa entre Av. Barão de Studart e a Av. D. Manuel $(1,8 \mathrm{~km})$

- Av. Francisco Sá entre Rua Padre Anchieta e e Rua Adriano Martins (0,6 $\mathrm{km}$ )

- Extensão total referente às vias exclusivas: 9,6 km

- Criação de bandas de $500 \mathrm{~m}$ ao redor das vias exclusivas

- Área referente aos troncais: 9,6 km x 1,0 $\mathrm{km}=9,6 \mathrm{~km}^{2}$

- Área urbanizada de Fortaleza $=271,50$ $\mathrm{km}^{2}$ (Adotada de 2010)

- $\operatorname{Razão}=9,6 / 271,50=3,53 \%$

- Vias exclusivas (contra fluxo):

- Av. Francisco Sá entre a Rua Padre Anchieta e a Rua Adriano Martins $(0,6$ $\mathrm{km}$ )

- Av. João Pessoa entre a Rua Padre Anchieta e a Rua 15 de novembro (3,0 $\mathrm{km})$

- Extensão vias exclusivas $=3,6 \mathrm{~km}$

- Criação de bandas de $500 \mathrm{~m}$ ao redor das vias exclusivas

- Área referente às vias exclusivas $=3,6$ $\mathrm{km} \times 1,0 \mathrm{~km}=3,6 \mathrm{~km}^{2}$

- Área urbanizada de Fortaleza (2001) = $271,50 \mathrm{~km}^{2}$ (adotada de 2010)

\begin{tabular}{|c|c|}
\hline & - $\quad$ Razão $=3,6 / 271,50=1,30 \%$ \\
\hline 2010 & 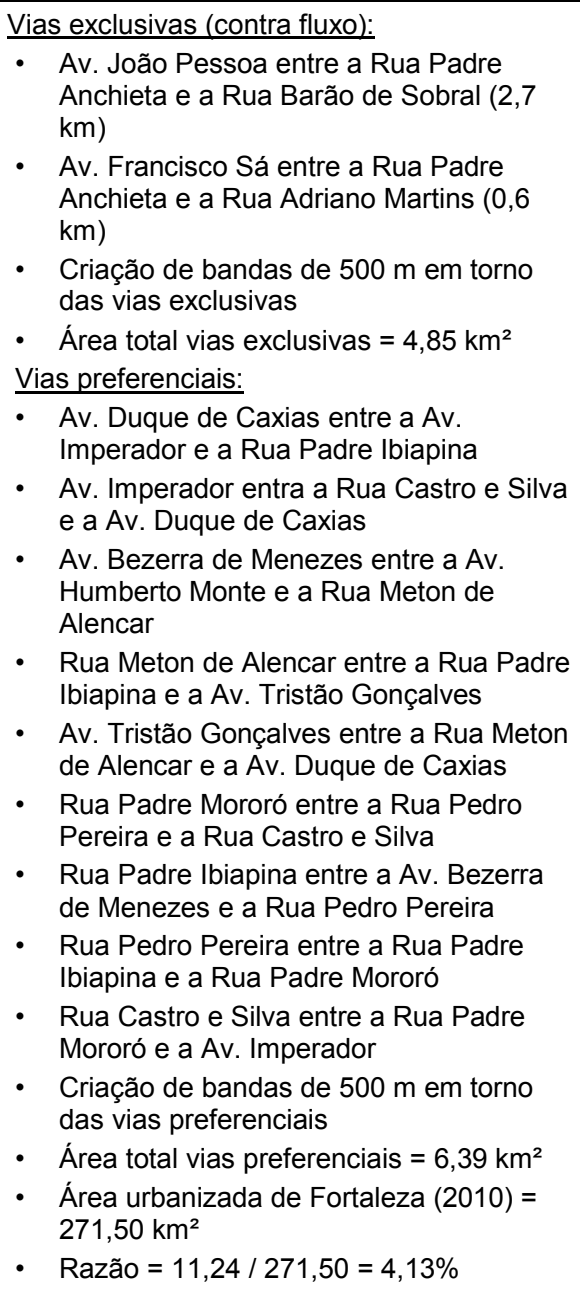 \\
\hline 2014 & $\begin{array}{l}\text { Vias exclusivas (contra fluxo): } \\
\text { - } \quad \text { Av. João Pessoa entre a Rua Padre } \\
\text { Anchieta e a Rua Barão de Sobral (2,7 } \\
\text { km) } \\
\text { - } \quad \text { Av. Francisco Sá entre a Rua Padre } \\
\text { Anchieta e a Rua Adriano Martins (0,6 } \\
\text { km) } \\
\text { - Criação de bandas de } 500 \text { m em torno } \\
\text { das vias exclusivas } \\
\text { - Área total vias exclusivas = 4,85 km² } \\
\text { Vias exclusivas (BRT) } \\
\text { - Trecho 1: Av. Bezerra de Menezes/Av. } \\
\text { Antônio Sales até o terminal do Papicu } \\
\text { (17,4 km) } \\
\text { - Trecho 2: Av. Augusto dos Anjos a partir } \\
\text { do Terminal do Siqueira, continuando na } \\
\text { Av. José Bastos até a Rua Castro e Silva } \\
\text { (11,6 km) } \\
\text { - Trecho 3: Av. Fernandes Távora entre a } \\
\text { Rua José Mendonça até o Terminal da } \\
\text { Lagoa (15,7 km) } \\
\text { Trecho 4.1: Av. Alberto Craveiro a partir } \\
\text { do Castelão até a Av. Gov. Raul Barbosa } \\
\text { (3,0 km) } \\
\text { - Trecho 4.2: Av. Gov. Raul Barbosa indo } \\
\text { pela Via Expressa até o Terminal do } \\
\text { Papicu (3,0 km) } \\
\text { - Trecho 5.1: Av. Dedé Brasil entre o } \\
\text { Terminal da Parangaba até o Estádio } \\
\text { Castelão (5,5 km) } \\
\text { Trecho 5.2: Av. Paulino Rocha a partir da }\end{array}$ \\
\hline
\end{tabular}




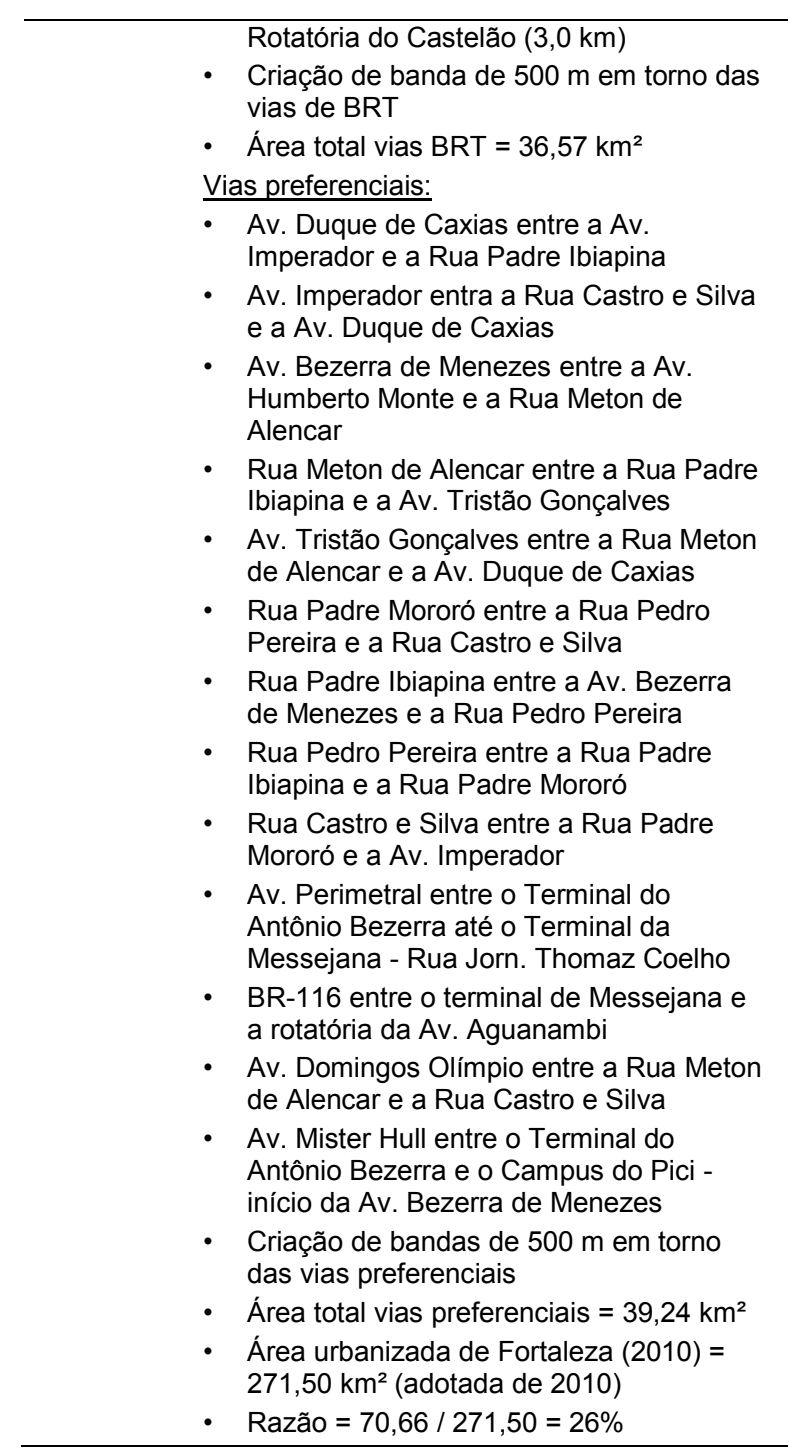

Método de Cálculo - Região Metropolitana

- Área de vias exclusivas em Fortaleza = $9,6 \mathrm{~km}^{2}$

- Não existiam vias exclusivas ou preferenciais para transporte público metropolitano na época (Técnico ARCE)

- Área urbanizada da Região Metropolitana de Fortaleza $=636,96 \mathrm{~km}^{2}$ (Adotada do cenário de 2010)

- Razão $=9,6 / 636,96=0,015(1,50 \%)$

- Para este cálculo não foram consideradas as linhas alimentadoras integradas à rede troncal

- Área de vias exclusivas em Fortaleza = $3,6 \mathrm{~km}^{2}$

- Não existiam vias exclusivas ou preferenciais para transporte público metropolitano na época (Técnico ARCE)

- Área urbanizada da Região Metropolitana de Fortaleza $=636,96 \mathrm{~km}^{2}$ (adotada do cenário de 2010)

- Razão $=3,6 / 636,96=0,006(0,60 \%)$

- Para este cálculo não foram consideradas as linhas alimentadoras integradas à rede troncal
- Área de vias exclusivas ou preferenciais em Fortaleza $=11,24 \mathrm{~km}^{2}$

- Não existem vias exclusivas ou preferenciais para transporte público metropolitano atual (Técnico ARCE)

- Para o cálculo da área efetivamente urbanizada, utilizou-se o programa Quantum Gis

- Área urbanizada da Região Metropolitana de Fortaleza $=636,96 \mathrm{~km}^{2}$

- Razão $=11,24 / 636,96=0,018(1,80 \%)$

- Para este cálculo não foram consideradas as linhas alimentadoras integradas à rede troncal

- Área de vias exclusivas ou preferenciais em Fortaleza $=70,66 \mathrm{~km}^{2}$

- Não existe previsão de vias exclusivas ou preferenciais para transporte público metropolitano (Técnico ARCE)

2014 - Área urbanizada da Região Metropolitana de Fortaleza $=636,96 \mathrm{~km}^{2}$ (Adotado de 2010)

- Razão $=70,66 / 636,96=0,111(11,10 \%)$

- Para este cálculo não foram consideradas as linhas alimentadoras integradas a rede troncal

Score e Normalização - Fortaleza

\begin{tabular}{lcc}
\hline Cenário & Score & $\begin{array}{c}\text { Score } \\
\text { Normalizado }\end{array}$ \\
\hline 1992 & $3,53 \%$ & 0,03 \\
\hline 2000 & $1,30 \%$ & 0,01 \\
\hline 2010 & $4,13 \%$ & 0,04 \\
\hline 2014 & $26,0 \%$ & 0,26 \\
\hline
\end{tabular}

Score e Normalização - Região Metropolitana

\begin{tabular}{lcc}
\hline Cenário & Score & $\begin{array}{c}\text { Score } \\
\text { Normalizado }\end{array}$ \\
\hline 1992 & $1,50 \%$ & 0,02 \\
\hline 2000 & $0,60 \%$ & 0,01 \\
\hline 2010 & $1,80 \%$ & 0,02 \\
\hline 2014 & $11,10 \%$ & 0,11 \\
\hline
\end{tabular}

\begin{tabular}{ll}
\hline Score & $\begin{array}{l}\text { Valores de Referência } \\
\text { Porcentagem da área urbana do município é } \\
\text { atendida por vias exclusivas ou preferenciais } \\
\text { para transporte coletivo por ônibus e linhas } \\
\text { alimentadoras integradas }\end{array}$ \\
\hline 1,00 & $100 \%$ \\
\hline 0,75 & $75 \%$ \\
\hline 0,50 & $50 \%$ \\
\hline 0,25 & $25 \%$ \\
\hline 0,00 & 0 \\
\hline
\end{tabular}




\begin{tabular}{ll}
\hline \hline Domínio & Sistemas de Transporte Urbano \\
\hline Tema & $\begin{array}{l}\text { Disponibilidade e qualidade do transporte } \\
\text { público }\end{array}$ \\
\hline Indicador & Extensão da rede de transporte público \\
\hline Definição & $\begin{array}{l}\text { Extensão total da rede de transporte } \\
\text { público em relação à extensão total do } \\
\text { sistema viário urbano. }\end{array}$ \\
\hline \hline
\end{tabular}

Fontes de Dados - Fortaleza

\begin{tabular}{|c|c|}
\hline 1992 & $\begin{array}{l}\text { - Extensão de linhas de ônibus (Técnico } \\
\text { ETUFOR) } \\
\text { - Extensão ferroviária (Anuário ETUFOR } \\
\text { 2001) } \\
\text { - Obs: Esta extensão ferroviária só veio a } \\
\text { mudar depois de 2001, por isso este } \\
\text { mesmo dado foi usado para o ano de } \\
2000 \text { (Técnico) }\end{array}$ \\
\hline 2000 & 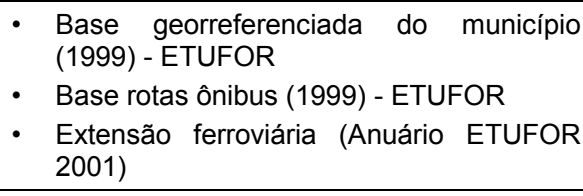 \\
\hline 2010 & $\begin{array}{l}\text { Base georreferenciada do município } \\
\text { (2011) - ETUFOR } \\
\text { - Base rotas ônibus (2011) - ETUFOR }\end{array}$ \\
\hline 2014 & $\begin{array}{l}\text { - Técnico em transportes ETUFOR } \\
\text { - Extensão ferroviária - (METROFOR, } \\
\text { 2012) }\end{array}$ \\
\hline \multicolumn{2}{|c|}{ Fontes de Dados - Região Metropolitana } \\
\hline $\begin{array}{l}1992 \\
2000\end{array}$ & $\begin{array}{l}\text { - Departamento de Trânsito do Ceará } \\
\text { (Núcleo Técnico de Transportes) }\end{array}$ \\
\hline 2010 & $\begin{array}{l}\text { - ARCE - Agência Reguladora de Serviços } \\
\text { Públicos Delegados do Estado do Ceará }\end{array}$ \\
\hline 2014 & $\begin{array}{l}\text { Departamento de Trânsito do Ceará } \\
\text { (Núcleo Técnico de Transportes) }\end{array}$ \\
\hline
\end{tabular}

\section{A. Método de Cálculo - Fortaleza}

- Extensão ferroviária $=46 \mathrm{~km}$

- Extensão total da rede de transporte público $=476 \mathrm{~km}$

1992

- Não foram obtidas informações acerca da extensão total do sistema viário na área urbana

- Extensão ferroviária $=46 \mathrm{~km}$

- Extensão total da rede de transporte público por ônibus (técnico) - 850 km

2000

- Não foram obtidas informações acerca da extensão total do sistema viário na área urbana

- Extensão ferroviária (adotada) $=46 \mathrm{~km}$

- Extensão total do sistema viário na área urbana (2011) - $4.040 \mathrm{~km}$

2010 - Criação de banda ao redor das vias para transporte coletivo, com distância de $1 \mathrm{~m}$

- Extensão total da rede de transporte público por ônibus (2011) - $1.000 \mathrm{~km}$

- Razão $=1046 / 4040=0,26(26 \%)$

2014 - Extensão ferroviária $=96 \mathrm{~km}$ (Atual +
implantação de $50 \mathrm{~km}$ )

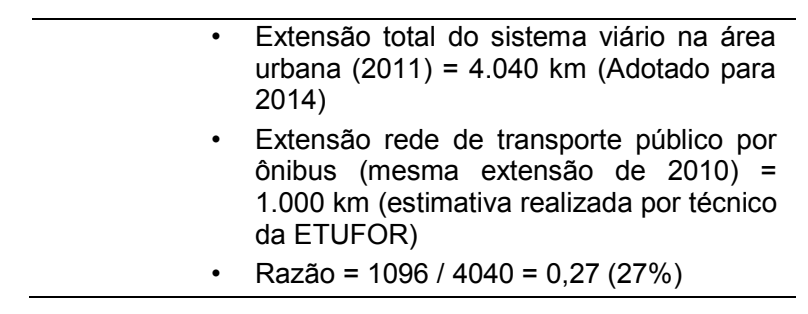

Método de Cálculo - Região Metropolitana

- De acordo com o técnico, a extensão da rede era aproximadamente $15 \%$ menor do

1992 que a de 2010

- Não foram obtidas informações sobre a extensão total do sistema viário da época

- De acordo com o técnico, a extensão da rede era aproximadamente $15 \%$ menor do

2000 . $\quad$ que a de 2010 extensão total do sistema viário da época

- Criação de banda ao redor das vias para transporte coletivo, com distância de $1 \mathrm{~m}$, para desconsiderar a sobreposição das linhas

- Extensão linhas Fortaleza $=1046 \mathrm{~km}$

2010 (ônibus + trem)

- Extensão linhas RMF + Fortaleza $=2008$ km (TransCAD)

- Extensão total do sistema viário RMF + Fortaleza $=12342,45 \mathrm{~km}$

- Razão $=16,3 \%$

- Extensão linhas Fortaleza $=1.096 \mathrm{~km}$

- As linhas metropolitanas só operarão até o limite do município de Fortaleza. (experiência do técnico do DETRAN)

- Extensão linhas RMF + Fortaleza (2010) = $2.008 \mathrm{~km}$

2014 - Extensão de linhas metropolitanas operando em Fortaleza $=207,72 \mathrm{~km}$

- Extensão linhas RMF + Fortaleza (2014) = $2008-207,72=1.800,28 \mathrm{~km}$

- Extensão total do sistema viário RMF + Fortaleza $=12342,45 \mathrm{~km}$ (adotada a do cenário de 2010)

- Razão $=14,60 \%$

Score e Normalização - Fortaleza

\begin{tabular}{lcc}
\hline Cenário & Score & $\begin{array}{c}\text { Score } \\
\text { Normalizado }\end{array}$ \\
\hline 1992 & Vazio & Vazio \\
\hline 2000 & Vazio & Vazio \\
\hline 2010 & $26,0 \%$ & 0,08 \\
\hline 2014 & $27,1 \%$ & 0,09 \\
\hline
\end{tabular}

Score e Normalização - Região Metropolitana

\begin{tabular}{lcc}
\hline Cenário & Score & $\begin{array}{c}\text { Score } \\
\text { Normalizado }\end{array}$ \\
\hline 1992 & Vazio & Vazio \\
\hline 2000 & Vazio & Vazio \\
\hline 2010 & $16,3 \%$ & 0,00 \\
\hline 2014 & $14,6 \%$ & 0,00 \\
\hline
\end{tabular}


Valores de Referência

Score Extensão da rede de transporte público em relação a extensão do sistema viário

\begin{tabular}{ll}
\hline 1,00 & Igual ou superior \\
\hline 0,75 & $80 \%$ \\
\hline 0,50 & $60 \%$ \\
\hline 0,25 & $40 \%$ \\
\hline 0,00 & Até $20 \%$
\end{tabular}




\begin{tabular}{ll}
\hline \hline Domínio & Sistemas de Transporte Urbano \\
\hline Tema & $\begin{array}{l}\text { Disponibilidade e qualidade do transporte } \\
\text { público }\end{array}$ \\
\hline Indicador & $\begin{array}{l}\text { Frequência de atendimento do transporte } \\
\text { público }\end{array}$ \\
\hline Definição & $\begin{array}{l}\text { Frequência média de veículos de } \\
\text { transporte coletivo por ônibus em linhas } \\
\text { urbanas no município, nos dias úteis e } \\
\text { períodos de pico }\end{array}$ \\
\hline \hline
\end{tabular}

\section{Fontes de Dados - Fortaleza}

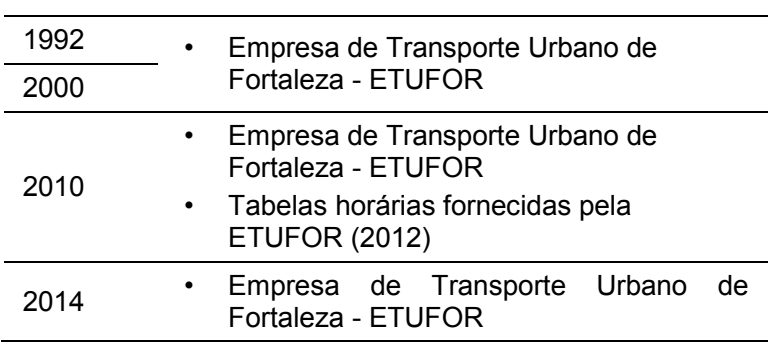

Fontes de Dados - Região Metropolitana

\begin{tabular}{lll}
\hline 1992 & $\begin{array}{l}\text { Não foram obtidas informações para este } \\
\text { cálculo }\end{array}$ \\
\hline 2000 & $\begin{array}{l}\text { Não foram obtidas informações para este } \\
\text { cálculo }\end{array}$ \\
\hline 2010 & $\begin{array}{l}\text { ARCE - Agência Reguladora de Serviços } \\
\text { Públicos Delegados do Estado do Ceará }\end{array}$ \\
\hline 2014 & $\begin{array}{l}\text { Não foram obtidas informações para este } \\
\text { cálculo }\end{array}$ \\
\hline
\end{tabular}

\section{Método de Cálculo - Fortaleza}

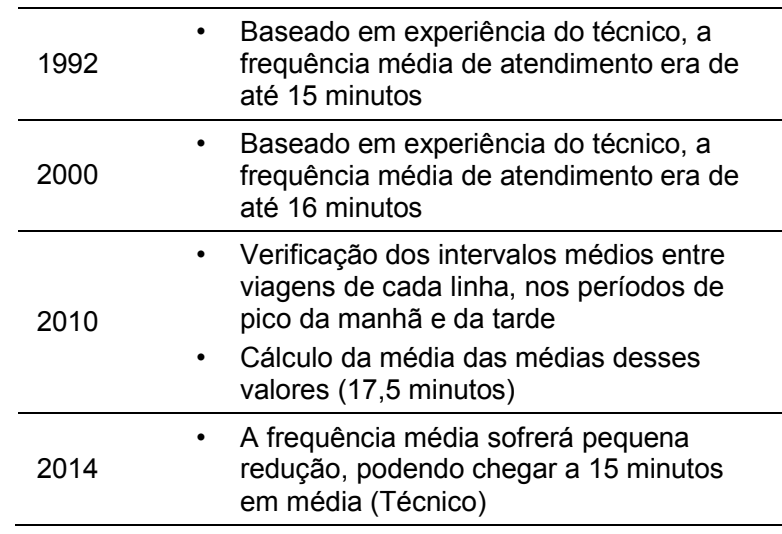

Método de Cálculo - Região Metropolitana

\begin{tabular}{lll}
\hline 1992 & Não calculado \\
\hline 2000 & Não calculado \\
\hline 2010 & $\begin{array}{l}\text { Cálculo da média dos headways de todas } \\
\text { as linhas urbanas e metropolitanas a } \\
\text { partir das informações da base } \\
\text { georreferenciada fornecida pela ARCE } \\
\text { (29 min) }\end{array}$ \\
\hline 2014 & Não calculado \\
\hline
\end{tabular}

Score e Normalização - Fortaleza

\begin{tabular}{lcc}
\hline Cenário & Score & $\begin{array}{c}\text { Score } \\
\text { Normalizado }\end{array}$ \\
\hline 1992 & 15,0 & 1,00 \\
\hline 2000 & 16,0 & 0,95 \\
\hline 2010 & 17,5 & 0,88 \\
\hline 2014 & 15,0 & 1,00 \\
\hline
\end{tabular}

Score e Normalização - Região Metropolitana

\begin{tabular}{ccc}
\hline Cenário & Score & $\begin{array}{c}\text { Score } \\
\text { Normalizado }\end{array}$ \\
\hline 1992 & Vazio & Vazio \\
\hline 2000 & Vazio & Vazio \\
\hline 2010 & 29,0 & 0,30 \\
\hline 2014 & Vazio & Vazio \\
\hline
\end{tabular}

\begin{tabular}{cl}
\hline Score & $\begin{array}{l}\text { Valores de Referência } \\
\text { Frequência média de atendimento do serviço } \\
\text { de transporte público por ônibus nos horários } \\
\text { de pico }\end{array}$ \\
\hline 1,00 & Até 15 minutos ou 4,00 ônibus/hora \\
\hline 0,75 & 20 minutos ou 3,00 ônibus/hora \\
\hline 0,50 & 25 minutos ou 2,4 ônibus/hora \\
\hline 0,25 & 30 minutos ou 2 ônibus/hora \\
\hline 0,00 & 35 minutos ou mais, ou 1,7 ônibus/hora \\
\hline
\end{tabular}




\begin{tabular}{ll}
\hline \hline Domínio & Sistemas de Transporte Urbano \\
\hline Tema & $\begin{array}{l}\text { Disponibilidade e qualidade do transporte } \\
\text { público }\end{array}$ \\
\hline Indicador & Pontualidade \\
\hline Definição & $\begin{array}{l}\text { Porcentagem das viagens em veículos de } \\
\text { transporte coletivo por ônibus respeitando a } \\
\text { programação horária. }\end{array}$ \\
\hline \hline
\end{tabular}

\section{Fontes de Dados - Fortaleza}

\begin{tabular}{|c|c|}
\hline 1992 & $\begin{array}{l}\text { - Empresa de Transporte Urbano de } \\
\text { Fortaleza - ETUFOR } \\
\text { - Relatório de eficiência mensal (1993) }\end{array}$ \\
\hline 2000 & $\begin{array}{l}\text { - Empresa de Transporte Urbano de } \\
\text { Fortaleza - ETUFOR } \\
\text { - Relatório de eficiência mensal (2000) }\end{array}$ \\
\hline 2010 & $\begin{array}{l}\text { - Empresa de Transporte Urbano de } \\
\text { Fortaleza-ETUFOR } \\
\text { - Relatório de eficiência mensal (2010) - } \\
\text { ETUFOR }\end{array}$ \\
\hline 2014 & $\begin{array}{l}\text { - Empresa de Transporte Urbano de } \\
\text { Fortaleza - ETUFOR }\end{array}$ \\
\hline
\end{tabular}

Fontes de Dados - Região Metropolitana

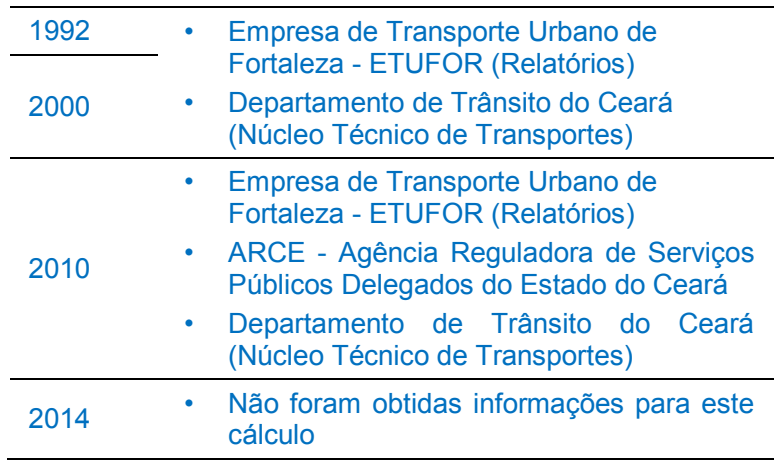

\section{Método de Cálculo - Fortaleza}

\begin{tabular}{|c|c|}
\hline 1992 & $\begin{array}{l}\text { - Viagens programadas no ano (1993) } \\
5.165 .848 \\
\text { - Viagens realizadas no ano (1993) } \\
5.121 .938 \\
\text { - } \text { Razão }=0,9915(99,2 \%) \\
\end{array}$ \\
\hline 2000 & $\begin{array}{l}\text { - Viagens programadas no ano (2000) } \\
6.150 .007 \\
\text { - Viagens realizadas no ano }(2000) \\
6.067 .868 \\
\text { - } \operatorname{Razão~}=0,9866(98,7 \%)\end{array}$ \\
\hline 2010 & $\begin{array}{l}\text { - Viagens programadas no ano (2010) } \\
6.283 .454 \\
\text { - Viagens realizadas no ano (2010) } \\
6.254 .145 \\
\text { - } \text { Razão }=0,9953(99,5 \%)\end{array}$ \\
\hline 2014 & $\begin{array}{l}\text { - Eficiência média de } 2012=98,9 \% \\
\text { - Adotar para } 2014 \text { (Técnico) }\end{array}$ \\
\hline
\end{tabular}

Método de Cálculo - Região Metropolitana
- Para Fortaleza a pontualidade calculada foi de $99,15 \%$

1992

\begin{tabular}{|c|c|}
\hline & $\begin{array}{l}\text { - De acordo com o técnico, a pontualidade } \\
\text { das grandes empresas girava em torno de } \\
95 \% \text { (Metropolitano) } \\
\text { - Será utilizada a mesma proporção para o } \\
\text { cenário de 2010, devido à falta de } \\
\text { informação sobre as viagens } \\
\text { metropolitanas realizadas nesta época } \\
\text { Pontualidade média ponderada = } 58,6 \% \times \\
99,15 \%+41,4 \% \times 95 \%=97,4 \%\end{array}$ \\
\hline 2000 & $\begin{array}{l}\text { - Pontualidade em Fortaleza }=98,66 \% \\
\text { - } \text { De acordo com o técnico, a pontualidade } \\
\text { das grandes empresas girava em torno de } \\
95 \% \text { (Metropolitano) } \\
\text { - Será utilizada a mesma proporção para o } \\
\text { cenário de } 2010 \text {, devido à falta de } \\
\text { informação sobre as viagens } \\
\text { metropolitanas realizadas nesta época } \\
\text { - Pontualidade média ponderada }=58,6 \% \times \\
98,66 \%+41,4 \% \times 95 \%=97,1 \%\end{array}$ \\
\hline 2010 & $\begin{array}{l}\text { - Para Fortaleza a pontualidade calculada } \\
\text { foi de } 99,53 \% \\
\text { - Viagens realizadas na capital = 6.254.145 } \\
\text { - Hoje, a ARCE não fiscaliza a pontualidade } \\
\text { dos veículos do sistema metropolitano. } \\
\text { - Viagens metropolitanas realizadas } \\
4.424 .851 \\
\text { - Para calcular a pontualidade geral da } \\
\text { RMF, será feita uma média ponderada a } \\
\text { partir das viagens realizadas para o ano } \\
\text { de } 2010 \\
\text { - Pontualidade média ponderada } \\
\text { \%Fortaleza x \%Pontualidade Fortaleza } \\
\text { \%Demais municípios x \%Pontualidade } \\
\text { Metropolitano } \\
\text { - \% Fortaleza = 58,6\% } \\
\text { - } \% \text { Demais municípios }=41,4 \% \\
\text { - Não é possível o cálculo devido à falta de } \\
\text { informações sobre o sistema } \\
\text { metropolitano }\end{array}$ \\
\hline 2014 & - Não calculado \\
\hline
\end{tabular}

Score e Normalização - Fortaleza

\begin{tabular}{lcc}
\hline Cenário & Score & $\begin{array}{c}\text { Score } \\
\text { Normalizado }\end{array}$ \\
\hline 1992 & $99,15 \%$ & 0,96 \\
\hline 2000 & $98,66 \%$ & 0,93 \\
\hline 2010 & $99,53 \%$ & 0,98 \\
\hline 2014 & $98,90 \%$ & 0,95 \\
\hline
\end{tabular}

Score e Normalização - Região Metropolitana

\begin{tabular}{lcc}
\hline Cenário & Score & $\begin{array}{c}\text { Score } \\
\text { Normalizado }\end{array}$ \\
\hline 1992 & $97,4 \%$ & 0,87 \\
\hline 2000 & $97,1 \%$ & 0,86 \\
\hline 2010 & Vazio & Vazio \\
\hline 2014 & Vazio & Vazio \\
\hline
\end{tabular}




\section{Valores de Referência}

Score Porcentagem das viagens por transporte coletivo por ônibus no mês analisado que respeitaram os horários programados

\begin{tabular}{ll}
\hline 1,00 & $100 \%$ \\
\hline 0,75 & $95 \%$ \\
\hline 0,50 & $90 \%$ \\
\hline 0,25 & $85 \%$ \\
\hline 0,00 & $80 \%$ ou menos \\
\hline
\end{tabular}




\begin{tabular}{ll}
\hline \hline Domínio & Sistemas de Transporte Urbano \\
\hline Tema & $\begin{array}{l}\text { Disponibilidade e qualidade do transporte } \\
\text { público }\end{array}$ \\
\hline Indicador & Velocidade média do transporte público \\
\hline Definição & $\begin{array}{l}\text { Velocidade média de deslocamento em } \\
\text { transporte público por ônibus (velocidade } \\
\text { comercial). }\end{array}$ \\
\hline \hline
\end{tabular}

Fontes de Dados - Fortaleza

\begin{tabular}{ll}
\hline 1992 & \\
\hline 2000 & $\begin{array}{l}\text { Empresa de Transporte Urbano de } \\
\text { Fortaleza - ETUFOR }\end{array}$ \\
\hline 2010 & \\
\hline
\end{tabular}

Fontes de Dados - Região Metropolitana

\begin{tabular}{lll}
\hline 1992 & & $\begin{array}{l}\text { Departamento de Trânsito do Ceará } \\
\text { (Núcleo Técnico de Transportes) }\end{array}$ \\
\hline 2000 & $\begin{array}{l}\text { ARCE - Agência Reguladora de Serviços } \\
\text { Públicos Delegados do Estado do Ceará }\end{array}$ \\
\hline 2010 & $\begin{array}{l}\text { Não foram obtidas informações para este } \\
\text { cálculo }\end{array}$ \\
\hline
\end{tabular}

Método de Cálculo - Fortaleza

\begin{tabular}{|c|c|}
\hline 1992 & $\begin{array}{l}\text { - Velocidade média geral = } 22 \mathrm{~km} / \mathrm{h} \\
\text { (Técnico) }\end{array}$ \\
\hline 2000 & $\begin{array}{l}\text { - Velocidade média geral }=20 \mathrm{~km} / \mathrm{h} \\
\text { (Técnico) }\end{array}$ \\
\hline 2010 & $\begin{array}{l}\text { Velocidade média geral = } 18,3 \mathrm{~km} / \mathrm{h} \text { (ou } \\
20 \mathrm{~km} / \mathrm{h} \text { para BRS) - Dados } 2012 \\
\text { (Técnico) }\end{array}$ \\
\hline 2014 & $\begin{array}{l}\text { - A velocidade média irá aumentar com os } \\
\text { projetos previstos para } 2014 \\
\text { - Velocidade média geral }=20 \mathrm{~km} / \mathrm{h} \\
\text { (Técnico) }\end{array}$ \\
\hline \multicolumn{2}{|c|}{ Método de Cálculo - Região Metropolitana } \\
\hline 1992 & $\begin{array}{l}\text { Velocidade média geral = } 22 \mathrm{~km} / \mathrm{h} \\
\text { (Técnico) } \\
\text { De acordo com o técnico do DETRAN, a } \\
\text { velocidade média do sistema } \\
\text { metropolitano era maior do que } 25 \mathrm{~km} / \mathrm{h} \text {, } \\
\text { em torno de } 30 \mathrm{~km} / \mathrm{h} \\
\text { - Para encontrar a velocidade média para } \\
\text { toda a Região Metropolitana de Fortaleza, } \\
\text { será feita uma média ponderada a partir } \\
\text { das quilometragens de cada município } \\
\text { As proporções utilizadas serão as } \\
\text { mesmas do cenário de } 2010 \\
\text { Velocidade Média Ponderada }= \\
\text { \%Fortaleza } \times \text { Velocidade Fortaleza }+ \\
\text { \%Demais municípios x Velocidade } \\
\text { Demais municípios } \\
\text { Velocidade Média Ponderada }=31,83 \% \text { x } \\
22 \mathrm{~km} / \mathrm{h}+68,17 \% \text { x } 30 \mathrm{~km} / \mathrm{h}=27,5 \mathrm{~km} / \mathrm{h} \\
\text { (aproximadamente) }\end{array}$ \\
\hline 2000 & $\begin{array}{l}\text { Velocidade média geral = } 20 \mathrm{~km} / \mathrm{h} \\
\text { (Técnico) } \\
\text { De acordo com o técnico do DETRAN, a } \\
\text { velocidade média do sistema } \\
\text { metropolitano era maior do que } 25 \mathrm{~km} / \mathrm{h} \text {, }\end{array}$ \\
\hline
\end{tabular}

em torno de $30 \mathrm{~km} / \mathrm{h}$

- Para encontrar a velocidade média para toda a Região Metropolitana de Fortaleza, será feita uma média ponderada a partir das quilometragens de cada município

- As proporções utilizadas serão as mesmas do cenário de 2010

- Velocidade Média Ponderada = $\%$ Fortaleza x Velocidade Fortaleza + \%Demais municípios $x$ Velocidade Demais municípios

- Velocidade Média Ponderada $=31,83 \% x$ $20 \mathrm{~km} / \mathrm{h}+68,17 \% \times 30 \mathrm{~km} / \mathrm{h}=27 \mathrm{~km} / \mathrm{h}$ (aproximadamente)

- Velocidade média geral $=18 \mathrm{~km} / \mathrm{h}$ (ou 20 $\mathrm{km} / \mathrm{h}$ para BRS) - Dados 2012 ETUFOR

- Velocidade média $25 \mathrm{~km} / \mathrm{h}$ (Pesquisa ARCE)

- Para encontrar a velocidade média para toda a Região Metropolitana de Fortaleza, será feita uma média ponderada a partir das quilometragens de cada município para este cenário

- Quilometragem total percorrida $=15.724$ $\mathrm{km}$

2010 - Quilometragem total percorrida em Fortaleza $=5004,8 \mathrm{~km}$

- Quilometragem total percorrida nos outros municípios da RMF = 10719,2 km

- Velocidade Média Ponderada = $\%$ Fortaleza x Velocidade Fortaleza + $\%$ Demais municípios $x$ Velocidade Demais municípios

- Velocidade Média Ponderada $=31,83 \% \mathrm{x}$ $18 \mathrm{~km} / \mathrm{h}+68,17 \% \times 25 \mathrm{~km} / \mathrm{h}=23 \mathrm{~km} / \mathrm{h}$ (aproximadamente)

2014 • Não calculado

Score e Normalização - Fortaleza

\begin{tabular}{lcc}
\hline Cenário & Score & $\begin{array}{c}\text { Score } \\
\text { Normalizado }\end{array}$ \\
\hline 1992 & 22,0 & 0,60 \\
\hline 2000 & 20,0 & 0,50 \\
\hline 2010 & 18,3 & 0,42 \\
\hline 2014 & 20,0 & 0,50 \\
\hline
\end{tabular}

Score e Normalização - Região Metropolitana

\begin{tabular}{lcc}
\hline Cenário & Score & $\begin{array}{c}\text { Score } \\
\text { Normalizado }\end{array}$ \\
\hline 1992 & 27,5 & 1,00 \\
\hline 2000 & 27,0 & 1,00 \\
\hline 2010 & 23,0 & 0,65 \\
\hline 2014 & Vazio & Vazio \\
\hline
\end{tabular}




\begin{tabular}{ll}
\hline Score & $\begin{array}{l}\text { Valores de Referência } \\
\text { Velocidade média do serviço de transporte } \\
\text { coletivo por ônibus em horário de pico }\end{array}$ \\
\hline 1,00 & Mais de $25 \mathrm{~km} / \mathrm{h}$ \\
\hline 0,75 & $25 \mathrm{~km} / \mathrm{h}$ \\
\hline 0,50 & $20 \mathrm{~km} / \mathrm{h}$ \\
\hline 0,25 & $15 \mathrm{~km} / \mathrm{h}$ \\
\hline 0,00 & Igual ou inferior a $10 \mathrm{~km} / \mathrm{h}$ \\
\hline
\end{tabular}




\begin{tabular}{ll}
\hline \hline Domínio & Sistemas de Transporte Urbano \\
\hline Tema & $\begin{array}{l}\text { Disponibilidade e qualidade do transporte } \\
\text { público }\end{array}$ \\
\hline Indicador & Idade média da frota de transporte público \\
\hline Definição & $\begin{array}{l}\text { Idade média da frota de ônibus e } \\
\text { microônibus urbanos no ano de referência } \\
\text { no município. }\end{array}$ \\
\hline \hline
\end{tabular}

Fontes de Dados - Fortaleza

\begin{tabular}{|c|c|}
\hline 1992 & $\begin{array}{l}\text { - Empresa de Transporte Urbano de } \\
\text { Fortaleza - ETUFOR } \\
\text { - Relatórios ETUFOR (1995) }\end{array}$ \\
\hline 2000 & $\begin{array}{ll}\text { - } & \text { Empresa de Transporte Urbano de } \\
& \text { Fortaleza - ETUFOR } \\
\text { - } & \text { Anuário de Transportes Urbanos de } \\
\text { Fortaleza (2001) }\end{array}$ \\
\hline 2010 & $\begin{array}{l}\text { - Empresa de Transporte Urbano de } \\
\text { Fortaleza - ETUFOR } \\
\text { - Relatórios ETUFOR } 2012\end{array}$ \\
\hline 2014 & $\begin{array}{ll}\text { - Empresa de Transporte Urbano de } \\
\text { Fortaleza - ETUFOR }\end{array}$ \\
\hline
\end{tabular}

Fontes de Dados - Região Metropolitana

\begin{tabular}{lll}
\hline 1992 & $\begin{array}{l}\text { Empresa de Transporte Urbano de } \\
\text { Fortaleza - ETUFOR } \\
2000\end{array}$ & $\begin{array}{l}\text { Departamento de Trânsito do Ceará } \\
\text { (Núcleo Técnico de Transportes) - } \\
\text { Relatórios }\end{array}$ \\
\hline 2010 & $\begin{array}{l}\text { Não foram obtidas informações para este } \\
\text { cálculo. }\end{array}$ \\
\hline
\end{tabular}

\section{Método de Cálculo - Fortaleza}

\begin{tabular}{lll}
\hline 1992 & $\bullet$ & Idade média $=3,87(1995)$ \\
\hline 2000 & $\cdot$ & Idade média $=4,17(2001)$ \\
\hline 2010 & $\cdot$ & Idade média $=3,68(2012)$ \\
\hline 2014 & $\cdot$ & Idade média em torno de 3,50 (Técnico). \\
& $\begin{array}{l}\text { A frota será renovada, mas não } \\
\text { completamente }\end{array}$ \\
\hline
\end{tabular}

Método de Cálculo - Região Metropolitana

\begin{tabular}{ll}
\hline & Idade média para o sistema de Fortaleza \\
& $=3,87$ (1995) \\
& Idade média para o sistema metropolitano \\
& $=4,37$ \\
& Para calcular a idade média de toda a \\
& Região Metropolitana de Fortaleza, será \\
& feita uma média ponderada a partir das \\
& frotas de veículos \\
- & Serão usadas as mesmas proporções \\
& encontradas para o cenário de 2010 \\
& Idade média ponderada $=79,7 \% \times 3,87+$ \\
& $20,3 \% \times 4,37=4,18$ \\
\hline & Idade média para o sistema de Fortaleza \\
& $=4,17$ (2001) \\
& Idade média para o sistema metropolitano \\
& $=4,23$ \\
& Para calcular a idade média de toda a \\
& Região Metropolitana de Fortaleza, será \\
& feita uma média ponderada a partir das \\
& frotas de veículos \\
\hline &
\end{tabular}

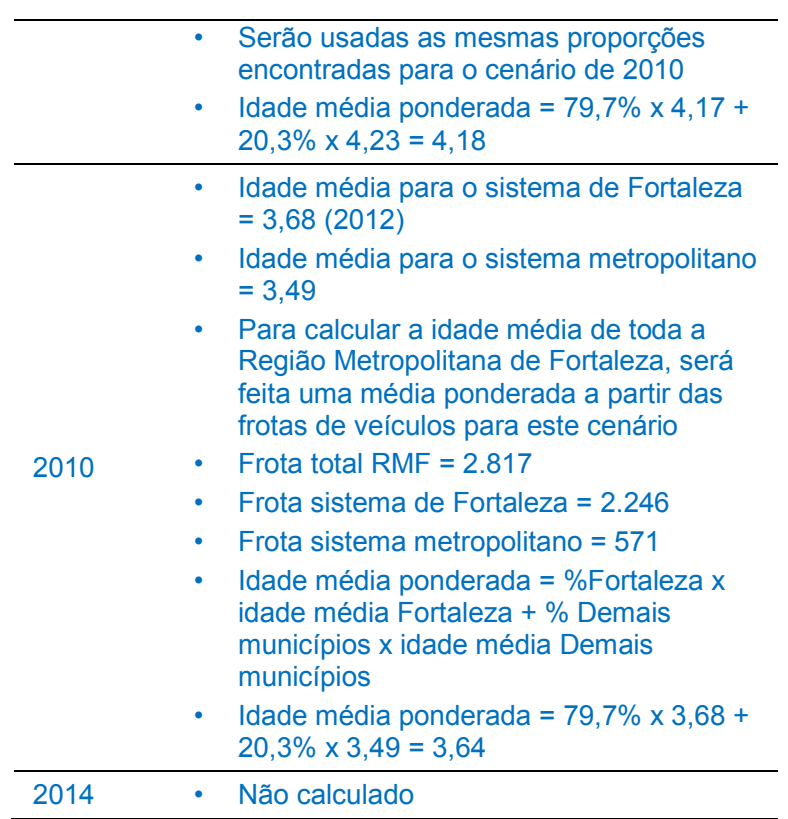

\section{Score e Normalização - Fortaleza}

\begin{tabular}{lcc}
\hline Cenário & Score & $\begin{array}{c}\text { Score } \\
\text { Normalizado }\end{array}$ \\
\hline 1992 & 3,87 & 1,00 \\
\hline 2000 & 4,17 & 1,00 \\
\hline 2010 & 3,68 & 1,00 \\
\hline 2014 & 3,50 & 1,00 \\
\hline
\end{tabular}

Score e Normalização - Região Metropolitana

\begin{tabular}{lcc}
\hline Cenário & Score & $\begin{array}{c}\text { Score } \\
\text { Normalizado }\end{array}$ \\
\hline 1992 & 4,18 & 1,00 \\
\hline 2000 & 4,18 & 1,00 \\
\hline 2010 & 3,64 & 1,00 \\
\hline 2014 & Vazio & Vazio \\
\hline
\end{tabular}

\begin{tabular}{ll}
\hline Score & $\begin{array}{l}\text { Valores de Referência } \\
\text { Idade média da frota de ônibus e microônibus } \\
\text { urbanos }\end{array}$ \\
\hline 1,00 & Até 5 anos \\
\hline 0,66 & 7 anos \\
\hline 0,33 & 9 anos \\
\hline 0,00 & 11 anos ou mais \\
\hline
\end{tabular}




\begin{tabular}{ll}
\hline \hline Domínio & Sistemas de Transporte Urbano \\
\hline Tema & $\begin{array}{l}\text { Disponibilidade e qualidade do transporte } \\
\text { público }\end{array}$ \\
\hline Indicador & Índice de passageiros por quilômetro (IPK) \\
\hline Definição & $\begin{array}{l}\text { Razão entre o número total de passageiros } \\
\text { transportados e a quilometragem percorrida } \\
\text { pela frota de transporte público do } \\
\text { município. }\end{array}$ \\
\hline \hline
\end{tabular}

Fontes de Dados - Fortaleza

\begin{tabular}{lll}
\hline \multirow{2}{*}{1992} & Empresa de Transporte Urbano de \\
& Fortaleza - ETUFOR (Relatório 1994) \\
\hline \multirow{2}{*}{2000} & $\begin{array}{l}\text { Empresa de Transporte Urbano de } \\
\text { Fortaleza - ETUFOR (Anuário ETUFOR } \\
\text { 2001) }\end{array}$ \\
\hline \multirow{2}{*}{2010} & $\begin{array}{l}\text { Empresa de Transporte Urbano de } \\
\text { Fortaleza - ETUFOR (Dados set/2012) }\end{array}$ \\
\hline \multirow{2}{*}{2014} & $\cdot \begin{array}{l}\text { Empresa de Transporte Urbano de } \\
\text { Fortaleza - ETUFOR }\end{array}$ \\
\hline
\end{tabular}

Fontes de Dados - Região Metropolitana

\begin{tabular}{lll}
\hline 1992 & & $\begin{array}{l}\text { Departamento de Trânsito do Ceará } \\
\text { (Núcleo Técnico de Transportes) }\end{array}$ \\
\hline 2000 & $\begin{array}{l}\text { ARCE - Agência Reguladora de Serviços } \\
\text { Públicos Delegados do Estado do Ceará } \\
(2011)\end{array}$ \\
\hline 2010 & $\begin{array}{l}\text { Não foram obtidas informações para este } \\
\text { cálculo. }\end{array}$ \\
\hline
\end{tabular}

Método de Cálculo - Fortaleza

\begin{tabular}{lll}
\hline 1992 & IPK $=2,77(1994)$ \\
\hline 2000 & $\cdot$ & IPK $=2,15(2001)$ \\
\hline 2010 & $\cdot$ & IPK $=2,36(2012)$ \\
\hline 2014 & $\begin{array}{l}\text { O IPK irá aumentar na mesma proporção } \\
\text { que aumentou entre } 2000 \text { e 2010 (9,8\% } \\
\text { aproximadamente) }\end{array}$ \\
& IPK estimado para 2014 =2,59 (Técnico) \\
\hline
\end{tabular}

Método de Cálculo - Região Metropolitana

\begin{tabular}{|c|c|}
\hline 1992 & $\begin{array}{ll}\text { - } & \text { IPK por anel tarifário } \\
\text { - } & \text { Anel } 1=2,61 \\
\text { - } & \text { Anel } 2=1,86 \\
\text { - } & \text { Anel } 3=1,47 \\
\text { - } & \text { Anel } 4=1,29 \\
\text { - } & \text { Anel } 5=0,96 \\
\text { - } & \text { Anel } 6=0,70 \\
\text { - } & \text { Média IPK }=1,48 \text { (adotada) } \\
\text { - } & \text { IPK Fortaleza = 2,77 } \\
\text { - } \quad & \text { IPK médio Ponderado = \%Fortaleza } \times \text { IPK } \\
& \text { Fortaleza + \%Demais municípios } \times \text { IPK } \\
& \text { Demais municípios } \\
\text { - } \quad \text { IPK Médio Ponderado = 31,83\% } \times 2,77+ \\
& 68,17 \% \times 1,48=1,89 \text { (aproximadamente) }\end{array}$ \\
\hline 2000 & $\begin{array}{l}\text { - } \text { De acordo com técnico do DETRAN, o } \\
\text { IPK permaneceu o mesmo }(1,48) \text {. } \\
\text { - } \quad \text { IPK Fortaleza }=2,15 \\
\text { - IPK médio Ponderado = \%Fortaleza x IPK } \\
\text { Fortaleza + \%Demais municípios x IPK } \\
\text { Demais municípios }\end{array}$ \\
\hline
\end{tabular}

\begin{tabular}{|c|c|c|}
\hline & & $\begin{array}{l}\text { IPK Médio Ponderado = 31,83\% } \times 2,15+ \\
68,17 \% \times 1,48=1,69 \text { (aproximadamente) }\end{array}$ \\
\hline 2010 & • & $\begin{array}{l}\text { IPK geral }=1,4559 \\
\text { IPK Fortaleza }=2,36 \\
\text { Para encontrar o IPK para toda a Região } \\
\text { Metropolitana de Fortaleza, será feita uma } \\
\text { média ponderada a partir das } \\
\text { quilometragens percorridas de cada } \\
\text { município para este cenário } \\
\text { Quilometragem total percorrida }=15.724 \\
\text { km } \\
\text { Quilometragem total percorrida em } \\
\text { Fortaleza = 5004,8 km } \\
\text { Quilometragem total percorrida nos outros } \\
\text { municípios da RMF = } 10719,2 \mathrm{~km} \\
\text { IPK médio Ponderado = \%Fortaleza } \times \text { IPK } \\
\text { Fortaleza + \%Demais municípios } \times \text { IPK } \\
\text { Demais municípios } \\
\text { IPK Médio Ponderado = } 31,83 \% \times 2,36+ \\
68,17 \% \times 1,46=1,75 \text { (aproximadamente) }\end{array}$ \\
\hline 2014 & - & Não calculado \\
\hline
\end{tabular}

\section{Score e Normalização - Fortaleza}

\begin{tabular}{lcc}
\hline Cenário & Score & $\begin{array}{c}\text { Score } \\
\text { Normalizado }\end{array}$ \\
\hline 1992 & 2,77 & 0,14 \\
\hline 2000 & 2,15 & 0,00 \\
\hline 2010 & 2,36 & 0,00 \\
\hline 2014 & 2,59 & 0,04 \\
\hline
\end{tabular}

Score e Normalização - Região Metropolitana

\begin{tabular}{lcc}
\hline Cenário & Score & $\begin{array}{c}\text { Score } \\
\text { Normalizado }\end{array}$ \\
\hline 1992 & 1,89 & 0,00 \\
\hline 2000 & 1,69 & 0,00 \\
\hline 2010 & 1,75 & 0,00 \\
\hline 2014 & Vazio & Vazio \\
\hline
\end{tabular}

\begin{tabular}{ll}
\hline Score & $\begin{array}{l}\text { Valores de Referência } \\
\text { IPK do serviço de transporte público por ônibus } \\
\text { no ano de referência (ou mês observado) }\end{array}$ \\
\hline 1,00 & $\begin{array}{l}\text { Igual ou superior a } 4,5 \text { até o limite de } 5 \\
\text { passageiros } / \mathrm{km}\end{array}$ \\
\hline 0,75 & 4 passageiros $/ \mathrm{km}$ \\
\hline 0,50 & 3,5 passageiros $/ \mathrm{km}$ \\
\hline 0,25 & 3 passageiros $/ \mathrm{km}$ \\
\hline 0,00 & Até 2,5 ou superior a 5 passageiros $/ \mathrm{km}$ \\
\hline
\end{tabular}




\begin{tabular}{ll}
\hline \hline Domínio & Sistemas de Transporte Urbano \\
\hline Tema & $\begin{array}{l}\text { Disponibilidade e qualidade do transporte } \\
\text { público }\end{array}$ \\
\hline Indicador & Passageiros transportados anualmente \\
\hline Definição & $\begin{array}{l}\text { Variação, em termos percentuais, do } \\
\text { número de passageiros transportados } \\
\text { pelos serviços de transporte público urbano } \\
\text { no município para um período de } 2 \text { anos. }\end{array}$ \\
\hline \hline
\end{tabular}

Fontes de Dados - Fortaleza

\begin{tabular}{lll}
\hline 1992 & $\begin{array}{l}\text { Empresa de Transporte Urbano de } \\
\text { Fortaleza - ETUFOR (Anuário ETUFOR } \\
2001)\end{array}$ \\
\hline 2000 & $\begin{array}{l}\text { Empresa de Transporte Urbano de } \\
\text { Fortaleza - ETUFOR (Relatórios ETUFOR } \\
2012)\end{array}$ \\
\hline 2014 & $\begin{array}{l}\text { Empresa de Transporte Urbano de } \\
\text { Fortaleza - ETUFOR }\end{array}$ \\
\hline
\end{tabular}

Fontes de Dados - Região Metropolitana

\begin{tabular}{lll}
\hline 1992 & Não foram obtidas informações para este \\
& cálculo. \\
\hline \multirow{2}{*}{$\begin{array}{l}\text { ARCE - Agência Reguladora de Serviços } \\
\text { Públicos Delegados do Estado do Ceará }\end{array}$} & $\begin{array}{l}\text { Empresa de Transporte Urbano de } \\
\text { Fortaleza - ETUFOR } \\
\text { Departamento de Trânsito do Ceará } \\
\\
\text { (Núcleo Técnico de Transportes) }\end{array}$ \\
\hline \multirow{2}{*}{$\begin{array}{l}\text { Empresa de Transporte Urbano de } \\
\text { Fortaleza - ETUFOR }\end{array}$} & $\begin{array}{l}\text { ARCE - Agência Reguladora de Serviços } \\
\text { Públicos Delegados do Estado do Ceará }\end{array}$ \\
\hline 2014 & $\begin{array}{l}\text { Não foram obtidas informações para este } \\
\text { cálculo }\end{array}$ \\
\hline
\end{tabular}

Método de Cálculo - Fortaleza

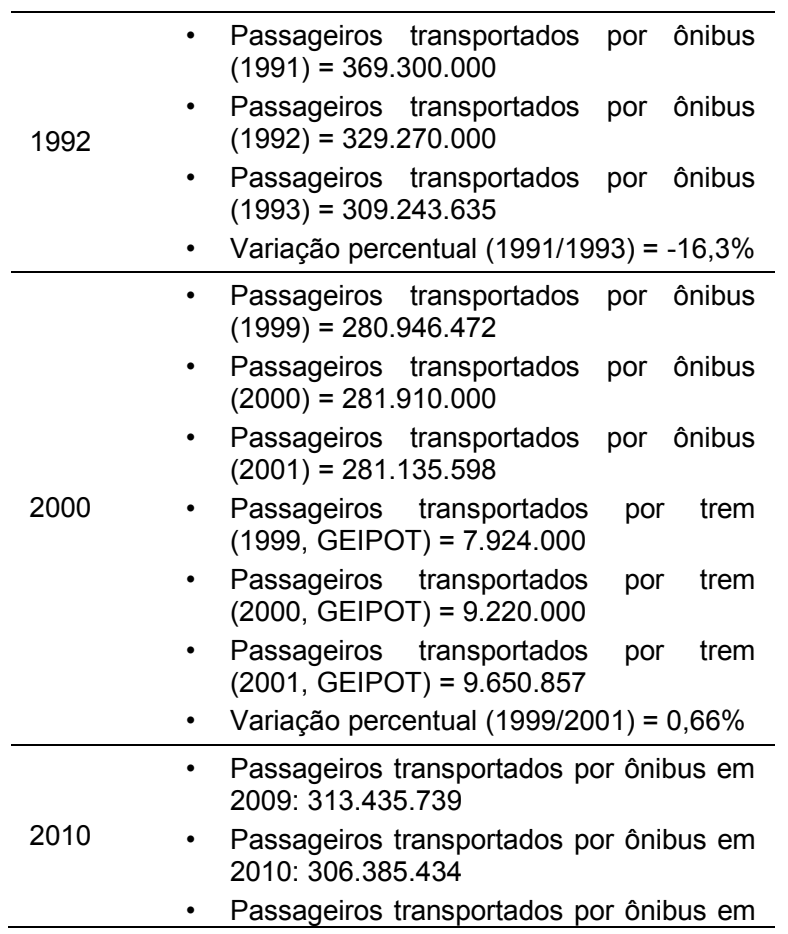

\begin{tabular}{|c|c|}
\hline & $\begin{array}{l}\text { 2011: 312.799.924 } \\
\text { - Variação percentual }(2009 / 2011)=-0,2 \% \\
\text { - } \begin{array}{l}\text { Considerou-se que a demanda } \\
\text { permaneceu constante }\end{array}\end{array}$ \\
\hline 2014 & $\begin{array}{l}\text { - Passageiros transportados por ônibus em } \\
\text { 2011: 312.799.924 } \\
\text { - Passageiros transportados por ônibus em } \\
\text { 2014: 332.799.924 (Aumento de } \\
\text { aproximadamente 6,5\%) - estimativa de } \\
\text { técnico consultado } \\
\text { - Variação percentual: crescimento de } 6,5 \%\end{array}$ \\
\hline
\end{tabular}

Método de Cálculo - Região Metropolitana

\begin{tabular}{|c|c|}
\hline 1992 & Não calculado \\
\hline 2000 & $\begin{array}{l}\text { FORTALEZA } \\
\text { - Passageiros transportados por ônibus } \\
(1999)=280.946 .472 \\
\text { - Passageiros transportados por ônibus } \\
(2000)=281.910 .000 \\
\text { - Passageiros transportados por ônibus } \\
(2001)=281.135 .598 \\
\text { METROPOLITANO } \\
\text { - Passageiros transportados (1999) = } \\
\text { 35.697.632 (DETRAN-CE) } \\
\text { - Passageiros transportados (2000) = } \\
\text { 34.734.021(DETRAN-CE) } \\
\text { - Passageiros transportados (2001) = } \\
\text { 30.590.483 na } \\
\text { TOTAL } \\
\text { - Total de passageiros transportados na } \\
\text { RMF }(1999)=316.644 .104 \\
\text { - Total de passageiros transportados na } \\
\text { RMF }(2000)=316.644 .021 \\
\text { Total de passageiros transportados na } \\
\text { RMF }(2001)=311.726 .081 \\
\text { Variação percentual (1999/2001) = - } \\
1,55 \%\end{array}$ \\
\hline 2010 & $\begin{array}{l}\text { FORTALEZA } \\
\text { - Passageiros transportados por ônibus em } \\
\text { 2009: } 313.435 .739 \\
\text { - Passageiros transportados por ônibus em } \\
\text { 2010: 306.385.434 } \\
\text { - Passageiros transportados por ônibus em } \\
\text { 2011: } 312.799 .924 \\
\text { METROPOLITANO } \\
\text { - Passageiros transportados (2009) = } \\
\text { 36.034.129 } \\
\text { - Passageiros transportados (2010) = } \\
\text { 38.769.164 } \\
\text { Passageiros transportados (2011) = } \\
\text { 41.975.374 } \\
\text { TOTAL } \\
\text { - Total de passageiros transportados na } \\
\text { RMF (2009)=349.469.868 } \\
\text { - Total de passageiros transportados na } \\
\text { RMF (2010)=345.154.598 } \\
\text { - Total de passageiros transportados na } \\
\text { RMF }(2011)=354.775 .298 \\
\text { - Variação percentual (2009/2011) = 1,52\% }\end{array}$ \\
\hline 2014 & - Não calculado \\
\hline
\end{tabular}


Score e Normalização - Fortaleza

\begin{tabular}{lcc}
\hline Cenário & Score & $\begin{array}{c}\text { Score } \\
\text { Normalizado }\end{array}$ \\
\hline 1992 & $-16,3 \%$ & 0,25 \\
\hline 2000 & $0,6 \%$ & 0,75 \\
\hline 2010 & $0,0 \%$ & 0,50 \\
\hline 2014 & $6,5 \%$ & 0,75 \\
\hline
\end{tabular}

Score e Normalização - Região Metropolitana

\begin{tabular}{|c|c|c|}
\hline Cenário & Score & $\begin{array}{c}\text { Score } \\
\text { Normalizado }\end{array}$ \\
\hline 1992 & Vazio & Vazio \\
\hline 2000 & $-1,55 \%$ & 0,25 \\
\hline 2010 & $1,52 \%$ & 0,75 \\
\hline 2014 & Vazio & Vazio \\
\hline \multicolumn{3}{|c|}{ Valores de Referência } \\
\hline Score & \multicolumn{2}{|c|}{$\begin{array}{l}\text { Foi observado para o número de } \\
\text { passageiros transportados em dois anos } \\
\text { distintos no município: }\end{array}$} \\
\hline 1,00 & \multicolumn{2}{|c|}{ Crescimento superior a $25 \%$} \\
\hline 0,75 & \multicolumn{2}{|c|}{ Crescimento inferior a $25 \%$} \\
\hline 0,50 & \multicolumn{2}{|c|}{$\begin{array}{l}\text { O número de passageiros transportados } \\
\text { permaneceu constante }\end{array}$} \\
\hline 0,25 & \multicolumn{2}{|c|}{ Decréscimo inferior a $25 \%$} \\
\hline 0,00 & \multicolumn{2}{|c|}{ Decréscimo superior a $25 \%$} \\
\hline
\end{tabular}




\begin{tabular}{ll}
\hline \hline Domínio & Sistemas de Transporte Urbano \\
\hline Tema & $\begin{array}{l}\text { Disponibilidade e qualidade do transporte } \\
\text { público }\end{array}$ \\
\hline Indicador & $\begin{array}{l}\text { Satisfação do usuário com o serviço de } \\
\text { transporte público }\end{array}$ \\
\hline Definição & $\begin{array}{l}\text { Porcentagem da população satisfeita com o } \\
\text { serviço de transporte público urbano e } \\
\text { metropolitano em todas as suas } \\
\text { modalidades. }\end{array}$ \\
\hline \hline
\end{tabular}

Fontes de Dados - Fortaleza

\begin{tabular}{|c|c|}
\hline 1992 & $\begin{array}{lll}\text { - Empresa de Transporte Urbano de } \\
\text { Fortaleza - ETUFOR }\end{array}$ \\
\hline \multirow{2}{*}{2000} & $\begin{array}{l}\text { - Empresa de Transporte Urbano de } \\
\text { Fortaleza - ETUFOR }\end{array}$ \\
\hline & $\begin{array}{l}\text { - Pesquisa de Opinião } 2000 \text { (Arquivo } \\
\text { biblioteca ETUFOR) }\end{array}$ \\
\hline \multirow{2}{*}{2010} & - Empresa de Transporte Urbano de \\
\hline & - Pesquisa de opinião 2012 (Arquivo digital) \\
\hline 2014 & $\begin{array}{l}\text { - Empresa de Transporte Urbano de } \\
\text { Fortaleza - ETUFOR }\end{array}$ \\
\hline
\end{tabular}

Fontes de Dados - Região Metropolitana

\begin{tabular}{lll}
\hline 1992 & $\bullet$ & $\begin{array}{l}\text { Departamento de Trânsito do Ceará } \\
\text { (Núcleo Técnico de Transportes) }\end{array}$ \\
\hline 2000 & $\begin{array}{l}\text { ARCE - Agência Reguladora de Serviços } \\
\text { Públicos Delegados do Estado do Ceará }\end{array}$ \\
\hline 2010 & $\begin{array}{l}\text { Não foram obtidas informações para este } \\
\text { cálculo. }\end{array}$ \\
\hline
\end{tabular}

Método de Cálculo - Fortaleza

\begin{tabular}{|c|c|}
\hline 1992 & $\begin{array}{l}\text { - Não existia pesquisa de opinião na época. } \\
\text { (Técnico) }\end{array}$ \\
\hline 2000 & $\begin{array}{l}\text { - Foram consideradas algumas questões da } \\
\text { pesquisa de satisfação (2000) } \\
\text { - Aspectos considerados: limpeza, } \\
\text { iluminação do ônibus, ventilação do } \\
\text { ônibus, conservação dos bancos, } \\
\text { comunicação visual, segurança, } \\
\text { regularidade nos horários, cumprimento do } \\
\text { itinerário, atendimento à solicitação de } \\
\text { paradas, velocidade, lotação, profissionais, } \\
\text { frequência, embarque e desembarque } \\
\text { (conforto e segurança), tempo de espera } \\
\text { - O percentual de satisfeitos foi obtido a } \\
\text { partir das respostas "bom" eótimo" } \\
\text { - Verificou-se que a população satisfeita } \\
\text { com o serviço de transporte público girava } \\
\text { em torno de } 54 \%\end{array}$ \\
\hline 2010 & $\begin{array}{l}\text { - Foram consideradas onze questões da } \\
\text { pesquisa de satisfação (2012) acerca da } \\
\text { qualidade do serviço } \\
\text { - Aspectos considerados: qualidade do } \\
\text { serviço, reclamações, valor da tarifa, } \\
\text { pontos de parada, tempo de espera, } \\
\text { tratamento dos motoristas, tratamento dos } \\
\text { cobradores, segurança, conservação do } \\
\text { ônibus, lotação, tempo de viagem } \\
\text { - O percentual de satisfeitos foi obtido a } \\
\text { partir das respostas "bom" e "ótimo" } \\
\text { - Calculou-se a média dos percentuais de }\end{array}$ \\
\hline
\end{tabular}

\begin{tabular}{ll}
\hline \multicolumn{3}{c}{ satisfeitos para cada questão } \\
\hline \multirow{3}{*}{2014} & Com as implantações dos projetos \\
& previstos para 2014, a situação do \\
& transporte público irá melhorar fazendo \\
& com que o nível de satisfação do usuário \\
& gire em torno de 80\% (Técnico) \\
\hline
\end{tabular}

Método de Cálculo - Região Metropolitana

- As pesquisas de opinião eram feitas na medida que existia a necessidade de estudos. De acordo com técnico do DETRAN, a satisfação do usuário girava em torno de $75 \%$

- As pesquisas de opinião eram feitas na medida que existia a necessidade de estudos. De acordo com técnico do DETRAN, a satisfação do usuário girava em torno de $75 \%$

- Pesquisa de opinião realizada pela ARCE em 2012 (Índice de Imagens)

- Aspectos considerados: Conforto nos veículos, análise das reclamações, conservação nos veículos, fornecimento de informações, limpeza nos veículos, modo de dirigir do motorista, tratamento dos funcionários, pagamento de passagens, segurança nos pontos de parada, segurança nos veículos, preço da passagem, tempo de espera pelo veículo, diversidade de origem e destino, tempo total de viagem

- Foram consideradas apenas os usuários que responderam "bom" e "ótimo"

- Usuários satisfeitos $=64 \%$

2014 • Não calculado

\section{Score e Normalização - Fortaleza}

\begin{tabular}{lcc}
\hline Cenário & Score & $\begin{array}{c}\text { Score } \\
\text { Normalizado }\end{array}$ \\
\hline 1992 & Vazio & Vazio \\
\hline 2000 & $54 \%$ & 0,54 \\
\hline 2010 & $40 \%$ & 0,40 \\
\hline 2014 & $80 \%$ & 0,80 \\
\hline
\end{tabular}

Score e Normalização - Região Metropolitana

\begin{tabular}{lcc}
\hline Cenário & Score & $\begin{array}{c}\text { Score } \\
\text { Normalizado }\end{array}$ \\
\hline 1992 & $75 \%$ & 0,75 \\
\hline 2000 & $75 \%$ & 0,75 \\
\hline 2010 & $64 \%$ & 0,64 \\
\hline 2014 & Vazio & Vazio \\
\hline
\end{tabular}




\begin{tabular}{ll}
\hline & $\begin{array}{l}\text { Valores de Referência } \\
\text { Porcentagem da população (ou dos } \\
\text { entrevistados) que está totalmente satisfeita (ou } \\
\text { percebe o serviço como excelente) com o sistema } \\
\text { de transporte público urbano e metropolitano }\end{array}$ \\
\hline 1,00 & $100 \%$ \\
\hline 0,75 & $75 \%$ \\
\hline 0,50 & $50 \%$ \\
\hline 0,25 & $25 \%$ \\
\hline 0,00 & 0 \\
\hline
\end{tabular}




\begin{tabular}{ll}
\hline \hline Domínio & Sistemas de Transporte Urbano \\
\hline Tema & Diversificação modal \\
\hline Indicador & Diversidade de modos de transporte \\
\hline Definição & $\begin{array}{l}\text { Número de modos de transporte disponíveis } \\
\text { na cidade. }\end{array}$ \\
\hline \hline
\end{tabular}

Fontes de Dados - Fortaleza

\begin{tabular}{lll}
\hline \multirow{2}{*}{1992} & Empresa de Transporte Urbano de \\
& Fortaleza - ETUFOR \\
\hline 2000 & $\begin{array}{l}\text { Empresa de Transporte Urbano de } \\
\text { Fortaleza - ETUFOR (Anuário 2001) }\end{array}$ \\
\hline 2010 & Empresa de Transporte Urbano de \\
\hline 2014 & Fortaleza - ETUFOR \\
\hline
\end{tabular}

Fontes de Dados - Região Metropolitana

\begin{tabular}{ll}
\hline 1992 & \\
\hline 2000 & $\begin{array}{l}\text { ARCE - Agência Reguladora de Serviços } \\
\text { Públicos Delegados do Estado do Ceará }\end{array}$ \\
\hline 2010 & \\
\hline
\end{tabular}

Método de Cálculo - Fortaleza

\begin{tabular}{ll}
\hline 1992 & a pé, bicicleta, automóvel, táxi, ônibus e \\
\hline 2000 & $\begin{array}{l}\text { ferroviário }=6 \text { (Técnico) } \\
2010\end{array}$
\end{tabular}

Método de Cálculo - Região Metropolitana

\begin{tabular}{ll}
\hline 1992 & a pé, bicicleta, automóvel, táxi, ônibus e \\
\hline 2000 & ferroviário = 6 (Técnico) \\
\hline 2010 & \\
\hline
\end{tabular}

Score e Normalização - Fortaleza

\begin{tabular}{lcc}
\hline Cenário & Score & $\begin{array}{c}\text { Score } \\
\text { Normalizado }\end{array}$ \\
\hline 1992 & 6,00 & 0,75 \\
\hline 2000 & 6,00 & 0,75 \\
\hline 2010 & 6,00 & 0,75 \\
\hline 2014 & 6,00 & 0,75 \\
\hline
\end{tabular}

Score e Normalização - Região Metropolitana

\begin{tabular}{lcc}
\hline Cenário & Score & $\begin{array}{c}\text { Score } \\
\text { Normalizado }\end{array}$ \\
\hline 1992 & 6,00 & 0,75 \\
\hline 2000 & 6,00 & 0,75 \\
\hline 2010 & 6,00 & 0,75 \\
\hline 2014 & 6,00 & 0,75 \\
\hline
\end{tabular}

\begin{tabular}{cl}
\hline Score & $\begin{array}{l}\text { Valores de Referência } \\
\text { Número de modos de transporte (público, semi- } \\
\text { público e privado) que a cidade dispõe }\end{array}$ \\
\hline 1,00 & $\begin{array}{l}7 \text { ou mais - a pé, bicicleta, automóvel, táxi, } \\
\text { ônibus, ferroviário (bonde, metro ou trem de } \\
\text { subúrbio), serviços especiais (car sharing) e } \\
\text { aquaviário (ferryboats e outros barcos). }\end{array}$ \\
\hline 0,75 & $\begin{array}{l}6 \text { - a pé, bicicleta, automóvel, táxi, ônibus e } \\
\text { ferroviário (bonde, metro ou trem de subúrbio). }\end{array}$ \\
\hline 0,50 & 5 - a pé, bicicleta, automóvel, táxi e ônibus. \\
\hline 0,25 & 4- a pé, bicicleta, automóvel e táxi. \\
\hline 0,00 & 3 - a pé, bicicleta e automóvel. \\
\hline
\end{tabular}




\begin{tabular}{ll}
\hline \hline Domínio & Sistemas de Transporte Urbano \\
\hline Tema & Diversificação modal \\
\hline Indicador & $\begin{array}{l}\text { Transporte coletivo x transporte } \\
\text { individual }\end{array}$ \\
\hline & $\begin{array}{l}\text { Razão entre o número diário de viagens } \\
\text { na área urbana ou metropolitana feitas } \\
\text { por modos coletivos de transporte e o } \\
\text { número diário de viagens feitas por } \\
\text { modos individuais de transporte } \\
\text { motorizados. }\end{array}$ \\
\hline \hline
\end{tabular}

\section{Fontes de Dados - Fortaleza}

\begin{tabular}{lll}
\hline 1992 & $\begin{array}{l}\text { Não foram encontradas informações para } \\
\text { este cálculo }\end{array}$ \\
\hline 2000 & $\begin{array}{l}\text { Empresa de Transporte Urbano de } \\
\text { Fortaleza - ETUFOR } \\
\text { Plano de Transporte Urbano de Fortaleza } \\
\text { (divisão modal) }\end{array}$ \\
\hline 2010 & $\begin{array}{l}\text { Não foram encontradas informações para } \\
\text { este cálculo }\end{array}$ \\
\hline 2014 &
\end{tabular}

Fontes de Dados - Região Metropolitana

\begin{tabular}{ll}
\hline 1992 & \\
\hline 2000 & $\begin{array}{l}\text { Não foram obtidas informações para este } \\
\text { cálculo }\end{array}$ \\
\hline 2010 & \\
\hline
\end{tabular}

\section{Método de Cálculo - Fortaleza}

\begin{tabular}{|c|c|c|c|}
\hline 1992 & - & \multicolumn{2}{|l|}{ Não calculado } \\
\hline 2000 & • & \multicolumn{2}{|c|}{$\begin{array}{l}\text { Total de viagens diárias na área urbana = } \\
3.500 .000 \\
\text { Divisão modal: deslocamento a pé }(37 \%) \text {; } \\
\text { ônibus ( } 37 \%) \text {; automóveis }(18 \%) \text {; } \\
\text { bicicletas e ciclomotores }(6 \%) \text {; trens } \\
\text { urbanos ( } 1 \% \text { ); táxi, mototáxi, transporte } \\
\text { alternativo e outros (1\%) } \\
\text { Viagens por transporte coletivo: } 1.295 .000 \\
\text { (ônibus) + } 35.000 \text { (trem) }+35.000 \text { (táxi, } \\
\text { mototáxi, transporte alternativo e outros) }= \\
1.365 .000 \\
\text { Viagens por transporte privado: } 630.000 \\
\text { (automóvel); } \\
\text { Razão = } 1.365 .000 / 630.000=2,17\end{array}$} \\
\hline 2010 & - & Não calculado & \\
\hline 2014 & - & Não calculado & \\
\hline \multicolumn{4}{|c|}{ Método de Cálculo - Região Metropolitana } \\
\hline 1992 & \multirow{4}{*}{\multicolumn{2}{|c|}{ - Não calculado }} & \\
\hline 2000 & & & \\
\hline 2010 & & & \\
\hline 2014 & & & \\
\hline \multicolumn{4}{|c|}{ Score e Normalização - Fortaleza } \\
\hline & & Score & $\begin{array}{c}\text { Score } \\
\text { Normalizado }\end{array}$ \\
\hline 1992 & & Vazio & Vazio \\
\hline 2000 & & 2,17 & 0,29 \\
\hline
\end{tabular}

\begin{tabular}{lll}
\hline 2010 & Vazio & Vazio \\
\hline 2014 & Vazio & Vazio \\
\hline
\end{tabular}

Score e Normalização - Região Metropolitana

\begin{tabular}{lcc}
\hline Cenário & Score & $\begin{array}{c}\text { Score } \\
\text { Normalizado }\end{array}$ \\
\hline 1992 & Vazio & Vazio \\
\hline 2000 & Vazio & Vazio \\
\hline 2010 & Vazio & Vazio \\
\hline 2014 & Vazio & Vazio \\
\hline
\end{tabular}

\begin{tabular}{ll}
\hline Score & $\begin{array}{l}\text { Valores de Referência } \\
\text { Razão entre o número diário de viagens na área } \\
\text { urbana feitas por modos coletivos e o número } \\
\text { diário de viagens feitas por modos individuais de } \\
\text { transporte motorizados }\end{array}$ \\
\hline 1,00 & Igual ou superior a 5 \\
\hline 0,75 & 4 \\
\hline 0,50 & 3 \\
\hline 0,25 & 2 \\
\hline 0,00 & Igual ou inferior a 1 \\
\hline
\end{tabular}




\begin{tabular}{ll}
\hline \hline Domínio & Sistemas de Transporte Urbano \\
\hline Tema & Diversificação modal \\
\hline Indicador & $\begin{array}{l}\text { Modos não-motorizados x modos } \\
\text { motorizados }\end{array}$ \\
\hline \multirow{2}{*}{ Definição } & $\begin{array}{l}\text { Razão entre o número diário de viagens na } \\
\text { área urbana ou metropolitana feitas por } \\
\text { modos não-motorizados de transporte e } \\
\text { número diário de viagens feitas por modos } \\
\text { motorizados de transporte. }\end{array}$ \\
\hline \hline
\end{tabular}

Fontes de Dados - Fortaleza

\begin{tabular}{lll}
\hline 1992 & $\begin{array}{l}\text { Não foram encontradas informações para } \\
\text { este cálculo. }\end{array}$ \\
\hline 2000 & \begin{tabular}{l} 
Empresa de Transporte Urbano de \\
Fortaleza - ETUFOR \\
$\begin{array}{l}\text { Plano de Transporte Urbano de Fortaleza } \\
\text { (divisão modal) }\end{array}$ \\
\hline 2010 \\
\hline 2014
\end{tabular}$\quad \begin{array}{l}\text { Não foram encontradas informações para } \\
\text { este cálculo }\end{array}$ \\
\hline
\end{tabular}

Fontes de Dados - Região Metropolitana

\begin{tabular}{ll}
\hline 1992 & \\
\hline 2000 & $\begin{array}{l}\text { Não foram obtidas informações para este } \\
\text { cálculo }\end{array}$ \\
\hline 2010 & \\
\hline
\end{tabular}

Método de Cálculo - Fortaleza

\begin{tabular}{lll}
\hline 1992 & $\cdot$ & Não calculado \\
\hline & $\cdot$ & Total de viagens diárias na área urbana $=$ \\
& 3.500 .000 \\
& $\cdot$ & Deslocamento a pé $(37 \%)=1.295 .000$ \\
2000 & - & Bicicletas $(6 \%)=210.000$ \\
& $\cdot$ & Modos não-motorizados $=1.505 .000$ \\
& - & Modos motorizados $(57 \%)=1.995 .000$ \\
& $\cdot$ & Razão $=1.505 .000 / 1.995 .000=0,75$ \\
\hline 2010 & & Não calculado \\
\hline 2014 &
\end{tabular}

Método de Cálculo - Região Metropolitana

\begin{tabular}{l}
\hline$\frac{1992}{2000}$ \\
\hline 2010 \\
\hline 2014
\end{tabular} Não calculado

Score e Normalização - Fortaleza

\begin{tabular}{|c|c|c|}
\hline Cenário & Score & $\begin{array}{c}\text { Score } \\
\text { Normalizado }\end{array}$ \\
\hline 1992 & Vazio & Vazio \\
\hline 2000 & 0,75 & 0,00 \\
\hline 2010 & Vazio & Vazio \\
\hline 2014 & Vazio & Vazio \\
\hline \multicolumn{3}{|c|}{ Score e Normalização - Região Metropolitana } \\
\hline Cenário & Score & $\begin{array}{c}\text { Score } \\
\text { Normalizado }\end{array}$ \\
\hline
\end{tabular}

\begin{tabular}{lll}
\hline 1992 & Vazio & Vazio \\
\hline 2000 & Vazio & Vazio \\
\hline 2010 & Vazio & Vazio \\
\hline 2014 & Vazio & Vazio \\
\hline
\end{tabular}

\section{Valores de Referência}

Razão entre o número diário de viagens na área

Score urbana feitas por modos não-motorizados e o número diário de viagens feitas por modos motorizados de transporte

\begin{tabular}{ll}
\hline 1,00 & Igual ou superior a 2 \\
\hline 0,75 & 1,75 \\
\hline 0,50 & 1,50 \\
\hline 0,25 & 1,25 \\
\hline 0,00 & Igual ou inferior 1 \\
\hline
\end{tabular}




\begin{tabular}{ll}
\hline \hline Domínio & Sistemas de Transporte Urbano \\
\hline Tema & $\begin{array}{l}\text { Regulação e fiscalização do transporte } \\
\text { público }\end{array}$ \\
\hline Indicador & Contratos e licitações \\
\hline Definição & $\begin{array}{l}\text { Porcentagem dos contratos de operação de } \\
\text { serviços de transporte público que se } \\
\text { encontram regularizados. }\end{array}$ \\
\hline \hline
\end{tabular}

\section{Fontes de Dados - Fortaleza}

\begin{tabular}{lll}
\hline 1992 & Empresa de Transporte Urbano de \\
2000 & Fortaleza - ETUFOR \\
\hline 2010 & $\begin{array}{l}\text { Empresa de Transporte Urbano de } \\
\text { Fortaleza - ETUFOR (Relatórios ETUFOR } \\
2012)\end{array}$ \\
\hline 2014 & $\begin{array}{l}\text { Empresa de Transporte Urbano de } \\
\text { Fortaleza - ETUFOR }\end{array}$ \\
\hline
\end{tabular}

Fontes de Dados - Região Metropolitana

\begin{tabular}{|c|c|}
\hline 1992 & \multirow{2}{*}{$\begin{array}{l}\text { - Departamento de Trânsito do Ceará } \\
\text { (Núcleo Técnico de Transportes) }\end{array}$} \\
\hline 2000 & \\
\hline & $\begin{array}{llll}\text { - Empresa de Transporte Urbano de } & \text { de } \\
\text { Fortaleza - ETUFOR } & & \end{array}$ \\
\hline 2010 & $\begin{array}{l}\text { - ARCE - Agência Reguladora de Serviços } \\
\text { Públicos Delegados do Estado do Ceará } \\
\text { (Relatório Anual de 2011) }\end{array}$ \\
\hline 2014 & $\begin{array}{l}\text { - ARCE - Agência Reguladora de Serviços } \\
\text { Públicos Delegados do Estado do Ceará }\end{array}$ \\
\hline \multicolumn{2}{|c|}{ Método de Cálculo - Fortaleza } \\
\hline 1992 & $\begin{array}{l}\text { A licitação tornou-se obrigatória a partir da } \\
\text { Constituição Federal de 1988, mas foi } \\
\text { dado um prazo de } 7 \text { anos de prorrogação } \\
\text { dos contratos da época e, este prazo } \\
\text { poderia ser renovado por mais sete anos } \\
\text { (Técnico) } \\
\text { - } 100 \% \text { regularizados }\end{array}$ \\
\hline 2000 & $\begin{array}{l}\text { A licitação tornou-se obrigatória a partir da } \\
\text { Constituição Federal de 1988, mas foi } \\
\text { dado um prazo de } 7 \text { anos de prorrogação } \\
\text { dos contratos da época e, este prazo } \\
\text { poderia ser renovado por mais sete anos } \\
\text { (Técnico) } \\
\text { - } 100 \% \text { regularizados }\end{array}$ \\
\hline 2010 & 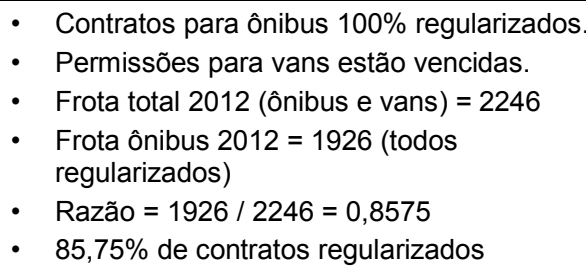 \\
\hline 2014 & $\begin{array}{l}\text { - Contratos para ônibus } 100 \% \text { regularizados } \\
\text { - Permissões para vans estão em processo } \\
\text { de andamento, mas o técnico afirma que } \\
\text { até } 2014 \text { todos os contratos estarão } \\
\text { regularizados }\end{array}$ \\
\hline
\end{tabular}

Método de Cálculo - Região Metropolitana

\begin{tabular}{ll}
\hline $1992 \quad$ De acordo com o técnico do DETRAN, \\
apenas 3 linhas estavam licitadas de um \\
total de 73 linhas (Metropolitano / 4\% \\
licitadas)
\end{tabular}

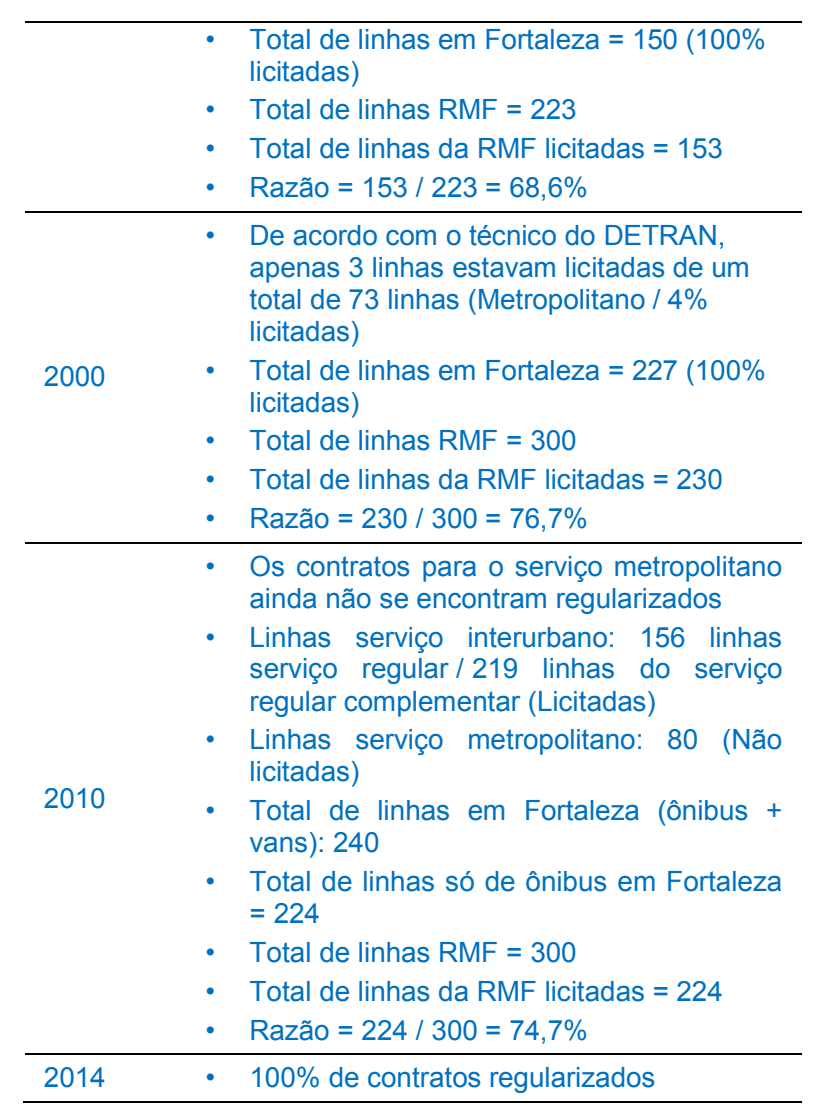

\section{Score e Normalização - Fortaleza}

\begin{tabular}{lcc}
\hline Cenário & Score & $\begin{array}{c}\text { Score } \\
\text { Normalizado }\end{array}$ \\
\hline 1992 & $100 \%$ & 1,00 \\
\hline 2000 & $100 \%$ & 1,00 \\
\hline 2010 & $85,75 \%$ & 0,86 \\
\hline 2014 & $100 \%$ & 1,00 \\
\hline
\end{tabular}

Score e Normalização - Região Metropolitana

\begin{tabular}{lcc}
\hline Cenário & Score & $\begin{array}{c}\text { Score } \\
\text { Normalizado }\end{array}$ \\
\hline 1992 & $68,6 \%$ & 0,69 \\
\hline 2000 & $76,7 \%$ & 0,77 \\
\hline 2010 & $74,7 \%$ & 0,75 \\
\hline 2014 & $100,0 \%$ & 1,00 \\
\hline
\end{tabular}

\begin{tabular}{ll}
\hline Score & $\begin{array}{l}\text { Valores de Referência } \\
\text { Porcentagem dos contratos de prestação de } \\
\text { serviços de transportes que se encontram } \\
\text { regularizados }\end{array}$ \\
\hline 1,00 & $100 \%$ \\
\hline 0,75 & $75 \%$ \\
\hline 0,50 & $50 \%$ \\
\hline 0,25 & $25 \%$ \\
\hline 0,00 & 0 \\
\hline
\end{tabular}




\begin{tabular}{|c|c|}
\hline Domínio & Sistemas de Transporte Urbano \\
\hline Tema & $\begin{array}{l}\text { Regulação e fiscalização do transporte } \\
\text { público }\end{array}$ \\
\hline Indicador & Transporte clandestino \\
\hline Definição & $\begin{array}{l}\text { Participação do transporte clandestino ou } \\
\text { irregular nos deslocamentos urbanos. }\end{array}$ \\
\hline \multicolumn{2}{|c|}{ Fontes de Dados - Fortaleza } \\
\hline 1992 & \multirow{4}{*}{$\begin{array}{l}\text { - Empresa de Transporte Urbano de } \\
\text { Fortaleza - ETUFOR }\end{array}$} \\
\hline 2000 & \\
\hline 2010 & \\
\hline 2014 & \\
\hline
\end{tabular}

Fontes de Dados - Região Metropolitana

\begin{tabular}{|c|c|}
\hline 1992 & \multirow{2}{*}{$\begin{array}{l}\text { Departamento de Trânsito do Ceará } \\
\text { (Núcleo Técnico de Transportes) } \\
\text { - Empresa de Transporte Urbano de } \\
\text { Fortaleza - ETUFOR }\end{array}$} \\
\hline 2000 & \\
\hline 2010 & ARCE - Agência Reguladora de Serviços \\
\hline 2014 & $\begin{array}{l}\text { - Empresa de Transporte Urbano de } \\
\text { Fortaleza - ETUFOR }\end{array}$ \\
\hline
\end{tabular}

\section{Método de Cálculo - Fortaleza}

- Expressiva, existindo serviços de natureza diversa, como vans peruas irregulares, mototáxi, táxi-lotação, ônibus piratas e automóveis (Técnico)

1992

- Em 1992/1993, foi criado um plano para acabar com o transporte clandestino

- Obs: Neste ano ainda não existiam vans e peruas irregulares. Elas entraram em operação em 1995

- Considerar score $=0$

- Inexpressiva ou inexistente, tendo sido 2000 combatidos, regulamentados ou incorporados ao sistema formal (Técnico)

- Inexpressiva ou inexistente, tendo sido

2010 combatidos, regulamentados ou
incorporados ao sistema formal (Técnico)

2014 - Inexpressiva ou inexistente, tendo sido combatidos, regulamentados ou incorporados ao sistema formal (Técnico)

Método de Cálculo - Região Metropolitana

- Sistema Metropolitano: Não existia transporte informal na época

- Fortaleza: Expressiva, existindo serviços de natureza diversa, como vans peruas irregulares, mototáxi, táxi-lotação, ônibus piratas e automóveis

- Portanto, como a participação do transporte clandestino era expressiva em alguma parte (Fortaleza) da Região Metropolitana de Fortaleza, o valor adotado para a RMF será de zero, aproximadamente peruas irregulares, mototáxi e táxi-lotação. OBS: a existência de mototáxi e táxi-

\begin{tabular}{|c|c|c|}
\hline & & \multirow[b]{2}{*}{$\begin{array}{l}\text { lotação era quase insignificante } \\
\text { Fortaleza: Inexpressiva ou inexistente, } \\
\text { tendo sido combatidos, regulamentados ou } \\
\text { incorporados ao sistema formal (Técnico) } \\
\text { Apesar de na capital existir uma } \\
\text { participação do transporte clandestino } \\
\text { inexpressiva ou inexistente, nos demais } \\
\text { municípios da RMF esta participação era } \\
\text { expressiva. Portanto o valor adotado para } \\
\text { a RMF será } 0,25\end{array}$} \\
\hline & & \\
\hline 2010 & 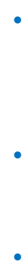 & $\begin{array}{l}\text { Sistema Metropolitano: Pequena, } \\
\text { predominando os serviços de vans e } \\
\text { peruas irregulares. Vale ressaltar que } \\
\text { existem automóveis lotação (Técnico) } \\
\text { Fortaleza: Inexpressiva ou inexistente, } \\
\text { tendo sido combatidos, regulamentados ou } \\
\text { incorporados ao sistema formal (Técnico) } \\
\text { O valor adotado para a RMF será de } 0,75\end{array}$ \\
\hline 2014 & & $\begin{array}{l}\text { Sistema Metropolitano: Pequena, } \\
\text { predominando os serviços de vans e } \\
\text { peruas irregulares (Técnico) } \\
\text { Fortaleza: Inexpressiva ou inexistente, } \\
\text { tendo sido combatidos, regulamentados ou } \\
\text { incorporados ao sistema formal (Técnico) } \\
\text { O valor adotado para a RMF será de } 0,75\end{array}$ \\
\hline
\end{tabular}

Score e Normalização - Fortaleza

\begin{tabular}{lcc}
\hline Cenário & Score & $\begin{array}{c}\text { Score } \\
\text { Normalizado }\end{array}$ \\
\hline 1992 & 0,00 & 0,00 \\
\hline 2000 & 1,00 & 1,00 \\
\hline 2010 & 1,00 & 1,00 \\
\hline 2014 & 1,00 & 1,00 \\
\hline
\end{tabular}

Score e Normalização - Região Metropolitana

\begin{tabular}{lcc}
\hline Cenário & Score & $\begin{array}{c}\text { Score } \\
\text { Normalizado }\end{array}$ \\
\hline 1992 & 0,00 & 0,00 \\
\hline 2000 & 0,25 & 0,25 \\
\hline 2010 & 0,75 & 0,75 \\
\hline 2014 & 0,75 & 0,75 \\
\hline
\end{tabular}

Score A participação do transporte clandestino no sistema de transporte público urbano é:

Inexpressiva ou inexistente, tendo sido
combatidos, regulamentados ou incorporados ao sistema formal

0,75 Pequena, predominando os serviços de vans e peruas irregulares

0,50 Pequena, predominando os serviços de vans e peruas irregulares e mototáxi

0,25 Expressiva, predominando os serviços de vans e peruas irregulares, mototáxi e táxi-lotação

Expressiva, existindo serviços de natureza diversa

0,00 como vans e peruas irregulares, mototáxi, táxilotação, ônibus piratas e automóveis 


\begin{tabular}{ll}
\hline \hline Domínio & Sistemas de Transporte Urbano \\
\hline Tema & Integração do transporte público \\
\hline Indicador & Terminais intermodais \\
\hline Definição & $\begin{array}{l}\text { Porcentagem dos terminais de transporte } \\
\text { urbano/metropolitano de passageiros que } \\
\text { permitem a integração física de dois ou } \\
\text { mais modos de transporte público. }\end{array}$ \\
\hline \hline
\end{tabular}

Fontes de Dados - Fortaleza

\begin{tabular}{lll}
\hline 1992 & & $\begin{array}{l}\text { Empresa de Transporte Urbano de } \\
\text { Fortaleza - ETUFOR }\end{array}$ \\
\hline 2000 & \\
\hline 2010 & $\begin{array}{l}\text { Secretaria Especial da Copa do Mundo de } \\
2014 \text { (SECOPA) }\end{array}$ \\
\hline 2014 &
\end{tabular}

Fontes de Dados - Região Metropolitana

\begin{tabular}{ll}
\hline 1992 & \\
\hline 2000 & ARCE - Agência Reguladora de Serviços \\
\hline 2010 & Públicos Delegados do Estado do Ceará \\
\hline 2014 &
\end{tabular}

\section{Método de Cálculo - Fortaleza}

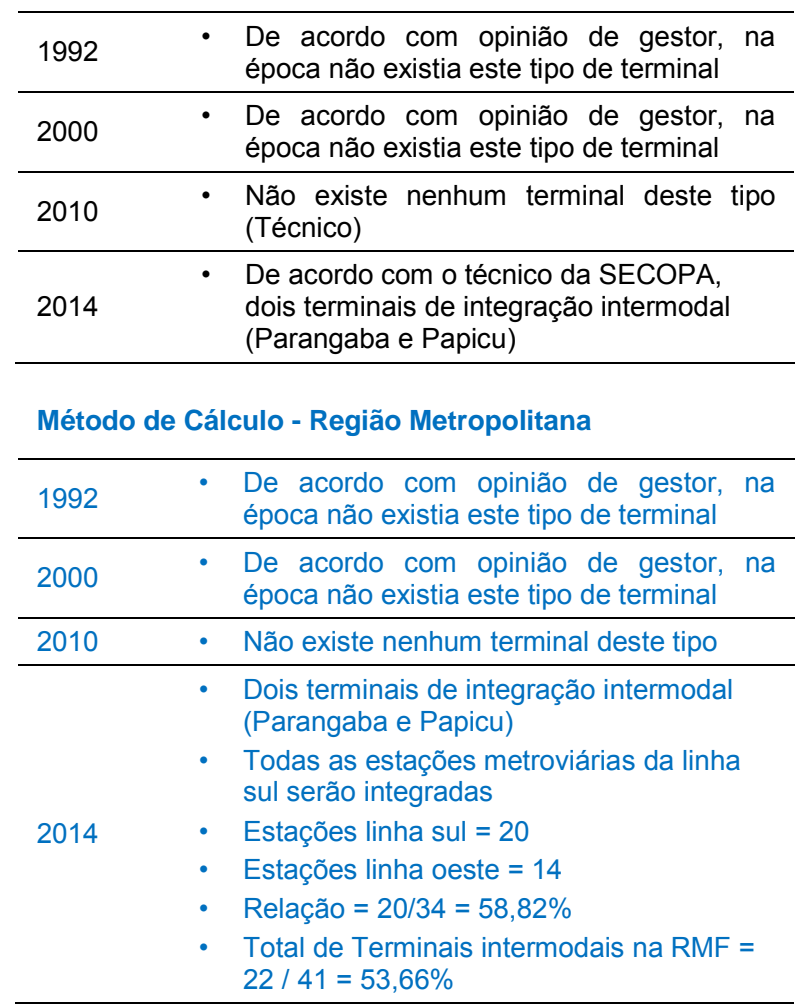

Score e Normalização - Fortaleza

\begin{tabular}{lcc}
\hline Cenário & Score & $\begin{array}{c}\text { Score } \\
\text { Normalizado }\end{array}$ \\
\hline 1992 & $0 \%$ & 0,00 \\
\hline 2000 & $0 \%$ & 0,00 \\
\hline 2010 & $0 \%$ & 0,00 \\
\hline 2014 & $28,57 \%$ & 0,28 \\
\hline
\end{tabular}

Score e Normalização - Região Metropolitana

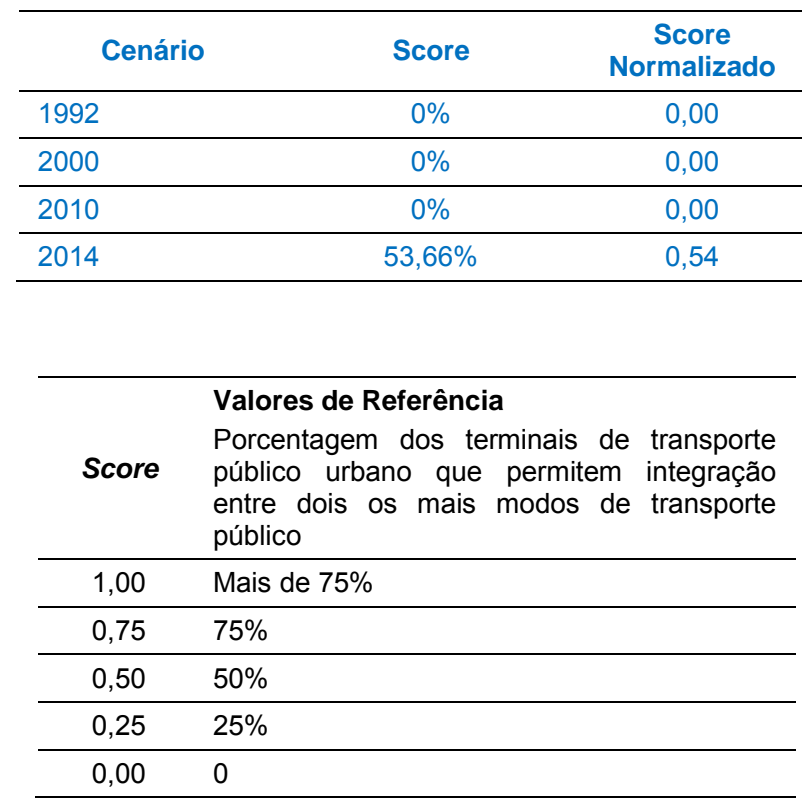




\begin{tabular}{ll}
\hline \hline Domínio & Sistemas de Transporte Urbano \\
\hline Tema & Integração do transporte público \\
\hline Indicador & Integração do transporte público \\
\hline Definição & $\begin{array}{l}\text { Grau de integração do sistema de } \\
\text { transporte público urbano e metropolitano. }\end{array}$ \\
\hline \hline
\end{tabular}

Fontes de Dados - Fortaleza

\begin{tabular}{ll}
\hline 1992 & \\
\hline 2000 & Empresa de Transporte Urbano de \\
\hline 2010 & Fortaleza - ETUFOR \\
\hline 2014 & \\
\hline
\end{tabular}

Fontes de Dados - Região Metropolitana

\begin{tabular}{ll}
\hline 1992 & ARCE - Agência Reguladora de Serviços \\
\hline 2000 & $\begin{array}{l}\text { Públicos Delegados do Estado do Ceará } \\
2010\end{array}$ Empresa de Transporte Urbano de \\
\hline 2014 & Fortaleza - ETUFOR
\end{tabular}

Método de Cálculo - Fortaleza

\begin{tabular}{|c|c|}
\hline 1992 & $\begin{array}{l}\text { De acordo com o técnico, é praticada } \\
\text { somente a integração física em terminais } \\
\text { fechados do sistema de transporte público } \\
\text { urbano, para o mesmo modo de transporte } \\
\text { (transferências intramodais) } \\
\text { - Obs: a integração temporal iniciou em } \\
\text { 2008/2009 }\end{array}$ \\
\hline 2000 & $\begin{array}{l}\text { De acordo com o técnico, é praticada } \\
\text { somente a integração física em terminais } \\
\text { fechados do sistema de transporte público } \\
\text { urbano, para o mesmo modo de transporte } \\
\text { (transferências intramodais) } \\
\text { - Obs: a integração temporal iniciou em } \\
\text { 2008/2009 }\end{array}$ \\
\hline 2010 & $\begin{array}{l}\text { De acordo com o técnico, é praticada a } \\
\text { integração física e tarifária temporal } \\
\text { somente em terminais fechados do } \\
\text { sistema de transporte público urbano, para } \\
\text { o mesmo modo de transporte } \\
\text { (transferências intramodais) } \\
\text { - Obs: a integração temporal é feita somente } \\
\text { na área central }\end{array}$ \\
\hline 2014 & $\begin{array}{l}\text { De acordo com o técnico, o sistema de } \\
\text { transporte público é totalmente integrado } \\
\text { com o uso de bilhete eletrônico para } \\
\text { integração intermodal e de sistemas } \\
\text { adjacentes (intermunicipais ou } \\
\text { metropolitanos) }\end{array}$ \\
\hline \multicolumn{2}{|c|}{ Método de Cálculo - Região Metropolitana } \\
\hline 1992 & $\begin{array}{l}\text { - Não existia integração física nem tarifária } \\
\text { (Metropolitano) } \\
\text { - Fortaleza: É praticada somente a } \\
\text { integração física em terminais fechados do } \\
\text { sistema de transporte público urbano, para } \\
\text { o mesmo modo de transporte } \\
\text { (transferências intramodais) } \\
\text { - O valor adotado para a RMF será de } 0,25\end{array}$ \\
\hline 2000 & $\begin{array}{l}\text { - Não existia integração física nem tarifária } \\
\text { (Metropolitano) } \\
\text { - Fortaleza: É praticada somente a } \\
\text { integração física em terminais fechados do }\end{array}$ \\
\hline
\end{tabular}

\begin{tabular}{|c|c|c|}
\hline & - & $\begin{array}{l}\text { sistema de transporte público urbano, para } \\
\text { o mesmo modo de transporte } \\
\text { (transferências intramodais) } \\
\text { O valor adotado para a RMF será de } 0,25\end{array}$ \\
\hline 2010 & - & $\begin{array}{l}\text { Não existe integração física nem tarifária } \\
\text { (Metropolitano) } \\
\text { Fortaleza: É praticada a integração física e } \\
\text { tarifária temporal somente em terminais } \\
\text { fechados do sistema de transporte público } \\
\text { urbano, para o mesmo modo de transporte } \\
\text { (transferências intramodais) Obs: a } \\
\text { integração temporal é feita somente na } \\
\text { área central } \\
\text { O valor adotado para a RMF será de } 0,50\end{array}$ \\
\hline 2014 & • & $\begin{array}{l}\text { É praticada a integração física e tarifária } \\
\text { temporal em terminais fechados e em } \\
\text { qualquer ponto do sistema de transporte } \\
\text { público urbano, para o mesmo modo de } \\
\text { transporte e entre diferentes modos } \\
\text { (transferências intramodais e intermodais) } \\
\text { - Metropolitano } \\
\text { Fortaleza: O sistema de transporte público } \\
\text { é totalmente integrado com o uso de } \\
\text { bilhete eletrônico para integração } \\
\text { intermodal e de sistemas adjacentes } \\
\text { (intermunicipais ou metropolitanos) } \\
\text { O valor adotado para a RMF será de } 0,75 \text {, } \\
\text { pois apenas em Fortaleza o sistema é } \\
\text { totalmente integrado }\end{array}$ \\
\hline
\end{tabular}

Score e Normalização - Fortaleza

\begin{tabular}{lcc}
\hline Cenário & Score & $\begin{array}{c}\text { Score } \\
\text { Normalizado }\end{array}$ \\
\hline 1992 & 0,25 & 0,25 \\
\hline 2000 & 0,25 & 0,25 \\
\hline 2010 & 0,50 & 0,50 \\
\hline 2014 & 1,00 & 1,00 \\
\hline
\end{tabular}

Score e Normalização - Região Metropolitana

\begin{tabular}{lcc}
\hline Cenário & Score & $\begin{array}{c}\text { Score } \\
\text { Normalizado }\end{array}$ \\
\hline 1992 & 0,25 & 0,25 \\
\hline 2000 & 0,25 & 0,25 \\
\hline 2010 & 0,50 & 0,50 \\
\hline 2014 & 0,75 & 0,75 \\
\hline
\end{tabular}




\begin{tabular}{cl}
\hline Score & Valores de Referência \\
\hline 1,00 & $\begin{array}{l}\text { O sistema de transporte público é totalmente } \\
\text { integrado com o uso de bilhete eletrônico para } \\
\text { integração intermodal e de sistemas adjacentes } \\
\text { (intermunicipais ou metropolitanos) }\end{array}$ \\
\hline $0,75 \quad \begin{array}{l}\text { É praticada a integração física e tarifária temporal } \\
\text { em terminais fechados e em qualquer ponto do } \\
\text { sistema de transporte público urbano, para o mesmo } \\
\text { modo de transporte e entre diferentes modos } \\
\text { (transferências intramodais e intermodais) }\end{array}$ \\
\hline $0,50 \quad \begin{array}{l}\text { É praticada a integração física e tarifária temporal } \\
\text { somente em terminais fechados do sistema de } \\
\text { transporte público urbano, para o mesmo modo de } \\
\text { transporte (transferências intramodais) }\end{array}$ \\
\hline $0,25 \quad \begin{array}{l}\text { É praticada somente a integração física em } \\
\text { terminais fechados do sistema de transporte público } \\
\text { urbano, para o mesmo modo de transporte } \\
\text { (transferências intramodais) }\end{array}$ \\
\hline 0,00 & $\begin{array}{l}\text { Não é praticada nenhuma forma de integração física } \\
\text { ou tarifária no sistema de transporte público urbano }\end{array}$ \\
\hline
\end{tabular}




\begin{tabular}{|c|c|}
\hline Domínio & Sistemas de Transporte Urbano \\
\hline Tema & Política Tarifária \\
\hline Indicador & Descontos e gratuidades \\
\hline Definição & $\begin{array}{l}\text { Porcentagem dos usuários do sistema de } \\
\text { transporte público que usufruem de } \\
\text { descontos ou gratuidade do valor da tarifa. }\end{array}$ \\
\hline \multicolumn{2}{|c|}{ Fontes de Dados - Fortaleza } \\
\hline 1992 & $\begin{array}{l}\text { - Empresa de Transporte Urbano de } \\
\text { Fortaleza - ETUFOR }\end{array}$ \\
\hline 2000 & $\begin{array}{ll}\text { - Empresa de Transporte Urbano de } \\
\text { Fortaleza - ETUFOR } \\
\text { - Anuário de Transportes Urbanos de } \\
\text { Fortaleza (2001) }\end{array}$ \\
\hline 2010 & $\begin{array}{ll}\text { - Empresa de Transporte Urbano de } \\
\text { Fortaleza - ETUFOR } \\
\text { - Anuário de Transportes Urbanos de } \\
\text { Fortaleza (2010) } \\
\end{array}$ \\
\hline 2014 & $\begin{array}{l}\text { Empresa de Transporte Urbano de } \\
\text { Fortaleza - ETUFOR }\end{array}$ \\
\hline \multicolumn{2}{|c|}{ Fontes de Dados - Região Metropolitana } \\
\hline 1992 & $\begin{array}{l}\text { - Não foram obtidas informações para este } \\
\text { cálculo }\end{array}$ \\
\hline 2000 & $\begin{array}{l}\text { Departamento de Trânsito do Ceará } \\
\text { (Núcleo Técnico de Transportes) } \\
\text { Empresa de Transporte Urbano de } \\
\text { Fortaleza - ETUFOR } \\
\end{array}$ \\
\hline 2010 & $\begin{array}{l}\text { - } \text { ARCE - Agência Reguladora de Serviços } \\
\text { Públicos Delegados do Estado do Ceará } \\
\text { - Empresa de Transporte Urbano de } \\
\text { Fortaleza-ETUFOR }\end{array}$ \\
\hline 2014 & $\begin{array}{l}\text { - Não foram obtidas informações para este } \\
\text { cálculo }\end{array}$ \\
\hline \multicolumn{2}{|c|}{ Método de Cálculo - Fortaleza } \\
\hline 1992 & $\begin{array}{l}\text { - Embarques realizados }(1994)= \\
290.645 .490 \\
\text { - Embarques com descontos }(1994)= \\
77.496 .398 \\
\text { - Obs: Não eram computados os embarques } \\
\text { gratuitos na época. Serão considerados } \\
\text { apenas os embarques com descontos. } \\
\text { Razão: } 77.496 .398 / 290.645 .490=0,2666 \\
(26,66 \%)\end{array}$ \\
\hline 2000 & $\begin{array}{ll}\text { - } & \text { Embarques realizados }(2001)= \\
& 281.135 .598 \\
\text { - } & \text { Embarques com descontos }(2001)= \\
& 96.795 .201 \\
\text { - } & \text { Embarques com gratuidades }(2001)= \\
& 2.531 .406 \\
\text { - } & \text { Razão }=99.326 .607 / 281.135 .598= \\
& 0,3533(35,33 \%)\end{array}$ \\
\hline 2010 & $\begin{array}{ll}\text { - } & \text { Demanda total }(2010)=306.385 .434 \\
\text { - } & \text { Embarques com descontos }(2010)= \\
& 58.359 .868 \\
\text { - } & \text { Embarques com gratuidades }(2010)= \\
& 12.156 .978 \\
\text { - } & \text { Razão }=70.516 .846 / 306.385 .434= \\
& 0,2302(23,02 \%)\end{array}$ \\
\hline 2014 & - Considerou-se a mesma porcentagem \\
\hline
\end{tabular}

\begin{tabular}{|c|c|}
\hline \multicolumn{2}{|r|}{ calculada em 2010. (Técnico) } \\
\hline \multicolumn{2}{|c|}{ Método de Cálculo - Região Metropolitana } \\
\hline 1992 & $\begin{array}{l}\text { De acordo com o técnico do DETRAN, até } \\
\text { o ano de } 2005 \text { não existiam descontos, } \\
\text { apenas gratuidades para idosos, o que } \\
\text { girava em torno de } 4 \% \\
\text { Não foram obtidas informações sobre a } \\
\text { quantidade de passageiros transportados } \\
\text { neste período }\end{array}$ \\
\hline 2000 & 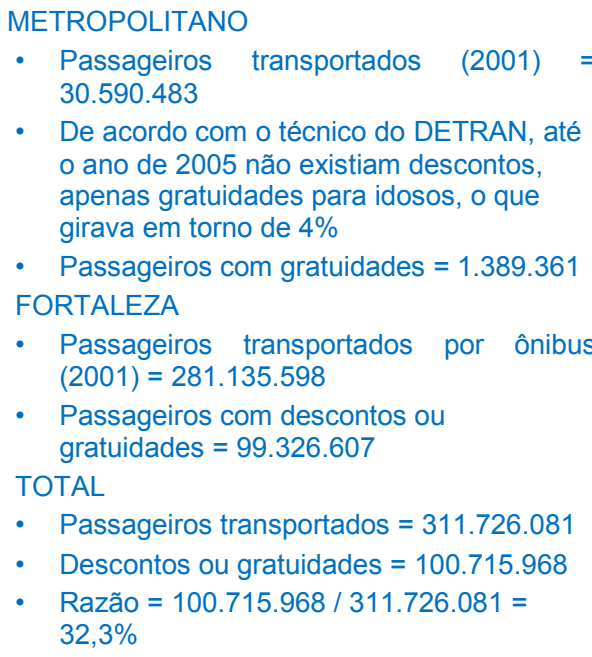 \\
\hline 2010 & 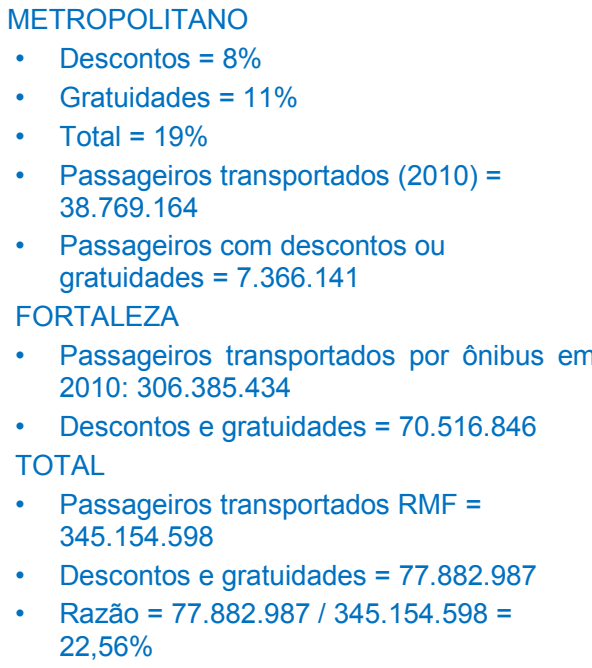 \\
\hline 2014 & - Não calculado \\
\hline
\end{tabular}

Score e Normalização - Fortaleza

\begin{tabular}{lcc}
\hline Cenário & Score & $\begin{array}{c}\text { Score } \\
\text { Normalizado }\end{array}$ \\
\hline 1992 & $26,66 \%$ & 0,58 \\
\hline 2000 & $35,33 \%$ & 0,37 \\
\hline 2010 & $23,02 \%$ & 0,67 \\
\hline 2014 & $23,02 \%$ & 0,67 \\
\hline
\end{tabular}

Score e Normalização - Região Metropolitana

\begin{tabular}{ccc}
\hline Cenário & Score & $\begin{array}{c}\text { Score } \\
\text { Normalizado }\end{array}$ \\
\hline 1992 & Vazio & Vazio \\
\hline 2000 & $32,3 \%$ & 0,44 \\
\hline
\end{tabular}




\begin{tabular}{lcc}
\hline 2010 & $22,6 \%$ & 0,78 \\
\hline 2014 & Vazio & Vazio \\
\hline
\end{tabular}

\section{Valores de Referência}

Porcentagem dos embarques (ou

usuários) do sistema de transporte

público no período de análise que

tiveram desconto ou gratuidade da

tarifa

\begin{tabular}{ll}
\hline 1,00 & Até $10 \%$ \\
\hline 0,75 & $20 \%$ \\
\hline 0,50 & $30 \%$ \\
\hline 0,25 & $40 \%$ \\
\hline 0,00 & $50 \%$ ou mais \\
\hline
\end{tabular}




\begin{tabular}{ll}
\hline \hline Domínio & Sistemas de Transportes Urbanos \\
\hline Tema & Política tarifária \\
\hline Indicador & Tarifas de transporte \\
\hline Definição & $\begin{array}{l}\text { Variação percentual dos valores de tarifa de } \\
\text { transporte público urbano para um período } \\
\text { de análise, comparada a índices } \\
\text { inflacionários para o mesmo período. }\end{array}$ \\
\hline \hline
\end{tabular}

Fontes de Dados - Fortaleza

\begin{tabular}{lll}
\hline 1992 & $\begin{array}{l}\text { Empresa de Transporte Urbano de } \\
\text { Fortaleza - ETUFOR }\end{array}$ \\
\cline { 1 - 1 } 2000 & $\begin{array}{l}\text { Relatórios sobre a evolução dos valores } \\
\text { da tarifa }\end{array}$ \\
\hline 2010 & $\begin{array}{l}\text { Empresa de Transporte Urbano de } \\
\text { Fortaleza - ETUFOR }\end{array}$ \\
\hline
\end{tabular}

Fontes de Dados - Região Metropolitana

\begin{tabular}{lll}
\hline 1992 & $\begin{array}{l}\text { Não foi possível obter informações para } \\
\text { este cálculo. }\end{array}$ \\
\hline 2000 & $\begin{array}{l}\text { Departamento de Trânsito do Ceará } \\
\text { (Núcleo Técnico de Transportes) }\end{array}$ \\
$2010 \quad \begin{array}{l}\text { Empresa de Transporte Urbano de } \\
\text { Fortaleza - ETUFOR }\end{array}$ \\
$\begin{array}{ll}\text { Instituto Brasileiro de Geografia e } \\
\text { Estatística - IBGE }\end{array}$ \\
\hline 2014 & $\begin{array}{l}\text { Não foi possível obter informações para } \\
\text { este cálculo }\end{array}$ \\
\hline
\end{tabular}

\section{Método de Cálculo - Fortaleza}

- Criação de tabela com variações de tarifas e índice IPCA/IBGE.

\begin{tabular}{|c|c|c|c|c|}
\hline \multirow{6}{*}{1992} & Data & Tarifa & $\begin{array}{l}\text { Variação } \\
\text { da Tarifa }\end{array}$ & $\begin{array}{c}\text { IPCA } \\
\text { Acumulado }\end{array}$ \\
\hline & Jul/92 & $\mathrm{Cr} \$ 1000$ & & \\
\hline & ago/93 & $\mathrm{CR} \$ 24$ & - & $2624 \%$ \\
\hline & jun/94 & $\mathrm{R} \$ 0,40$ & - & $4004 \%$ \\
\hline & \multicolumn{2}{|c|}{ Total } & - & $6628 \%$ \\
\hline & \multicolumn{4}{|c|}{$\begin{array}{l}\text { - IPCA acumulado: BCB - Calculadora do } \\
\text { cidadão }\end{array}$} \\
\hline \multirow{6}{*}{2000} & \multicolumn{4}{|c|}{$\begin{array}{l}\text { - Criação de tabela com variações de } \\
\text { tarifas e índice IPCA/IBGE }\end{array}$} \\
\hline & Data & Tarifa & $\begin{array}{l}\text { Variação } \\
\text { da Tarifa }\end{array}$ & $\begin{array}{c}\text { IPCA } \\
\text { Acumulado }\end{array}$ \\
\hline & out/99 & $\mathrm{R} \$ 0,90$ & & \\
\hline & jan/01 & $R \$ 1,00$ & $11,11 \%$ & $9,52 \%$ \\
\hline & mar/02 & $\mathrm{R} \$ 1,10$ & $10,00 \%$ & $9,27 \%$ \\
\hline & \multicolumn{2}{|c|}{ Total } & $21,11 \%$ & $18,79 \%$ \\
\hline
\end{tabular}

- IPCA acumulado: BCB - Calculadora do cidadão

- Analisando a tabela, pode-se perceber que a variação das tarifas é superior a variação do IPCA para o mesmo período

\begin{tabular}{|c|c|c|c|c|}
\hline \multirow{7}{*}{2010} & \multicolumn{4}{|c|}{$\begin{array}{l}\text { - Criação de tabela com variações de } \\
\text { tarifas e índice IPCA/IBGE }\end{array}$} \\
\hline & Data & Tarifa & $\begin{array}{l}\text { Variação } \\
\text { da Tarifa }\end{array}$ & $\begin{array}{c}\text { IPCA } \\
\text { Acumulado }\end{array}$ \\
\hline & mai/09 & $R \$ 1,80$ & & \\
\hline & $\mathrm{mar} / 11$ & $R \$ 2,00$ & $11,11 \%$ & $11,26 \%$ \\
\hline & fev/13 & $R \$ 2,20$ & $10,00 \%$ & $12,53 \%$ \\
\hline & \multicolumn{2}{|c|}{ Total } & $21,11 \%$ & $23,79 \%$ \\
\hline & \multicolumn{4}{|c|}{$\begin{array}{l}\text { - IPCA acumulado: BCB - Calculadora do } \\
\text { cidadão } \\
\text { - Analisando a tabela, pode-se perceber } \\
\text { que a variação das tarifas é inferior a } \\
\text { variação do IPCA para o mesmo período }\end{array}$} \\
\hline 2014 & \multicolumn{4}{|c|}{$\begin{array}{ll}\text { - } & \text { Tarifa } 2012=\mathrm{R} \$ 2,00 \\
\text { - } & \text { Tarifa } 2013=\mathrm{R} \$ 2,20 \\
\text { - } & \text { Tarifa } 2014=\mathrm{R} \$ 2,25 \text { (Técnico) } \\
\text { - } & \text { O IPCA provavelmente vai aumentar } \\
& \text { menos do que a tarifa (Técnico) }\end{array}$} \\
\hline
\end{tabular}

Método de Cálculo - Região Metropolitana

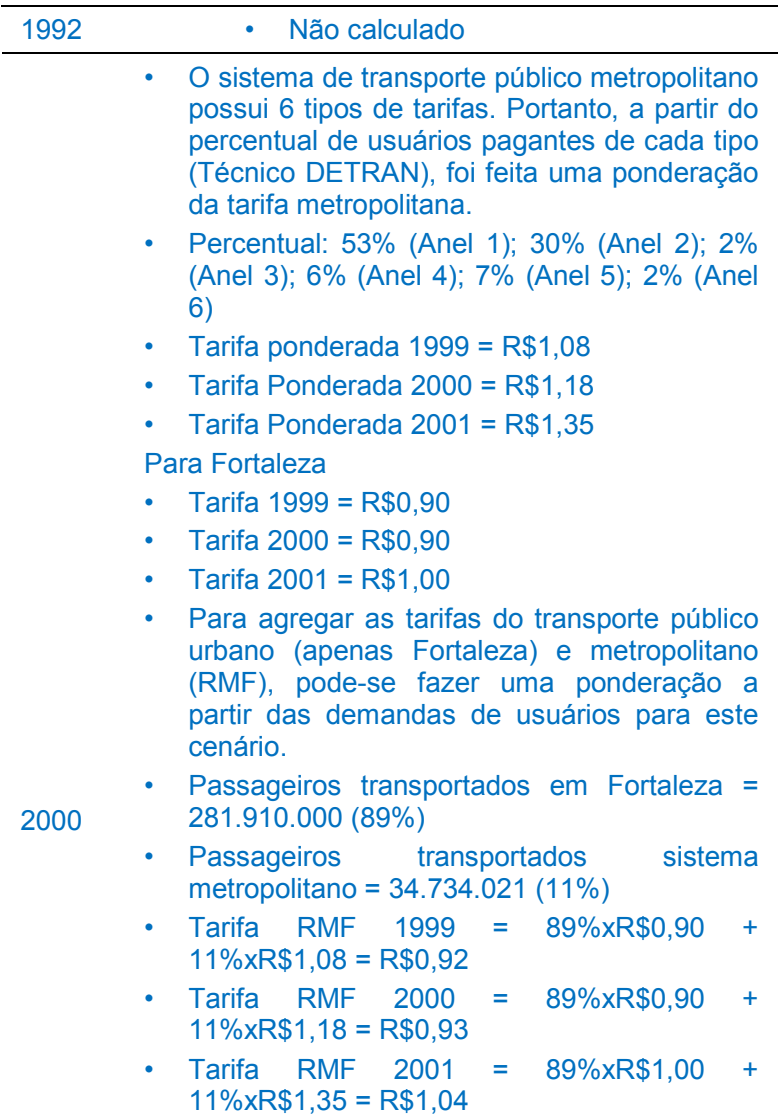

\begin{tabular}{|c|c|c|c|}
\hline Data & Tarifa & $\begin{array}{l}\text { Variação } \\
\text { da Tarifa }\end{array}$ & $\begin{array}{c}\text { IPCA } \\
\text { Acumulado }\end{array}$ \\
\hline jan/99 & $\mathrm{R} \$ 0,92$ & & \\
\hline jan/00 & $\mathrm{R} \$ 0,93$ & $1,09 \%$ & $9,62 \%$ \\
\hline jan/01 & $R \$ 1,04$ & $11,83 \%$ & $6,58 \%$ \\
\hline \multicolumn{2}{|c|}{ Total } & $12,92 \%$ & $16,20 \%$ \\
\hline \multicolumn{4}{|c|}{$\begin{array}{l}\text { - IPCA acumulado: BCB - Calculadora do } \\
\text { cidadão } \\
\text { - Analisando a tabela, pode-se perceber que a } \\
\text { variação das tarifas foi inferior à variação do }\end{array}$} \\
\hline
\end{tabular}




\begin{tabular}{|c|c|c|c|c|}
\hline & \multicolumn{4}{|c|}{ IPCA para o mesmo período } \\
\hline & \multicolumn{4}{|c|}{$\begin{array}{l}\text { O sistema de transporte público metropolitano } \\
\text { possui } 6 \text { tipos de tarifas. Portanto, a partir do } \\
\text { percentual de usuários pagantes de cada tipo } \\
\text { (Técnico DETRAN), foi feita uma ponderação } \\
\text { da tarifa metropolitana. }\end{array}$} \\
\hline & \\
\hline & \multicolumn{4}{|c|}{ - Tarifa ponderada $2010=\mathrm{R} \$ 2,42$} \\
\hline & \multicolumn{4}{|c|}{ - Tarifa Ponderada $2011=\mathrm{R} \$ 2,89$} \\
\hline & \multicolumn{4}{|c|}{ - Tarifa Ponderada $2012=\mathrm{R} \$ 3,04$} \\
\hline & \multicolumn{4}{|c|}{ Para Fortaleza } \\
\hline & \multicolumn{4}{|c|}{ - Tarifa $2010=\mathrm{R} \$ 1,80$} \\
\hline & \multicolumn{4}{|c|}{ - Tarifa $2011=\mathrm{R} \$ 2,00$} \\
\hline & \multicolumn{4}{|c|}{ - Tarifa $2012=\mathrm{R} \$ 2,00$} \\
\hline & \multicolumn{4}{|c|}{$\begin{array}{l}\text { - Para agregar as tarifas do transporte público } \\
\text { urbano (apenas Fortaleza) e metropolitano } \\
\text { (RMF), pode-se fazer uma ponderação a } \\
\text { partir das demandas de usuários para este } \\
\text { cenário. }\end{array}$} \\
\hline \multirow{10}{*}{2010} & \multicolumn{4}{|c|}{$\begin{array}{l}\text { Passageiros transportados } \\
\text { metropolitano }=38.769 .164(11 \%)\end{array}$} \\
\hline & \multicolumn{4}{|c|}{$\begin{array}{l}\text { Tarifa RMF } 2010=89 \% \times R \$ 1,80+ \\
11 \% \times R \$ 2,42=R \$ 1,86\end{array}$} \\
\hline & \multicolumn{4}{|c|}{$\begin{array}{l}\text { Tarifa RMF } 2011=89 \% \times R \$ 2,00 \\
11 \% \times R \$ 2,89=R \$ 2,10\end{array}$} \\
\hline & \multicolumn{4}{|c|}{$\begin{array}{l}\text { Tarifa RMF } 2012=89 \% \times R \$ 2,00 \\
11 \% \times R \$ 3,04=R \$ 2,11\end{array}$} \\
\hline & Data & Tarifa & $\begin{array}{l}\text { Variação } \\
\text { da Tarifa }\end{array}$ & $\begin{array}{c}\text { IPCA } \\
\text { Acumulado }\end{array}$ \\
\hline & jan/10 & $\mathrm{R} \$ 1,86$ & & \\
\hline & dez/11 & $\mathrm{R} \$ 2,10$ & $12,90 \%$ & $12,79 \%$ \\
\hline & $\mathrm{dez} / 12$ & $\mathrm{R} \$ 2,11$ & $0,50 \%$ & $6,37 \%$ \\
\hline & \multicolumn{2}{|c|}{ Total } & $13,40 \%$ & $19,16 \%$ \\
\hline & \multicolumn{4}{|c|}{$\begin{array}{l}\text { - IPCA acumulado: BCB - Calculadora do } \\
\text { cidadão } \\
\text { - Analisando a tabela, pode-se perceber que a } \\
\text { variação das tarifas foi inferior à variação do } \\
\text { IPCA para o mesmo período. }\end{array}$} \\
\hline 2014 & \multicolumn{4}{|c|}{ - Não calculado } \\
\hline
\end{tabular}

Score e Normalização - Fortaleza

\begin{tabular}{lcc}
\hline Cenário & Score & $\begin{array}{c}\text { Score } \\
\text { Normalizado }\end{array}$ \\
\hline 1992 & 0,00 & 0,00 \\
\hline 2000 & 0,00 & 0,00 \\
\hline 2010 & 0,66 & 0,66 \\
\hline 2014 & 0,00 & 0,00 \\
\hline
\end{tabular}

Score e Normalização - Região Metropolitana

\begin{tabular}{ccc}
\hline Cenário & Score & $\begin{array}{c}\text { Score } \\
\text { Normalizado }\end{array}$ \\
\hline 1992 & Vazio & Vazio \\
\hline 2000 & 0,66 & 0,66 \\
\hline 2010 & 0,66 & 0,66 \\
\hline 2014 & Vazio & Vazio \\
\hline
\end{tabular}

\begin{tabular}{lll}
\hline \multirow{2}{*}{ Score } & $\begin{array}{l}\text { Aalores de Referência } \\
\text { apresentaram, em relação ao índice } \\
\text { inflacionário selecionado: }\end{array}$ \\
\hline 1,00 & Não houve aumento da tarifa \\
\hline 0,66 & Aumento inferior ao índice \\
\hline 0,33 & Aumento equivalente ao índice \\
\hline 0,00 & Aumento superior ao índice \\
\hline
\end{tabular}




\begin{tabular}{ll}
\hline \hline Domínio & Sistemas de Transporte Urbano \\
\hline Tema & Política tarifária \\
\hline Indicador & Subsídios públicos \\
\hline Definição & $\begin{array}{l}\text { Subsídios públicos oferecidos aos sistemas } \\
\text { de transporte urbano/metropolitano. }\end{array}$ \\
\hline \hline
\end{tabular}

Fontes de Dados - Fortaleza

\begin{tabular}{lll}
\hline 1992 & $\bullet$ & $\begin{array}{l}\text { Empresa de Transporte Urbano de } \\
\text { Fortaleza - ETUFOR }\end{array}$ \\
\hline 2000 & & $\begin{array}{l}\text { Empresa de Transporte Urbano de } \\
2010\end{array}$ \\
\hline 2014 & Fortaleza - ETUFOR (2012) \\
\hline & $\begin{array}{l}\text { Empresa de Transporte Urbano de } \\
\text { Fortaleza - ETUFOR }\end{array}$ \\
\hline
\end{tabular}

Fontes de Dados - Região Metropolitana

\begin{tabular}{|c|c|}
\hline 1992 & - ARCE - Agência Reguladora de Serviços \\
\hline 2000 & Públicos Delegados do Estado do Ceará \\
\hline 2010 & $\begin{array}{l}\text { - Empresa de Transporte Urbano de } \\
\text { Fortaleza - ETUFOR } \\
\text { - ARCE - Agência Reguladora de Serviços } \\
\text { Públicos Delegados do Estado do Ceará }\end{array}$ \\
\hline 2014 & $\begin{array}{l}\text { - Empresa de Transporte Urbano de } \\
\text { Fortaleza - ETUFOR } \\
\text { - ARCE - Agência Reguladora de Serviços } \\
\text { Públicos Delegados do Estado do Ceará }\end{array}$ \\
\hline
\end{tabular}

Método de Cálculo - Fortaleza

\begin{tabular}{lll}
\hline 1992 & Não existia subsídio (Técnico) \\
\hline 2000 & Não existia subsídio (Técnico) \\
\hline \multirow{2}{*}{2010} & $\begin{array}{l}\text { Existem 4 tipos de subsídios: Imposto } \\
\text { sobre Serviço (ISS); Taxa de vistoria } \\
\text { mensal (portadores de deficiência); Taxa } \\
\text { de gerenciamento; ICMS do óleo diesel } \\
\text { (Técnico) }\end{array}$ \\
\hline \multirow{2}{*}{2014} & $\begin{array}{l}\text { Os subsídios que atuam em 2012 irão } \\
\text { atuar também em 2014 (Técnico) }\end{array}$ \\
\hline
\end{tabular}

Método de Cálculo - Região Metropolitana

\begin{tabular}{lll}
\hline 1992 & - & Não existia subsídio na Região \\
& Metropolitana de Fortaleza. \\
\hline 2000 & Não existe subsídio para sistema de \\
& transporte público metropolitano \\
& Para o sistema de Fortaleza, existem 4 \\
& tipos de subsídios: Imposto sobre Serviço \\
& (ISS); Taxa de vistoria mensal (portadores \\
& de deficiência); Taxa de gerenciamento; \\
& ICMS do óleo diesel (Técnico) \\
2010 & Os subsídios existentes não funcionam \\
& para a totalidade do sistema e não \\
& funcionam apenas para os serviços \\
& deficitários. Portanto, o valor do score se \\
& encontra entre 1,00 e 0,75. Será adotado o \\
& valor de 0,80 \\
& A planilha de cálculo foi adaptada \\
\hline & Não existe previsão de subsídios para o \\
& sistema metropolitano para 2014 (Baseado \\
& em experiência do técnico) \\
& Para Fortaleza, os subsídios que atuam no \\
& cenário atual (2010) irão atuar também em \\
& 2014 (Técnico) \\
\hline
\end{tabular}

\begin{tabular}{ll}
\hline Os subsídios previstos não funcionarão \\
para a totalidade do sistema e não \\
funcionarão apenas para os serviços \\
deficitários. Portanto, o valor do score se \\
encontrará entre 1,00 e 0,75 . Será adotado \\
o valor de 0,80 \\
A planilha de cálculo foi adaptada \\
\hline
\end{tabular}

Score e Normalização - Fortaleza

\begin{tabular}{lcc}
\hline Cenário & Score & $\begin{array}{c}\text { Score } \\
\text { Normalizado }\end{array}$ \\
\hline 1992 & 0,00 & 0,00 \\
\hline 2000 & 0,00 & 0,00 \\
\hline 2010 & 1,00 & 1,00 \\
\hline 2014 & 1,00 & 1,00 \\
\hline
\end{tabular}

Score e Normalização - Região Metropolitana

\begin{tabular}{lcc}
\hline Cenário & Score & $\begin{array}{c}\text { Score } \\
\text { Normalizado }\end{array}$ \\
\hline 1992 & 0,00 & 0,00 \\
\hline 2000 & 0,00 & 0,00 \\
\hline 2010 & 0,80 & 0,80 \\
\hline 2014 & 0,80 & 0,80 \\
\hline
\end{tabular}

\begin{tabular}{cl}
\hline Score & $\begin{array}{l}\text { Valores de Referência } \\
\text { Há subsídios: }\end{array}$ \\
\hline 1,00 & $\begin{array}{l}\text { Públicos para a totalidade do sistema de } \\
\text { transporte público urbano e metropolitano, } \\
\text { visando a redução da tarifa de transporte }\end{array}$ \\
\hline $0,75 \quad \begin{array}{l}\text { Públicos para serviços deficitários (alta } \\
\text { capacidade ou metro-ferroviários) e serviços } \\
\text { especiais de transporte (pessoas com } \\
\text { necessidades especiais, etc) }\end{array}$ \\
\hline $0,50 \quad \begin{array}{l}\text { Público somente para serviços deficitários } \\
\text { (alta capacidade ou metro-ferroviários) }\end{array}$ \\
\hline $0,25 \quad \begin{array}{l}\text { Há somente mecanismos de subsídio interno } \\
\text { para compensação em sistema de transporte } \\
\text { urbano com tarifa única }\end{array}$ \\
\hline 0,00 & $\begin{array}{l}\text { Não há qualquer subsídio público ou } \\
\text { mecanismos de compensação para os } \\
\text { sistemas de transporte urbano/metropolitano }\end{array}$ \\
\hline
\end{tabular}

